\title{
TOURISM DISTRIBUTION IN A TRANSITIONAL ECONOMY: HOTEL OWNERSHIP AND DISTRIBUTION CHANNELS IN VIETNAM
}

\author{
BY \\ TUAN NGOC LE \\ A thesis submitted to the Victoria University of Wellington \\ in fulfilment of the requirements for the degree of \\ Doctor of Philosophy in Tourism Management
}

Victoria University of Wellington 2016 


\begin{abstract}
This thesis investigates how the different up-market hotel ownership modes establish distribution channels to reach domestic and international tourism markets in the context of Vietnam's transitional economy, which has been transforming from a centrally planned to a socialist market oriented economy since 1986. It seeks to understand the current distribution channel structures of various hotel ownership modes; to explore the ways in which a number of factors influence distribution structures; and to examine the implications of these structures and factors for hotel and tourism development in Vietnam and in other economies with similar socio-political characteristics. A conceptual framework for hotel distribution channels is developed from a combination of the predominantly Western literature and the fragmented literature on hotel distribution in transition economies. The conceptual framework enables the researcher to investigate the linkages and relationships among the components that constitute the current Vietnamese hotel distribution systems.
\end{abstract}

A qualitative approach is applied to address the supply-side issues of hotel distribution with data collected in the three largest urban cities located in the Northern, Central and Southern parts of Vietnam. The data collection methods were in-depth semi-structured interviews and document compilation. Different groups of participants from the Vietnam tourism industry including senior staff of sales and marketing of the four- and five-star hotels, international tour operators, high-ranking government officials of central and provincial authorities of tourism, key officers of trade organisations and academics from these cities were interviewed.

The research presents the current distribution channel structures employed by four hotel ownership modes to reach domestic and international travellers. The findings also reveal that international joint venture and wholly foreign-owned hotels have effectively established their distribution channels to reach the international market. The entry of these international ownership modes as a result of Vietnam's economic reform has forced state- and domestic privately-owned hotels to also build market-driven distribution structures. Economic restructuring in the context of Vietnam's international integration has been the key element in creating the legal system, economic 
development, international tourist demand, technological advances, patterns of demand, hotel ownership and management modes that have driven the development of distribution. The research concludes that different hotel ownership and management modes and the distribution channel structures of up-market hotels are the products of Vietnam's economic restructuring. The research suggests further economic renovation to meet the country's commitments to international organisations, and to generate an equal tourism and hotel business environment in Vietnam. 


\section{ACKNOWLEDGEMENTS}

First and foremost, I would like to express my sincere gratitude to my supervisors, Professor Douglas G. Pearce and Professor Karen A. Smith, who provided me with the opportunity to start this journey and went along with me to an end of my $\mathrm{PhD}$ road. With timely guidance, valuable suggestions, patience, understanding and support from my supervisors, this thesis was successfully completed. Your characters and working manners have influenced and formulated a part of my future academic and normal life. I also send big thanks to all lecturers within the Tourism Management Group, and staff in School of Management, Victoria Business School, for their advice, encouragement and support throughout my study. Without your kind assistance, this thesis would not have been written.

Many thanks to my boss at the Vietnam National Administration of Tourism who allowed me to leave my job to study in Wellington. I am also grateful to my colleagues at the Vietnam National Administration of Tourism who shared my job duties over last four years. A big thank to the Joint Scholarship Programmes between the Vietnamese Ministry of Education and the Victoria University of Wellington that granted me this scholarship. Without the four years of funds, it would have been challenging and difficult for me to come to the end of my journey.

I am so grateful to all my family members for their moral support, particularly my beloved wife and little son who are always on the same journey with me. I deeply understand that you had to overcome a lot of difficulties to adapt yourselves to a new living environment far away from home. Big thanks to my parents for their unconditional love and support. Thanks to my younger brothers and a sister-in-law for taking good care of our parents when I was away. This study is also for my grandmother who passed away when I was based in Wellington, I have never forgotten your face when I last saw you in this world before I returned to New Zealand from a field-trip in 2013.

Last but not the least, I would like to thank all my research participants for their valuable cooperation and materials. Thanks to all my friends and $\mathrm{PhD}$ candidates $\mathrm{I}$ know in Wellington. Without your friendship and suggestions, my journey would have been less enjoyable and applicable. Thank you all for being a part of this research. 


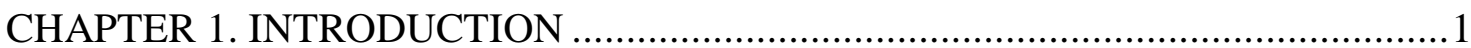

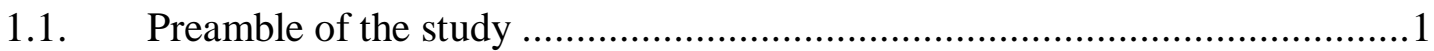

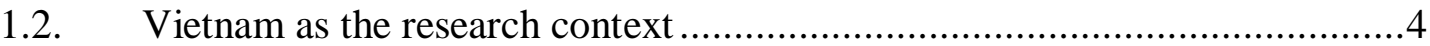

1.2.1. An overview of Vietnam as a transitional economy ..................................5

1.2.1.1. Historical development ...............................................................6

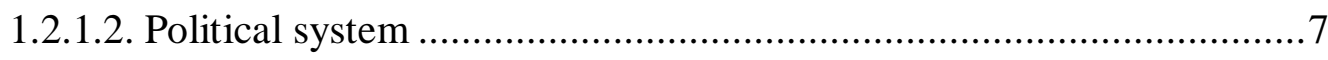

1.2.1.3. Economic development .............................................................. 7

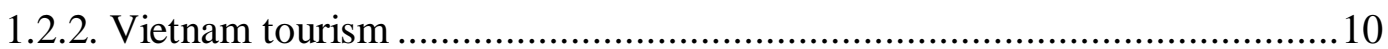

1.2.3. Vietnamese hotel and hotel ownership modes ....................................... 12

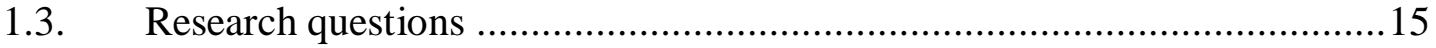

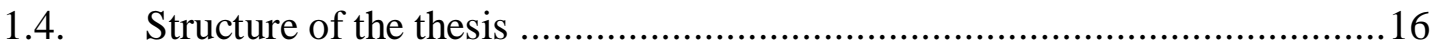

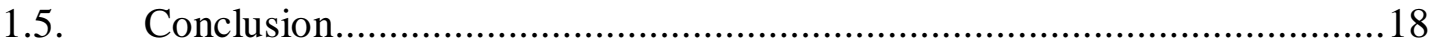

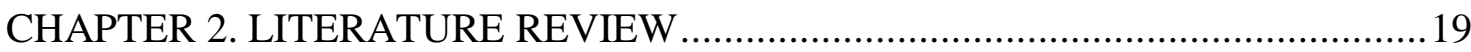

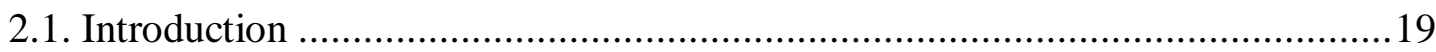

2.2. Essential characteristics of transition economies..........................................20

2.3. Ownership, business operations and distribution in transition economies..........23

2.4. Tourism and hotels in transition economies ...............................................28

2.5. Tourism and hotel distribution channels .........................................................31

2.5.1. Tourism and hotel distribution in the Western literature ............................31

2.5.2. Hotel distribution channels in transition economies.................................34

2.6. Research on tourism and hotel distribution channels in Vietnam .......................36

2.6.1. The development of Vietnamese hotels and distribution...........................36

2.6.2. Studies on hotel ownership and distribution channels in Vietnam...............39

2.7. Conceptual framework for hotel distribution channels in Vietnam ....................41

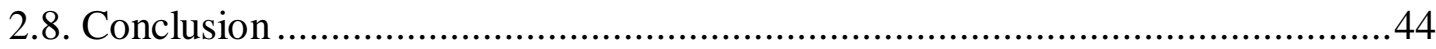

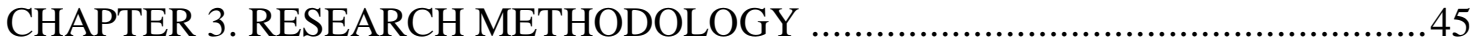

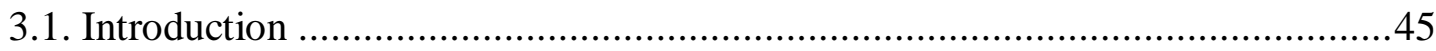

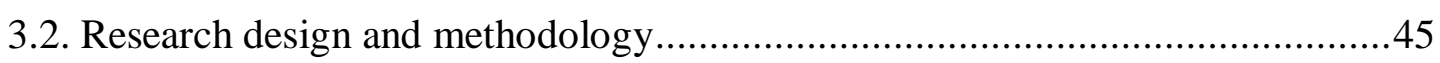

3.2.1. Research questions and research paradigm ........................................45

3.2.2. Research context and research sites......................................................49

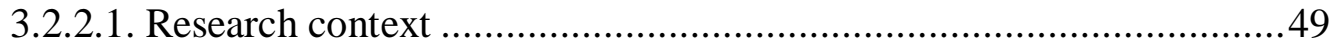

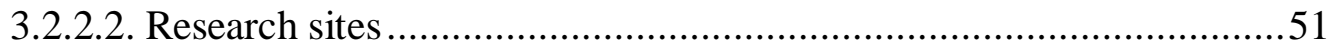

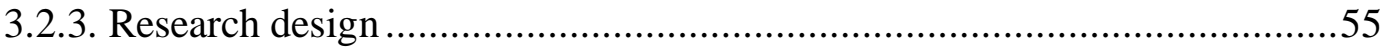

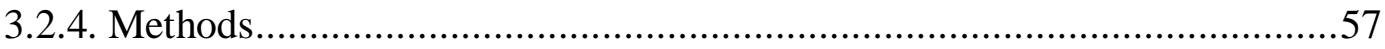




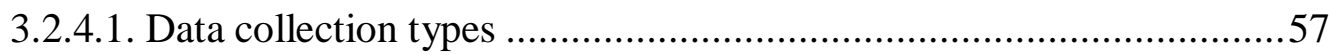

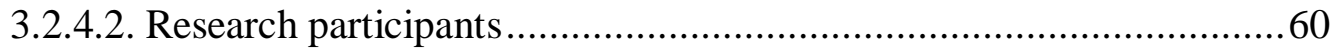

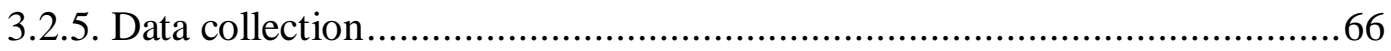

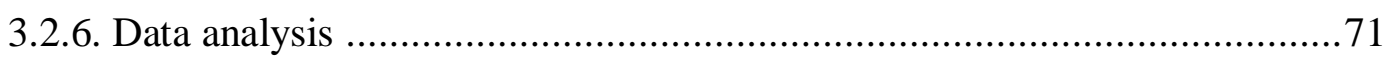

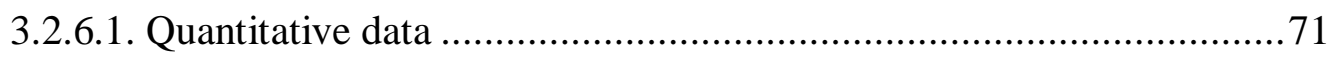

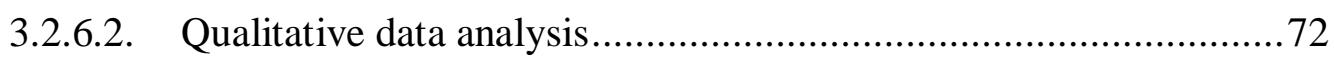

3.3. Strengths and limitations of the research methodology .................................. 75

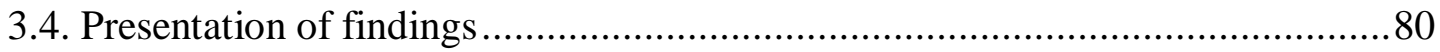

CHAPTER 4. THE DISTRIBUTION CHANNEL STRUCTURES OF STATE- AND DOMESTIC PRIVATELY-OWNED HOTELS .................................................... 81

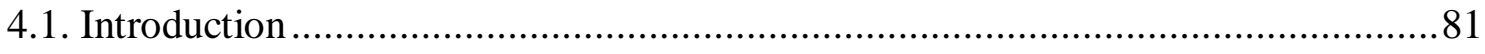

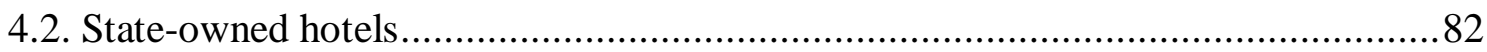

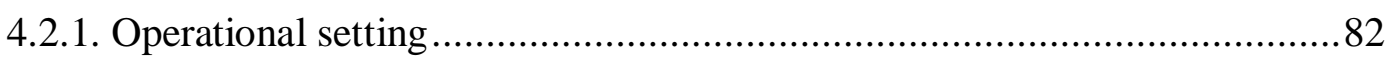

4.2.2. Description of the study's state-owned hotels........................................ 84

4.2.3. Patterns of demand and distribution of SOHs ......................................... 87

4.2.4. Distribution channel structural diagrams ............................................... 91

4.2.5. State-owned hotels' distribution channel structure ................................99

4.2.5.1. The structure for international guests ....................................... 92

4.2.5.2. The structure for domestic travellers staying at SOHs ................... 101

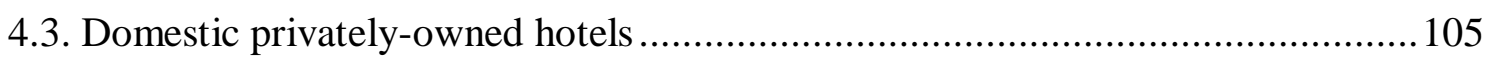

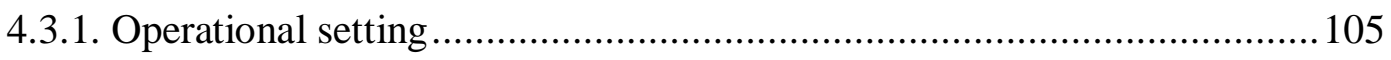

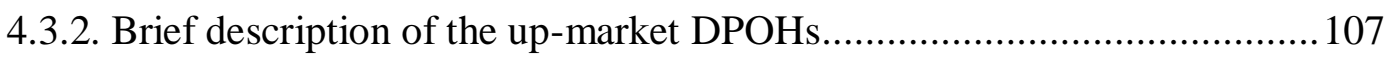

4.3.3. Patterns of demand and distribution of DPOHs ................................... 113

4.3.4. Domestic privately-owned hotels' distribution channel structure..............119

4.3.4.1. The structure for international guests ........................................ 119

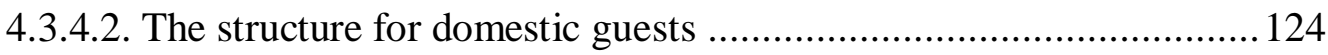

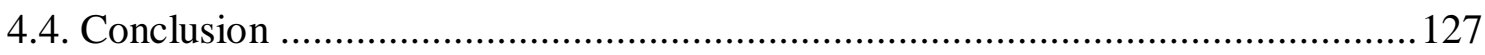

CHAPTER 5. THE DISTRIBUTION CHANNEL STRUCTURES OF INTERNATIONAL JOINT VENTURE AND THE WHOLLY FOREIGN- OWNED

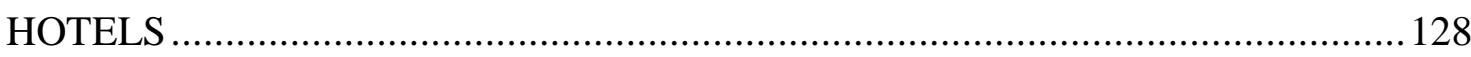

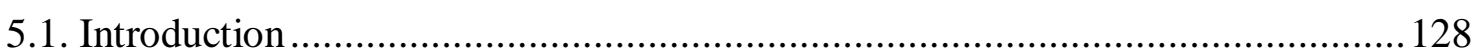

5.2. Common operational setting for foreign-related hotels .................................. 128

5.3. The international joint venture hotels ......................................................... 131

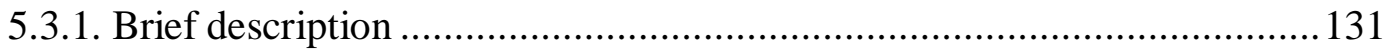

5.3.2. Patterns of demand and distribution .................................................. 137

5.3.3. The current structures of distribution channels for IJVHs ...................... 141

5.3.3.1. The structure for international guests ........................................ 143

5.3.3.2. The structure for domestic guests .......................................... 152 


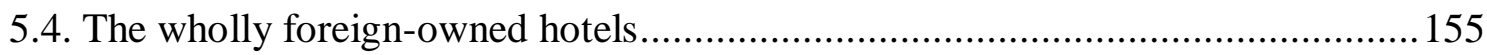

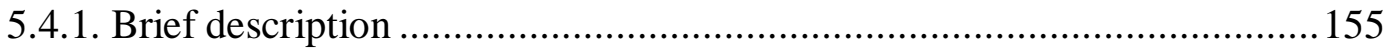

5.4.2. Patterns of demand and distribution channels .................................... 157

5.4.3. The current structures of distribution channels of foreign-owned hotels .. 158

5.4.3.1. The structure for international guests ......................................... 158

5.4.3.2. The structure for domestic travellers .......................................... 162

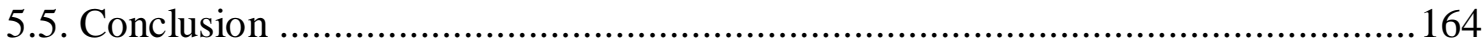

CHAPTER 6. PATTERNS OF DEMAND AND DISTRIBUTION CHANNEL STRUCTURES ACROSS THE FOUR OWNERSHIP MODES ............................ 168

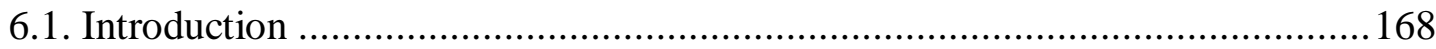

6.2. Commonalities and differences of demand patterns and distribution ............... 168

6.3. Similarities and differences of the current structures of distribution channels . 174

6.3.1. Structures for international guests ....................................................... 174

6.3.1.1. Channel members ....................................................................... 174

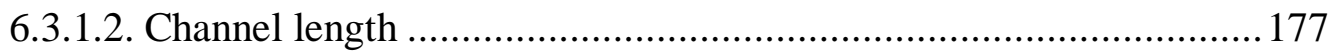

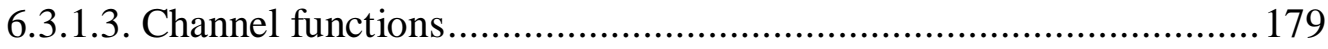

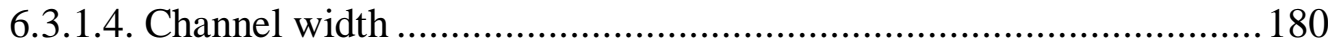

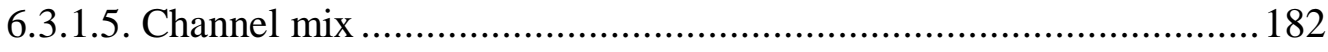

6.3.2. The structures for domestic travellers.............................................. 182

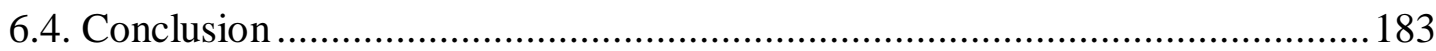

CHAPTER 7. FACTORS INFLUENCING THE CURRENT HOTEL DISTRIBUTION CHANNEL STRUCTURES ACROSS THE FOUR HOTEL OWNERSHIP MODES

186

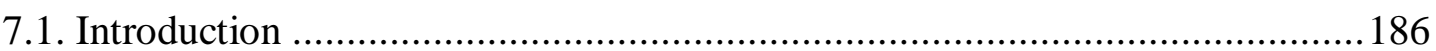

7.2. Factors influencing the current hotel distribution channel structures ............... 186

7.2.1. Vietnam's economic renovation and transitional economy ..................... 187

7.2.1.1. Vietnam's legal system.......................................................... 191

7.2.1.2. Vietnam's economic development ................................................. 198

7.2.1.3. Vietnamese and international tourist demand ...............................202

7.2.1.4. Vietnam and international technological advances ........................ 204

7.2.1.5. Financial and banking development......................................... 207

7.2.1.6. International transportation to Vietnam........................................ 208

7.2.2. Ownership and management modes ....................................................208

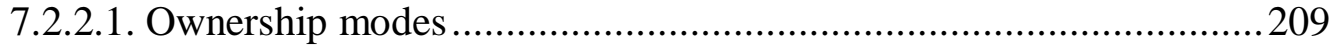

7.2.2.2. Hotel management modes........................................................... 216

7.2.2.3. Other factors within ownership and management modes............... 223

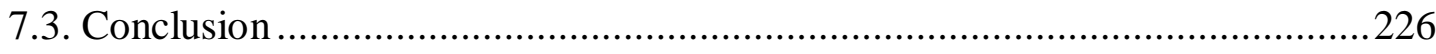


CHAPTER 8. IMPLICATIONS OF THE CURRENT DISTRIBUTION CHANNEL STRUCTURES AND FACTORS INFLUENCING THESE STRUCTURES ..........228

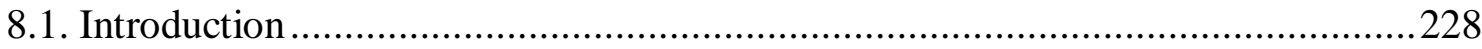

8.2. Summarised factors influencing aspects of distribution channel structures .........228

8.3. Implications of the current hotel distribution channel structures ........................231

8.3.1. Up-market hotels and other tourist accommodation establishments .........231

8.3.2. Implications for travel intermediaries .................................................. 238

8.3.3. Implications for policy makers ........................................................ 240

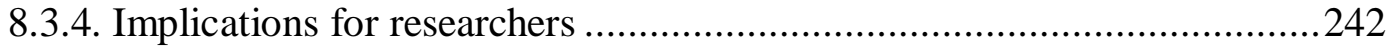

8.4. Implications of factors influencing the distribution channel structures ...............243

8.4.1. Implications for up-market hotels and other accommodation establishments 244

8.4.2. Implications for travel intermediaries ....................................................245

8.4.3. Implications for policy makers ............................................................ 247

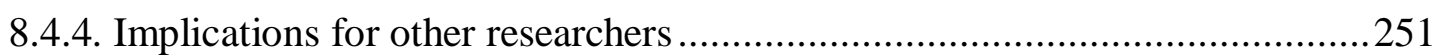

8.5. Implications for relevant parties in other economies ..........................252

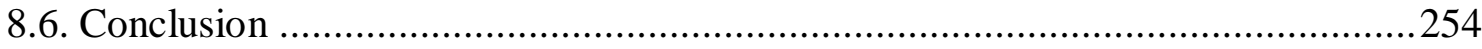

CHAPTER 9. DISCUSSION AND CONCLUSIONS .........................................256

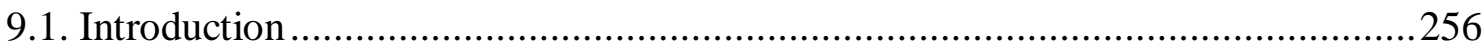

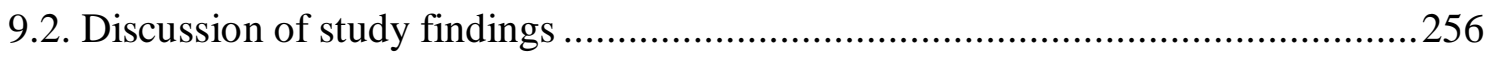

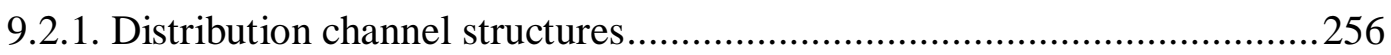

9.2.2. Factors influencing distribution channel structures..............................260

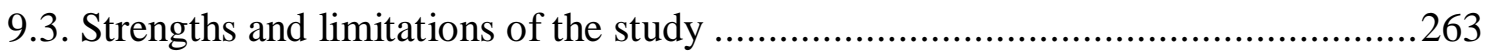

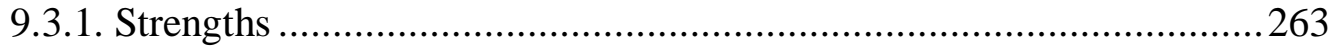

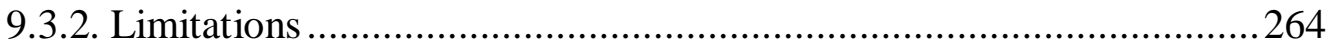

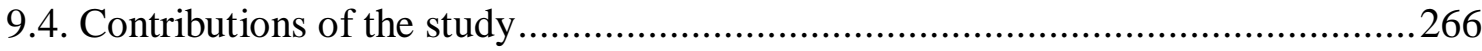

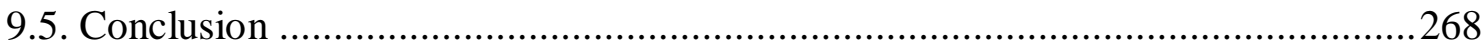

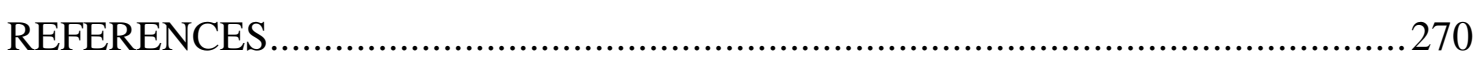

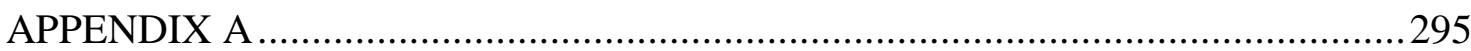

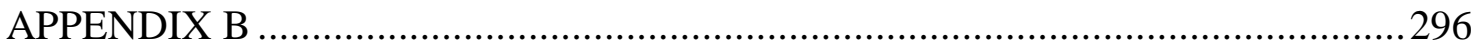

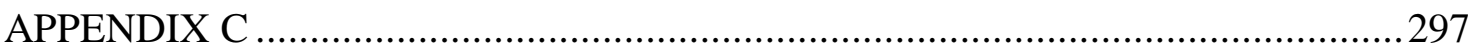

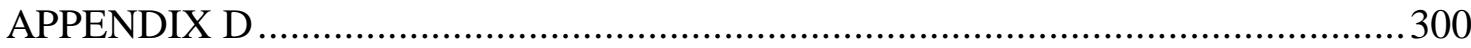

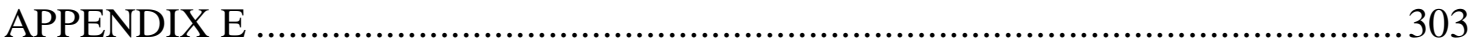

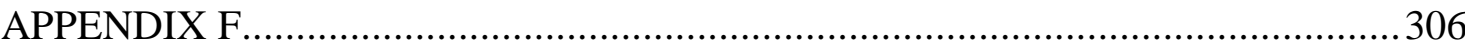




\section{LIST OF TABLES}

Table 1.1. The development of Vietnam tourism in the period 2001 - 2014: Key indicators

Table 1.2. Vietnamese hotels categorised by ownership modes in 2010 .

Table 1.3. Vietnamese up-market hotels by quality and ownership modes

Table 2.1. The emergence of Vietnamese hotel ownership modes and hotel distribution channels since 1960 .

Table 3.1. Number of four and five star hotels in main tourism destinations in Vietnam

Table 3.2. Participant recruitment.

Table 3.3. Types of interviews and data in the field

Table 3.4. Predefined topics of interviews

Table 3.5. An analytical framework for analysing quantitative data

Table 4.1. Capacity and patterns of demand and distribution for the selected SOHs in 201

Table 4.2. Management modes of the DPOHs studied

Table 4.3. Independent domestic privately-owned hotels

Table 4.4. Hotels under the domestic hotel chains in three cities

Table 4.5. Capacity and patterns of demand and sales for selected DPOHs in 2012 .

Table 5.1. Joint venture hotels over other hotel ownership modes by the end of 2012

Table 5.2. Capacity and patterns of demand and sales for selected in 2012

Table 5.3. Capacity and patterns of demand and sales of the two FOHs in 2012...

Table 6.1. Average figures of capacity and patterns of demand and room nigh sales of each hotel ownership mode.

Table 6.2. Capacity and patterns of demand and sales for the selected up-market hotels by locations. 
Table 6.3. Capacity and patterns of demand for the selected up-market hotels by star rating.

Table 6.4. Key similarities and differences of using distribution channel members across the four ownership modes.

Table 6.5. Key similarities and differences of channel length, channel width, channel functions and channel mix across the four ownership modes......................................................................

Table 7.1. Hotel ownership structure and management modes of hotels studied

Table 8.1. Summarised factors influencing the hotel distribution channel structures. 


\section{LIST OF FIGURES}

Figure 1.1. Average economic growth rate of Vietnam since $1986 \ldots \ldots \ldots \ldots \ldots \ldots . . . .6$

Figure 2.1. Distribution channels in China for consumer products................ 27

Figure 2.2. Multiple tourism distribution channels............................. 32

Figure 2.3. Distribution channels for chain hotels in Wellington: (a) independent leisure travellers

Figure 2.4. Mode of system for distribution of seaside holiday hotels

Figure 2.5. Conceptual framework for hotel distribution channels in a transitional economy

Firgure 3.1. Research procedures.......................................... 46

Figure 3.2. Vietnam Map............................................ 52

Figure 3.3. Components of data analysis: Interactive mode................... 72

Figure 3.4. An analytical framework to analyse qualitative data.................. 73

Figure 4.1. Type of international guests in four and five star SOHs (percentage of guests).

Figure 4.2. Channels used by the international guests to book rooms at the SOHs (percentage of guests).

Figure 4.3. Distribution channel structure of the up-market state owned hotels for the international guests.

Figure 4.4. Distribution channel structure of the up-market state owned hotels for the domestic guests.

Figure 4.5. Distribution channel structure of the up-market DPOHs for the international guests.

Figure 4.6. Distribution channel structure of the up-market DPOHs for the domestic guests.

Figure 5.1. Patterns of demand and distribution channels of the four- and five-star IJVHs in Hanoi, Danang and Ho Chi Minh City...

Figure 5.2. Distribution channel structure of the up-market for the international guests.

Figure 5.3. Distribution channel structure of the up-market for the domestic 
guests.

Figure 5.4. Distribution channel structure of the up-market FOHs for the international guests.....

Figure 5.5. Distribution channel structure of the up-market FOHs for the domestic travellers

Figure 7.1. Factors influencing distribution channel structures of the different hotel ownership modes in three largest cities in Vietnam.... 


\section{LIST OF ACRONYMS}

ASEAN

CRO

$\mathrm{DPOH}$

FDI

FIT

$\mathrm{FOH}$

GDP

GDS

IBO

IJVH

IMF

OTA

SOE

$\mathrm{SOH}$

TA

TO

VCP

VNA

VNAT

WTO
The Association of Southeast Asian Nations

Central Reservation Office

Domestic Privately-Owned Hotel

Foreign Direct Investment

Free Independent Traveller

The Wholly Foreign-Owned Hotel

Gross Domestic Product

Global Distribution System

Inbound Tour Operator

International Joint Venture Hotel

International Monetary Fund

Online Travel Agent

State-Owned Enterprise

State-Owned Hotel

Travel Agent

Tour Operator

Vietnamese Communist Party

Vietnam National Assembly

Vietnam National Administration of Tourism

World Trade Organisation 


\section{CHAPTER 1. INTRODUCTION}

\subsection{Preamble of the study}

Although tourism numbers have fluctuated, tourism has become one of the leading economic sectors of the Southeast Asian region since the 1990s (Bui \& Jolliffe, 2011), and a major socio-economic driver for economic growth and tools for development of state members (ASEAN, 2010). In Vietnam, tourism has been considered the top national priority for economic development because of its contribution to the national socioeconomic achievements (VNAT, 2015). Over the past decades, Vietnam has transformed from a pure command to a socialist market oriented economy. International tourist arrivals rose from 250,000 in 1990 to 7.8 million in 2014 and domestic travellers recorded an increase from one million in 1990 to 35 million in 2013 (VNAT, 2005; VNAT, 2014). Tourism receipts constituted around five percent of Vietnam's gross domestic product (GDP) in 2009 and 2010 (VNAT, 2011), and six percent in 2014 (VNAT, 2015a). In 2002, the Vietnam tourism industry accounted for 4,773 tourist accommodation establishments with 72,200 rooms; this figure reached 15,381 accommodations and 277,600 rooms in 2012. This growth in Southeast Asian tourism in general and in Vietnam in particular has been a result of an improvement of these countries' policies, tourism products and services as well as their marketing efforts (ASEAN, 2010; Hitchcock, King \& Parnwell, 2009).

The expansion and development of tourism distribution channels has been a significant factor in this growth of tourism. According to Pearce (2007, p. 44), distribution channels are "a system or set of linkages by which a supplier makes products available or by which a consumer accesses products, for example via wholesalers and retail travel agents or a third party website". Distribution is regarded as one of the most important components in marketing as it determines the competitiveness of tourism organisations and destinations (Buhalis, 2000). Specifically, Buhalis and Laws (2001) concluded that distribution channels significantly influence the prosperity of tourism destinations and tourism enterprises since they provide information and facilitate the tourism transaction. Pearce (2007, p. 3) contends that: "distribution is about taking your product to the market. In a competitive environment finding and using the right paths to the market place is essential to the success of your business". 
As a key component of marketing and the bridge between supply and demand, distribution channels become particularly important in transitional economies such as China, Vietnam and some countries in Central Eastern Europe, which are moving from a pure command or centrally planned to a market-oriented economy. In command economies, decisions on what and how to produce, and for whom, are taken by the government (Stahl \& Alexeev, 1985), the distribution of goods and services is a function of a government plan for production and allocation of resources rather than of market forces (Beresford, 2001). Therefore, in the transitional period where an economy is moving from a centrally planned into a market economy, developing effective paths to the market become critical. Samiee (1993) noted strong links between a country's economic development, its marketing system, and the development of distribution channels in developing countries. As their economies grow rapidly, the capacity of traditional marketing channels often fails to cope with the demand for speedier circulation of services and products. Therefore, distribution reform can create new channels of distribution to facilitate the marketing services and purchasing process. A radical economic reform may also have profound impacts on distribution when a government of a transitional economy such as China wants to speed up the establishment of the market economy and to promote a disciplined market system (Luk, 1998).

The economic transition process brings about changes that in turn influence the way in which tourism develops and tourism products are distributed. In the hotel sector, hotel distribution channels share similar attributes mentioned by Luk (1998) and Samiee (1993), since some transitional countries have generated new distribution systems allowing consumers to book services and to facilitate the purchase of products prior to their production (Qu, Ennew \& Sinclair, 2004; Qu \& Ennew, 2005). In addition, expanded hotel distribution channels indirectly create a more equal hotel business environment by generating competition among hotel ownership modes (Nguyen, 2009). However, hotel distribution practices are strongly affected by the economic and political environment within which they operate (Johnson, 1997; Page, Brunt, Busby, \& Connel, 2001). Government regulations that constrain competition and protect established state hotels have a disadvantageous impact on the development of a free market $(\mathrm{Qu}$ et al., 2004). In line with a wide range of literature investigating the hypothesis that ownership modes influence firm productivity (Qu \& Ennew, 2005; Ramstetter \& Ngoc, 2013), this 
thesis explores the contention that ownership within transitional economies has been an important factor influencing market orientation or paths to the market of the hotels.

In Vietnam, Tran (2015) noted that Vietnam's transition to a socialist market-oriented economy is considered as an unprecedented economic mode in the world. The Vietnamese Constitution outlines that Vietnam applies the socialist market-oriented economy based on various forms of ownership including private and public sectors in which state economy plays a leading role. Consequently, policy makers face a dilemma when putting this highest law into effect by proposing equal functions of different ownership modes in laws, for instance, Civil Code and Law on Enterprise. Accordingly, how to create a competitive business environment is a pertinent question if the State continues to subsidise state owned enterprises (SOEs) (VGP, 2015a). The World Bank (2012) reported that Vietnam's internal economic activities as a new economy are an attractive subject to explore since ownership modes and other fields of economy are related. As an example of successful economic reform (Van Arkadie \& Mallon, 2003), Ramstetter and Ngoc (2013) noted that Vietnam is an interesting case in which to investigate relationships between the economic transition, ownership and productivity of enterprises, for instance multinational corporations are likely to be relatively efficient and the SOEs are generally relatively inefficient (Beresford, 2008; Ramstetter \& Ngoc, 2013).

In tourism, a process of equitisation and privatisation of state-owned hotels ( $\mathrm{SOHs}$ ) and roles of distribution channels performed by non-state hotels are seen to have a mutual relationship. However, studies examining distribution channel structures of the different hotel ownership modes to get a better understanding of changes in the hotel and tourism development in Vietnam and other transitional economies have not been found. Suntikul, Butler and Airey (2008, 2010a, 2010b) contended that published research on tourism in Vietnam is small, and studies which investigate the distribution system do not exist (Maruyamar \& Trung, 2011; Venard, 1996). Although there are numerous reports from the Vietnam National Administration of Tourism (VNAT), tourism and hotel distribution channels are much more complicated than reported, well beyond the simple descriptive statistics in national records and official VNAT documentation. Hence, it is timely to investigate this under-researched topic and the complex 
relationship between hotel ownership modes and their distribution channel structures in Vietnam as an example of a transitional economy's politic economic restructuring.

This thesis attempts to fill the above gap in the literature on the tourism and hotel distribution in Vietnam and in other transitional economies by addressing the primary research question: Taking the case of up-market hotels in Vietnam, how do the different hotel ownership modes in a transitional economy structure distribution channels? The study employs a qualitative approach to address the supply-side issues of hotel distribution in Vietnam. The two data collection methods are used, namely: (1) interviewing participants drawn from VNAT, some provincial tourism authorities, trade organisations, academics and tour operators as well as senior sales and marketing staff in high-end hotels in the three largest cities in Vietnam: Hanoi, Danang and Ho Chi Minh City, and (2) compiling secondary documents. There are four reasons for choosing this methodological design. First, the supply-side perception provides opportunities for the researcher to get insights into the Vietnamese hotel sector, which consists of various parties involving a process of producing and managing the hotels. Second, supply-side research enables the researcher to investigate the various distribution channels of suppliers since "suppliers frequently use a range of channels to distribute their products and services: direct sales onsite or in the market are complemented by the use of a variety of intermediaries" (Pearce \& Schott, 2005, p. 50). Third, the existing data and statistical figures published by the government are inconsistent, unreliable and challenging to gain access to. Fourth, published studies on Vietnamese tourism in general and in tourism distribution systems are paid little attention. The up-market hotels consisting of the four- and five-star hotels provide a sample of four hotel ownership modes.

This introductory chapter will outline Vietnam as the research context including background on Vietnam and its tourism and hotel sector. The research questions will be presented, followed by the structure of the thesis.

\subsection{Vietnam as the research context}

Vietnam was selected as an example of a transitional economy to investigate distribution channel structures of various up-market hotel ownership modes for a number of reasons. The main reason is that Vietnam is a country being paid increasing 
attention by international researchers because of its socio-economic growth, institutional changes and the opening up of new geographical spaces for fieldwork of researchers since its transformation from a centrally planned to a socialist marketoriented economy in 1986, called Doi Moi ${ }^{1}$. This country offers a good example of a transition economy (OECD, 2013; Pham, 2013; Scott, Miller \& Lloyd, 2006; Van Arkadie \& Mallon, 2003). Vietnam has become a popular tourist destination for international holidaymakers, and its tourism industry has grown rapidly over the past few years (Bui \& Jolliffe, 2011; Lai \& Vinh, 2013). In addition, a study of tourism and hotel distribution channel structures in relation to hotel ownership modes in Vietnam has not yet been undertaken. Finally, the researcher's working experience as an official of the VNAT brings about advantages and interests of conducting this topic. It permits the researcher to feel very personally involved in steps of the research process (Fink, 2000). The working background and personal relationship with the Vietnamese hotel industry practitioners also allowed the researcher to gain access to selective groups of participants to conduct the fieldwork. This will be discussed in Section 3.2.2.

\subsubsection{An overview of Vietnam as a transitional economy}

Vietnam had an estimated 90.5 million inhabitants in 2014 , the world's $13^{\text {th }}$ mostpopulous country and the eighth-most-populous Asian country (Vuong Linh, 2014). This section provides context regarding its historical developments, political system and economic development. Being located on the eastern part of the Indochinese peninsula in Southeast Asian region with an area of 331,690 square kilometres, Vietnam has a long land border of $4,550 \mathrm{~km}$, bordering China to the north, Laos to the northwest, Cambodia to the southwest and the Eastern Sea or South China Sea of the Pacific Ocean to the east. According to Gates, Noerlund and Vu (2014), Tran (2013) and the World Bank (2015), in the middle of 1980s Vietnam was an agricultural country that was influenced by an inappropriate and inefficient socialist economic mode, dated means of production and low productivity. Since 1986, Doi Moi has transformed Vietnam from one of the poorest countries in the world (with per capita income below

\footnotetext{
1 Doi Moi (in English: Renovation) is a terminology given to the economic reforms initiated by the Vietnamese Communist Party at the $6^{\text {th }}$ National Congress in 1986 with the goal to transform Vietnamese command economy into a socialist-oriented market economy. Doi Moi is popularly understood as an economic reform.
} 
$\$ 100)$ to a lower-middle-income country (per capita income of approximately $\$ 2,000$ ) by the end of 2014 (Tran, 2013; World Bank, 2015). Doi Moi has also created the increasing integration of Vietnam into the world economy (Tran, 2013).

\subsubsection{Historical development}

Vietnam's historical development is categorised into five main periods, namely feudal dynastic Vietnam, French colonialism from 1858 to 1945, and the French War from 1945 to 1954, Vietnam War from 1954 to 1975, reunification and economic reform from 1976 to present. After a long period of feudalism, in the $19^{\text {th }}$ century Western capitalist countries brought imperialism and colonialism to Vietnam. Through missionaries and trade, the French ruled Vietnam and then began large-scale exploitation in the country. Capitalist production relations entered Vietnam, promoting the formation and evolution of internal capitalist factors, narrowing and breaking up the existing feudal production relations (Cooke, Li \& Anderson, 2011). Vietnam's economy thus moved from an agricultural economy to a colonized country under the control of the French capitalists. A new social structure appeared along the line of capitalism, and the separation between landlords and farmers became deeper while new social classes, such as the working class, the bourgeoisies and petit bourgeoisies gradually appeared (Michaud, 2000; MOFA, 2015). In August 1945, the Vietnamese people launched a general uprising to grab power. With the Proclamation of Independence on $2^{\text {nd }}$ September 1945, the Democratic Republic of Vietnam was founded. However, it was not until the victory of Dien Bien Phu in May 1954 and the Geneva Accord signed in July 1954 that the war against the French colonialists ended. According to the Geneva Accord, Vietnam was temporarily divided into two regions in the run-up to the general elections: The North (north of latitude $17^{0} \mathrm{~N}$ ) was managed by the Soviet Union and its allies; the South was controlled by the French and the USA. During the period of separation, North Vietnam applied a centrally planned economy based on a mode of the former Soviet Union; the Republic of South Vietnam was established under the market economy mode of the USA (Asselin, 2007; Tran, Nguyen \& Nguyen, 2000). The Geneva Accord opened up an opportunity of independence and freedom for Vietnam, but general elections were never held until the fall of Saigon in 1975 (Asselin, 2007; Dang, 2004; Devillers, 1962; Lewy, 1980; Short, 2014). 
The Vietnam War ended in 1975 and Vietnam was reunified, and the country began a trial-and-error process to find a suitable path of development (Gates et al., 2014; Tran et al., 2000). Ten years after the liberalisation, Vietnam's post-war economy encountered a number of socioeconomic difficulties because of the destruction of the war, the USA's embargo, and the inappropriate and bureaucratic mode of the command economy (Tran et al., 2000; Tran, 2013). At the sixth Congress of the Communist Party in July 1986, the Doi Moi policies were launched with the focus on economic restructuring (Pham, Trinh \& Nguyen, 2007; Tran et al., 2000). This marked an important milestone in the new phase of Vietnam's development; notably Vietnam has become the second largest rice exporter in the world. Vietnam also exports a huge number of other commodities such as telephones, electronics, computers and accessories, crude oil, textiles, shoes, coffee, cashew nuts and seafood (MOFA, 2015; Pham et al., 2007; VGP, 2015; VNAT, 2015; VOV, 2015). Tourism has been an important economic sector since 1994 when the Vietnamese Communist Party (VCP) issued Directive No 46/CT-TU that identified tourism development as an essential strategy of the national socioeconomic policies.

\subsubsection{Political system}

The Constitution shows that the Socialist Republic of Vietnam is a socialist country administered by law and of the people. In Vietnam, the people are the masters, all the power belongs to the people based on the alliance of three classes: working class, the peasantry and the intelligentsia. The state power is unified to numerous state agencies, which coordinate with and control one another in the exercise of the legislative, executive and judicial powers. The people exercise the state power under the form of direct democracy and of representative democracy through the National Assembly, People's Councils and other state departments. The political system of the Socialist Republic of Vietnam includes the components constituting political power, namely VCP, the State, the National Assembly, the Government, the People's Courts and the People's Procuracies. In Vietnam, VCP is the force leading the State and society. Its political ideology is formulated from the Marxist-Leninist doctrine and Ho Chi Minh Thought (VNA, 2013).

\subsubsection{Economic development}

Doi Moi and reform measures in the late of 1980s led to a number of laws being revised and promulgated under the new political economic mode for developing economy, 
generating economic changes in Vietnam (Figure 1.1). Since 1986, Vietnam has sustained economic growth at a relatively high level, presenting an average increase from four percent between 1986 and 1990 to 8.2 percent in 1991 to 1995 . Between 1996 and 2000, because of the impact of the Asian Financial Crisis, growth slowed down (to about five percent). From 2000 to 2010, since growth accelerated again in 2000 and stabilised during the period (about 7.26 percent per annum). From 2011 to 2013, the average GDP growth rate was around six percent per annum. Between 2008 and 2013, GDP per capita of Vietnam rose from US \$1,024 to over US \$2,000 by the end of 2014 (World Bank, 2015).

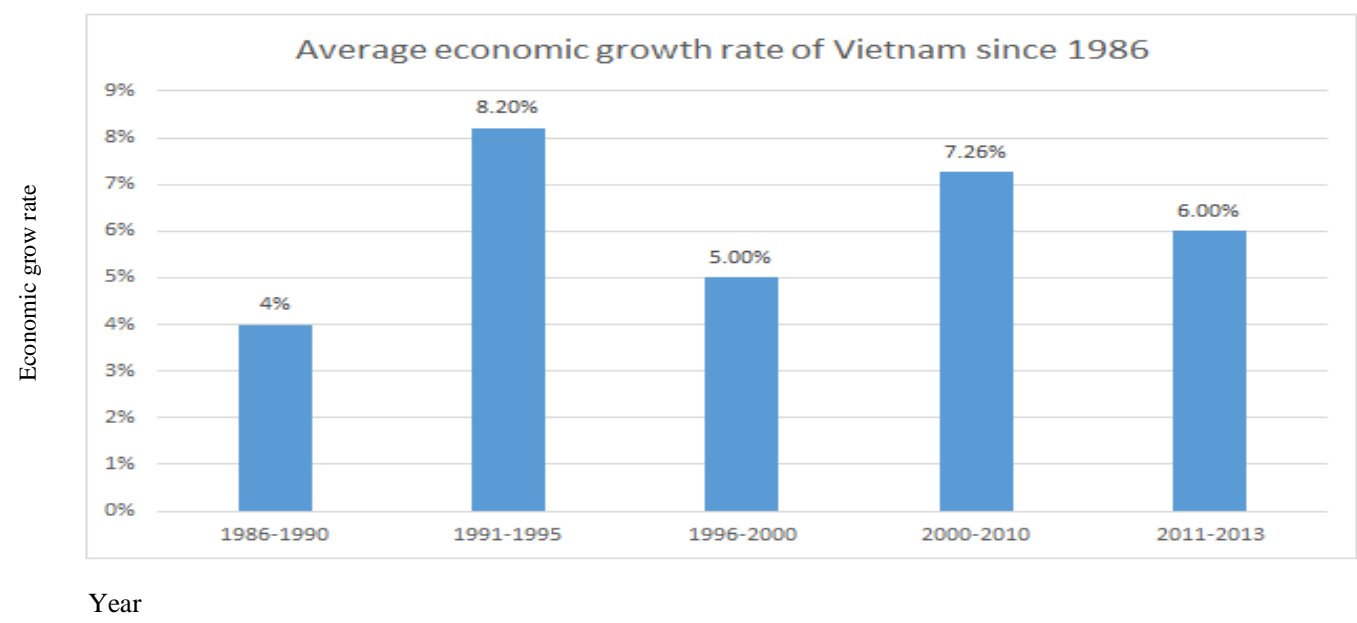

Figure 1.1. Average economic growth rate of Vietnam since 1986 (Source: World Bank, 2015)

Along with economic growth, Vietnam's economic structure has witnessed significant changes. In agriculture, these reforms boosted productivity and moved labour from the traditional agriculture to more modern practices (Beresford, 2001, 2008; Tran, 2013). Economic structure moved towards an increase of shares of industries and services because of the inflows of foreign direct investments (FDI), the booming of domestic private sector and the open door policy. By 2008, employment in non-agriculture sectors had risen to 45 percent, compared with 25 percent in 1985 . The changes of the national economic structure have also been found in exports (Pincus, 2015). In the late 1980s, about 80 percent of exports were recorded by primary commodities, such as rice, coffee, crude oil and coal, but by 2005, along with the expansion of manufactured exports, that share had declined to about 50 percent (Irvin, 1995; Le \& Yue, 2006; MOFA, 2015; Pham, 2013; Tran, 2013). 
More recently, the Vietnamese economy has entered a new stage that has been characterized by macroeconomic turmoil (Tran, 2013). At the turn of the century, Vietnam's economy seemed to return to its track of high economic growth after the influence of the Asian Financial Crisis in 1997 and 1998 (Fforde, 2002; Pham et al., 2007); however, the instability of the macro economy can be observed by the fluctuation of consumer price index inflation and GDP growth rate. Inflation rate rose from very low numbers (approximately four percent in 2002 and three percent in 2003) and increased sharply up to almost 20 percent in 2008 and 19 percent in 2011, respectively (GSO, 2015a; Pham et el., 2007; Tran, 2013).

Many economists argue that a main cause of Vietnamese economic uncertainty is the increase in the state's credit to the SOEs, and the government preferential treatment of SOEs remains an obstacle for the development of the non-state economic sector who are known as an engine of economic growth (Nguyen \& Van Dijk, 2012; Pham et el., 2007). The SOEs were allowed to restructure and group into state economic groups that have been able to have impacts on the direction of economic policies and the allocation of resources. These SOEs had already been given special privileges in gaining access to large capital and land resources of the country but they produced a low productivity compared with investment rate (Nguyen \& Van Dijk, 2012; O'Toole, Morgenroth \& Ha, 2015; Ramstetter \& Ngoc, 2013). Moreover, Tran (2013) commented that Vietnam's integration into the world business community is another reason for the economic instability. Also, Vietnam's membership of the WTO in 2007 has stimulated increasing inflows of foreign direct investments (FDI). Due to the inappropriate monetary system, the rapid influxes of foreign capital brought about an expansion of the money supply that caused a high inflation rate (Tran, 2013).

In short, Doi Moi marked Vietnam's transition to a middle-income socialist market economy, promoting Vietnam to move towards the socialist market-oriented economy. The economic take-off observed since then is exceptional among developing countries when GDP growth has reached eight percent per annum. In terms of macroeconomic stability, during the process of Doi Moi, Vietnam has shown relatively a good performance. According to the World Bank, Vietnam was able to quit the poverty trap and emerged as a lower-middle-income economy in 2008 when the country's per capita 
gross national income exceeded the threshold of US \$1,000 (Cling, Razafindrakoto \& Roubaud, 2013).

\subsubsection{Vietnam tourism}

This section focuses on introducing Vietnam tourism regarding its developmental periods, key growth indicators and the roles of tourism in Vietnam's socio-economic development. Reports of the VNAT on the $50^{\text {th }}$ anniversary of the Vietnam tourism foundation (VNAT, 2015) and Truong's (2013) research identified three phases of tourism development: (1) from 1960 to 1975, (2) from 1975 to 1990, and (3) from 1990 to present. The 1960 milestone was chosen by VNAT as the first Vietnam Tourism Company was established on $9^{\text {th }}$ July 1960. In the first period, when Vietnam was divided into North and South regions, Vietnam Tourism Company on behalf of the North Vietnam government mainly served guests of the government, experts and a small number of international tourists from socialist countries. This company also organised holidays for Vietnamese people, soldiers and government officials. Despite the difficult condition of the war, a number of state-owned hotels (SOHs) and guesthouses were built in Hanoi and in some mountainous areas. In this phase, SOHs were operated under the centrally planned economy that meant the government allocated guests to each hotel (VNAT, 2005).

From 1975 to 1990 , the operation of Vietnam tourism gradually spanned across the nation when the country was liberated and unified. In the North, VNAT was established in June 1978 as a body of the Council of Ministers to manage the tourism and hotel industry. In Middle and South Vietnam, as a part of a new government after the war, a number of state-owned tourism companies were established such as Vietnam Tourism in Danang, Vietnam Tourism in Ho Chi Minh City (formerly Saigon), and Saigon Tourist; these took over hotel properties and travel companies from the former Republic of Vietnam. Regardless of their ownership modes, all of the hotels under the former Republic of Vietnam were nationalised and became SOHs. Tourism continued to develop under the command economy until Vietnam's recommendation of Doi Moi in 1986 (VNAT, 2005).

Since 1990, Vietnam tourism has been considered as one of the fastest growing destination internationally. This was from a very low starting point with just 250,000 
Table 1.1. The development of Vietnam tourism in the period 2001-2014: Key indicators

\begin{tabular}{|c|c|c|c|c|c|c|c|c|c|c|c|c|c|c|}
\hline \multirow{2}{*}{ Indicator } & \multicolumn{14}{|c|}{ Year } \\
\hline & 2001 & 2002 & 2003 & 2004 & 2005 & 2006 & 2007 & 2008 & 2009 & 2010 & 2011 & 2012 & 2103 & 2014 \\
\hline $\begin{array}{l}\text { International arrivals } \\
\text { (in thousand) }\end{array}$ & 2,330 & 2,628 & $2,428.7$ & $2,927.9$ & $3,477.5$ & $3,583.5$ & $4,229.4$ & $4,235.8$ & $3,772.36$ & $5,049.85$ & 6,014 & 6,847 & 7,572 & 7,847 \\
\hline Growth rate (per cent) & & $13 \%$ & $-8 \%$ & $21 \%$ & $19 \%$ & $3 \%$ & $18 \%$ & $0 \%$ & $-11 \%$ & $34 \%$ & $19 \%$ & $14 \%$ & $11 \%$ & $4 \%$ \\
\hline $\begin{array}{l}\text { Average length of stay of } \\
\text { international tourists }\end{array}$ & 5.5 & 5.4 & 5.0 & 5.5 & 5.7 & 5.8 & 6.0 & 6.2 & 6.8 & 7.3 & - & - & 10.2 & - \\
\hline $\begin{array}{l}\text { Tourism GDP (in thousand } \\
\text { million) }\end{array}$ & 10.10 & 10.93 & 10.30 & 12.82 & 13.84 & 23.23 & 20.50 & 24.38 & 27.10 & 37.4 & - & - & - & 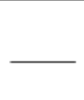 \\
\hline $\begin{array}{l}\text { Percentage of tourism GDP } \\
\text { over national GDP }\end{array}$ & 3.46 & 3.49 & 3.06 & 3.55 & 3.52 & 5.46 & 5.43 & 4.99 & 5.25 & 5.8 & 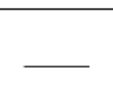 & 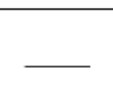 & 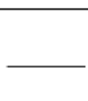 & $\ldots$ \\
\hline Labour force in tourism & 150,662 & 196,873 & 208,777 & 241,685 & 275,128 & 310,67 & 319,177 & 424,740 & 440,277 & 478,06 & - & - & - & 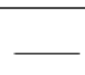 \\
\hline International tour operators & - & - & - & - & 428 & 504 & 620 & 701 & 795 & 888 & 980 & 1,132 & 1,305 & - \\
\hline $\begin{array}{l}\text { Tourist accommodation } \\
\text { establishments }\end{array}$ & 4,366 & 4,773 & 5,620 & 6,567 & 7,603 & 8,516 & 9,633 & 10,638 & 11,314 & 12,090 & 13,756 & 15,381 & - & - \\
\hline Total room number & - & 72,200 & - & 92,500 & - & 160,500 & 178,350 & 202,780 & 216,670 & 237,110 & 256,740 & 277,660 & - & 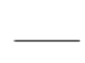 \\
\hline $\begin{array}{l}\text { Average room occupancy } \\
\text { rate (per cent) }\end{array}$ & - & - & - & 50 & - & 60 & 60.7 & 60 & 57 & 58 & 60 & 59 & 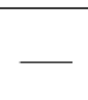 & 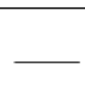 \\
\hline
\end{tabular}

Key: ___ Missing data

Sources: GSO, 2014; VNAT, 2013b and VNAT, 2015b. 
foreign visitors in 1990 to approximately 7.6 million visitors in 2013, being recognised the fifth position among member countries of the Association of Southeast Asian Nations (ASEAN) (ASEAN, 2015). From 2001 to 2014, it recorded an increase of international arrivals of approximately 10 percent per annum. In terms of job creation, the industry generated 3.8 percent of the country's total jobs, with approximately 1.4 million employees including 478,000 employed directly in tourism by 2010 (Table 1.1). This growth, and the increasing contribution of tourism to GDP from 3.5 percent to 5.8 percent in 2010, have changed the industry's recognition by government. In October 1994, Directive 46/CT-TU of CPV confirmed that: "developing tourism is an important strategic direction in socioeconomic development, tourism contributes to the process of industrialisation and modernization of the country". This guidance played a very important part in further development of tourism and led to laws supporting tourism. In 2015, according to WEF (2015), Vietnam tourism was ranked $15^{\text {th }}$ in South East and Southern Asia, and $75^{\text {th }}$ globally in terms of business environment, safety and security, health and hygiene, resource and labour market, information and communication technology readiness, travel and tourism policy and enabling conditions, infrastructure, and natural and cultural resources.

In short, the tourism sector has been a major factor in job creation, economic development and international integration, having played a crucial role in Vietnam's overall socio-economic growth (UNWTO, 2012 b and c; VNAT, 2013b). Mok and Lam (1997) and Lam (2013) identified some key factors that have shaped the Vietnamese tourism industry since 1986: the environment, politics and the involvement of government. Although this industry has been identified as a leading economic sector and being given priority in the development policy of the government, specific constraints hinder Vietnam's tourism development. They include historical factors, poor infrastructure, simplified tourism products and services, an inefficient and unstable legal system, inadequate skilled labour, and an unfavourable country image.

\subsubsection{Vietnamese hotel and hotel ownership modes}

Economic reform has contributed to the rapid development of tourist accommodation establishments in general and the hotel sector in particular. Before 1987, the Vietnamese government held a monopoly on tourism whereby only SOHs provided accommodation services. The Foreign Investment Law was promulgated in 1987, enabling foreigners to 
invest in hotel businesses. The Law on Enterprise in 1990 and the Law on Domestic Private Owned Enterprise in 1990 allowed Vietnamese individuals to own a hotel. The Ordinance on Tourism in 1999 and its replacement Law on Tourism in 2005 have identified seven types of tourist accommodations including hotel, holiday village, tourist villa, tourist serviced apartment, camping site and guesthouse. These laws clearly regulated terms and conditions for hotel businesses in Vietnam. Accordingly, there was a dramatic increase in tourist establishments, from 350 in 1990 to 9,633 in 2007 (Table 1.1). The hotel sector, which occupied the largest proportion of accommodation service suppliers with 3,651 hotels and 99,197 rooms in 2010, has expanded with various styles including city hotels, hotel resorts, floating hotels, and motels.

In terms of ownership modes, the Vietnamese hotel sector comprises four modes of ownership, namely SOHs, domestic privately-owned hotels (DPOHs), international joint venture (IJVHs), and wholly foreign-owned hotels (FOHs) (Table 1.2). Under the current Law on Investment, overseas business partners and investors are allowed to establish wholly foreign-owned enterprises or hold unlimited shares of the capital in the IJVHs except equitised and privatised SOHs.

Table 1.2. Vietnamese hotels categorised by ownership modes in 2010

\begin{tabular}{|c|c|c|c|c|}
\hline Hotel ownership models & $\begin{array}{c}\text { Number of } \\
\text { hotels } \\
(\mathbf{n}=\mathbf{3 , 6 5 1 )}\end{array}$ & $\begin{array}{c}\text { Number of } \\
\text { rooms } \\
(n=99,197)\end{array}$ & $\begin{array}{c}\text { Percentage of } \\
\text { the hotels } \\
(\%)\end{array}$ & $\begin{array}{c}\text { Percentage of } \\
\text { the rooms } \\
(\%)\end{array}$ \\
\hline State owned hotels & 383 & 25,072 & 10.49 & 25.27 \\
\hline Domestic private hotels & 3,202 & 60,679 & 87.70 & 61.17 \\
\hline International joint venture hotels & 56 & 8,946 & 1.53 & 9.02 \\
\hline Wholly foreign owned hotels & 10 & 4,500 & 0.27 & 4.54 \\
\hline Total & 3,651 & 99,197 & $100 \%$ & $100 \%$ \\
\hline
\end{tabular}

Source: VNAT, 2010

Tables 1.2 and 1.3 show all Vietnamese hotels and the up-market hotels in terms of ownership modes throughout the country in 2010 and 2011. Among 3,651 hotels, the DPOHs made up the largest proportion (88 percent of the country's total hotels and 61 percent of total rooms), followed by the SOHs with 10 percent of hotels and 25 percent of rooms. The foreign ownership hotels accounted for a very small number since the 
IJVHs exhibited only 1.53 percent of the total hotel numbers and 9.02 percent of rooms. There have been only 10 FOHs with 4,500 rooms in 2010, representing $0.27 \%$ and $4.54 \%$ of total hotel numbers and hotel rooms. Table 1.3 indicates that the up-market hotels constituted a small part of the hotel sector as the hotels classified from four to five stars made up approximately five percent of the total number and 30 percent of rooms (with 184 over 3,651 and 29,816 over 99,197 respectively). The reason why this study focuses on four-and five-star hotels located in Hanoi, Danang and Ho Chi Minh City to examine the distribution channel structures is explained below in Section 3.2.2.

Table 1.3. Vietnamese up-market hotels by quality and ownership modes

\begin{tabular}{|c|c|c|c|c|c|c|c|c|c|c|}
\hline \multirow{3}{*}{$\begin{array}{l}\text { Vietnamese } \\
\text { upmarket hotels }\end{array}$} & \multicolumn{8}{|c|}{ Hotel ownership modes } & \multicolumn{2}{|c|}{ Total } \\
\hline & \multicolumn{2}{|c|}{ SOHs } & \multicolumn{2}{|c|}{ DPOHs } & \multicolumn{2}{|c|}{ IJVHs } & \multicolumn{2}{|c|}{ FOHs } & \multirow[b]{2}{*}{$\begin{array}{l}\text { Number } \\
\text { of } \\
\text { hotels }\end{array}$} & \multirow[b]{2}{*}{$\begin{array}{l}\text { Number } \\
\text { of rooms }\end{array}$} \\
\hline & $\begin{array}{l}\text { Number } \\
\text { of } \\
\text { hotels }\end{array}$ & $\begin{array}{l}\text { Number } \\
\text { of } \\
\text { rooms }\end{array}$ & $\begin{array}{l}\text { Number } \\
\text { of } \\
\text { hotels }\end{array}$ & $\begin{array}{l}\text { Number } \\
\text { of } \\
\text { rooms }\end{array}$ & $\begin{array}{l}\text { Number } \\
\text { of } \\
\text { hotels }\end{array}$ & $\begin{array}{l}\text { Number } \\
\text { of } \\
\text { rooms }\end{array}$ & $\begin{array}{l}\text { Number } \\
\text { of } \\
\text { hotels }\end{array}$ & $\begin{array}{l}\text { Number } \\
\text { of } \\
\text { rooms }\end{array}$ & & \\
\hline 5 star hotels & 2 & 560 & 18 & 4,240 & 20 & 5,999 & 6 & 2,466 & 46 & 13,265 \\
\hline 4 star hotels & 41 & 4,125 & 73 & 5,982 & 22 & 5,632 & 2 & 812 & 138 & 16,551 \\
\hline Total & 43 & 4,685 & 91 & 10,222 & 42 & 11,631 & 8 & 3,278 & 184 & 29,816 \\
\hline
\end{tabular}

Source: VNAT, 2011

Differences are found among the up-market hotels of different ownership modes concerning the number of hotels and rooms (see Table 1.3). In 2011, DPOHs accounted for the largest proportion of establishments (91), followed by SOHs and IJVHs with 43 and 42 hotels, respectively. However, foreign ownership hotels dominated the high-end hotel market since five-star IJVHs and FOHs represented about 56 percent of hotel number and 64 percent of total rooms. Among 43 SOHs, only two hotels, both in Ho Chi Minh City, are rated as five stars. Meanwhile all of the IJVHs are operating under globally recognised hotel brands such as Hilton, Marriott, Meliá, Nikko, Grand Mercure, Novotel, Pullman and Sofitel of Accor, Crowne and InterContinental of IHG and Sheraton of Starwood. All of the DPOHs and SOHs are applying independent and semiindependent management modes. This will be discussed in detail in Sections 3.2.4, 4.2.2, 5.3 and 5.4. 
In conclusion, the brief review of Vietnamese hotel development reveals that the context of Vietnam's economic reform has created favourable conditions for hotel development, promoting Vietnam from a low starting point to an emerging tourist destination in Southeast Asian region. Doi Moi not only has generated the diversity of hotel ownership modes (SOHs, DPOHs, IJVHs and FOHs) and different hotel star ratings, but also it has contributed to shaping a competitive hotel business environment. Moreover, the appearance of global hotel groups has in turn confirmed the Vietnamese hotel position in the international tourism market.

\subsection{Research questions}

This research attempts to fill the gap in the literature of the hotel distribution in Vietnam and in transitional economies by addressing the primary research question: Taking the case of up-market hotels in Vietnam, how do the different hotel ownership modes in a transitional economy structure distribution channels? The study has three subresearch questions:

1. What is the current structure of hotel distribution channels of different ownership modes in a transitional economy?

2. What factors influence the existing structure of hotel distribution channels of different ownership modes?

3. What are the implications of these structures and factors for hotel and tourism development in Vietnam?

This research adopts a post-positivist approach to guide the researcher' set of beliefs to address the above research questions, to identify the relationship between the researcher and the research participants and/or research subjects, and to decide the methodological approach or the process of this research. The post-positivist paradigm applied in this study is explained in detail in Section 3.2.1. Specifically, for research question One, diagrams of the current hotel distribution channel structures of the four hotel ownership models will be depicted to show the direct and indirect channels connecting hotels with consumers. Channel mix, direct and indirect distribution, channel member, channel length, channel width and channel functions within each structure as well as commonalities and differences between these structures will be presented. Research question Two will investigate the key factors, which shape and influence the existing structure of distribution channels of the different hotel ownership models. A wide range 
of factors will be discussed including Vietnam's economic renovation and transitional economy in the context of the country's integration into the world, hotel ownership and management model and patterns of demand. Research question Three considers the implications of hotel distribution channel structures of the different ownership models and factors influencing these structures for hotel and tourism development in Vietnam. The study findings have relevance for Vietnamese hotels, travel intermediaries, policy makers and researchers, and also for other transition economies and countries with similar socio-economic characteristics such as some countries in Central and Eastern European Countries (CEE), China, Cuba and Myanmar.

\subsection{Structure of the thesis}

This thesis consists of nine chapters. Having introduced the thesis and research context in Chapter One, Chapter Two reviews the literature. Essential characteristics of transitional economies are explored, including ownership, business operations and distribution. This is followed by the literature on tourism and hotels in developed and transitional economies as well as tourism and hotel distribution channel structure. The conceptual framework developed from these investigated literatures is drawn. Other background information relating to the development of tourism in Vietnam, the research sites, operational settings and brief descriptions of the four hotel ownership modes is presented in Chapters Two to Five to better contextualise the specific points being made there.

Chapter Three is research methodology, and presents the overall research development process, justifies the methodological design including the research context, choice of the qualitative supply-side approach, and the methods of data collection and analysis. Indepth qualitative semi-structured interviews and compiling secondary documents are used. Participants are selected from the up-market hotels located in Hanoi, Danang and Ho Chi Minh City, various government departments at central and provincial levels, international TOs in these cities, trade organisations and academics.

Chapters Four and Five are structured in the same way. Chapter Four presents the distribution channel structures for international and domestic tourists applied by SOHs and DOPHs. The operational setting, brief descriptions of these hotel ownership modes and patterns of demand and their distribution channels are firstly investigated. Diagrams 
of the current distribution channel structures undertaken by these hotel ownership modes are depicted. Channel mix, direct and indirect distribution, channel members, channel length, channel width and channel functions are finally discussed. Chapter Five starts with the operational setting shared by IJVHs and FOHs. The chapter reviews in detail the Constitutions of Vietnam and various versions of foreign investment laws that contributed important roles in generating a business environment for foreign investors today. It then presents the main characteristics of the selected hotels within each ownership mode, patterns of demand and the distribution channel structures used to distribute their products and services to international guests and domestic travellers.

Chapter Six then draws together the patterns of demand and distribution across the four hotel ownership modes in terms of market mix, types of travel of international guests as well as proportion of room night sales from the international markets to find out similarities and differences of these hotels' distribution channel structures.

Chapter Seven identifies and explores factors that influence the current distribution channel structures of different hotel ownership modes regarding aspects of distribution mentioned in Chapters Four and Five. A wide range of factors are analysed based on a conceptual framework including Vietnam's economic renovation and transitional economy in the context of the country's international integration, hotel ownership and management modes and patterns of demand.

Chapter Eight presents the implications of the current hotel distribution structures for the hotels, travel intermediaries, policy makers and researchers in Vietnam and elsewhere in transitional economies and the world. This is followed by the implications of the factors identified in Chapter Seven. Recommendations for further research are also mentioned in this chapter.

Chapter Nine presents discussion and conclusions of the thesis. This chapter firstly summarises the study findings and then discusses main findings. It is followed by investigations of strengths and limitations of the research. Contributions are drawn before concluding thoughts of the thesis. 


\subsection{Conclusion}

This chapter has outlined an introduction, research context and overview of the thesis. It has emphasized that examining hotel distribution channels in relation to hotel ownership modes in the context of transitional economies such as Vietnam is a research gap and an interesting issue in the literature of tourism and hotel distribution channels. To better understand the hotel distribution channels in Vietnam as a transition economy, the study identifies distribution channel structures of various hotel ownership modes, factors influencing these structures as well as implications of the existing influential factors and structures. 


\section{CHAPTER 2. LITERATURE REVIEW}

\subsection{Introduction}

This chapter reviews the literature on tourism and hotel distribution channels in the context of transitional economies to propose a conceptual framework of hotel distribution channels in Vietnam. First, an overview of transitional economies' characteristics will be highlighted. Second, ownership, business operations and distribution in these countries will be discussed. Third, tourism and hotel issues including tourism and hotel distribution channels in some transitional economies will be outlined. This is followed by a review of research on tourism and hotel distribution channels including a snapshot of Western literature in tourism and hotel distribution as well as some other transitional economies and in Vietnam. These examinations of Western literature and transitional countries shed light on the research gap in the literature of hotel distribution channel research. Finally, a conceptual framework will be proposed and elaborated upon to guide the research design. The framework enables the researcher to investigate the linkages and relationships among the components that constitute the current hotel distribution channel structures in a transitional economy.

Transitional economies comprise of a number of countries located in Central and Eastern Europe (CEE), Baltic states such as Estonia and Latvia, some economies in the Commonwealth of Independent States (CIS), including Russia, and countries in Asia such as China, Laos and Vietnam. As such, use of the term transition has become identical with forms of post-communist countries' economic restructuring processes (Hall, 2008; IMF, 2000). Showing a small difference with CEE and CIS in terms of political ideology, China and Vietnam are both led by single political parties, that is, Chinese Communist Party and the Vietnamese Communist Party. These two countries pursue economic transformation without apparent ideological change: China is in transition to socialism with Chinese characteristics and Vietnam follows a model of a socialist market-oriented economy (Chon, Pine, Lam \& Zhang, 2013; Hall, 2008; Zhu $\&$ Fahey, 2000). With these socio-political commonalities, the dominance of literature in China's transitional economic context and the absence of tourism research in Vietnam, a number of sections within this chapter will concentrate on reviewing 
literature on China rather than CEE and other transitional economies to examine the research gap.

\subsection{Essential characteristics of transition economies}

Although transitional economies have received a great deal of attention as examples of socio-economic development and political transition, few researchers have generalised main characteristics of the transition process of these countries (Svejnar, 2013). This is because we still lack a solid understanding of the process, and transitional economies may differ from one to another regarding cultural, political, social and historical factors, the level of income and wealth as well as the nature and extent of economic distortions (De Melo, Denizer \& Gelb, 1996; Svejnar, 2013; Tsang, Nguyen \& Erramilli, 2004; Zecchini, 2013). Each economy has individually faced short-term difficulties, and longer-term challenges on institutional, structural and behavioural changes such as high rates of unemployment and inflation, lack of entrepreneurship and skills, infrastructure and a sophisticated legal system as well as corruption (Beck \& Laeven, 2006; De Melo et al., 1996; Kornai, 1993; Svejnar, 2002).

However, a few studies have pointed out that post-communist countries share certain typical features, such as transformation from a planned to a market economy, gradual privatization of state-owned enterprises (SOEs), and the opening up of the domestic economy to international trade and global investments (Aukutsionek, 1997; Szondi, 2007; Tsang et al., 2004). Estrin and Mickiewicz (2011), Havrylyshyn and Wolf (1999) and the IMF (2000) outlined some features of these transitional economies. First, restructuring and privatizing the entire economy and SOEs as means to promote the transition from a command to a market economy. In the transitional phase, marketbased restructuring involves both survival-driven changes aimed at reducing existing inefficiencies and growth-oriented changes to re-orient the enterprise's processes and products to current market requirements (Commander \& Svejnar, 2012). Second, liberalising economic activity means reducing and eliminating subsidies and state ownership to create an equal business environment with the participation of other ownership types (Commander \& Svejnar, 2012; IMF, 2000). Liberalisation allows most prices to be determined in a free market mechanism of the world's market economies. This characteristic is linked to an important feature of a market economy, by which decisions regarding investment, production, and distribution are driven by supply and 
demand under a free price system. Finally, the policies of restructuring, privatising and liberalising the economy that play important roles in the transitioning process are based on an effective legal framework and market instruments. The legal and institutional reform process has been re-identifying the role of the state in these economies (IMF, 2000).

The collapse of socialist governments in CEE and CIS countries including Russia was considered as one of the most remarkable socio-economic and political changes in the late $20^{\text {th }}$ century, generating a subsequent restructuring from state-command to marketdriven economies (Prishchepov, Radeloff, Baumann, Kuemmerle \& Müller, 2012). The transition has involved attempts to change the institutional system, to decentralise, stabilise and restructure the economies (Svejnar, 2013). In terms of institutional building, the entire set of formal institutions has been restructured to build market interactions from scratch, including private ownership, a system of private property, capital markets and an appropriate legal and institutional infrastructure (Bevan, Estrin \& Meyer, 2004). A trend of economic restructuring has been asserted by Bruha and Podpiera (2007), De Melo et al. (1996) and Nellis (1999), that is, the privatisation of SOEs and full liberalization of price has been given priority. Privatisation has become a motivator of economic development and the transitioning process (Hall 1998; Harrison, 2001), promoting a competitive business environment by reducing state ownership (Choi, Lee, \& Williams, 2011; Grinter, 2006; Mak, 2008; Sun, Tong, \& Tong, 2002).

Several researchers mentioned that a notable characteristic of transitional economies such as China and Vietnam is the proliferation of various modes of companies including SOEs, domestic private owned-enterprises, international joint ventures and wholly foreign-owned ones, and a rise of competition among them to reach domestic and international markets (Li, Cui \& Lu, 2014; Thi Hong Nguyen, Wood \& Wrigley, 2013; Vo \& Nguyen, 2012). Tsang et al. (2004) contended that domestic companies in transitional countries are forced to compete with foreign ownership corporations to gain market shares. Customers in transition economies are also becoming increasingly sophisticated, demanding innovation and service. However, most of the local companies lack the technological, managerial, and marketing capabilities to meet customers' needs and to compete in market-oriented economies. In some other transitional economies in Eastern Europe, these characteristics are also found when these countries have opened 
to international trade. This opening has brought about a more efficient allocation of resources according to world market prices and foreign direct investment (FDI) (Estrin, Hanousek, Kočenda \& Svejnar, 2009). FDIs in transition economies have significantly created the growth and business environment transparency of transitional economies, contributing to speed up the transitional process by formulating a basis for more effective corporate governance and by stimulating enterprise restructuring (Djankov \& Murrell, 2002; Iwasaki \& Tokunaga, 2014). The FDIs may also promote technical innovation, and speed up the restructuring of enterprises in addition to providing capital account relief (Bevan \& Estrin, 2004) as this type of investment has been one of the main drivers of economic restructuring, contributing to the region's integration into the European Union and global markets (Medve-Bálint, 2014).

As mentioned at the onset of this chapter, a characteristic of China and Vietnam is a slow or non-democratic transition to a market economy with no change in political regime. In Vietnam, it was noted by Athukorala and Tien (2012) and Fforde (2002) that though the opening-up of the economy to FDI has also been a key element of Doi Moi in Vietnam, the transformation and the construction of the institutions of civil society have been slow because of the conservative transition. Apart from China and Vietnam, the conservative transition is also found elsewhere in a specific field of economy, that is, tourism when Phillips (1996) asserted that two groups of gatekeepers of structural transformation in tourism have been recognised: new managers who believed in vertical structures and entrenched cultural expectations and those businesspersons who were likely to desire to reconstruct communist society and adopt new conditions. To some extent, this finding has also been mentioned in Chinese and Vietnamese tourism research via the studies of Lloyd (2004), Qu, Ennew and Sinclair (2004, 2005), Suntikul (2010), Suntikul, Butler and Airey (2008, 2010a, 2010b).

The characteristics of transitional economies identified by researchers are particularly relevant in Vietnam since the Vietnamese Constitution has identified its economic development policies to included the following (VNA, 2013):

- The policies of restructuring, liberalising the economy to attract domestic and international investments via an open door scheme; 
- Relationships between business environment, proliferation of various ownership enterprises and the economic restructuring from statecommand to market-driven economies; and

- Marketization and privatisation of SOEs to reach markets.

These features will be firstly used as foundations to review the literature of ownership, business operation, tourism and hotel distribution, and research on tourism and hotel distribution channels in Vietnam. Transitional economies' characteristics will also be used to shed light on operational settings that different hotel ownership modes operate towards international tourism markets. These characteristics will be returned to in Chapters Eight and Nine where implications and discussions of the current hotel distribution channel structures of various hotel ownership modes and factors influencing them for the hoteliers, tour operators, policy makers, and researchers are written.

\subsection{Ownership, business operations and distribution in transition economies}

The majority of research conducted in transitional economies has focused on changes of the political, socio-economic, business environment and the nature of on-site enterprises in a post-communist era. Among factors causing this transformation, ownership has been a centre of heated debates. This is because economic restructuring, privatization and transformation in these countries were directly driven by policies to create new forms of the SOEs, the proliferation of various firm ownership modes, and the opening up to international trade and investments (Jones \& Mygind, 1999; Su \& He, 2012; Tang, $\mathrm{Xi}$, Chen, \& Wang, 2006). Research conducted in transitional economies including Vietnam concluded that ownership modes are closely associated with numerous fields of enterprise such as effectiveness, innovation, market orientation and productivity, reflecting the impact of economic reforms on businesses (Choi et al., 2011; Le \& Buck, 2011; Qu et al., 2005; Ramstetter \& Ngoc, 2013; Su \& He, 2012).

To date, studies of transitional economies have questioned ownership and ownership modes regarding the difference between state and private, domestic and foreign, and the influence of ownership and political reform on company development as well as on the privatisation of SOEs. In China, $\mathrm{Su}$ and $\mathrm{He}$ (2012) found that firm efficiency is negatively related to SOEs while positively associated with public and employee share ownership. As the largest shareholder changes from government or government- 
controlled legal entity to other types of legal entity, firm efficiency significantly improves, $\mathrm{Su}$ and $\mathrm{He}$ concluded that enterprises with more independent management style are more efficient. Also in China, Qu and Ennew (2005) highlighted that ownership modes affect the development and organisation of tourism enterprises in the market. In non-state owned companies, the general managers have much power to organise their companies and make decisions on financial issues, and on employing motivation rewarding and dismissing labourers. However, state ownership, with its dated management mechanisms and systems, is one of the barriers to the development of market-oriented organisation in the tourism industry (Mak, 2008; Qu \& Ennew, 2005). The notion of quasi-lifetime employment in Chinese state-owned companies means that employees could be dismissed only for serious misconduct. The lack of a mobile workforce that resulted from this quasi-lifetime employment and un-written law had not allowed the general directors to respond to market intelligence (Qu et al., 2004; $\mathrm{Qu} \&$ Ennew, 2005). A similar situation occurs in Vietnam as the quasi-lifetime employment is regarded as a legacy of the command economy in SOEs, hindering the current organisational structure, progress of equitisation and privatisation of SOEs. One of the controversial methods applied by the Vietnamese government to maintain lifelong jobs for a number of state labourers, particular of high position staff, is that the government keeps ownership in equitized and privatised enterprises up to 51 percent (Pham, 2014). Another difference between Vietnamese SOEs and non-state corporations is the government's preferential treatment of SOEs over private ownedenterprises. The responsibility of managing directors who are representatives of the government to operate the business is not clear. This corporate governance reduces the mobility and competitiveness level of SOEs compared with non-state and international enterprises (Anh Vu, 2015; Nguyen \& Van Dijk, 2012).

Regarding the relationship between ownership structures, firm innovation performance, and the management mode of enterprise, Choi et al. (2011) outlined the relationship between ownership structures and firm innovation performance in China. They found the volume of patent registration to be strongly influenced by foreign ownership in the firm. Inside ownership and investment leads to lower innovation performance (Choi et al., 2011; Müller \& Wärneryd, 2001). Choi et al. (2011) and Estrin et al. (2009) also noted a significant relationship between ownership structure and company innovation performance. Ownership is considered to be the source of differences among SOEs, 
privatised enterprises, those transitioning to privatisation, international joint ventures, and the foreign-owned companies which needs to be taken into account by policy makers when focusing their attention on reforming state ownership. Vo, Swierczek and Nguyen (2013) suggested in the context of Vietnam that privatized firms with less state ownership perform better than those with more state ownership.

In terms of efficiency among types of enterprise and functions of governments in transition economies, Commander and Svejnar (2008), Tang et al. (2006) and Sun, Tong and Tong (2002) contended that government ownership is less efficient than private ownership. Governments play an important role for entrepreneurship development, particularly with respect to their role in creating the institutional framework that enables and/or constrains entrepreneurship (Smallbone, Welter, Voytovich \& Egorov, 2010). Indeed, almost all enterprises in transition economies started as SOEs with their initial objectives consistent with the principles of central planning. To escape these limitations of backward corporate governance, a combination of privatisation, entry of new private enterprises, and fundamental changes in the legal systems has been at the core of the development (Commander \& Svejnar, 2008). In Slovenia, state funding has a negative influence on the development of companies in which the government holds ownership shares because of its passive investment policy (Cvelbar \& Mihaliè, 2007). The state often pursues not only economic but also political interests; the business environment created by government therefore tends to benefit the SOEs over the others, causing an unequal competition among types of enterprises. Accordingly, various ownership modes play an important role in shaping the companies' development and their operations. It also reveals the ability of an enterprise and directly reflects the equality of the business environment where enterprises compete with each other. Therefore, Hassard, Morris, Sheehan and Yuxin (2010) argued that central to the process of economic reform has been the marketization of SOEs.

These above findings of ownership structures, enterprise efficiency, domestic and foreign ownership and privatisation of SOEs are consistent with numerous studies conducted in other transition economies (Estrin et al., 2009; Hamm, King \& Stuckler, 2012; Kokko \& Thang, 2014; Ramstetter \& Ngoc, 2013; Svejnar, 2002; Truong, 2013; Tsang, Nguyen \& Erramilli, 2004). However, such political factors and economic features of enterprises are found in only a very limited number of studies in the Vietnam 
tourism and hotel industry. Suntikul et al. (2010b) investigated the effects of FDIs in tourism accommodation on developments and practices in Vietnam's accommodation market in relation to Doi Moi to get insights into business environment and challenges of SOEs to compete against IJVHs in quality. Lloyd (2003, 2004) examined the impact of government regulation and its pro-SOE policy on the development of private smallscale tour operators in Vietnam. Lloyd concluded that there is a problem of business environment since small tour operators have been subject to erratic responses by government authorities, informal payments and aggressive competition from SOEs. In the research on tourism and hotels, though factors of political reform, state and private tourism enterprise, domestic and foreign hotels, and ownership and management mode may influence enterprises' resources, objectives, target market, the nature of products and services as well as distribution channel structures, studies exploring these relationship have been neglected by researchers.

The economic reform leading to market liberalization, competitive pressure, and consumers' demands have combined to transform transition economies' distribution systems of firms from being supply-driven to being increasingly responsive and marketdriven (Cadilhon, Moustier, Poole, Tam \& Fearne, 2006; Jiang \& Prater, 2002; Luk, 1998; Maruyamar \& Trung, 2011). Distribution is recognised as "the means of making a supplier's product or service available to the consumer in the right form, in the right quantity, in the right place and at the righ time" (Pearce, 2007, p. 44). In China, under a command economy, the structure of distribution channels was strictly organized in line with the administration system, which caused disconnection among production, distribution, and consumption (Shi \& Zhang, 2009). In the transitioning period, the structure of distribution channels has been changed from the administratively determined mechanism to a market driven one to meet the consumers' needs (Luk, 1998). Jiang and Prater (2002) note that three main forces, the booming economy, entering the World Trade Organisation (WTO) and e-commerce, are changing and modernising China's distribution system.

A few researchers have directly investigated a relationship between the economic reform policies and changes of distribution system of commodity (Luk, 1998; Holton \& Sicular, 1991; Jiang \& Prater, 2002; Maruyamar \& Trung, 2011; Venard, 1996). Notably, Luk (1998) noted that channel design and distribution mechanism of goods 
have been widely recognized as vital components of market entry strategy in transition economies. It requires marketers to discover causalities governing channel members' behaviour, the transaction mechanism, and the structure of the available distribution systems. In China, exploring causalities pertains to investigating factors, particularly ownership and government roles, that influence the distribution channel design (Jiang \& Prater, 2002). When designing a channel structure, practitioners deal with three elements: the relevant types of channels used, the number of channels, and the ownership mode of enterprise. This is because success is dependent on the number of marketing channels used and the composition of each channel, appropriate numbers of wholesalers and retailers based on available resources, and, therefore, channel structure differs among types of business ownership (Luk, 1998).

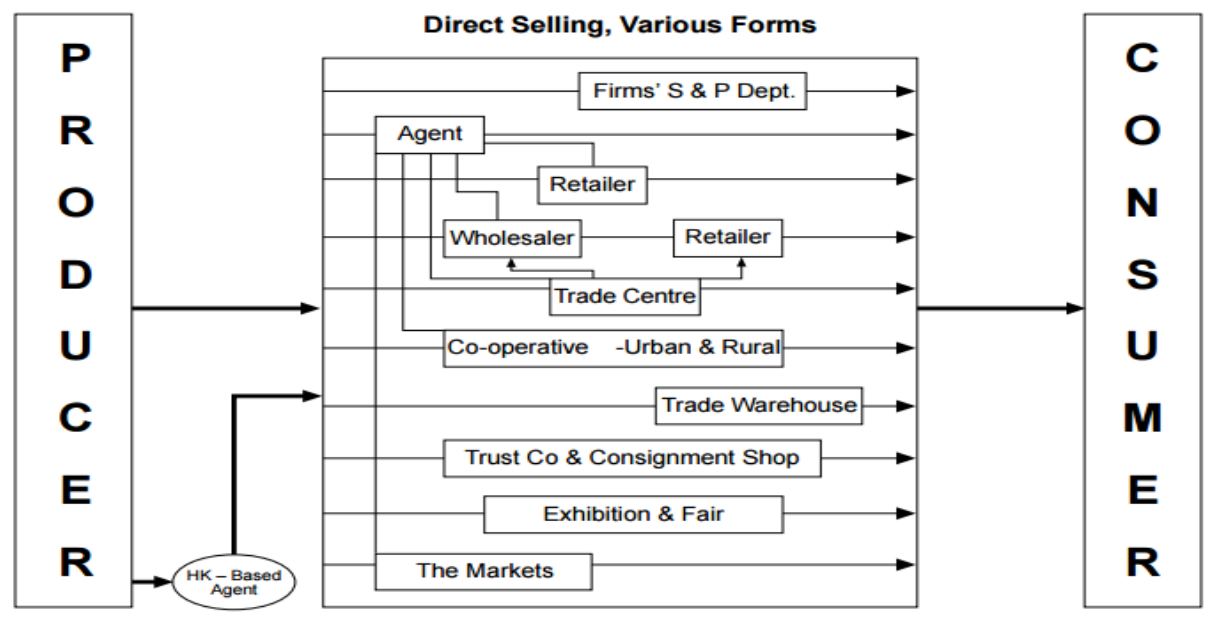

Figure 2.1. Distribution channels in China for consumer products (Source: Luk, 1998, p. 59)

Luk (1998) depicted a number of distribution channel structures of consumer goods and industrial products under a centrally planned economy and transitioning period. In these structures, different channels and channel members were used to distribute products to consumers including direct and indirect channels (Figure 2.1). In Vietnam, Cadilhon et al. (2003, 2005, 2006) and Maruyamar and Trung (2011) took a critical look at the supply chain in retail distribution of food and commodities to find the actual operation and retail renovations of local modern retailers, the structure and the background of competition. This research of distribution systems in Vietnam from the supply-side illustrates the ways in which Vietnamese enterprises have changed their distribution channel structure to approach markets and barriers that hinder this process, that is, 
inappropriate policies of the government and poor infrastructure. However, the studies of Cadilhon et al. (2003, 2005, 2006), Jiang and Prater (2002), Luk (1998) and Maruyamar and Trung (2011) examined logistics and the distribution channels that enterprises used to reach only the domestic commodity market; the international market that plays an important role in transition economies has been ignored by these researchers.

\subsection{Tourism and hotels in transition economies}

The transition process and tourism, which have a symbiotic relationship, have been paid attention by a number of researchers. Williams and Balaz (2000) note that changes in tourism are influenced by the economic, social and political transformation. The tourism industry contributes to a shift in consumer expenditure and it is positioned in the vanguard of privatisation and market liberalisation. The development of tourism has a direct impact on economies in transition through its net contribution to GDP and to employment. Hall (1991, 1998, 2001, 2008) and Jaakson (1996) argued that tourism's multifaceted connection in this context covers some specific features, including: (1) helping to integrate transitional countries into the global market economy; (2) promoting investment in, and upgrading of tourism services; (3) opening up the potential for travel both within and between countries. Moreover, Harrison (2001) and Balaz and Williams (2005) stated that economies in various stages of transition are likely to develop tourism as an important component of their national profile. In this respect, tourism plays roles as a management transfer instrument via FDIs and a leader in the privatisation process (Harrison, 2001).

This interdependent relationship and features between tourism and economic transformation have received less attention from researchers in the context of countries in CEE and in Asia. Williams (2002) noted that tourism in some countries in CEE became increasingly subject to globalisation because the organisation of outbound tourism changed over time, initiating a milestone of democratic change, reinternationalisation of markets and globalisation as people have travelled freely within a country and abroad (Jaakson, 1996). As a part of establishing functioning markets, the state tour operators and travel agents, who were the sole providers of holidays, were privatised and a number of new private owned travel companies emerged as a result of the economic transition (Williams, 2002). In China, tourism has steadily changed from a 
political activity into an economic one, and is regarded as one means of fostering economic development, internationalisation and the Chinese image (Chon et al., 2013; Jackson, 2006). Similarly, Vietnamese tourism has strongly impacted on the entire Vietnamese economy since Doi Moi, particularly as the government has allowed a liberalisation of trade in tourism with overseas companies (Cooper, 2000). The Vietnamese government faces the necessity of balancing its socialist ideology with the globalising and commercialising influence of the international tourism market on politics, economics and Vietnamese society in general (Suntikul, 2010). These studies generally explore features of tourism in relation to economic restructuring, but little attention is paid to the hotel sector except the following details.

The ownership mode has emerged as a controversial issue in transition economies as the question of ownership and control has inspired scholars. On the one hand, ownership can be generally used as a proxy for control of enterprises. This is particularly so with international joint ventures when the local management is responsible for the relations with external stakeholders, whereas the foreign parent controls the intra-company production process and overall implementation of company strategy (Child, 2002; Karhunen, Löfgren \& Kosonen, 2008; Wong, Luk \& Li, 2005). In many cases, ownership is an indicator of control because equity position often affects and determines the board of directors (Tallman, Sutcliffe \& Antonian, 1997). On the other hand, an increasing number of researchers have pointed to situations in which ownership and control are not positively related to each other. This is because control over operations may be achieved through non-equity contractual methods, and equity investment does not necessarily indicate that the investor might take an active role in the management of the venture. Some shareholders may prefer being a silent partner and investor to get profitability (Karhunen et al., 2008).

A number of studies have pointed out that ownership associates with the productivity gap between internationally and domestically private-owned properties and SOHs. In the context of China and Vietnam, Gu, Ryan and $\mathrm{Yu}$ (2012) asserted that the internationalization of the Chinese tourist accommodation sector has experienced dramatic development. International hotel companies first penetrated the Chinese market to serve high expenditure tourists. These hotel firms promoted brand awareness to Chinese consumers for future outbound business, hoping to attract Chinese tourists to 
their properties when travelling overseas. At present, both international and domestic hotels face challenges in business operations. International hotels in China have been enjoying competitive advantages in knowledge capital and global network support. However, such advantages could soon be challenged as more domestic hotels begin to internationalize their operations to gain access to the global market (Tang et al., 2006; Yu \& Huimin, 2005).

In Vietnam, political transition has affected developments in the accommodation sector in a number of ways. Suntikul et al. $(2008,2010 b)$ are the researchers providing a picture of Vietnam accommodations before and after Doi Moi. Under the command economy, the Vietnamese government was the only supplier of tourist accommodation, but now SOEs no longer hold a monopoly as private and international investors have also become involved. The appearance of the IJVHs in the accommodation sector in Vietnam has redefined the market parameters and has played a part in encouraging reforms in the way SOEs operate. State- and domestic private-owned accommodation have been forced to assume a more dynamic, customer-oriented stance by the competition brought by IJVHs (Suntikul et al., 2010b).

The main reasons for this difference between SOHs and non-state hotels are elaborated on by some researchers. The evaluation criteria of management in SOHs are unclear and subjective, and the pressure of revenue from SOHs is less than for other types of hotels. Mak (2008) revealed that it is necessary to reflect on the problems of SOHs. State ownership must be substituted by private ownership, which in turn requires immediate state-sector privatization and transferring the state's shares in state firms to private holders. Privatization will create a new market, which then forces newly privatized firms to act in competitive and market-oriented ways. Furthermore, Bachvarov (1997) examined the Bulgarian hotel industry and commented that Bulgarian SOHs received a lot of support from the government, which resulted in an unequal hotel business environment for the community of hoteliers. From the perspective of management issues, compared with the domestic, international joint venture or FOHs managed by international hotel groups or professional hotel management companies, the Vietnamese and Chinese SOHs in which the employees, including managers, are appointed by the state and the assets belong to the government are at the greatest disadvantage in management modes. Management decisions that should be made within the SOHs are 
determined by external bodies, while the responsibilities that ought to be external are internalized. The existence of insider control and ineffective external supervision have restricted the proper operation of these SOHs (Nguyen, 2009; Tang et al., 2006). Hence, it is argued that ownership has become a controversial issue of the hotel industry in transition economies, affecting the hotel management modes and reflecting the developments in the economic and political environment within which they operate (Johnson, 1997). The symbiotic relationship between tourism and transitional economies as well as ownership have been paid little attention by scholars in relation to distribution channels although these factors influence the hotel's position in the tourism market, and a good distribution system reflects the hotel resources and chances of selling its products and services more than its competitors.

\subsection{Tourism and hotel distribution channels}

Since tourism distribution channels have attracted a growing amount of attention in the context of economically advanced countries (Pearce \& Schott, 2005), this section will firstly review Western literature in order to provide insights into tourism distribution. Secondly, research on hotel distribution channels conducted in transition economies will be examined. Then, these two streams of literature will shed light on tourism and hotel distribution channels in Vietnam.

\subsubsection{Tourism and hotel distribution in the Western literature}

In marketing, distribution is understood as the place element of the marketing mix (along with price, product, and promotion) which provides "sufficient information to the right people at the right time and in the right place" to allow a purchase decision, a booking, and product payment to be made (O'Connor \& Frew, 2002, p. 33). A channel is defined as a method or system for distribution (Oxford Dictionaries, 2015). In other words, distribution is considered as the part of the marketing mix which provides the products available to consumers and acts as the bridge between supply and demand (Middleton \& Clarke, 2001). In a competitive environment, designing and using the right paths to the market place is crucial to the success of the business (Pearce, 2007). However, distribution channels vary according to size, types, and the target market of business organisation. The structure of distribution organised by an enterprise is dependent on the supporting network where the company operates (Middleton \& Clarke, 2001). 
According to Buhalis and Laws (2001, p. 8), distribution channels "provide information for prospective tourists; bundle tourism products together; and also establish mechanism that enable consumers to make, confirm, and pay for reservation". Hence, the objectives of using a channel are twofold, namely, to make relevant and timely information conveniently available to the hotel's potential customers and to make it easier for guests to reserve the property (O'Connor \& Frew, 2002). Based on these functions, Ujma (2001) found that the distribution channel structure can be characterised by a number of intermediaries which act independently and often conflict with each other. As illustrated in Figure 2.2, a tourism distribution system involves the channel structures, which connect tourists with providers by direct linkages and indirect linkages via a series of conventional and electronic intermediaries. In Figure 2.2, GDSs are computer database used by retail travel agents to reserve tourism products. CROs are used by hotel chains or other tourism firms with multiple locations to handle bookings (Pearce, 2007).

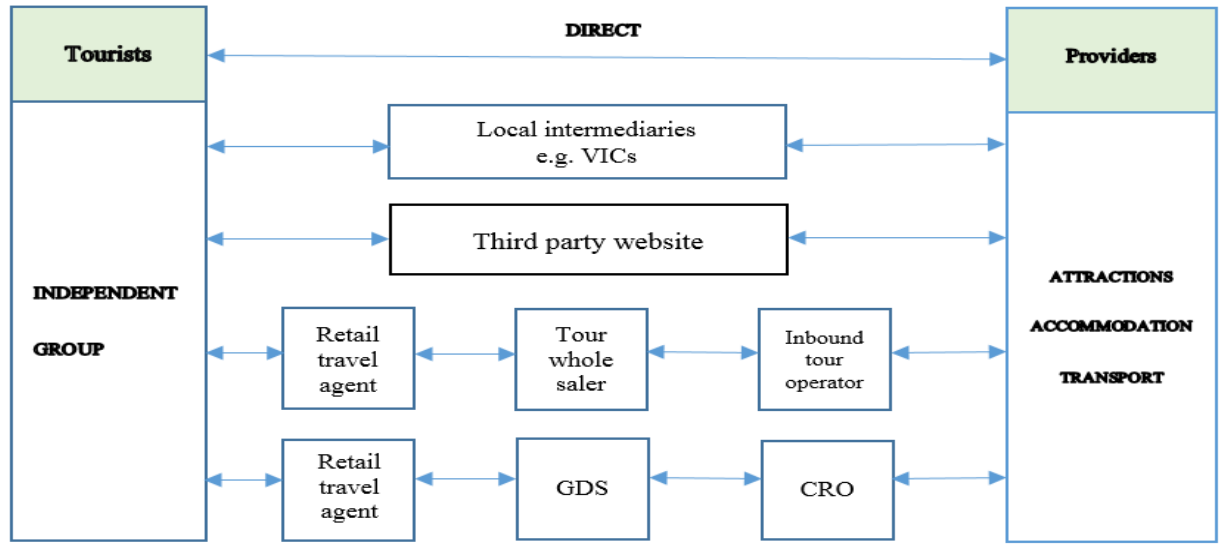

Keys: GDS: global distribution system; CRO: central reservation office

Figure 2.2. Multiple tourism distribution channels (Source: Pearce, 2007, p. 4)

Hotels often use multiple paths to meet the needs of the various consumers in the tourism market (O'Connor \& Frew, 2002). Distribution strategy has the greatest impact on hotel profitability (Pearce, 2009b), and distribution systems are a key to overcome this challenge (O’Connor \& Frew, 2002). Studies of Crichton and Edgar (1995), O'Connor and Frew (2002) and Pearce (2007, 2009b) have pointed out that this challenge is more difficult in the ever-changing, competitive, and global accommodation market. Hotels must carefully weigh their distribution decisions in light of their organisational goals and performance standards (Crichton \& Edgar, 1995). The use of a single channel or a combination of channels to attract tourists depends on the 
hotel's targeted market, hotel style or business characteristics, and product characteristics (Kang, Brewer \& Baloglu, 2007; Pearce, 2008). These direct and indirect channels, which are formulated from both consumers' demands for information, booking, and payment and the suppliers' needs for identification (Kaven, 1974; Pearce, 2009b), provide multiple choices and opportunities for different types of consumers to make their decisions on booking accommodation. While direct channels allow hotels and consumers to meet, indirect channels sell rooms through intermediaries such as travel agents, hotel representatives, tour operators, airlines, the centralised reservation and sales operations of chain hotels (Kaven, 1974), and online channels like third party websites, global distribution system, central reservations office (Pearce, 2009a). However, distribution channels used by tourism or hotel businesses vary according to size, types, and the target market of the business organisation. The structure of distribution is strongly dependent on the supporting network where these enterprises operate (Middleton \& Clarke, 2001). Most large hotels tend to use all possible methods to sell products and services to their potential consumers (Ujma, 2001). Ujma's statement can be illustrated in Figure 2.3, which presents a system of distribution channels that chain hotels in Wellington-New Zealand, use to sell their products. This structure provides the author with a detailed view of hotel distribution channels in a market economy before investigating problems in Vietnam.

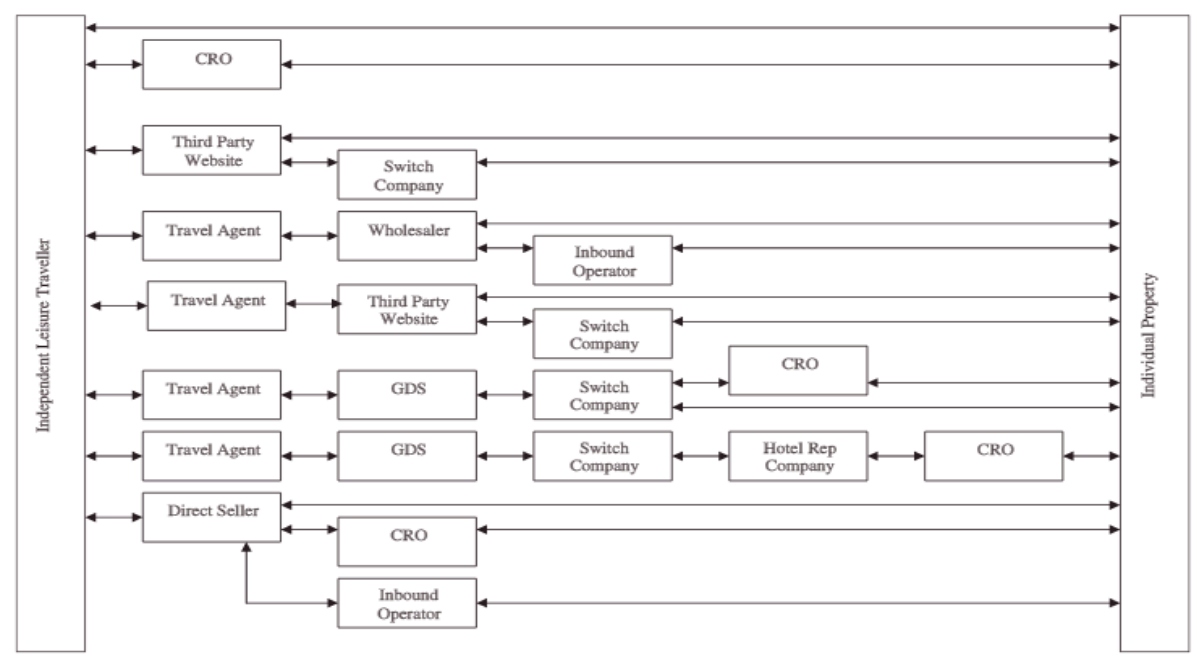

Figure 2.3. Distribution channels for chain hotels in Wellington: (a) independent leisure travellers (Source: Pearce, Tan \& Schott, 2004, p. 401) 


\subsubsection{Hotel distribution channels in transition economies}

A small number of studies conducted in the setting of transition economies have highlighted distribution as being one of the key components of the hotel marketing mix. Marinov and Kazandzhieva (2010) investigated coastal hotel distribution in Bulgaria and found that the channels for distribution of hotel products were both direct and indirect and they played a vital part in generating hotel revenue. Marinov and Kazandzhieva (2010) proposed a mode (Figure 2.4) which presents the different types of distribution channels to help hoteliers achieve optimum effectiveness in taking products to tourists. These researchers also identified some internal and external factors influencing the hotel distribution structures such as the hotel marketing budget and government policies. However, their study neglected to analyse the hotel ownership mode as an element formulating the distribution channel structure.

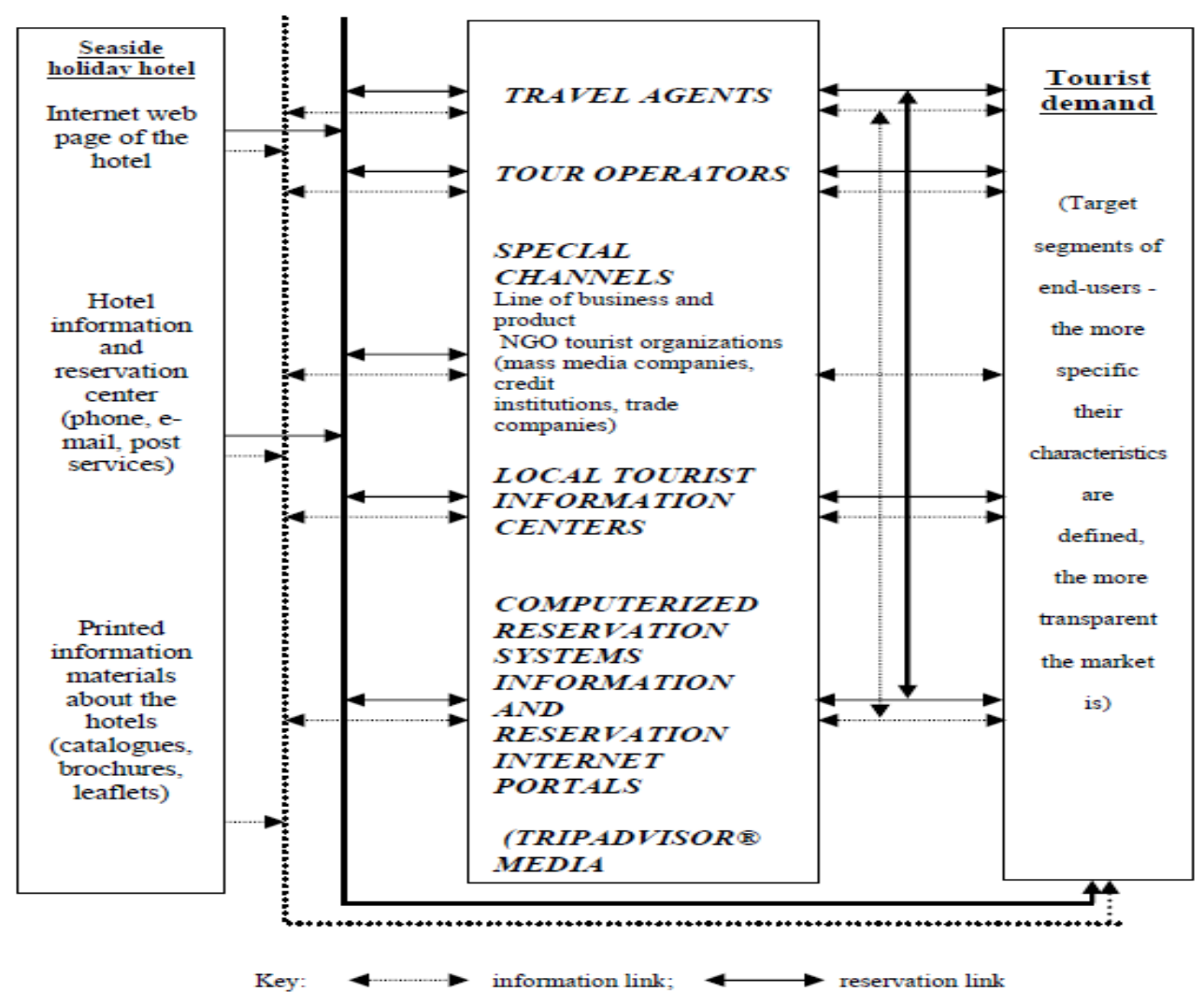

Figure 2.4. Mode of system for distribution of seaside holiday hotels (Source: Marinov \& Kazandzhieva, 2010, p. 33).

Some other studies of hotel distribution, hotel markets and paths to the tourism market of hotels in transition economies have suggested that the selection of distribution channels is influenced by a range of internal and external factors. The internal factors 
include ownership structure, hotel style, the scale of operation, location, target consumers, products, and marketing budget and strategy (Marinov \& Kazandzhieva, 2010; Qu et al., 2005). Qu et al. (2004) showed that ownership structure and government regulation had a great impact on paths to the market in the hotel and travel sector. In China, research suggests that the hotel sector is more market oriented than the travel services and that competition in the hotel sector is much less regulated than in the travel services arena. This is because China's travel services are dominated by stateowned companies while the hotel sector is generally regarded as its most competitive sector because of the diversity of ownership and the opening up to international investors (Qu et al., 2005). Qu et al. (2004) also highlighted that Chinese hotels' paths to the market are influenced by organisational factors, hotel resources and their business culture. Regarding external factors, hotel distribution is affected by political changes and the economic development level of the country, particularly in transition economies where the public sector is highly involved in formulating policies (Harrison, 2001), the market institutions are still inadequate, and financial and banking systems almost exclusively serve state-owned firms (McMillan \& Woodruff, 2002). In transition economies, the government acts as regulator, stimulator of investment, promoter of tourism opportunities and coordinator of tourism activities amongst government departments (Page et al., 2001). In other words, the development of hotels' distribution in transition countries is dependent on the government's objectives to facilitate tourist travel, and policies that are formulated to guide the organisation, management, and development of tourism. Zapalska and Brozik (2004) add that the impact of numerous factors and events can create a hostile business environment in any economy. This unfavourable business environment still exists in some transition countries because of inadequate and inefficient legal systems.

In addition to the business environment factors, hotel distribution systems in transition economies are influenced by other dimensions including consumers' needs, wishes and desires, and emotional attachment towards services (Marinov \& Kazandzhieva, 2010). While there may be a relatively stable type of distribution in economically advanced countries, emerging markets such as India and transitional economies (China and Vietnam) still have difficulty in establishing an effective distribution mechanism. In Vietnam, a number of factors that have forced the hotels to adjust their business objectives more frequently than those of developed countries such as a considerable 
number of small and medium hotels, unclear target markets, limited marketing budget, the unstable business environment, and the rapid changes of macro policies (Lloyd, 2003, 2004; Suntikul et al., 2008). These above studies mostly focused on analysing some factors in the context of transition economies that influence tourism and travel businesses, hotel development, distribution channels used by tourism and hotel enterprises to approach tourism market. The relationship between hotel distribution channel structures, hotel ownership modes and factors influencing them in transition economies has been ignored by scholars. For instance, Qu et al. (2005) investigated two national samples of Chinese hotels and travel services to identify their paths to market, and market orientation. These researchers found that there are differences between the hotels and travel service companies in reaching their market because of ownership factor. They, however, neglected to either investigate channel structure or draw the distribution channel structure of these businesses. Lloyd $(2003,2004)$ and Suntikul et al. (2008) concentrated on analysing the influence of the government's policies on the development of tourism and hotels since Doi Moi in Vietnam rather than a wide range of factors influencing tourism and hotel distribution channels.

\subsection{Research on tourism and hotel distribution channels in Vietnam}

\subsubsection{The development of Vietnamese hotels and distribution}

Section 1.2.2 identified three phases in the development of the Vietnamese tourism industry: (1) from 1960 to 1975 ; (2) 1975 to 1990, and (3) 1990 to present. VNAT (2015) also use these phases to categorise Vietnamese hotel sector development in terms of the emergence of hotel ownership modes and distribution channel members. In each phase, political, socio-economic and institutional changes have created distinctive features of the hotels with regard to ownership modes, the appearance of up-market hotels, hotel business environment and hotel market. Although this work by VNAT identifies the available channel members for hotels to approach domestic and international guests, hotel management modes and the ways in which the Vietnamese hotels utilise these channel members to distribute their products and services to the end guests have not yet received attention by either academics or Vietnam tourism policy makers.

A review of Vietnamese tourism and hotel development based on VNAT's $(2005,2015$; Table 2.1) reports suggest that the context of Vietnam's economic reform has created 
different development phases of the country's hotel sector. Doi Moi has also generated ownership modes across types of hotels. In each period, the hotel sector exhibits the transformation of service from being supply-oriented under command economy to a demand-driven mechanism under a market economy. These changes are due to the policies of Doi Moi and other factors that lead to the diversity of hotel ownership modes creating a competitive business environment. The emergence and information of the four hotel ownership modes and their management modes in the context of Vietnam's Doi Moi will be presented in more detail in Sections 4.2.4 and 5.3.3. Here, the three phases of hotel development are described regarding ownership modes and channel members as follows.

Table 2.1. The emergence of Vietnamese hotel ownership modes and hotel distribution channels since 1960

\begin{tabular}{|c|c|c|c|c|}
\hline \multirow{2}{*}{ Phases } & \multirow{2}{*}{ Hotel ownership models } & \multirow{2}{*}{ Main distribution channel members } & \multicolumn{2}{|r|}{ Guests } \\
\hline & & & Domestic & International \\
\hline 1960 to 1975 & SOHs & $\begin{array}{l}\text { No direct channel members } \\
\text { Indirect channel members: } \\
\text { - Vietnam Tourism Company } \\
\text { - Government departments } \\
\text { - Trade Union organisations } \\
\text { - State owned enterprises }\end{array}$ & Yes & $\begin{array}{l}\text { Mainly invited guests of } \\
\text { the government from } \\
\text { socialist countries }\end{array}$ \\
\hline 1975 to 1990 & $\begin{array}{l}\text { - SOHs } \\
\text { - DPOH } \\
\text { - Appearance of IJVs } \\
\text { - A floating wholly foreign } \\
\text { owned hotel operated in Ho Chi } \\
\text { Minh City since } 1987\end{array}$ & $\begin{array}{l}\text { Direct channel members: Landline, telegraph, } \\
\text { walk-in guests. } \\
\text { Indirect channel members: } \\
\text { - Limited number of state owned international } \\
\text { tour operators } \\
\text { - Few international joint venture and wholly } \\
\text { foreign owned tour operators } \\
\text { - Trade Union organisations }\end{array}$ & Yes & $\begin{array}{l}\text { - Mainly invited guests } \\
\text { of the government from } \\
\text { socialist countries } \\
\text {-A number of leisure } \\
\text { and business guests } \\
\text { from the Western }\end{array}$ \\
\hline 1990 to present & $\begin{array}{l}\text { - } \mathrm{SOHs} \\
\text { - } \mathrm{DPOH} \\
\text { - IJVs } \\
\text { - FOHs }\end{array}$ & $\begin{array}{l}\text { Direct channel members: Website, email, } \\
\text { landline, walk-in guests. } \\
\text { Indirect channel members: } \\
\text { - A huge number of international tour operators } \\
\text { and domestic tour operators } \\
\text { - Some international joint venture and wholly } \\
\text { foreign owned tour operators } \\
\text { - Electronic channels such as third party } \\
\text { website, GDS, CRO. }\end{array}$ & Yes & $\begin{array}{l}\text { - A booming of various } \\
\text { types of guests } \\
\text { including free } \\
\text { independent travellers, } \\
\text { leisure package tourists } \\
\text { and business travellers } \\
\text { from Asia, Europe, } \\
\text { North America, and } \\
\text { Oceania. }\end{array}$ \\
\hline
\end{tabular}

Source: VNAT $(2005,2015)$

From 1960 to 1975, Vietnamese hotels in the North were owned by the government of North Vietnam. These hotels provided services for members of the Vietnamese Central 
Trade Union called the Vietnam General Confederation of Labour ${ }^{2}$ and delegates from the governments of China and former Soviet Bloc countries. The legal intermediaries who could connect consumers with the hotels were the single state owned-tour operators (the Vietnam Tourism Company), government departments such as Vietnam Embassies, and state owned-enterprises. In this stage, the SOHs were the sole providers of accommodation for different types of domestic and international guests. According to VNAT's report, this study ignored hotels in the South Vietnam in 1960 to 1975. These hotels will be mentioned to in the next phase.

In the second phase (1975 to 1990), Vietnamese hotels began to develop within a transitional economy. The development gained momentum after Doi Moi when government allowed different economic sectors and modes of ownership to become involved in hotel business activities. The structure of the hotel distribution channels consisted of indirect distribution channels such as wholesalers (licensed state-owned, international joint venture and wholly foreign-owned tour operators), and retailers (branches of tour operators). Direct booking from guests could happen but seldom did due to the poor supporting network of landline telephones, and the banking system. For overseas tourists, according to Circular No. 04/2002/TTLT-BCA-BNG dated $29^{\text {th }}$ November 2002 of the Ministry of Foreign Affairs and the Ministry of Public Security, their visa applications must contain the invitation letter from one of the wholesalers, and be approved by the Vietnamese Immigration under the Ministry of Public Security before issuing (VNA, 2000). In other ways, foreign tourists could also apply for tourist visas directly via Vietnam Embassies. In this phase, a few IJVHs and FOHs appeared and started doing business in Vietnam under management contracts with global hotel groups. For instance, the wholly foreign-owned hotel named Saigon Floating Hotel was managed by Australia's Southern Hotels, and the Thong Nhat Hotel became a joint venture with Pullman Metropole Hotel under the brand Pullman.

From 1990 to present, Directive No 46/CT-TU of the Vietnamese Communist Party states that Vietnam develops tourism based on the country's historical values, natural resources, and high quality accommodation. Up-market hotels are increasingly reaching international standards and a variety of consumers' requirements and expectations. The

\footnotetext{
${ }^{2}$ In Vietnam, each state organisation including SOEs and governmental departments has its own trade union division that has operated according to Laws on Trade Union issued by the Vietnamese National Assembly in 1990 and 2012.
} 
hotel sector has exhibited a rapid rate of growth and the structure of hotel distribution channels has gradually developed to meet the tourists' needs (VNAT, 2010). For instance, before 1986 international tourists purchased services through the Vietnam Tourism Company and some state bodies. Now they can book rooms through different sources such as websites, local or international tour operators (TOs), local travel agents (TAs), online travel agents (OTAs) and overseas wholesalers and TOs. Nonetheless, hotels under the different forms of ownership present a difference in terms of their ability to take their products to the market (ITDR, 2005). Firstly, hotels which are owned by the government tend to use some traditional channels like international tour operators, travel agents and brochures to distribute products. Secondly, hotels owned by domestic private enterprises are mainly small and medium sized operations, but they account for the largest proportion of the hotel sector (ITDR, 2005). This ownership type often displays poor knowledge of distribution structure because of the family management style and hotel owners' background (VNAT, 2010). Thirdly, the IJVHs and FOHs who operate under high pressure of profit, and professional hotel management, exhibit a higher quality of service, contributing to fundamental changes in image of Vietnamese hotels (ITDR, 2005; VNAT, 2015).

\subsubsection{Studies on hotel ownership and distribution channels in Vietnam}

In Vietnam, there has been significant evidence that shows features connecting tourism and hotel distribution with economic transition and ownership modes. This transitional process has impacted on various socio-economic facets of this country, particularly the changing of ownership modes (Muller, 2007). The open door policies of Vietnam have also brought opportunities for its hotels to expand and develop the market, widening the opportunities for the hotels to reach the international tourism market (VNAT, 2005). In fact, ownership in terms of public ownership as a legacy of the command economy and private ownership as the nature of market economy has become the main characteristic of the Vietnamese socialist oriented market economy (Lloyd, 2004). In the service sector, the tourism system has reflected these influences (Berger, 2005). Two critical changes in terms of ownership in the Vietnamese hotels have been observed. Firstly, the market-oriented system has encouraged the proliferation of non-state-owned hotels. From having only state run hotels before Doi Moi, the hotel sector now consists of a variety of ownership modes: DPOHs, FOHs and IJVHs in addition to the SOHs (VNAT, 2005). Secondly, the appearance of various hotel ownership modes has spurred 
competition in the industry and has reflected government policies towards the market economy (Bui et al., 2006).

Suntikul et al. (2008, 2010a, 2010b) contended that the number of published studies on tourism in Vietnam is small, and research which examines the entire distribution system does not exist (Maruyamar \& Trung 2011; Venard, 1996). Research projects stored online by the Vietnam Institute for Tourism Development Research (ITDR) reveal that Vietnamese researchers have largely ignored tourism and hotel distribution as well as their relationship with Vietnam's transitional economy. Instead, domestical researchers focused on tourism and hotel development, products and services, tourism integration into the region and the world, and master plans for the entire country as well as for individual provinces and regions (ITDR, 2015).

In the sparse literature of this topic, only a small number of Vietnamese studies have examined channel members in the tourism and hotel distribution channel structure such as travel agents, tour operators or websites. Information technology is also considered in some research as an application to promote Vietnamese tourism. Two studies of Vietnamese hotel distribution channels focused on e-commerce as a means of reaching guests. Su (2009) investigated e-marketing used by Vietnamese hotels in the context of information technology development. The researcher found that there are three main groups of factors affecting the adoption of internet and web technology in Vietnam hotel marketing: organizational factors; innovation factors in term of perceived benefits, organizational compatibility and ease of use; and the business environmental factors in term of competitive pressure, customer power and government regulation. In another study of e-marketing, Bui et al. (2006) concluded that despite Ho Chi Minh City being the biggest tourism centre of Vietnam, hotels were facing difficulties in applying ecommerce to promote hotel marketing activities. The major factors hindering this adoption included the supporting networks, roles of government and e-commerce infrastructure. The studies of Bui et al. (2006) and Su (2009) only focused on Vietnamese hotels' ability to use and adopt e-marketing as a distribution channel. However, these researchers have ignored the fact that hotel distribution channels are wider than just online channels. 
Also focusing on the relationship between information technology and tourism, Thi Phuong Thao and Swierczek (2008) investigated how the internet and IT in Vietnam have brought about benefits for tour operators and travel agents in reaching consumers, building customer relationship as well as loyalty. These researchers found that the main obstacles to internet use were organizational weaknesses, poor IT infrastructure, mistrust of the internet system and legal issues. Bui (2009) explored the potential of Vietnam online tourism and the way to promote tourism products and services via a study of Skydoor software application. However, no empirical study has yet been found that examines the distribution channel structures of different hotel ownership modes to get a better understanding of changes in the hotel development and how the hotels have approached domestic and international tourism markets both in Vietnam and other transitional economies. While VNAT has described the historic development of hotels, tourism and hotel distribution channels are much more complicated than reported by VNAT, going well beyond the simple descriptive statistics in national records and official VNAT documentation. Hence, it is timely to investigate this under-researched topic in Vietnam.

\subsection{Conceptual framework for hotel distribution channels in Vietnam}

The conceptual framework presented in Figure 2.5 firstly enables the researcher to investigate the linkages and relationships among the components that constitute the current hotel distribution systems in a transitional economy. It is based on ideas drawn from a combination of the predominantly Western literature on hotel distribution channels and the fragmented literature on distribution in transition economies. Miles and Huberman (1994, p. 18) noted that a conceptual framework presents and explains the key factors and "their presumed relationships" in a graphical form which researchers examine. The framework constitutes the foundation for this research project and guides the research methodology.

The framework consists of three parts. First, the right-hand side of the diagram represents the current hotel distribution channels with the different channel structure that each hotel ownership mode can use. Second, the left-hand section depicts a process of economic development from a command to a market economy in transitional countries such as Vietnam: the influence of these economies on government policies, 
International Factors

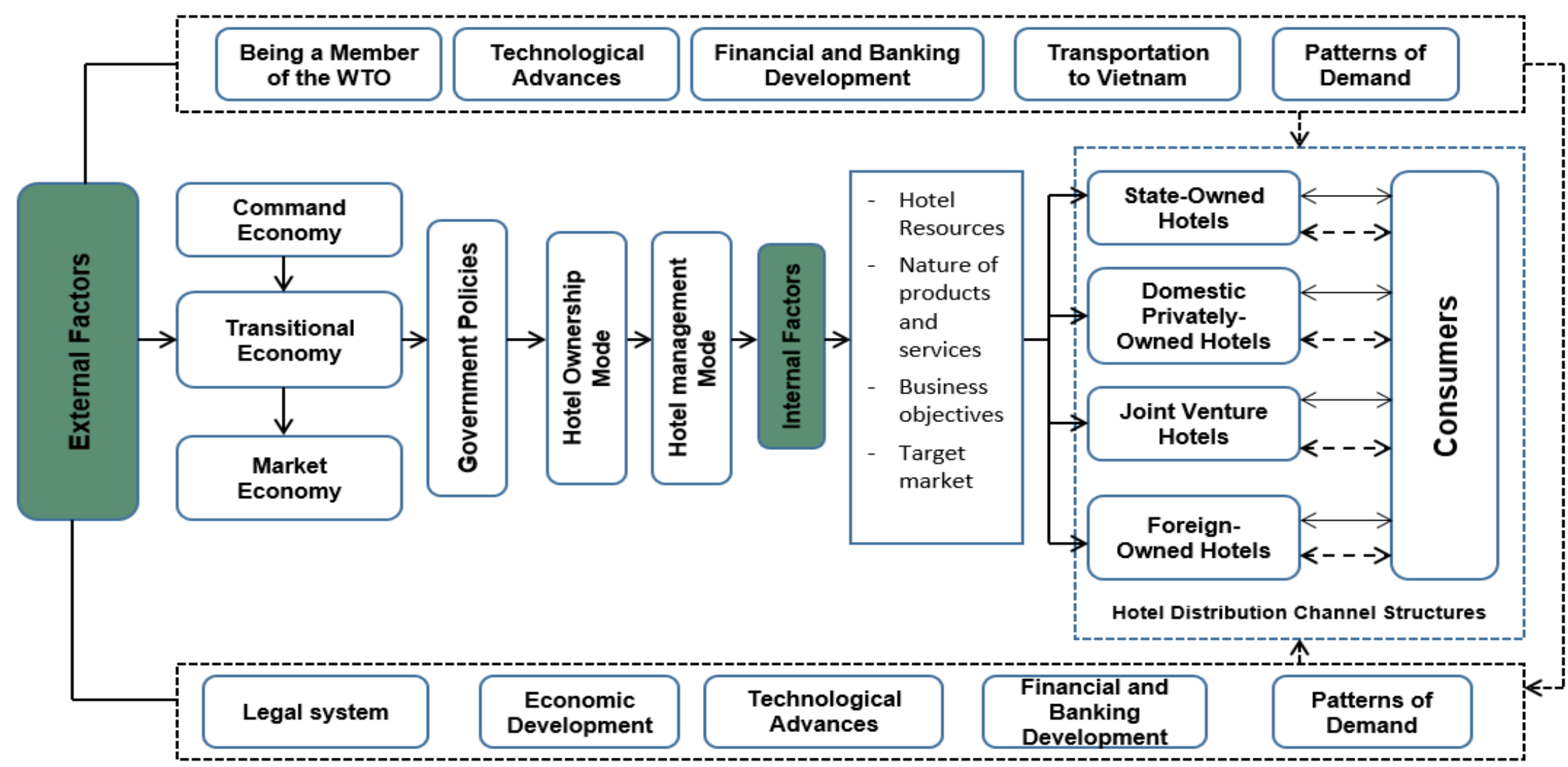

National Factors

Key:

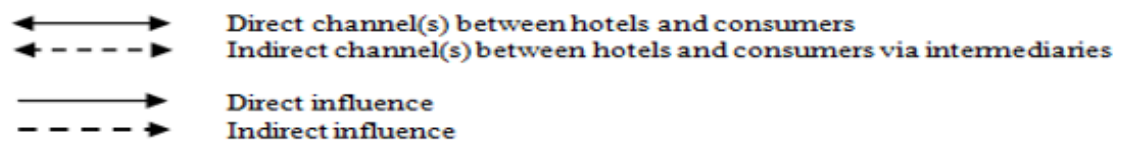

Figure 2.5. Conceptual framework for hotel distribution channels in a transitional economy 
hotel ownership modes, hotel management modes and the internal factors. Third, the outer part refers to the external forces including the national and international factors, which influence the transitional economy and the existing structures of hotel distribution channels. While two-way arrows show the direct or indirect distribution channels connecting hotels and consumers, one-way arrows represent relationships as well as direct and indirect influences between three parts.

The right-hand part of the framework is developed from Figures 2.1 to 2.4 and represents the current structures of hotel distribution channels of the different hotel ownership modes in a transitional economy. In this part, each hotel ownership mode uses direct and indirect channels to distribute its products to consumers. The channel structures used by these hotel modes might be similar or different because designing and using the distribution systems depends on the individual hotel style, hotel ownership and operation, business objectives and marketing strategy. More specifically, the structure of distribution channels for each hotel ownership mode is potentially based on internal hotel factors such as hotel resources, the nature of product and services, hotel business objectives, and target market that is particularly affected by ownership and management modes. Differences in ownership modes may influence the ability of hotels to reach consumers and create a productivity gap between the various types of hotels.

The current structure of hotel distribution channels reflects the indirect impacts of other factors like the economic transition, government regulations, and external forces. In transition economies, governments are highly involved in formulating policies to move from a command to a market economy; they are the regulators and stimulators of investment, promoters of tourism opportunities, and coordinators of tourism activities among government departments. Other national and international factors influencing the hotel distribution channel structures and consumers' travel attitudes may include transportation, financial services, banking systems, technological advances, the legal system and levels of economic development. The external factors that drive the market, the competitiveness of hotels, and government attitudes may have impacts on the hotel distribution channel structures and consumers, but hotel ownership modes may adapt to them differently due to the internal factors. 


\subsection{Conclusion}

This chapter has focused on reviewing literature in tourism and hotel distribution channels in the context of transitional economies and in Vietnam. A conceptual framework for hotel distribution channels has been proposed, enabling the researcher to investigate the linkages and relationships among the components that constitute the current hotel distribution channel structures in Vietnam. The chapter shows that distribution is an important area for the hotels in both advanced and transitional countries. Distribution channels play a prominent role in bringing success to businesses by providing information and guiding consumers' needs, enhancing the links between guests and hotels and facilitating the booking and purchasing process through direct and indirect linkages. In the hotel sector, it is argued that each hotel has its own strategies to establish distribution channels. When designing and implementing these structures, several factors influence this process including internal and external factors. In transitional economies, the literature highlights that a firm's distribution channels may have a relationship with political changes, government policies, and ownership since these factors affect the ways in which firms approach the consumers. However, the literature review points out that studies examining the current distribution channel structures of different up-market hotel ownership modes in the context of Vietnam's economic reform have not been found. 


\section{CHAPTER 3. RESEARCH METHODOLOGY}

\subsection{Introduction}

This chapter presents the overall research development process and justifies the methodological design, including: (1) the elaboration of the research questions, (2) an outline of the research context in relation to research methodology, (3) the choice of a qualitative supply-side approach, and (4) the methods of data collection and analysis. A qualitative supply-side approach is applied with data collected in the three largest urban cities, namely Hanoi Capital City in northern Vietnam, Danang City in Central Vietnam, and Ho Chi Minh City in southern Vietnam. Different groups of participants from the Vietnam tourism industry including senior sales and marketing staff in four- and fivestar hotels, international TOs, high-ranking government officials of national and provincial authorities of tourism, key officers of trade organisations and academics from these cities took part in the research. The data collection methods were in-depth semistructured interviews and document compilation. The chapter also describes the strengths and limitations of the methodology and outlines the presentation of research findings.

\subsection{Research design and methodology}

The choice of research design reflects decisions about the priority being given to a range of dimensions of the research process. The research design represents and articulates the researcher's plan and the structure of investigation that will be followed when seeking answers to the posed research questions. Its role is to provide answers to the research questions (Kerlinger \& Lee, 2000). The research design serves as a blueprint that outlines the overall research programme and guides the researcher in collecting, analysing, and interpreting data based on the research questions and the conceptual framework (Yin, 2014). Figure 3.1 illustrates the research design, and procedures that the researcher has experienced to design this study, namely: developing research questions and research context, designing research, collecting and analysing data, and presenting and interpreting findings.

\subsubsection{Research questions and research paradigm}

The methodology applied in this study is guided by the research paradigm identified in Section 1.3. The methodological approach is also determined by the research questions 


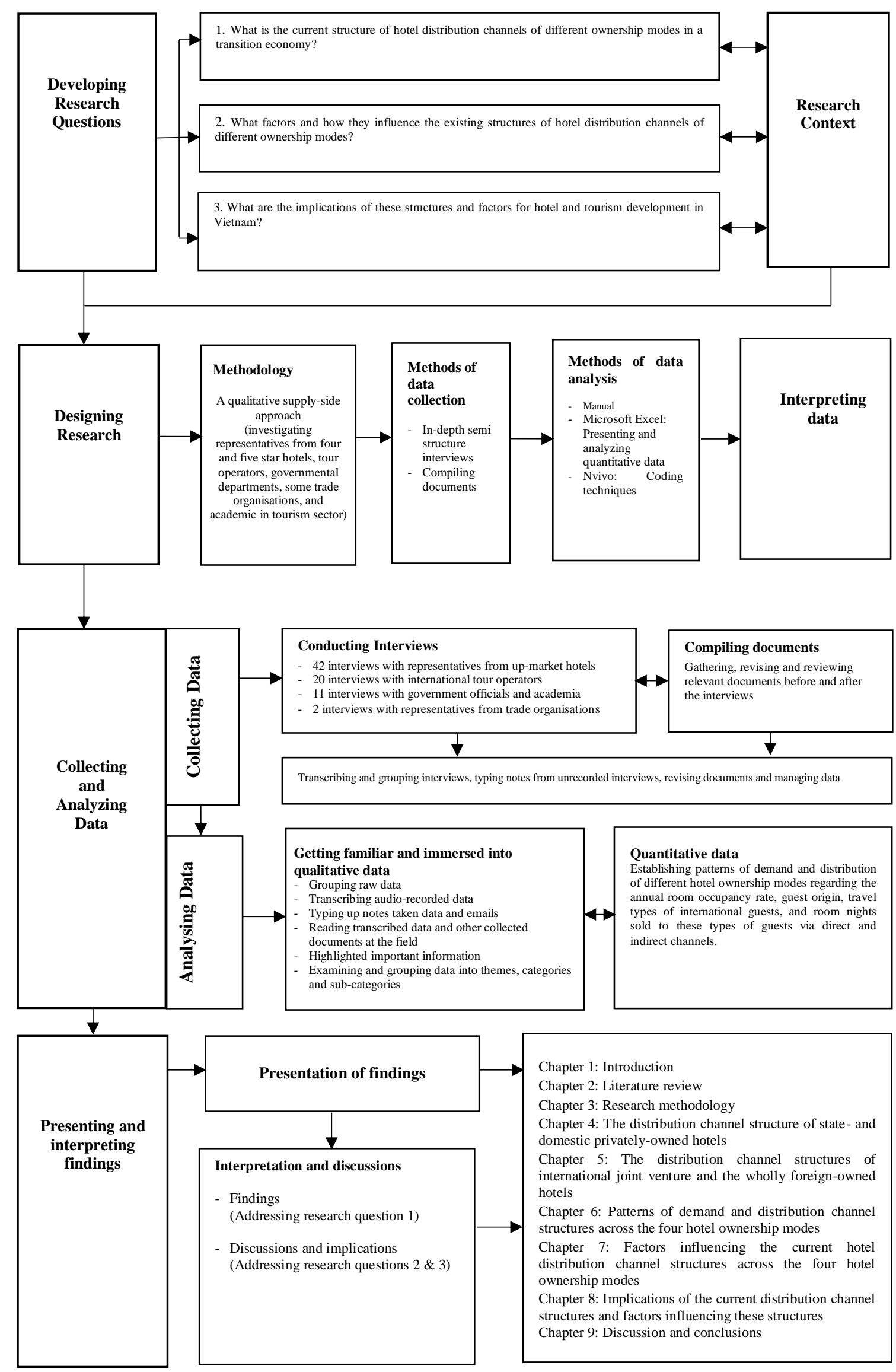

Figure 3.1. Research procedures 
outlined in that section that drive the inquiry and by the current state of knowledge being reported (Brotherton, 2008; Janesick, 1994; Morse, 1994; Yin, 2009). Janesick (1994) asserts that all research begins with a topic and question of interest identifying the research question(s) is probably the most important step to be taken in a study (Yin, 2014). In particular, when these questions are elaborated, the researcher has in his mind the required information that needs to be collected and analysed, and sets expectations for outcomes of the research (Blaikie, 2003). The primary question of this research is: Taking the case of up-market hotels in Vietnam (four- and five-star hotels), how do the different hotel ownership modes in a transitional economy structure distribution channels? Three sub-questions are defined, namely: (1) what is the current structure of hotel distribution channels of different ownership modes in a transitional economy? (2) what factors exist and how do they influence the existing structures of hotel distribution channels of the different ownership modes? and (3) what are the implications of these structures and factors for hotel and tourism development in Vietnam?

Research Question One requires information to identify the current structure of hotel distribution channels of the various ownership modes. Hence, it is necessary to identify the existing direct and indirect channels connecting hotels with consumers in order to establish the distribution structure. Pearce et al. (2007) noted that there have been several basic approaches to describe distribution channels: (1) the number and types of intermediaries that occur between service suppliers and the tourists; (2) the intermediaries' size, and geographical coverage; and (3) the level of integration that arises between channel members and the extent of concentration that exists. Data were collected through interviews and documents focusing on the nature of each business in terms of their target markets, the distribution channels used, their role in the distribution, strategies followed, relationships established and partnerships developed.

Research Question Two investigates the factors which shape and influence the existing distribution channel structures of the different hotel ownership modes. The conceptual framework suggests that the structures of hotel distribution channels are affected by internal and external factors. The internal factors may include Vietnam's economic reform and transitional economy, ownership modes, hotel management modes, hotel resources, hotel business objectives, target markets and the nature of products and services as well as patterns of demand. Data related to the external factors gathered 
included Vietnam's membership of the World Trade Organisation, international tourist demand, technological advances, financial services and banking systems and international transportation to Vietnam. In terms of Vietnam's economic reform, legal systems, economic development, Vietnamese tourist demand, Vietnam's technological advances and financial and banking development would be taken into account. The data on factors were collected from interviews with different groups of participants and secondary documents.

Research Question Three considers the implications of hotel distribution channel structures of the different ownership modes and factors influencing these structures for hotel and tourism development in Vietnam. Based on the literature and conceptual framework, these structures may be similar or different due to a wide range of factors, particularly the internal factors. Thus, information on why these similarities and differences occur, how the various tourism and hotel industry members are affected and react to them, and government's attitudes and actions towards these issues were collected via interviews. In addition, since hotel ownership and management modes are presumed to be important factors influencing the distribution channel structures of different hotel ownership modes, data related to the relationships between ownership and hotel management mode, hotel business environment and the Vietnam's economic transition to market economy as well as the involvement of the Vietnamese government were also mainly gathered through interviewees.

As mentioned in Section 1.3, the post-positivist paradigm guides the researcher's set of beliefs to address the above research questions, to position the researcher's role, and to decide the process of this study. Theoretically, post-positivists assume that reality is socially constructed and consequently contains multiple perspectives (Creswell, 2009). In other words, post-positivism "represents the thinking after positivism, challenging the traditional notion of the truth of knowledge and recognising that we cannot be positive about our claims of knowledge when studying the behaviours and actions of humans" (Creswell, 2014, p. 7). Post-positivists also believe that the world is governed by laws and theories (Creswell, 2014), and post-positivist researchers hold a deterministic philosophy in which causes, effects or outcomes are central to the research. Under this school of thought, different groups of participants from numerous government departments, tourism industry practitioners, trade organisations and 
academics were interviewed to gain their perspectives on addressing the above research questions which are clarified in Sections 3.2.4.2. Political theories and other secondary documents that influence the research were also compiled and analysed. The postpositivist paradigm notes the epistemological position should be objective although it is acknowledged that there may be researcher bias (Jennings, 2010). Therefore the positionality of the researcher is clearly mentioned in Sections 3.3, 9.3.1 and 9.3.2. The research paradigm and research questions determine the ways that methodology and methods are established in the following sections within this chapter.

\subsubsection{Research context and research sites}

\subsubsection{Research context}

In addition to the research questions, the research context is an important consideration in choosing the methodology (Brotherton, 2008; Yin, 2009). This section focuses on challenges that researchers have experienced when conducting research in a transitional economy (Vietnam) regarding the data availability, data collection, the methodology, and the implications for the methodological design.

Researchers who have investigated tourism distribution channels have recognised the need to deal with the commercially sensitive nature of information when collecting data (Pearce \& Taniguchi, 2007; Pearce, 2012; Schott, 2007). This consideration is even more challenging in Vietnam since the researcher has to gather data under different and changing political, cultural, and social circumstances (Maruyamar \& Trung, 2011). For instance, the term and concept of "transition economy" is regarded as a sensitive definition in Vietnam because the Vietnamese government is diplomatically calling for the global recognition of its country as a market economy on the road to a full market economy by 2018. In fact, 45 countries have recognized Vietnam as a market economy, although this list importantly excludes most members of the World Trade Organisation and the most economically developed countries including Canada, France, Germany, Great Britain, Italy, Japan and the USA (Bich Diep, 2013; Vo, 2013).

Filer and Hanousek (2002) contended that collecting sufficient data was extremely difficult when carrying out research in transition economies, especially microeconomic data on individuals and firms. This practice has led many researchers to obtain specific data through various unofficial back channels where costs can be considerably lower or 
through relationships with the local officials. For instance, Cervino and Cubillo (2005) were confronted with this situation when carrying out research on hotel and tourism development in Cuba; important data were only released through speeches given by government officials and reports of governmental departments since there was no integrated source of information. Luk (1998) and Qu et al. (2005) had difficulty in assessing the representativeness of their samples because of the lack of published information about the target population when these researchers investigated the structures of distribution channels of commodities and the influence of ownership structure on market orientation in the tourism industry in China. With the insufficiencies and scarcity of available data, for the most part, exploratory approaches were applied to formulate the first step of their studies and the researchers had to gather information through interviews. For some of the secondary data, published sources were examined and used to collect data (Cervino \& Cubillo, 2005).

In the case of Vietnam, the official statistics are considered to be incomplete, fragmented and inaccurate. The number of published studies on tourism in general and hotel distribution channels in particular is also scant (Hai Minh, 2013; Maruyamar \& Trung, 2011; Suntikul et al., 2008, 2010a, 2010b; Venard, 1996). At present, there are few sources of information and analysis which are independent of the government. Vietnamese policymakers and people alike are flummoxed by statistics put out by official agencies that are inconsistent and often at odds with each other and even with international organizations (Bich Diep, 2013; Hai Minh, 2013; Maruyamar \& Trung, 2011). This fact is also consistent with a statement of De Melo et al. (1996) regarding data weakness, that is, during transition the output of state enterprises was often exaggerated, while the size of the private sector tends to be underreported. There seem to be contradictions inherent in the Vietnamese government's goals of political control and economic liberalization that have resulted in contradictory policies and publications of statistical figures (Lloyd, 2004). According to the World Bank, Vietnam' statistical capacity index in 2013 was 71 points out of 100. With this score, the statistical capacity of Vietnam ranked 64 out of 149 countries in the investigated list, continuing to be in a group of countries with average statistical capacity (Hai Minh, 2013). In addition, publications from Vietnam regarding the humanities and social sciences are overwhelmingly in local media and professional journals and virtually absent from science citation indexes (Pham, 2014). Moreover, personal relationships that are still 
powerful in the Vietnamese society are the key factors leading to the success of any research fieldwork. Official introductions are not often handled unless they are accompanied by frequent personal contact: close relationships with the business community and/or the governmental departments possibly ease access to data (Maruyamar \& Trung, 2011). Maruyamar and Trung admitted that their study of modern domestic retailers in Vietnam would never have been realized without the cooperation and extraordinary help from the Association of Vietnamese Retailers and Vice President of this organization.

These contextual factors partially affect the way that researchers design their research methodology, especially in identifying research participants and accessing the secondary data. For instance, Bui et al. (2006) who investigated the e-commerce of hotels in Ho Chi Minh City as an electronic channel to attract consumers, used an exploratory case study. This allowed researchers to collect information from the main parties affecting and affected by the implementation of e-tourism and marketing. A selected group of government officials was queried regarding the current state of tourism, government policies, and strategies involving e-commerce. In Maruyamar and Trung's (2011) study, the context of Vietnam was taken into account by employing multiple methods of collecting the primary data. In-depth interviews with CEOs of the major domestic retailers and top-level government officials were selected based on the advice and arrangement of Association of Vietnam Retailers where researchers had close relationships. These interviewees provided a wealth of information and points that could not be explained through the poor quantity statistics.

\subsubsection{Research sites}

The research questions and contextual factors suggest that a qualitative approach is appropriate. This is in line with other research (Bui et al., 2006) conducted in Vietnam where the literature on the research problem is scarce and fragmented, and relevant data are hard to collect. In this study, Hanoi, Danang and Ho Chi Minh City (see Figure 3.2) were selected as research sites because of their cultural, political, socio-economic and tourism characteristics. The selection of three cities across Vietnam on the one hand increases the generalisability of data. On the other hand, three cities with their inherent features of culture, history and economic development level may shed light on factors 
that influence the hotel distribution channel structures of the different hotel ownership modes as well as the employed methodology.

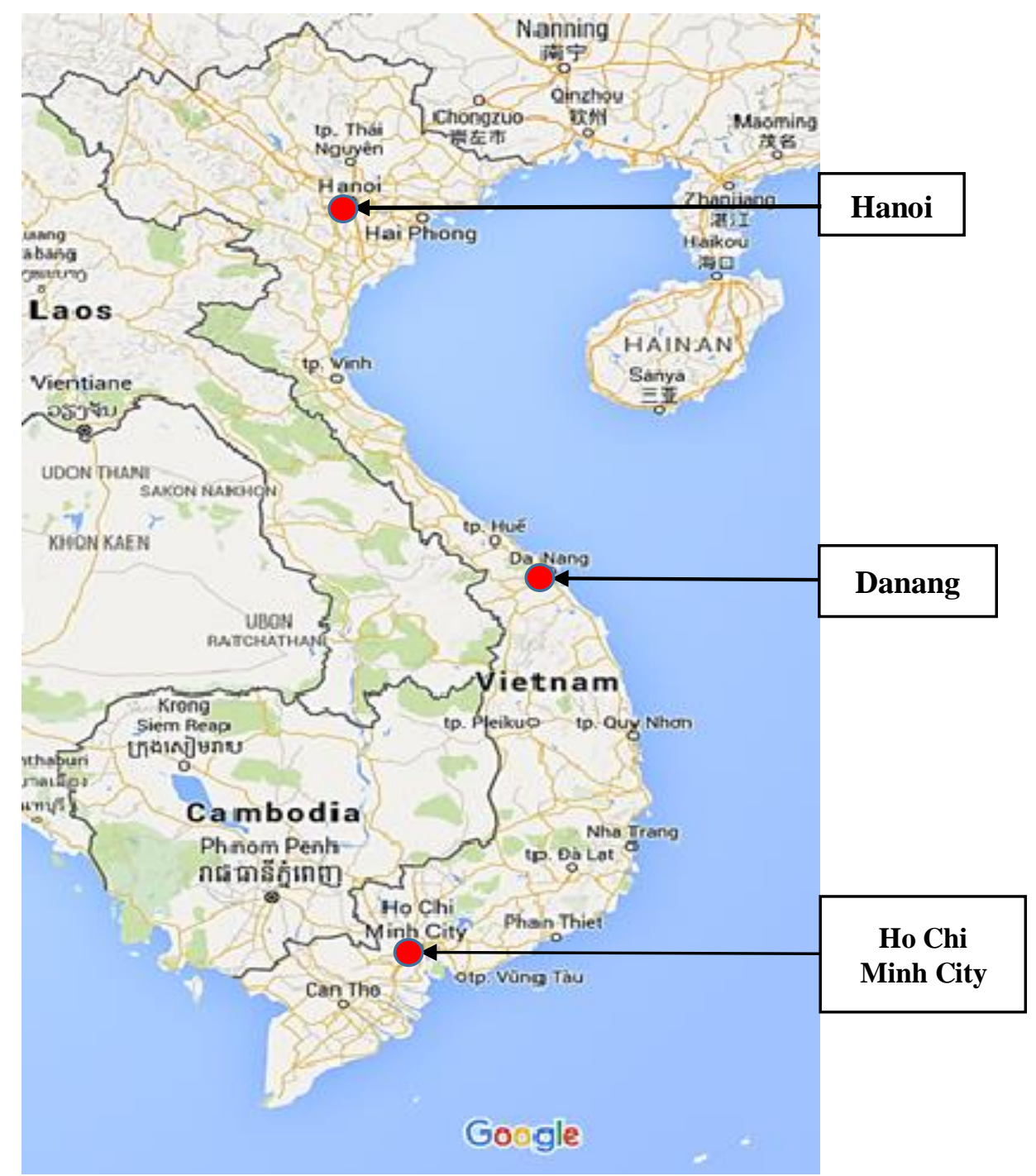

Figure 3.2. Vietnam Map (Source: Google, 2015)

Hanoi, Danang and Ho Chi Minh City share some commonalities as political, socioeconomic and cultural centres in North, Central and South Vietnam. Hanoi is the national political and administrative centre, and is recognised as the national centre of culture, science, education and economy and the international exchange hub of the whole country. It hosts the headquarters of the Vietnamese central party, state, government and socio-political organizations and foreign diplomatic missions as well as international organizations. It is also the place where the country's most important internal and external events take place (HNAT, 2010; VNA, 2010). Danang, which is 
located in the middle of Central Vietnam, is the largest city in this region and one of the country's most important ports. The city has been categorised as the commercial, educational and political centre of Central Vietnam since 2003 (DAD, 2015; Vietnam Government, 2003). Ho Chi Minh City is not only the largest political and commercial city in the Southern region but also a scientific, technological, industrial and tourism hub of Vietnam. Under the name of Saigon of the former Republic of Vietnam from 1955 to 1975 , the city was the capital of the Republic of Vietnam, being once known as the pearl of the Orient and the Paris of the East (Harms, 2012; VGP, 2015c).

As three largest international airports located within, the three largest cities are considered as large centres of Vietnam's tourism (VNAT, 2015c). Hanoi has taken great advantages of its location, cultural and capital status to develop a diversity of tourism products including MICE and cultural tourism. In 2014, there were approximately three million international tourists coming to Hanoi out of about 7.9 million foreigners travelling to Vietnam (Quynh Anh, 2015; VNAT, 2015b). According to VNAT (2015e), Hanoi currently has 25 tourist properties classified as four- and five-stars. Thirteen of these are rated as five star hotels (out of 72 properties rated five stars across the country). Five hundreds and ninety international tour operators (IBOs or international TOs) have been licenced in Hanoi (VNAT, 2015f). Noi Bai International Airport (the biggest airport in Northern Vietnam) takes a key part in connecting Hanoi with other regions of Vietnam and the world. In 2014, there were about 29 international airlines operating at Noi Bai and an average of more than 250 flights daily (Vietnam Airlines, 2014).

In Danang, tourism has been identified as one of the key economic sectors because of its landscapes, the world-class beach, historical values, economic gateway and as the political centre of Central Vietnam. It is also centrally located on the main road connecting the north and south of Vietnam and with other countries. Apart from Vietnam Airlines, there are 19 international direct routes to Da Nang airport operated by airlines from countries such as China, Japan, Malaysia, Singapore, South Korea and Thailand (DAD, 2015). Strengths of this city are cultural tourism, MICE and beach holidays, which have been effectively promoted to domestic and international tourists. In 2014, Danang had 15 tourist hotels classified four and five stars and sixty one local international tour operators have been licensed (Danang Tourism, 2014). International 
tourists to Danang accounted for approximately 900,000 arrivals out of 7.8 million visitors coming to Vietnam in 2014 (Nguyen, 2015).

In terms of tourism and international transportation, Ho Chi Minh City is the biggest tourism centre in Vietnam. The city has become an important transportation hub for the country and the Southeast Asia region since Tan Son Nhat International Airport (the largest airport in Vietnam) is a gateway to many different parts of the world (ACV, 2014). According to VNAT (2015e), Ho Chi Minh City had 36 hotels classified as fourand five-stars of which 16 are five-star hotels. In 2014, Ho Chi Minh City welcomed over four million international tourists compared with about 7.9 million foreign travellers visiting Vietnam (Tran Nhat Minh, 2015). International tourists coming to Ho Chi Minh City have frequently accounted for 50 to 70 percent of total international arrivals of Vietnam since 1990 (VGP, 2015b).

While all three cities are important tourism destinations, they have some differences in terms of culture that influence other aspects of their socio-economic features. Hanoi's culture is an interface among layers of culture formulated from numerous periods of history. Nowhere else in Vietnam is there a strong mix of Confucian thought and a legacy of Vietnamese feudalism that make Hanoians more conservative than people of other regions of Vietnam (Hoang \& Nguyen, n.d.). Hanoi is more rigid about regulations and hostile to private business. Ho Chi Minh City is the economic centre of the Southern Vietnam that remains ahead of the capital in per capita income, entrepreneurship, and foreign investment (Bui et al., 2006; Tran et al., 2000). It is also considered a city of cultural diversity, with a convergence of old and new culture from people across the country with cultures from capitalist countries (Ho Chi Minh City, 2011). Danang tends to share a commonality with Southern Vietnam' culture, especially Ho Chi Minh City (DCST, 2009). In line with these findings, Nielsen Vietnam's survey about consumers in Hanoi and Ho Chi Minh City indicated that Ho Chi Minh City people are more realistic, individual and open-minded than those of Hanoi (Hong Phuc, 2015).

Research sites with similarities of politics, economic development level, international transportation, tourism and hotel products and services have reduced possible biases of data when these cities were selected. Nonetheless, some differences of culture between 
Hanoi, Danang and Ho Chi Minh City are used to explain the ways in which participants from these regions took part in this research as well as factors influencing the hotel distribution channel structures. The choice of three urban cities permitted the researcher to consider the implication of distribution channels from region to region when investigating relationships between the existing hotel distribution channel structures and the economic transition.

\subsubsection{Research design}

Researchers adopt either quantitative or qualitative approaches or mixed methods to investigate their problems in social sciences. However, there have been debates about which methodology is the best (Davies, 2003; Gelo, Braakmann, \& Benetka, 2008; Jennings, 2010). While qualitative researchers suppose that rich descriptions of the social world are valuable, quantitative researchers with their etic, nomothetic commitments are less concerned with such detail (Denzin \& Lincoln, 2005). Quantitative research requires the reduction of phenomena to numerical values in order to carry out statistical analysis; qualitative research involves collection of data in a nonnumerical form (Gelo et al., 2008). Qualitative methods are commonly applied when it is necessary to understand a concept or phenomenon that has received little attention by researchers (Creswell, 2009). This approach also enables researchers to highlight detailed and in-depth snapshots of the participants under study since it provides a slice of life from the participants being studied (Jennings, 2010), and an insight into how people make sense of their experiences, which cannot be easily provided by other research methods (Liamputtong \& Ezzy, 2005).

The mixed method approach is recognised by the mixing or blending of two streams of collected data, namely the qualitative and quantitative data to provide a stronger understanding of the problem than either by itself. This method is designed to reduce the limitations of particular types of data, and to increase the strengths of data by the combination of them. However, the choice of mixed method is dependent on such factors as the timing of the data collection, type of design most suited for a field, and the choice based on a single researcher or team (Creswell, 2014). These factors are the considerable disadvantages that hinder the choice of mixed method for this study, which will be discussed in detail in this section and in Section 3.2.4. 
Within tourism studies, researchers have also employed and advocated the use of qualitative, quantitative or mixed methods to address the research problem based on the research purposes, and other factors influencing the research design such as limitations of time and resources. However, the qualitative approach is widely used in tourism research when richer information is obtained from a few cases rather than the more limited information from a large number of cases that is more typical of quantitative research (Jennings, 2010; Veal, 2006). This approach is suitable for the study of tourism distribution channels because in this field there is a need to examine the fundamental factors that have influenced the different parties' behaviour (Buhalis \& Laws, 2001).

In line with the few previous studies investigating research issues in Vietnam (Bui et al., 2006; Maruyamar \& Trung, 2011) and the research context (Section 3.2.2.1), this research employs a qualitative approach to address the supply-side issues of hotel distribution in Vietnam for the following reasons. First, the existing inconsistency and unreliability of the statistical figures, the considerable challenges of gaining access to data, the small number of published studies on tourism, and the little attention to distribution systems in Vietnam have suggested that the qualitative approach is likely to be most appropriate. Second, the supply-side approach provides opportunities for the researcher to get insights into the Vietnamese hotel sector, which consists of the upmarket hotels and various parties involving a process of producing and managing the accommodation goods and services for the travellers, regardless of their motivations (Smith, 1988). Moreover, supply-side research enables researchers to explore the various distribution channels of suppliers since "suppliers frequently use a range of channels to distribute their products and services: direct sales onsite or in the market are complemented by the use of a variety of intermediaries" (Pearce \& Schott, 2005, p. 50). March (1996, p. 338) also noted that "from a managerial perspective, attention on suppliers creates the opportunity for generating meaningful managerial insights". For this study, the supply-side approach enables the researcher to gain easier access to the participants from the Vietnam tourism industry and hotel sector as the researcher has a collegial and personal relationship with them. Third, the qualitative supply-side approach is also consistent with other research investigating the tourism distribution channels in developed countries and emerging economies (Buhalis, 2000; March, 1996; Pearce \& Tan, 2004; Sharda \& Pearce, 2006; Stuart, Pearce \& Weaver, 2005). Also, the exploratory approach was applied or recommended in a few studies examining some 
aspects of distribution channels, retail system, e-marketing and e-commerce in Vietnam (Bui et al., 2006; Luk, 1998; Maruyamar \& Trung, 2011; Pham, Pham \& Nguyen, 2011; $\mathrm{Su}, 2009)$.

\subsubsection{Methods}

\subsubsection{Data collection types}

The main qualitative methods are interviews, participant observations and focus groups (Bryman, 2012; Creswell, 2014; Jennings, 2010). Each type of data collection has inherent advantages and disadvantages that the researcher must take into account when choosing the appropriate tool(s) to gather data. Firstly, interview, including the semistructured and unstructured, are known as a prominent data collection strategy in both qualitative and quantitative research (Bryman, 2012). It seeks to identify the multiple realities of the social world being studied and gather rich empirical materials and detailed descriptions of the investigated problem. Interview is conducted based on an informally structured conversation or an engagement between the researcher and participant(s) by using a checklist of questions. Secondly, participant observation involves taking field notes on the behaviour and activities of individuals at the research site. Thirdly, focus groups are focused or semi-structured group interviews are used to elicit opinions and attitudes. Lastly, published or private documents that the researcher may collect before or during the research process provide mute data supporting other data's evidence (Creswell, 2014; Jennings, 2010).

The data methods selected were in-depth semi-structured interviews and document compilation. These methods firstly allowed information coming from the interviews to be corroborated, elaborated and triangulated with information from the other sources. Using interviews and documents reduced personal and methodological biases and enhanced the study generalisability (Decrop, 1999). Secondly, these methods are in line with some previous studies conducted in transition economies in general and in Vietnam in particular where the researchers have collected data through interviews and published documents. Thirdly, regarding the reasons why methods of participant observation and focus group were not applied, these types of data collection present some notable disadvantages in relation to this study. For instance, the limitations of participant observation on the present setting only and of being unable to observe the opinions or attitudes of participant do not allow the researcher to get the deep 
information around the research problem, in the research setting that is associated with a specific length of Vietnam tourism and hotel development. In the focus group method, the researcher needs to persuade the participants to turn up at a particular time based on the initial agreement, but information gained from this method is often dominated by strong personalities though there are several people speaking at the same time (Bryman, 2012; Creswell, 2009). In fact, it is difficult for the researcher to organise a team of sales and marketing staff of every single hotel to observe and to interview them while a key person from each team such as director of sales and marketing or sales manager could be arranged easier to talk with the researcher instead. As a result, in-person interviews are more appropriate within this research. The restrictions of participant observation and focus group prevented the researcher from getting broader insights from hotels into the existing structure of hotel distribution channels, its influential factors from every single type of hotel ownership and its relationship with ownership modes and the economic transition of Vietnam in a certain period, not present time only.

\section{Interviews}

Interviewing is probably the most frequently employed method of data collection in general and in qualitative tourism studies in particular (Bryman, 2012, Jennings, 2005; King \& Horrocks, 2010). Cohen and Crabtree (2006) argued that when the researcher does not get more than one chance to interview someone, the in-depth semi-structured interview is best used as it gives the researcher a clear set of instructions, and questions can be prepared ahead of time. In other words, this allows the interviewer to be prepared and appear competent during the interview. In-depth semi-structured interviews also allow the research participants the freedom to express their views in their own terms. Data gained from semi-structured interviews are considered reliable (Cohen \& Crabtree, 2006). In keeping with the majority of previous supply-side distribution channel studies (Buhalis, 2000; King \& Choi, 1999; March, 1996; Smith, 2007; Yamamoto \& Gill, 2002), in-depth semi-structured interviews have been considered "the most common method for collecting data on the supply-side of tourism distribution channels, particularly in sectors where there is a scarcity of previous research" (Smith, 2007, p. 324). This way of data collection has provided the main stream of data in the supplyside studies on distribution (Pearce, Tan, \& Schott, 2004). Moreover, interviewing is appropriate because in this field there is a need to examine the fundamental factors that have influenced the different parties' behaviour (Buhalis \& Laws, 2001) and interviews 
are a means to understanding and exploring the phenomenon in the research participants' own words (Bryman, 2008; Patton, 2002). In-depth semi-structured interviews not only allow the researcher greater flexibility compared with structured interviews, but also establish "an element of trust between hoteliers [participants] and the researcher and enable them to offer truthful and accurate answers" (Buhalis, 2000, p. 119).

In-depth semi-structured interviews also have advantages for gathering empirical data on complex and sensitive issues from participants in Vietnam as the researcher can take advantage of the personal relationship in the tourism and hotel sector as well as time to establish relationships more easily to move towards the examination of such issues. This characteristic has become increasingly important in the research context of Vietnam where, as Maruyamar and Trung (2011) contended, official introductions for researchers to conduct fieldwork are not considered unless the researcher has close relationships with the business community and/or the governmental departments or they have frequent personal contact.

As semi-structured interview questions are often developed from predefined topics of research problems (Corbin \& Strauss, 2008; Jennings, 2010). In this study, a common list of topics was proposed for the four groups of participants. However, they varied in emphasis due to the dissimilar characteristics of the participants. Based on these topics, a mixture of open and closed questions was constructed with the aim of gathering both qualitative and quantitative data (see Appendices F, G, H). Warm-up questions referred to the respondents' background or their organisations, then open questions allowed the researcher to gain qualitative data covering the structure of hotel distribution channels (Research Question One), the factors influencing the hotel distribution channels (Research Question Two) as well as the implications of the channels that each hotel used (Research Question Three).

Apart from the qualitative data gained from the open questions, closed questions were designed with a view to enhance comparability of qualitative answers (Bryman, 2012) between the four ownership modes. These closed questions generated numerical data for hotels in the three cities regarding number of rooms, annual room occupancy, market segments, proportion of sales from segments, and travel type and number of inbound guests. Separating these figures into four hotel ownership modes and locations enabled 
comparision of the existing hotel distribution channel structures, influential factors and an assessment of the implications of these possible similarities and differences of these structures.

\section{Document compilation}

Compiling and analysing relevant documents was undertaken in combination with interviewing as a means of triangulation. Documents that included printed and electronic materials from governmental bodies, trade organisations, hotels and the local tour operators had prominent advantages. Firstly, documents are a complementary means of tracking change and development, and verify the findings from the interviews to reduce the impact of potential biases or vice versa. Secondly, compiled documents are an effective means of gathering and corroborating data when participants have forgotten the details during the conversations (Bowen, 2009). For instance, the majority of representatives from the hotel and travel sectors had less complete knowledge of the nature and milestones of the Vietnamese economic reform than older respondents who had worked through the changes. Another example is that Decree No. 72/2013/ND-CP of the government issued dated 15 July 2013 on managing, providing and using the internet services and electronic information on the internet indirectly indicates that the freedom of Vietnamese internet users is still under control. This document explains the dilemma of hoteliers in expanding and developing the e-marketing channel through social networks or internet.

\subsubsection{Research participants}

The goal of sampling here was to select participants in a way that is relevant to the research questions and research context. Instead of spreading out all over the country, the sampling focuses on choosing key participants from certain governmental departments, trade organisations, academics, hotels and tour operators in Hanoi, Danang and Ho Chi Minh City according to the wealth and relevance of information they have. Before conducting the fieldwork, different groups of participants were identified to invite them to participate in the research including:

- Senior staff of sales and marketing departments in four- and five-star hotels in the three cities.

- Senior staff of sales and marketing departments of international TOs. 
- High ranking government officials from VNAT and the provincial departments of tourism in Hanoi, Danang and Ho Chi Minh City, and leaders of some trade organisations.

- Academics.

All participants were recognised as being able to provide the researcher with relevant knowledge and information about distribution channels of the up-market hotels in these cities in Vietnam. However, representatives from the up-market hotels were the key participants who provided the necessary information to establish the hotel distribution channel structures used, the factors directly influencing these structures, and the initial implications for the Vietnam hotel and tourism industry. The representatives from selected tour operators who are the largest intermediaries in Vietnam commercially connecting the hotels and the end customers provided evidence of the main middle parties in the distribution structure. Other groups of respondents (from government, trade organisations and academics) were chosen with the purpose of complementing and filling in the gap of information from hotels' participants and tour operators regarding the transitional period of Vietnam and broader economic issues of Vietnam.

\section{Representatives from four hotel ownership modes in three cities}

Up-market hotels play a key element in promoting Vietnam tourism values and attracting international tourists (VNAT, 2011). The star rating classification standards of Vietnam indicates that four- and five-star hotels share relatively the same standards of quality in terms of facilities and amenities, services, staff qualifications and hygiene requirements. The main differences between these hotels are based on some compulsory factors, for example, the four-star hotels must have at least 80 rooms and five-stars have 100 rooms, and the frequency of turn-down service, timing of food and beverage supply and concierge services are lower in five-star hotels.

The Vietnamese tourism law divides accommodation establishments into six categories: hotel, tourist villa, tourist serviced apartment, tourist camping site, tourist guesthouse and homestay (VNA, 2005). According to a hotel survey conducted by ITDR (ITDR, 2005), tourist accommodation establishments of under-50-rooms accounted for approximately 93 percent of the total tourist establishments of Vietnam. This figure partially reflected the low quality and weak competitiveness of the Vietnamese hotel 
industry. Most of the under-50-room accommodations were guesthouses or family management mode-based hotels with poor standards of facilities and services. The ITDR (2005) asserted that these small establishments had not yet paid significant attention to modern sales and marketing activities, particularly the application of information and communication technology in global sales such as GDS. Hence, their ability to attract the international tourists was very limited. Gaining access to available databases of hotels, and the final decision to choose 64 up-market hotels and hotel representatives of different ownership modes in three cities are discussed as follows.

Firstly, in gaining access to the detailed list of these desired respondents, the researcher was faced with a variety of published statistical figures of various governmental departments and consulting organisations. The statistics from VNAT (2013) and the related provincial departments of tourism were inconsistent from consulting companies such as Grant Thornton Vietnam. According to VNAT (2013b), the up-market hotels in Hanoi, Danang and Ho Chi Minh City exhibited the largest proportion (31 percent) of the up-market hotels within 64 hotels classified with four- and five-stars out of 205 throughout the country (DCST, 2013; HCST, 2013; HNAT, 2013; VNAT, 2014a). However, Grant Thornton's (2013) hotel survey results showed that the Vietnam hotel sector included 77 five-star hotels and 202 four-star hotels nationwide in June 2013 (279 in total). The list of hotels provided by VNAT and provincial departments of tourism was used by the researcher during the fieldwork because VNAT and local tourism organisations of tourism are the legal bodies responsible for classifying star ratings for the hotels.

Secondly, VNAT's (2013) statistics reveal that among the four types of ownership in the Vietnamese hotel sector (SOHs, DPOHs, IJVHs, and FOHs), only the four- and five-star hotel group represents all these ownership modes. The lower rated hotels currently do not include FOHs. Hanoi and Ho Chi Minh City are the two cities that have the FOHs, one five-star hotel is located in Hanoi, and another four-star FOH in Ho Chi Minh City. In the past, some FOHs were seen in Danang (such as Seahorse Resort and Spa and Fusion Maia Resort), however, these hotels have been transformed into international joint ventures and domestic ownership due to the stock market and merging and acquisition activities in Vietnam (VNAT, 2013). Hence, Danang hotels were seen as an interesting example of the movement of hotel sector in Vietnam's 
transition economy. Furthermore, the larger and up-market hotels' target markets are clearer than those of small hotels. They often pay more attention to the marketing activities by using as many channels as possible to distribute products to enhance the room occupancy rates (Ujma, 2001). These hotels also attract a range of visitor segments: business travellers, independent and packaged leisure tourists. As a result, the focus on up-market hotels not only allows the researcher to have full observation of the four hotel ownership modes which the lower quality accommodations could not present, but also provides an opportunity to explore the up-to-date structure of distribution channels that these high-end hotels are using.

Table 3.1. Number of four- and five-star hotels in main tourism destinations in Vietnam

\begin{tabular}{|c|c|c|c|}
\hline \multirow{2}{*}{ Province/city } & \multicolumn{2}{|c|}{ Hotel } & \multirow{2}{*}{ Main tourism products ${ }^{* \dot{x} * \dot{*} *}$} \\
\hline & 4 star & 5 star & \\
\hline Quang Ninh - Ha Long* & 15 & 2 & Beach holiday, exploring Ha Long Bay \\
\hline Hai Phong* & 8 & 0 & Beach holiday, exploring Cat Ba Archipelago Biosphere Reserve \\
\hline Lao Cai-Sapa* & 1 & 0 & $\begin{array}{l}\text { Exploring ethnic people culture in Sapa, experiencing the } \\
\text { mountainous climate }\end{array}$ \\
\hline Hanoi Capital City** & 10 & 11 & $\begin{array}{l}\text { MICE tourism, exploring the historical capital city of Vietnam, } \\
\text { exploring culture of Hanoi }\end{array}$ \\
\hline Thua Thien Hue* & 9 & 4 & Cultural heritages \\
\hline Danang City ${ }^{* * *}$ & 5 & 8 & MICE tourism, beach holiday, cultural tourism products \\
\hline Quang Nam - Hoian* & 13 & 4 & Beach holiday, exploring the ancient town - Hoian \\
\hline Khanh Hoa - Nha Trang* & 5 & 7 & Beach holiday \\
\hline Binh Thuan - Mui Ne* & 14 & 0 & Beach holiday \\
\hline Ho Chi Minh City**** & 16 & 14 & MICE tourism, exploring culture and heritages \\
\hline Ba Ria - Vung Tau* & 10 & 2 & Beach holiday \\
\hline Can Tho City* & 4 & 0 & Experiencing the culture activities relate to river and canals \\
\hline Total (1) & 110 & 52 & \\
\hline Nationwide Total (2) & 152 & 53 & \\
\hline Percentage of (1) over (2) & $\mathbf{7 2} \%$ & $98 \%$ & \\
\hline
\end{tabular}

(Source: DCST, 2013***; HCST, 2013****; HNAT, 2013**; VNAT, 2013b*; VPM, 2013b*****) 
Thirdly, the selection of four- and five-star hotels in Hanoi, Danang and Ho Chi Minh City is important to investigate the up-market hotel distribution structures in urban cities. This choice means that the up-market hotels in other cities or tourism centres were excluded. In Vietnam, 12 provincial tourism centres including Hanoi, Danang and Ho Chi Minh City that have been recognised as the main tourism destinations making up 79 percent of the total up-market hotels nationwide, ninety eight per cent of five-star hotels are in these provinces (see Table 3.1). Across 12 provinces, most (64) four- and fivestar hotels are in Hanoi, Danang and Ho Chi Minh City. Apart from the three selected cities, most of the destinations shown in Table 3.1 are located along the coastline and their main tourism products are based on beach activities. Therefore, as discussed in Section 3.2.2.2, Hanoi, Danang and Ho Chi Minh City are seen as cities taking advantage of being economic and cultural centres of regions to design urban tourism products such as MICE. The similarity of tourism products as well as the high concentration of up-market hotels in these cities allowed the researcher to establish the common structures of hotel distribution channels among types of ownership modes and cities. The hotel representatives who were selected and invited to take part in the research are mentioned in Section 3.2.5.1. Specifically, they were general managers, senior sales and marketing staff.

\section{Representatives from international tour operators in three cities}

The sampling of this group was to conduct interviews with managing directors and senior sales and marketing staff of IBOs in Hanoi, Danang and Ho Chi Minh City (see Appendix F). In Vietnam, IBOs or international TOs play a major role in the inbound market as they are traditionally the main generators of international tourists and have become big customers of hotels. Being bridges between service suppliers and tourists, the travel companies also, importantly, reduce the language barriers of guests and the local suppliers for whom English is still unpopular (VNAT, 2005). Representatives from IBOs in Hanoi, Danang, and Ho Chi Minh City were selected because all the large IBOs are headquartered in these cities (VNAT, 2005). This group of representatives has a specific understanding of hotel distribution channels based on their consumers' needs, including the customised tourist segment and package tours. With this in mind and taking the limitations of time, resources, and recommendation of VNAT into account, the researcher sent invitation letters to 40 IBOs to invite them to participate in the research. Ten companies had received the Top Ten Inbound Tour Operators Award 
2011 from VNAT and VITA. The criteria to be the Top Ten international tour operators consisted of requirements regarding annual volume of guests, high enterprise income after tax, tax payment, monthly income of employees (Doan Loan, 2012). In addition, 30 IBOs in Hanoi, Danang and Ho Chi Minh City with whom the researcher had personal relationships with the managing directors or other key staff were approached, ensuring a high response rate (see Section 3.2.2.1). These IBO representatives provided an overall picture of intermediaries who are connecting international guests with hotels in Vietnam.

\section{Representatives from government, trade organisations, and academics}

A group of high-ranking government officials in tourism authorities at the central level such as VNAT are based in Hanoi and in the provincial departments from Hanoi City, Danang City, and Ho Chi Minh City to be contacted. Next, academics, executives from trade organisations and associations like VITA and VISTA were invited to take part in the research. As Song (2012) notes these organisations could assist the channel members in handling tourists, but more importantly policies promulgated by them influence the formulation and development of distribution channels of hotels. These people could give valuable information about the present structure of distribution channels that each type of hotel ownership uses; the nature of hotels, general tourists' demands, the targeted markets of each hotel type, strategies to develop distribution channels, factors influencing hotel distribution and candid information regarding the economic reform of Vietnam. Trade organisations and associations are considered to be working places of retired high ranking governmental officials (Nhat Anh, 2013). For example, the chairman of VITA is a former General Director of Saigon Tourist Holding Company (the largest SOE) and the chairman of VISTA also used to be a Director of Travel Industry Department of VNAT.

A list of 21 representatives from this group were proposed to invite to take part in the research is as follows.

Government departments:

- A Vice Chairman of VNAT

- Director of Hotel Management Department of VNAT

- Director of Travel management Department of VNAT

- Director of Tourism Market Department of VNAT 
- Director of Office Administration of VNAT (former Deputy Director of TMD)

- Deputy Director of Office Administration of VNAT (former Rector of Hanoi Tourism College)

- Director of Institute for Tourism Development Research (ITDR)

- Director of Environmentally Socially Responsible Tourism Project funded by the European Union (ESRT) (former Deputy Director of ITDR and Hotel Department of VNAT)

- Director of Hotel Management Department of Hanoi Department of Culture, Sports and Tourism (HaCST)

- Director of Tourism Market Department of HaCST

- Director of Hotel Management Department of Danang Department of Culture, Sports and Tourism (DCST)

- Former Director of Hotel Management Department of DCST

- Director of Tourism Market Department of DCST

- Director of Hotel Management Department of Ho Chi Minh City Department of Culture, Sports and Tourism (HoCST)

- Director of Tourism Market Department of HoCST

Trade organisation:

- General Secretary of VITA

- Chairman of VISTA

- Chairman of Vietnam Hotel Association

Academics:

- Dean of Tourism Studies Faculty, Hanoi University of Social Sciences and Humanities

- Dean of Tourism, Hanoi National Economics University

- A Vice Rector of the Hanoi Tourism College

\subsubsection{Data collection}

Data collection took place from June to October 2013. The first group that the researcher contacted and sent formal letters to was VNAT. This had to be done because VNAT is the central government organisation responsible for nationwide tourism activities. VNAT provided a list of contacts for selecting other participants. The researcher got referral letters from VNAT and sent them together with a research 
information sheet, research interview questions and consent forms to all the participants identified to invite them to take part in the research. Specifically, in line with the previous study conducted in Vietnam by Maruyamar and Trung (2011), these research documents were sent out by post to the general managers or head persons of organisations who were asked to handle invitations if they felt able to do so or pass it on to the relevant staff such as director of marketing or sales of hotels if he or she was more appropriate. This strategy was adopted to ensure that the responses came from the key informant within the organisation. Apart from this procedure, the researcher sought additional support via personal and collegial relationship with VNAT's leaders to help make phone calls to various participants to ensure that the remaining interviews outside VNAT were conducted.

From mid-June 2013, efforts were made on-site to invite the identified respondents to participate voluntarily in the research. Many follow-up emails and research invitation letters were sent again to the selected participants.

In total, 64 representatives from four- and five-star hotels were contacted, 40 IBOs, multiple people in the three Departments of Culture, Sports and Tourism in Hanoi, Danang and Ho Chi Minh City, three from trade organisations, and three academics. As identified in the consent forms sent to these representatives prior to meetings, the aim was to talk to people face to face, and the interviews were audio-recorded. Notes were taken during the interviews. However, personal emails were used as an alternative since a number of representatives selected this form to reply the checklist of questions. These forms of primary data collected could vary across participants because in-person talks allowed the researcher to explore more details from interviewees based on their strengths.

After numerous appointments were made, the final number of participants interviewed and/or who responded by email was 75: 42 hotel representatives, 20 IBOs, and 13 respondents from governmental bodies, trade organisations, and educational institutions (see Table 3.2). Both FOHs agreed to take part in the research. The SOHs had a response rate of $73 \%$, the DPOHs 64 percent and 62 percent for the IJVHs. The response rate from governmental bodies was 61 percent, and two of the three trade organizations took part in the research. The IBOs exhibited the lowest response rate of 
only 50 percent. The response rate may have been influenced by the topic being perceived as commercially sensitive. Most of the invited participants in Hanoi and from the DPOHs in Ho Chi Minh City initially refused to take part in the research, and much time was given to explaining what this thesis was about in order to get their participation. However, some subsequently answered the checklist of questions by personal emails.

Table 3.2. Participant recruitment

\begin{tabular}{|c|c|c|c|c|c|c|c|}
\hline & \multicolumn{7}{|c|}{ Participants } \\
\hline & $\begin{array}{c}\text { State } \\
\text { Owned } \\
\text { Hotels }\end{array}$ & $\begin{array}{c}\text { Domestic } \\
\text { Private } \\
\text { Hotels }\end{array}$ & $\begin{array}{c}\text { International } \\
\text { Joint Venture } \\
\text { Hotels }\end{array}$ & $\begin{array}{c}\text { Foreign } \\
\text { Owned } \\
\text { Hotels }\end{array}$ & $\begin{array}{c}\text { Government } \\
\text { Officials and } \\
\text { Academics }\end{array}$ & IBOs & $\begin{array}{c}\text { Trade } \\
\text { Oganisations }\end{array}$ \\
\hline $\begin{array}{l}\text { Invited } \\
\text { Participants }\end{array}$ & 11 & 22 & 29 & 2 & 18 & 40 & 3 \\
\hline Declined & & & & & & & \\
\hline Participants & 3 & 8 & 11 & 0 & 7 & 20 & 1 \\
\hline $\begin{array}{l}\text { Agreed } \\
\text { Participants }\end{array}$ & 8 & 14 & 18 & 2 & 11 & 20 & 2 \\
\hline Response rate & $73 \%$ & $64 \%$ & $62 \%$ & $100 \%$ & $61 \%$ & $50 \%$ & $67 \%$ \\
\hline
\end{tabular}

Table 3.3. Types of interviews and data in the field

Participants

\begin{tabular}{lcccccccc}
\cline { 2 - 9 } Data & SOHs & DPOHs & IJVs & FOHs & $\begin{array}{c}\text { Government } \\
\text { Officials and } \\
\text { Academics }\end{array}$ & IBOs & $\begin{array}{c}\text { Trade } \\
\text { Oganisations }\end{array}$ & $\begin{array}{c}\text { Total and } \\
\text { Percentage }\end{array}$ \\
\hline Audio recorded & 6 & 4 & 8 & 1 & 10 & 14 & 2 & $45(60 \%)$ \\
\hline Notes Taking & 1 & 4 & 4 & 0 & 0 & 2 & 0 & $11(15 \%)$ \\
\hline Email interviews & 1 & 6 & 6 & 1 & 1 & 4 & 0 & $19(25 \%)$ \\
\hline Total & 8 & 14 & 18 & 2 & 11 & 20 & 2 & $75(100 \%)$ \\
\hline
\end{tabular}

Source: Interview data (2013)

The length and quality of interviews were different according to the participant and even the region. As stated in the research information sheet and consent forms sent to participants prior to the interviews, the in-depth interviews would be either voicerecorded or notes would be taken. Sixty percent of the interviews were audio-recorded. For the remainder, only notes (15 percent) were taken or the participants responded 
through their personal e-mail accounts (25 percent) (see Table 3.3). The length of interviews was around 30 minutes to one hour. These differences of interviewing timeframe were recognised to relate to details and quality of data, causing the frequency of quotations in Chapters Four, Five, Six and Seven.

In every case, permission was given to attribute information to participants' organisation and business. In terms of interviewing language, four interviews were conducted in English, the others were all in Vietnamese. Most of the interviews took place at the interviewees' offices; some were conducted in a cafe or in hotel lobbies. Different checklists of questions were constructed based on predefined topics (Table $3.4)$.

Table 3.4. Predefined topics of interviews

\begin{tabular}{|c|c|c|c|c|}
\hline Participants & $\begin{array}{l}\text { Representatives } \\
\text { from four hotel } \\
\text { ownership models }\end{array}$ & $\begin{array}{c}\text { Representatives } \\
\text { from inbound tour } \\
\text { operators }\end{array}$ & $\begin{array}{l}\text { Representatives } \\
\text { from government } \\
\text { and academics }\end{array}$ & $\begin{array}{l}\text { Representatives } \\
\text { from trade } \\
\text { organisations }\end{array}$ \\
\hline The nature of hotel & $\mathbf{x}$ & $\mathbf{x}$ & $\mathbf{x}$ & $\mathbf{x}$ \\
\hline Hotel Ownership structure & $\mathbf{x}$ & $\mathbf{x}$ & $\mathbf{x}$ & $\mathbf{x}$ \\
\hline Hotel organisational factors & $\mathbf{x}$ & $\mathbf{x}$ & $\mathrm{x}$ & $\mathrm{x}$ \\
\hline Targeted market of hotel & $\mathbf{x}$ & $\mathbf{x}$ & $\mathrm{x}$ & $\mathbf{x}$ \\
\hline Channel that hotel is using to distribute products & $\mathbf{x}$ & $\mathbf{x}$ & $\mathbf{x}$ & $\mathrm{x}$ \\
\hline Strategies to design hotel distribution channels & $\mathbf{x}$ & $\mathbf{x}$ & $\mathrm{x}$ & $\mathrm{x}$ \\
\hline Factors affecting the hotel distribution channels & $\mathbf{x}$ & $\mathbf{x}$ & $\mathbf{x}$ & $\mathbf{x}$ \\
\hline $\begin{array}{l}\text { Current state of tourism, government policies and } \\
\text { strategies affecting the hotel distribution channels } \\
\text { and the move to a market economy }\end{array}$ & $\mathbf{x}$ & $\mathbf{x}$ & $\mathbf{x}$ & $\mathbf{x}$ \\
\hline $\begin{array}{l}\text { Reason(s) why distribution systems of a specific } \\
\text { model of hotel ownership is possibly different } \\
\text { from the others }\end{array}$ & $\mathrm{x}$ & $\mathbf{x}$ & $\mathbf{x}$ & $\mathbf{x}$ \\
\hline $\begin{array}{l}\text { Implications on the channels that each type of } \\
\text { hotel ownership used }\end{array}$ & $\mathrm{x}$ & $\mathbf{x}$ & $\mathbf{x}$ & $\mathbf{x}$ \\
\hline
\end{tabular}

Key: $\mathbf{X}$ indicates strongly emphasised by the researcher, and $\mathrm{x}$ indicates less emphasised by the researcher 
A wide range of printed and electronic documents were also compiled. Before the interviews, the online secondary sources of documents from websites of hotels, IBOs, VNAT, the Vietnamese General Statistics Office (GSO), the Vietnamese government and some relevant organisations were retrieved (such as information on hotels and tour operators, average length of stay and expenditure of international arrivals in Vietnam, and the master plan of Vietnam tourism development). These documents and sources were read to ensure that the researcher gained sufficient information and background of respondents for the interviews. Publicly printed documents of the VCP, the Vietnam National Assembly (VNA), the Vietnamese Government, the WTO via the Vietnamese Ministry of Trade and Industry, and VNAT such as the VCP's resolutions on tourism development, laws on service sector, directives, circulars, decisions of government on service development and commitments of Vietnam to WTO in terms of trade were also examined and collected to corroborate the interviews.

During the interviews, some interesting emerging themes or topics helped the researcher identify the necessary documents that would be useful for validating the interviewing data. For instance, Decree No 72/2013/ND-CP dated 15 July 2013 of the government controlling and preventing freedom in the internet, especially social networks, was widely criticised by interviewees and the document was accessed for analysis as a part of the study.

Similarly, the working documents of Vietnam's accession to the WTO allowed the researcher to get a globally accepted definition of the Vietnamese state-owned enterprise as well as its committed roadmap to a full market economy by 2018. An example of hotel star rating dossier and the hotel star classification standard were collected to help obtain insights into the required checklist of items for hotel classification. They give an overall picture of four- and five-star rating in Vietnam. However, although the researcher desired to have the annual marketing reports of hotels and travel enterprises, particularly the internal marketing reports of hotels and TOs, all of the interviewees denied access due to their business policy, commercial sensitiveness and confidentiality. 


\subsubsection{Data analysis}

\subsubsection{Quantitative data}

Data analysis began by working with quantitative data which was drawn from interviews with representatives from the hotel sector. This included hotel room data, annual room occupancy rate, guest origin, main travel types of international guests, and proportion of room nights sold to these guests via direct and indirect distribution channels of each hotel within its specific ownership mode. As numerical data accounted for the minor part in the whole primary dataset, manual methods with the support of Microsoft Excel were employed to record the data for each hotel according to an analytical framework (Table 3.5). Then, the average figures of each hotel ownership mode, location, star rating and overall averages were calculated. These averages were used to describe patterns of demand and distribution and prompted the researcher to look for factors that have created possible commonalities and differences of the hotel distribution channel structures across the four ownership modes. A limitation is that, there were some missing figures in the quantitative data because a number of hotels did not provide full detail of their business outputs in the interviews.

Table 3.5. An analytical framework for analysing quantitative data

\begin{tabular}{|c|c|c|c|c|c|c|c|c|c|}
\hline \multirow[b]{2}{*}{ Hotel } & \multicolumn{2}{|c|}{ Room } & \multicolumn{2}{|c|}{ Guest origin } & \multicolumn{3}{|c|}{ Types of international guests } & \multicolumn{2}{|c|}{ Sales $^{(a)}$} \\
\hline & Number & $\begin{array}{c}\text { Annual } \\
\text { occupancy } \\
\text { rate } \\
(\%)\end{array}$ & $\begin{array}{l}\text { Domestic } \\
\text { guests } \\
(\%)\end{array}$ & $\begin{array}{c}\text { International } \\
\text { Guests } \\
(\%)\end{array}$ & $\begin{array}{c}\text { Business } \\
(\%)\end{array}$ & $\begin{array}{l}\text { FIT } \\
(\%)\end{array}$ & $\begin{array}{c}\text { Leisure } \\
\text { packaged } \\
(\%)\end{array}$ & $\begin{array}{c}\text { Direct } \\
(\%)\end{array}$ & $\begin{array}{c}\text { Indirect } \\
(\%)\end{array}$ \\
\hline \multicolumn{10}{|l|}{ Hotel I } \\
\hline \multicolumn{10}{|l|}{ Hotel 2} \\
\hline \multicolumn{10}{|l|}{ Hotel 3} \\
\hline \multicolumn{10}{|l|}{ Hotel 4} \\
\hline \multicolumn{10}{|l|}{$\cdots$} \\
\hline \multicolumn{10}{|c|}{$\begin{array}{l}\text { Average by } \\
\text { locations }\end{array}$} \\
\hline \multicolumn{10}{|c|}{$\begin{array}{l}\text { Average by } \\
\text { star rating }\end{array}$} \\
\hline $\begin{array}{l}\text { Overall } \\
\text { average }\end{array}$ & & & & & & & & & \\
\hline
\end{tabular}

(a) Proportion of room nights sold to international guests via direct and indirect distribution channels 


\subsubsection{Qualitative data analysis}

Data collection in qualitative studies often produces a huge range of data that are not ready for analysis until they are condensed (Berg, 2004; Yin, 2009). The data types collected in the fieldwork within this study yielded a large amount of raw data in the form of audio recordings, notes taken, email responses and the relevant documents. All of these sources of data made the researcher either interested or confused because of the useful contents and length; hence managing the data becomes critical as it would help the researcher to "get a sense of the whole" before analysing data (Patton, 2002, p. 440). Within this study, the huge raw dataset was organized by groups of participants, and for the hotels, by type of ownership. Audio-recorded interviews were transcribed and kept by the researcher for analysing data or for other purposes such as checking of interviewees; email interviews were stored and categorized according to the groups of representatives; notes that were taken during unrecorded interviews were typed up.

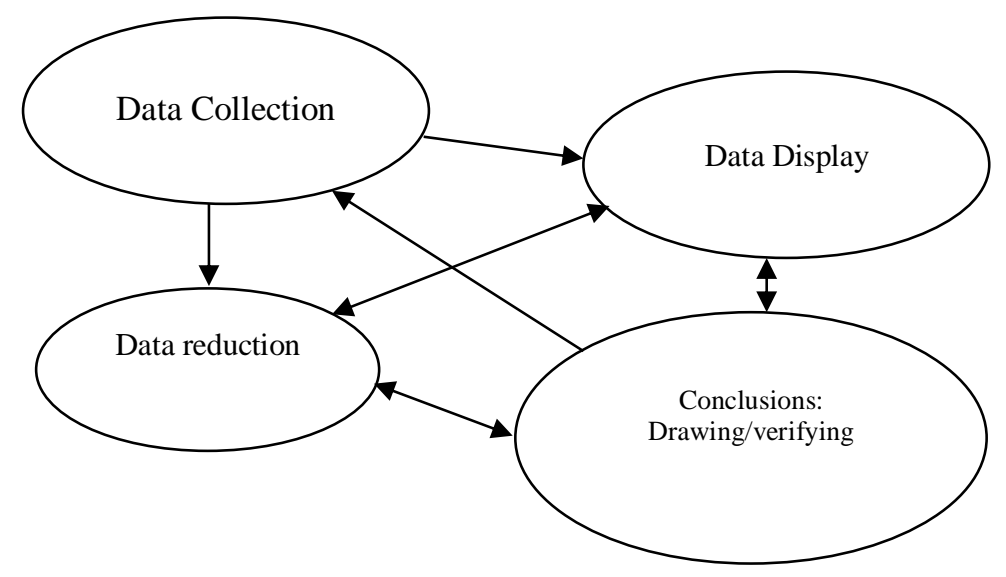

Figure 3.3. Components of data analysis: Interactive Mode (adapted from Miles \& Huberman, 1994, p. 12)

Qualitative data analysis, as illustrated in Figure 3.3, consists of three important procedures: data reduction, data display, and conclusion drawing and verification (Miles \& Huberman, 1994). In data reduction, the researcher deals with a process of selecting, focusing, simplifying, abstracting and transforming the data in transcriptions and texts. When the data were ready to use, notes were taken to find out important and useful paragraphs during reading through each participant's transcription according to themes defined in Table 3.4. Different colours were also utilised to highlight the key phrases. Data from interviews with the four groups of participants were the main sources of data with the documents used as a complementary data source to elaborate the information 
provided by participants as well as clarifying the ideas or themes emerged during the interviews.

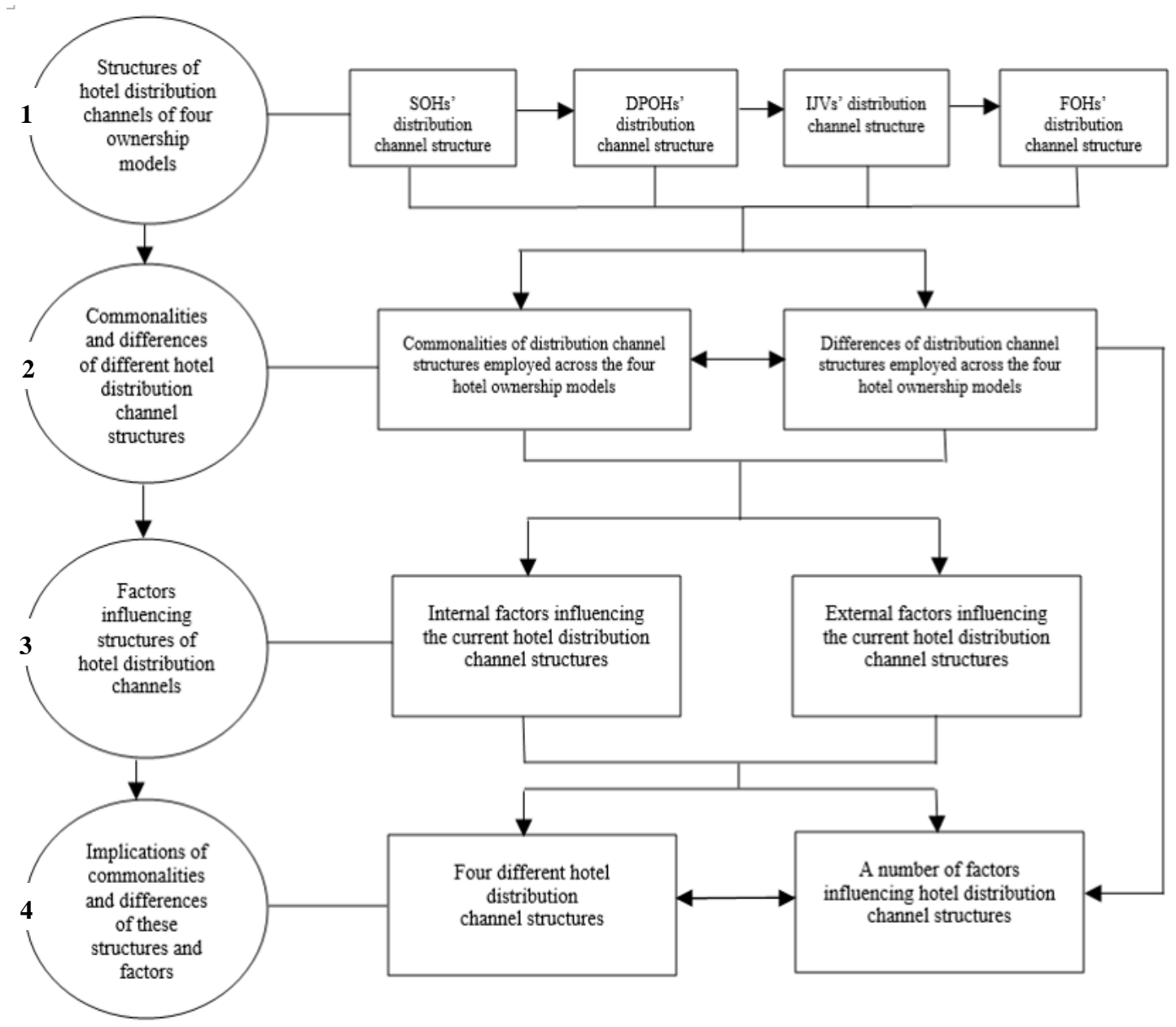

Figure 3.4. An analytical framework to analyse qualitative data

Figure 3.4 presents the analytical framework that was developed to guide different stages of analysing qualitative data. The raw data from various participants and secondary documents were manually assembled separately to establish a picture of each step. Step One gathered data to depict the existing distribution channels used by the SOHs, DPOHs, IJVHs and FOHs. Step Two identified the commonalities and differences of the distribution channel structures employed by the four hotel ownership modes. Step Three pulled out the internal and external factors influencing these structures. Step Four discussed the implications of possible commonalities and differences of various hotel distribution channel structures as well as these influential factors. Notably, although Step Two did not directly address the first research question, this step gathered and analysed data to find out the commonalities and differences of the 
four distribution channel structures. Thus, it shed light on the ways that Step Four was conducted to analyse factors influencing these structures.

In addition to the hotel respondents, data from international TOs included the intermediaries' views on these four types of hotel ownership in terms of their nature of products and services and professional level to cooperate with travel companies. Moreover, information provided by governmental departments, trade organisations and academics was grouped to examine the relationship between Vietnam's international integration and Doi Moi with hotel ownership and management modes and distribution channel structure. These data were used to elaborate and expand the implications of these structures and factors for hotel and tourism development in a transitional economy. By doing this, the researcher got familiarized with data to accelerate the process of locating the topics based on the research questions, the conceptual framework, and particularly checklist of interview questions (Bryman, 2008).

The analytical framework (Figure 3.4) also guides different stages of analysing qualitative data electronically. When data were broken down into groups as indicated in the above stages, they were coded by using computer-assisted software (Nvivo 9) that helped the researcher code text to retrieve the coded text via nodes and sub-nodes. According to Figure 3.4, four themes were identified, namely (1) hotel distribution channel structures, (2) commonalities and differences of hotel distribution channels structures, (3) factors influencing these structures, and (4) implications of these current structures and influential factors. From these themes, categories and sub-categories emerged and were developed based on the analytical framework and checklists of interview questions. For example, Theme One was developed into four categories including the distribution channel structures employed by the four hotel ownership modes; sub-categories in this theme were direct and indirect channels that each type of hotel ownership used to approach domestic and international tourists. Theme Two was divided into two categories: commonalities and differences of hotel distribution channel structures of the four ownership modes. Sub-categories of this theme were used to point out similarities and differences consisting of channel mix, direct and indirect distribution, channel members, channel length, channel width, and channel functions. The researcher also used the axial coding technique to clarify the relationships between categories from different groups of participants, so that results from this analysis 
generated an overall picture of the up-market hotel distribution channel structures of a transitional economy. Along with the process of qualitative data analysis, where relevant, quantitative data was used to elaborate and illustrate non-numerical findings.

Although data gained via interviews and documents were consistent with each other in most cases, the triangulation technique was frequently used to enhance and to complement validation of interview data provided by each group of participants and documentation. Generally, interviews generated much of the required information on hotel distribution channel structures of various types of hotel ownership and factors influencing them as well as some aspects of implications for beneficial parties. However, there was some missing or incomplete information with regard to definitions hotel distribution channels, economic facts and figures, legal documents, historical milestones as well as Vietnam's international integration. Possible contradictory statistical numbers from different sources and groups of participants also occurred. In order to embrace these differences or shortcomings, data were cross checked with documentation published by governmental departments. Some missing information about channels used to reach domestic guests and electronic channel members such as CRO and GDS in the interviews was also filled in by looking at the literature or websites of these business organisations.

\subsection{Strengths and limitations of the research methodology}

The first strength of the research methodology is the mix of different groups of participants working in the Vietnam tourism industry including hoteliers, tour operators, government officers, trade organisations and academics. This selection has ensured the vigour and validation of data as each group of representatives' knowledge of Vietnam's hotel sector, hotel distribution channels and Vietnam's transitional economy complemented others. For instance, senior staff of sales and marketing from the four hotel ownership modes provided significant information with regard to hotel patterns of demands, distribution channel structures and some factors which directly and indirectly influence the ways in which the hotels establish channels to reach international tourism market. IBOs in Vietnam who act as travel intermediaries not only drew a picture of themselves but also information of relationships between them with various hotel modes and their overseas counterparts as well as the end consumers was gained. High-ranking representatives from the government departments of tourism were particularly good at 
discussing macro issues of the country such as transitional milestones of the economy, legal system and overall trend of Vietnam's tourism and hotel development.

The second strength comes from the first, and is the triangulation of data sources and the wealth of the data collected. Multiple data sources such as interviews, secondary documents gained from the Vietnamese government, VNAT, Grant Thornton Vietnam and other government departments were used in the analysis. This plays an important role in identifying and verifying different knowledge and information of Vietnam's tourism and hotel development, and hotel distribution channels since Vietnam's introduction of Doi Moi. Meanwhile, interviews provide mostly sufficient information in relation to the current distribution channel structures of various hotel ownership modes and some factors influencing these structures. The secondary documents have strengthened the precision of interviews since respondents were unlikely to remember clearly a number of details in the interviews such as political economic events, legal documents and statistical figures. Moreover, the data collected were extensive and provided an excellent source of information to address the research questions even though hotel distribution channels, transitional economy are commercially sensitive themes to most of the hotels in Vietnam. Also, the term of transitional economy is politically sensitive in the context of Vietnam where Vietnamese Communist Party is diplomatically calling for other countries to recognise it as a market economy, however, interviews were generally straight-forward.

The third strength is the high response rate, and all of the interviewees allowing their information and opinions to be attributed to their businesses. Table 3.2 indicated that in addition to both FOHs agreeing to participate, response rates from other groups of participants were high, around 60 percent to 70 percent, and even IBOs achieved 50 percent. These achievements are significant in the context of conducting research in Vietnam where researchers have noted that it is challenging to gain access to participants, particularly high ranking government officials. Moreover, the agreement of interviewees to cite their name or their organisation in the research brings about a huge significance, particularly participants from the hotel sector since it was noted in Section 3.2.2.2 that there were inherent differences of the hotels located in Hanoi, Danang and Ho Chi Minh City regardless their ownership mode. Therefore, names of the hotels 
cited in the research enable the readers to better understand the context and findings, and to facilitate explanations of findings.

Fourthly, positionality of the researcher is another strength. As mentioned in Chapter 1, conducting data collection in Vietnam is challenging. Being an officer of VNAT, the researcher has a variety of personal relationships with members of the Vietnam tourism industry; therefore, in most of these cases, the researcher was able to gain access to gate keepers and appropriate participants. Unpublished reports and documents of the government were also gathered by using networking to contact people inside the government. In addition, positionality also plays a certain role in the data analysis. As mentioned, tourism studies in English are extremely scant in Vietnam, and most of the secondary documents were in Vietnamese and were changing rapidly. Taking this advantage, the researcher had been updated with these documents, and could use them as a means of triangulation. Moreover, working experience in the Vietnamese tourism industry provided the researcher with information about the nature of each hotel ownership mode that ensured the right path to explore data.

Finally, having multiple research sites is also a strength. The three largest cities in the North, Centre and South of Vietnam were selected to collect data. By doing this, the picture of hotel distribution channel structures of the Vietnamese urban up-market hotels is depicted. Moreover, opportunities to get insights into some factors influencing hotel distribution channel structures of the hotels were taken into account to make comparisons among the hotels across the country, for example, the open culture of Saigon people and more service-minded staff in Southern Vietnam in comparison with conservative culture of Northern Vietnam.

The study also has a number of limitations regarding the data collection methods. (1) Only four- and five-star hotels located in Hanoi, Danang, and Ho Chi Minh City among the 63 provinces of Vietnam have been chosen as the sample. (2) As the study employs a supply-side approach, questions of demand and the behaviour of consumers are only addressed indirectly. (3) The positionality of the researcher was regarded as an influential factor in gaining access to the participants. (4) Some parts of data provided by the different groups of respondents through interviews do not meet the research's expectations regarding the sensitive issues. 
Firstly, by taking the case of the up-market hotels in Vietnam, only four- and five-star hotels located in Hanoi, Danang, and Ho Chi Minh City among 63 provinces of Vietnam have been chosen as the sample. This selection ensured that all types of hotel ownership would be investigated since the lower star rating hotels do not include FOHs. This sampling has a limitation that the lower quality and small hotels as well as hotels in other provinces, rural and mountainous areas are not considered even though these small and medium hotels play an important role in developing the market mechanism in transition economies and in Vietnam. The statistics reported that small and medium tourist accommodation establishments took up approximately 93 percent of the total number of accommodations in Vietnam (ITDR, 2005). Thus, the research does not provide a complete picture of tourist accommodation distribution channel structures in a transition economy, Vietnam, but highlights the ways in which higher quality tourist accommodation approaches tourists.

Secondly, as the study employs a supply-side approach, questions of demand and the behaviour of consumers were only addressed indirectly. As a result, this research does not directly address the demand-side or an integrated approach of both supply and demand due to the methodological considerations. More precisely, visitors who serve as the end consumers were referred to indirectly through some on-site suppliers, intermediaries and the Vietnam tourism industry members. It is obvious that the tourism and hotel distribution channels function to bridge the accommodation suppliers and consumers directly and indirectly through a series of intermediaries. Therefore, there are various members involved in the distribution process, and studies on hotel and tourism distribution correspondingly applied either supply, demand-side approaches, or an integrated approach to explore the channel structures (Pearce, Tan \& Schott, 2004; Smith \& Garnham, 2006; Smith, 2007). Nonetheless, the demand-side has been underexplored within the distribution channels literature (Pearce \& Schott, 2005; Smith, 2007). Examining the demand-side requires a huge research resource to choose the appropriate participants out of a vast number of international arrivals to gain the needed information. In tourism, the demand is "the total number of persons who travel, or wish to travel, to use tourist facilities and services at places away from their places of work and residence" (Wall \& Mathieson, 2006). Also, demand is not homogeneous and tourists can be categorised in a variety of ways (Pearce, 2008). This application and possible limitations are discussed later in the coming sections: 3.2 .4 and 3.3 of this 
Chapter. This limitation is returned to in Chapter Eight regarding recommendations for further research.

Thirdly, the positionality of the researcher was regarded as an influential factor in gaining access to the participants, and this had both positive and potentially more negative consequences. Qualitative research is interpretive, and it is vital to consider the positionality and the role of the researcher because we are not neutral and objective in the research process. Our points of view, biases and experiences all affect the way that research is carried out. Creswell (2009) indicated that inquirers explicitly identify reflexively their biases, values and personal background. Ethical issues may also arise in relation to the researcher's role.

As an official of the VNAT, and with the research participation invitation letters, referral letters and verbal recommendations of the top leaders of VNAT, the researcher gained access to the field in the persona of a governmental official and a $\mathrm{PhD}$ student of the Victoria University of Wellington. Due to a huge range of reasons including the time constraint of participants or the political system of Vietnam that hinders outside researchers entering the field or businesses, selected representatives were likely to be reluctant to disclose too much to outsiders because they wish to avoid trouble with the authorities or simply business secrets. However, being considered as a government official gave me some advantages or initial authority to gain access to the desired respondents. In this regard, a lot of emails and phone calls to respondents were made to draw on the researcher's background and personality, and current role as a $\mathrm{PhD}$ student as well as to emphasise that the only purpose of visiting the site was to get data for undertaking a $\mathrm{PhD}$ thesis. It is believed that interview appointments were actually scheduled on the basis of respondents' support for the author's research rather than his official position. Along with the above strength of positionality, the researcher's role and background in the research may also cause certain biases in the data and data analysis although the steps to conduct the fieldwork were strictly followed by the researcher according to the ethics approval of the Victoria University of Wellington.

Fourthly, there were some missing quantitative data, and the researcher was unable to gain access to internal marketing strategies and reports of the hotels and IBOs. Quantitative data provided by the hotels were also uneven. For example, some hotels revealed all the figures of guest types and sales of room nights via direct and indirect 
channels, but a small number of the hotels did not, hence the overall average figures in the finding chapters have been affected.

Lastly, some parts of the data provided by the different groups of respondents through interviews do not meet the researcher's expectations. Despite these advantages in gaining access to the desired participants, it was still difficult to arrange interviews with the hotel representatives and local government officials in Hanoi where the researcher did not have strong social relationships although Hanoi is his working and living place. Many of the interviewees from the hotels in Hanoi declined to participate in the research or to have interviews audio recorded, and most of these interviews were made through emails or notes during the talks. In contrast, the interviews in Ho Chi Minh City and Danang were mostly audio recorded. This phenomenon might be explained by the fact that the Hanoi business community and Hanoians have witnessed and experienced many political ups and downs of the country, and are very sensitive to political issues or authorities since a referral letter with red stamp of VNAT was sent to them. This fact also reflects the limited democracy of Vietnam where a single political party leads the country and taxpayers are unfriendly with the government.

\subsection{Presentation of findings}

The results obtained from this methodological approach will be presented in the following chapters. In Chapters Four and Five, the current structures of distribution channels of the four hotel ownership modes will be presented. Chapter Six will discuss similarities and differences of patterns of demands and distribution across the four hotel ownership types. Chapters Seven will present the findings regarding internal and external factors influencing the above hotel distribution channel structures. Then, Chapter Eight will discuss implications of the current structures of distribution channels of the four hotel modes as well as factors influencing them for different members within the Vietnam tourism and hotel industry, in other transitional economies and elsewhere in the world including hoteliers, travel intermediaries, policy makers and academics. In this chapter, recommendations for further research are also mentioned. Chapter Nine discusses the thesis findings, the strengths and limitations as well as contributions of the thesis. It also concludes the thesis. 
CHAPTER 4. THE DISTRIBUTION CHANNEL STRUCTURES OF STATEAND DOMESTIC PRIVATELY-OWNED HOTELS

\subsection{Introduction}

In this chapter, the different structures of hotel distribution channels of two hotel ownership modes in urban cities will be presented based on interviews and secondary data. The SOHs are the first ownership mode to be examined, followed by DPOHs. This order provides an insight into the way that the up-market hotels owned by the Vietnamese government and people in Hanoi, Danang and Ho Chi Minh City have changed due to Vietnam's Doi Moi to reach the tourism market.

First, starting with SOHs, the operational setting is examined to detail milestones of the legal and socio-economic background of Vietnam under which these two types of hotel ownership have developed. Although the broader background of Vietnam hotel and tourism was mentioned in earlier chapters, this chapter looks in more detail at the specific characteristics of each type of hotel ownership in relation to the establishment of distribution channels. Second, a brief description of the selected hotels gives some basic information in terms of their history, capacity and business objectives. Third, the patterns of demand and sales for the hotels are presented. The distribution mix is analysed in terms of how the hotels market their products and services to domestic and international guests including business travellers, free independent travellers (FITs) and leisure packaged tourists through the direct and indirect channels. The percentage of domestic guests and international guests is also mentioned to show comparisons and variations among hotels within the same ownership mode.

Lastly, the most important parts of this chapter are the current structures of hotel distribution channels of the two ownership modes (Sections 4.2.4 and 4.3.4). Generally, a tourism distribution channel is a system of intermediaries that facilitates the sale and delivery of tourism services from suppliers to consumers (Buhalis \& Laws, 2001). The distribution channel structure is defined in the way that the suppliers of tourism products and services are organised to perform various distribution functions (Song, 2012). The services move through a number of parties who coordinate their activities to make the offering available to the end consumers; "each organisation is a customer to 
the previous one and a supplier to the next one in an industry's value chain" (Ujma, 2001, p. 34). In this study, these structures are presented to show the ways that hotels and their end consumers meet directly or indirectly via a series of intermediaries such as wholesalers, international tour operators (TOs), domestic travel companies and travel agents (TAs). They are graphically portrayed in a way that follows a number of previous studies investigating tourism and hotel sales channels (Kaven, 1974; Marinov \& Kazandzhieva, 2010; Pearce, Tan, \& Schott, 2004, 2007; Pearce, 2007; Ujma, 2001).

\subsection{State-owned hotels}

\subsubsection{Operational setting}

Tourist accommodation establishments possessed by the Vietnamese government today make up a small proportion of the total accommodation and the hotel market segment across the country, approximately 10 percent in quantity and 19 percent of the entire room percentage (ITDR, 2005). Within the hotel sector, the SOHs that were the products of a command economy have continued to operate their businesses under the particular circumstances of Vietnam's transition economy. Before 1986, these SOHs had a single function of serving tourists and foreigners according to the centrally planned allocation of international arrivals and foreign experts who worked in Vietnam. However, Doi Moi caused a fall in the number of SOHs due to the privatisation and equitisation policy ${ }^{3}$ and the development of a multi-sectoral economy with the different modes of ownership in the late 1990s. More precisely, the number of Vietnamese state hotels firstly levelled off and then decreased considerably since the government has determined that the hotels are not one of the industries that the government holds either all or a majority share (Interviewees; WTO, 2006) ${ }^{4}$. All the SOHs have been reorganising, equitising and privatising under the supervision of government under a semi-independent management mode where both an appointed governmental body and a

\footnotetext{
${ }^{3}$ Equitisation is a process of transforming a state-owned enterprise (SOE) into a joint-stock company. The Vietnamese government states that the equitization is not always privatisation; it is considered as partial privatization because after the equitisation of SOEs especially where the state still hold over 50 percent of shares, these equitised enterprises are still called SOEs. In some sectors, the Vietnamese government continues to hold the entire controlling role through investment and management such as goods of national defense and security, electricity, publication (Vo, 2006; VPM, 2007b).

4 "Viet Nam had undertaken a programme of "equitization", i.e., transformation of 100 percent State-owned enterprises (SOEs) into joint-stock or limited liability companies subject to the Enterprise Law, to help restructure, upgrade and enhance the efficiency of SOEs. The level of the State's equity in an equitized company was not set and could therefore vary. The equitization process foresaw diversity of ownership, including by the State and the employees of the equitized enterprise, and was implemented with consideration to the interests of the employees. Pursuant to Prime Minister's Decision No. 155/2004/QD-TTg of 24 August 2004, which had superseded Prime Minister's Directive No. 20/1998/CT-TTg of 21 April 1998, SOEs had been classified in three groups: (i) enterprises which would remain 100 percent State-owned and would not be equitized, (ii) enterprises in which the State would retain a majority of shares (i.e., greater than 50 percent but less than 100 percent), and (iii) enterprises in which the State would dispose of all its shares or retain a minority stake" (WTO, 2006, p.22).
} 
tenure-authorised representative of the state owned capital exercise the power of management (VGov, 2010; VNA, 2005). In principle no new state-owned hotels have been built since 2003 but expansion and renovation of the facilities and services of the existing hotels are allowed (Deputy Director of Hotel Department, VNAT). However, the process of equitisation and privatisation of the SOHs has been slow due to the conflict of interest among the central and local governments and from the individuals who hold key positions and are getting benefits from the SOHs (Chairman of VISTA; Director of ITDR). This has affected the operation of SOHs in several ways. For instance, all the state hotels are now structured under the semi-independent management mode where both an appointed governmental body and a tenure-authorised representative of the state-owned capital exercise the power of management (Representative of a SOH in Ho Chi Minh City).

Sharing similar characteristics of SOHs throughout the country, the operation of the upmarket urban SOHs has also faced a number of challenges. Firstly, SOHs are becoming less competitive and seen to generate lower business efficiency in comparison with the other types of ownership (ITDR, 2005; Interviewees from the selected government departments). The market share of SOHs is also decreasing as other types of hotel ownership, particularly the IJVHs, have developed significantly in recent years regarding both quantity and quality (ITDR, 2005). Secondly, SOHs are under pressure of restructuring in terms of equitisation and privatisation. The restructuring of hotels is a political task determined by the government in upgrading the competitiveness of the national economy and in agreement with both domestic laws and some international treaties. This situation poses questions and leads to hesitation for both the leaders and staff of hotels in organising their hotels' sales and marketing activities as the management mode of hotels will probably be modified when ownership subsequently changes. Therefore, the inherent characteristics and the development trend of the SOHs have placed these hotels under two important missions regarding the market approach and restructuring and stabilising hotel operations (Director of ITDR). While competing with other ownership modes for the tourism market enables SOHs to have consumers and revenue, the completion of the political missions given by the relevant government departments such as preparing the document of equitisation and organising events hosted by some governmental bodies takes the hotel resources and reduces their 
competitive strengths. As the Sales Manager of the Victory Hotel, a four-star stateowned hotel in Hanoi stated:

We have to accomplish two parallel important missions, one is to approach the tourism market to get customers and of course to gain the planned revenue, another is to meet the political missions assigned by the relevant government departments, particularly the Ministry of Culture, Sports and Tourism that our hotel is under.

Likewise, the General Director of the Institute for Tourism Development Research mentioned the political missions undertaken by SOHs:

The state-run enterprises in general and SOHs in particular have to undertake some socio-political missions assigned by the government along with their objective of profitability, thus the emergence of numerous ownership modes has created competitive business environment. Because the nature of the problem is a competition between the state and private sector, each party has its own advantages and disadvantages.

Indeed, the up-market SOHs in Vietnam are pursuing their own purposes to meet their main objectives, namely marketing to consumers to achieve revenue and harmonising their political mission with the financial targets. Since most of the SOHs were privatised and there are no up-market SOHs in Danang, the following section of this chapter presents background information relating to the patterns of demand of the high-end SOHs found in Hanoi and Ho Chi Minh City.

\subsubsection{Description of the study's state-owned hotels}

Looking at the overall characteristics of these state properties provides useful background to understanding how these hotels were established and have implemented their distribution channel structure. Of the eight SOHs, one is a four-star hotel in Hanoi and the others are a mix of four- and five-star hotels in Ho Chi Minh City.

In Hanoi, the Victory Hotel is currently the only 100 percent $\mathrm{SOH}$ in the up-market hotel range. The hotel, which is under the Ministry of Culture, Sports and Tourism, is 
located in Hanoi West Lake, a very suitable location for hospitality business. Construction of this hotel was started in 1973 and it began operation on 26th July 1975 on the occasion of the Moncada victory of the Cuban people. Originally, the hotel was a gift of the Cuban government, given to Vietnam when the Paris Agreement on ending the war and restoring peace in Vietnam was reached on January 27, 1973 (Dinh Phuong, 2010). The history of the Victory Hotel and its transformation into the tourism market can be categorised into three main phases. First, from 1975 to 1988, the hotel was under the command economy period of Vietnam, so the capital mobilization, products and services design and the business plan were decided by its owners, namely the Vietnam Tourism Company, the VNAT, and some other relevant government departments. Second, from 1988 to 1995 , the hotel gradually moved into the international hotel market under the initial step towards the economic transition of Vietnam. Third, from 1995 to the present, the Victory Hotel has been considered to be a semi-independent hotel in terms of its legal business registration but the VNAT and the Ministry of Culture, Sports and Tourism hold the direct authority in assigning the authorised representatives of state capital such as the chairman of the board of directors, general manager and chief accountant. The Victory Hotel has 175 rooms offering a wide range of fairly luxurious facilities and services and has begun the process of equitisation and privatisation. Regarding the ability to approach and widen the market segment in order to increase the room occupancy rate, the Victory Hotel is coping with a number of issues of which the limited marketing budget and human resource skills are the most challenging.

In Ho Chi Minh City, seven SOHs classified from four to five stars are also under state ownership but are a little different to the Victory Hotel in their history, and how they were established and are currently being managed. Many of these hotels that were built during the first half of the $20^{\text {th }}$ century under French colonisation (Grand, Majestic, Rex, Palace and Continental) or during the course of the Vietnam War (First, Royal City and Oscar) used to be owned by both domestic and overseas private capitalists under the market economy of the former Republic of Vietnam. Initially, these private properties were smaller in size and some of them were commercially exploited for other purposes such as discotheques, restaurants or showrooms. However, when the war ended and reunification between North and South Vietnam was carried out in 1975, the whole country was subject to the command economy mode of North Vietnam (Tran, Nguyen 
\& Nguyen, 2000). These private-owned hotels were nationalised under the direct management and supervision of the Ho Chi Minh City Tourist Company (Saigontourist) $^{5}$, a SOE established in August 1975. Like other hotels and resorts in which Saigontourist later invested throughout the country, the legal representatives of the state ownership including the general manager and chief accountant are appointed according to the tenure basis directly by Saigontourist and indirectly by the Ho Chi Minh City People's Committee. The hotel business plan, annual revenue and profit after tax of each hotel are also approved by the head office of Saigontourist (Interviewees from Hotels First, Majestic, Palace, Rex; Saigontourist, 2014). This management mode differs slightly from the Victory Hotel in Hanoi which is under the direct control of a government department, the Ministry of Culture, Sports and Tourism.

Together with the overall developmental trend towards the market-oriented economy of Vietnam, the growth of Saigontourist and its member hotels in Ho Chi Minh City can be divided into four major periods. The first stage is from 1975 to 1985 under the official name of the Ho Chi Minh City Tourist Company. In 1975, Saigontourist was the first tourism company established under the Revolutionary Authority to manage some hotels nationalised from the previous owners such as Caravelle, Continental, Majestic, Rex and Palace. In this period, the company and its member hotels operated their business under the command economy of Vietnam. The second stage is from 1986 to 1996. When Vietnam introduced Doi Moi and opened its door to the world, Saigontourist expanded and integrated its business into the world by being a pioneer in cooperating with foreign investors to establish joint venture companies to build and renovate some four- and five-star hotels in Ho Chi Minh City. In the third period, from 1996 to 2003 under the official name of the Saigon Tourist Corporation, the Prime Minister classified Saigontourist as a special enterprise under the direct management of the government and the Ho Chi Minh City People's Committee by a decision of 30 March 1999. This was a milestone in the development of Saigontourist and changed its function, both domestically and abroad. Its hotels were accordingly renovated again to serve the increasing number of tourists. In the fourth period, from 2003 to present under the name of Saigontourist Holding, Saigontourist and its member hotels have been re-organising

${ }^{5}$ In March 1999, the Ho Chi Minh City Tourist Company was renamed to Saigon Tourist Corporation (Saigontourist). In April 2005, the Saigon Tourist Corporation was renamed again to Saigontourist Holding (Saigontourist). The abbreviation of Saigontourist is unchanged over the periods. 
under the relationship of the parent company and subsidies according to a decision of the Prime Minister. The head office is now organised to be in charge of managing and supporting its subsidiaries across Vietnam and overseas in the different business fields such as hotels, restaurants, travel services and entertainment parks. The research department and the sales and marketing department were established to design and promote all the products and services of the whole company rather than those of a single business sector. As there is no central reservation office, each hotel has to plan its own business provided that the financial target assigned by the head office is achieved. This means that budget and other resources such as staff allocated for marketing activities are limited. However, member hotels have the advantage of getting some bookings from Saigontourist Travel Services Company which is also a subsidiary of Saigontourist Holding (Interviewees from SOHs in Ho Chi Minh City, 2013; Saigontourist, 2014; Tien Dat \& Minh Anh, 2013).

\subsubsection{Patterns of demand and distribution of SOHs}

Most of the interviewees from the SOHs recognised that in order to gain the targeted revenue and financial objectives, their distribution strategy has become an important function in hotel sales and marketing activities that can have the greatest impact on profitability in the increasingly competitive environment of hotel business in Vietnam. In order to adapt to the market-based economy, most of these SOHs have established on-site sales and marketing departments and their own sales representative offices or have the business partners within Vietnam undertaking the sales and marketing tasks. In the period of the command economy, these departments did not exist because inbound guests were allocated by the government to hotels. At present, selling and promoting strategies are carried out to attract various types of guests from the different market segments. As the Director of Sales and Marketing of the First Hotel, a four-star SOH in Ho Chi Minh City, mentioned:

For each type of guest and market segment, the hotel establishes a specific strategy of sales and marketing with the various channels to approach the consumers. The packages of products are accordingly designed with some value-added services and facilities. For instance, the hotel focuses on providing the leisure-packaged tourists with standard rooms and breakfast but the 
Table 4.1. Capacity and patterns of demand and distribution for the selected SOHs in 2012

\begin{tabular}{|c|c|c|c|c|c|c|c|c|c|c|}
\hline \multirow[t]{2}{*}{ Hotels } & \multirow[t]{2}{*}{ Location } & \multicolumn{2}{|c|}{ Rooms } & \multicolumn{2}{|c|}{ Guest Origin } & \multicolumn{3}{|c|}{ Types of International Guest } & \multicolumn{2}{|c|}{ Sales $^{\mathrm{a}}$} \\
\hline & & Number & $\begin{array}{c}\text { Annual } \\
\text { occupancy rate } \\
\text { (percent) }\end{array}$ & $\begin{array}{l}\text { Domestic } \\
\text { (percent) }\end{array}$ & $\begin{array}{l}\text { International } \\
\text { (percent) }\end{array}$ & $\begin{array}{l}\text { Business } \\
\text { (percent) }\end{array}$ & $\underset{\text { (percent) }}{\text { FIT }}$ & $\begin{array}{l}\text { Leisure } \\
\text { packaged } \\
\text { (percent) }\end{array}$ & $\begin{array}{c}\text { Direct } \\
\text { (percent) }\end{array}$ & $\begin{array}{l}\text { Indirect } \\
\text { (percen } \\
t)\end{array}$ \\
\hline Victory Hotel $\left(4^{*}\right)$ & Hanoi & 175 & 68 & 40 & 60 & 7 & 15 & 75 & 15 & 85 \\
\hline First Hotel $\left(4^{*}\right)$ & Ho Chi Minh City & 152 & 60 & 5 & 95 & 70 & 9 & 21 & 20 & 80 \\
\hline Royal City Hotel Saigon $\left(4^{*}\right)$ & Ho Chi Minh City & 127 & 80 & 6 & 94 & 55 & 13 & 32 & 40 & 60 \\
\hline Oscar Hotel $\left(4^{*}\right)$ & Ho Chi Minh City & 105 & 70 & 20 & 80 & N/A & $\mathrm{N} / \mathrm{A}$ & Mostly & 10 & 90 \\
\hline Rex Hotel $\left(5^{*}\right)$ & Ho Chi Minh City & 286 & 72 & 10 & 90 & 80 & $\mathrm{~N} / \mathrm{A}$ & 20 & 40 & 60 \\
\hline Grand Hotel (4*) & Ho Chi Minh City & 226 & 72 & 15 & 85 & 60 & $\mathrm{~N} / \mathrm{A}$ & 38 & 20 & 80 \\
\hline Palace Saigon $\left(4^{*}\right)$ & Ho Chi Minh City & 144 & 75 & 20 & 80 & 8 & 22 & 70 & 25 & 75 \\
\hline Majestic Hotel $\left(5^{*}\right)$ & Ho Chi Minh City & 175 & 75 & 5 & 95 & 45 & 35 & 20 & 45 & 55 \\
\hline Average in Hanoi & & 175 & 68 & 40 & 60 & 7 & 15 & 75 & 15 & 85 \\
\hline Average in Ho Chi Minh City $(\mathrm{n}=7)$ & & 174 & 72 & 12 & 88 & 44 & 20 & 36 & 29 & 71 \\
\hline Average by 4 star hotels $(\mathrm{n}=6)$ & & 155 & 71 & 18 & 82 & 35 & 15 & 50 & 22 & 78 \\
\hline Average by 5 star hotels $(\mathrm{n}=2)$ & & 231 & 74 & 8 & 92 & 45 & 35 & 20 & 42 & 58 \\
\hline Overall average $(\mathrm{n}=8)$ & & 174 & 72 & 15 & 85 & 37 & 19 & 44 & 27 & 73 \\
\hline
\end{tabular}

a International guests only

Source: Interview data, 2013 
business travellers are offered a package of higher quality rooms with better breakfast, free of charge laundry and airport transfers.

Table 4.1 shows room size, annual occupancy rate and patterns of demands: guest origin, travel types and proportion of sales of international guests via direct and indirect channels. The average room number of the eight SOHs is 174. The annual room occupancy rate is around 72 percent. The origin of guests is categorised into the percentages of room nights sold to domestic and international travellers. The travel types of international guests are recorded by purpose(s) of travel, namely percentage of business travellers, FITs and leisure-packaged tourists. International guests accounted for 85 percent of room nights and domestic travellers 15 percent. Leisure-packaged tourists made up the largest segment of international guests (44 percent), followed by the business travellers (37 percent). Almost three quarters of the international tourists who stayed at these SOHs used indirect channels to arrange their accommodation while 27 percent used direct distribution channels. In most cases, five-star hotels had a higher percentage of the business travellers and usage of direct channels. The selected hotels were not able to provide a similar breakdown for their domestic guests. However, other aspects of the channels used by Vietnamese travellers were obtained from the interviews and secondary documents.

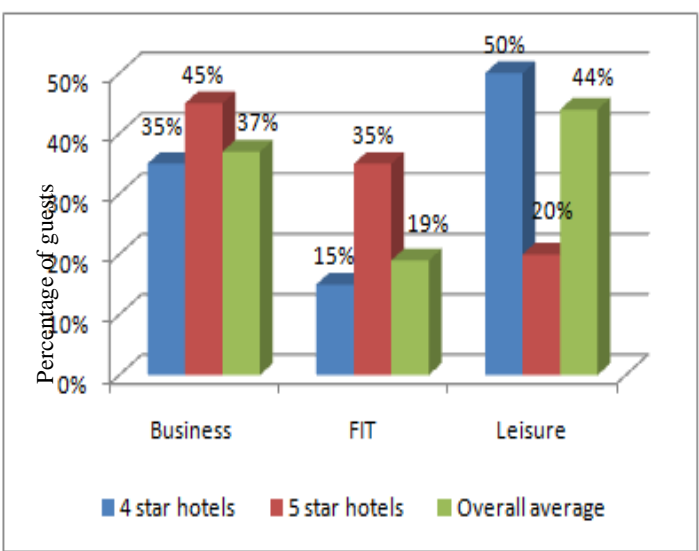

Figure 4.1. Type of international guests in four- and five-star SOHs (percentage of guests)

Source: Interview data, 2013

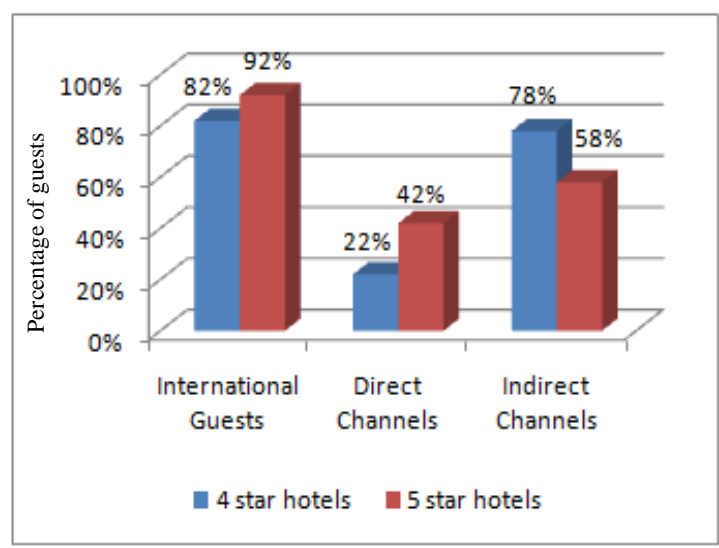

Figure 4.2. Channels used by the international guests to book rooms at the SOHs (percentage of guests)

Source: Interview data, 2013

Differences are also found among the four- and five-star state hotels concerning their market mix (see Figure 4.1 and 4.2). The five-star hotels attracted more international 
guests to stay with them, 92 percent of the total occupants in comparison with 82 percent at the four-star hotels. In the two five-star hotels, direct sales generated 40 percent and 45 percent of the total international guests. The usage of direct distribution channels by these hotels tends to indicate a link with the business guests and FITs who represent a larger share of the market in the five-star hotels, with 45 percent and 35 percent respectively. On the other hand, the four-star hotels that serve a higher number of the leisure-packaged tourists (50 percent of the total international guests) seem to be more reliant on intermediaries (78 percent of total sales to international guests).

The Victory Hotel in Hanoi and the seven SOHs in Ho Chi Minh City were identified and categorised in terms of their distribution mix. Although there is no difference in terms of ownership and business purposes, small variations occur regarding the use of distribution channels to gain access to the market. In particular, the Victory Hotel achieved an annual average room occupancy rate of 68 percent, with 40 percent of the occupants being domestic guests. Direct channels brought about only 15 percent of the total international guests, and the indirect sales channels generated 85 percent. The leisure-packaged tourists that were mainly sent to hotels by intermediaries constituted the highest share of overseas guests at the hotel ( 75 percent). The state-owned hotels in Ho Chi Minh City presented some differences to the Victory Hotel. The annual room occupancy rate in 2012 of these hotels was 72 percent. International guests were dominant ( 88 percent), and the international business travellers (44 percent) exceeded the leisure packaged tourists (36 percent) because of the dynamic economic environment of Ho Chi Minh City (Ho Chi Minh City, 2011). At the First Hotel, international guests made up 95 percent of the total room occupants, many of whom were business travellers (70 percent). Some of the interviewees (from the First Hotel, Grand Hotel, Majestic Hotel and Rex Hotel) indicated that the direct distribution channels are becoming a growing trend to attract business travellers and FITs since the direct sales generated a higher number of guests from 10 percent (a four-star hotel) to 45 percent (a five-star one). They also noted that hotels' websites and smartphone-based applications are upgrading together with the strategies to market the direct distribution channels in a more user friendly way to the end consumers (the First and Rex Hotel in Ho Chi Minh City). 
In general, facilities and services of the SOHs with the same star rating in Ho Chi Minh City are considered to be more professional and of a globally acceptable quality than the hotel in Hanoi due to the earlier history of development (ITDR, 2005). Hotel staff in Ho Chi Minh City are also more service-minded than these of North Vietnam including Hanoi (ITDR, 2005). The reason for this is that the SOHs in Ho Chi Minh City inherited the heritage of the early hotel development of the former Republic of Vietnam where the hotel level of professionalism in the sales and marketing activities was formulated. This has matured under the dynamic setting of the economy in the largest city in Vietnam. This is also why there was a higher proportion of business travellers staying in the SOHs in Ho Chi Minh City.

\subsubsection{Distribution channel structural diagrams}

For each distribution channel structure diagram (in Chapters Four and Five), a common approach is used. This presentation is developed from a study by Pearce (2008) who introduces a generalised mode emphasising the needs of tourists and different functions required to meet them. In each structure, a number of elements including channel length, types of channel member as well as their functions and market segments are displayed and discussed. In the accompanying text, channel mix and channel width are also examined in connection with how hotels deal with specific types of channel and intermediaries to approach the tourism market. Each diagram is presented as follows:

- The distribution channel structure for international guests is presented first since this segment generated a dominant proportion of hotel room sales revenue, followed by the structure for domestic travellers.

- Hotels and three types of international guests (business travellers, free independent travellers (FITs), and leisure-packaged tourists) and domestic travellers are functionally connected by the various horizontal arrows signifying the direct and indirect distribution channels. By using the direct channels, the hotels meet the end guests' demands themselves, whereas the indirect channels refer to the relationships between hotels and tourists via a number of intermediaries.

- Each structure diagram contains direct and indirect channels whose length is determined by the number of member categories, that is, the number of different types of intermediary between hotels and the end consumers. There are 
conventional channel members such as wholesalers, TOs, TAs and airlines, and electronic ones like hotels' websites, third party websites or online travel agents (OTAs) and global distribution system (GDS) located either in Vietnam, in the market or elsewhere in the world outside the guests' destination and market.

- Seven functions of channel members are identified by one-way or two-way arrows representing the direction in which these roles are undertaken to link the defined members in these structures: information exchange, advice, negotiation, booking, payment, information provision and payment of fees or commissions. Relationships between hotels and their guests or hotels with intermediaries are reflected by these arrows. When indirect distribution is employed, the number and direction of functions recognised within each channel may vary between each channel. Multiple arrows are used to show the business relationships and functions of distribution channels between two members instead of just a single one as in previous studies (Luk, 1998; Marinov \& Kazandzhieva, 2010; Pearce, Tan \& Schott, 2004; Pearce, 2007).

- The business relationships among channel members are explained in the text but channel mix is not shown on the diagrams as the hotels apply their experience to manage channels to approach guests. Channel width (the number of businesses of each member type) is also explained as hotels sign agreement contracts with hundreds to thousands of domestic, international, international joint venture TOs and overseas wholesalers to sell their rooms.

\subsubsection{State-owned hotels' distribution channel structure}

\subsubsection{The structure for international guests}

To reach international guests, who made up 85 percent of SOHs' guests, multiple direct channels are applied and various types of intermediary located both in Vietnam, in the overseas market or in between are utilised (Figure 4.3). By using direct channels, the hotels meet the ultimate guests' demands themselves through sales and marketing channels (e.g. hotels' websites, local hotel representative office, telephone, mail or faceto-face sales). The indirect channels are a mix of travel trade intermediaries, such as tourism information centres, airlines, overseas wholesalers and TOs and TAs, Vietnamese TOs and TAs, international joint venture travel companies in Vietnam and a number of electronic ones, namely GDSs and OTAs. Unlicensed TOs and TAs that 


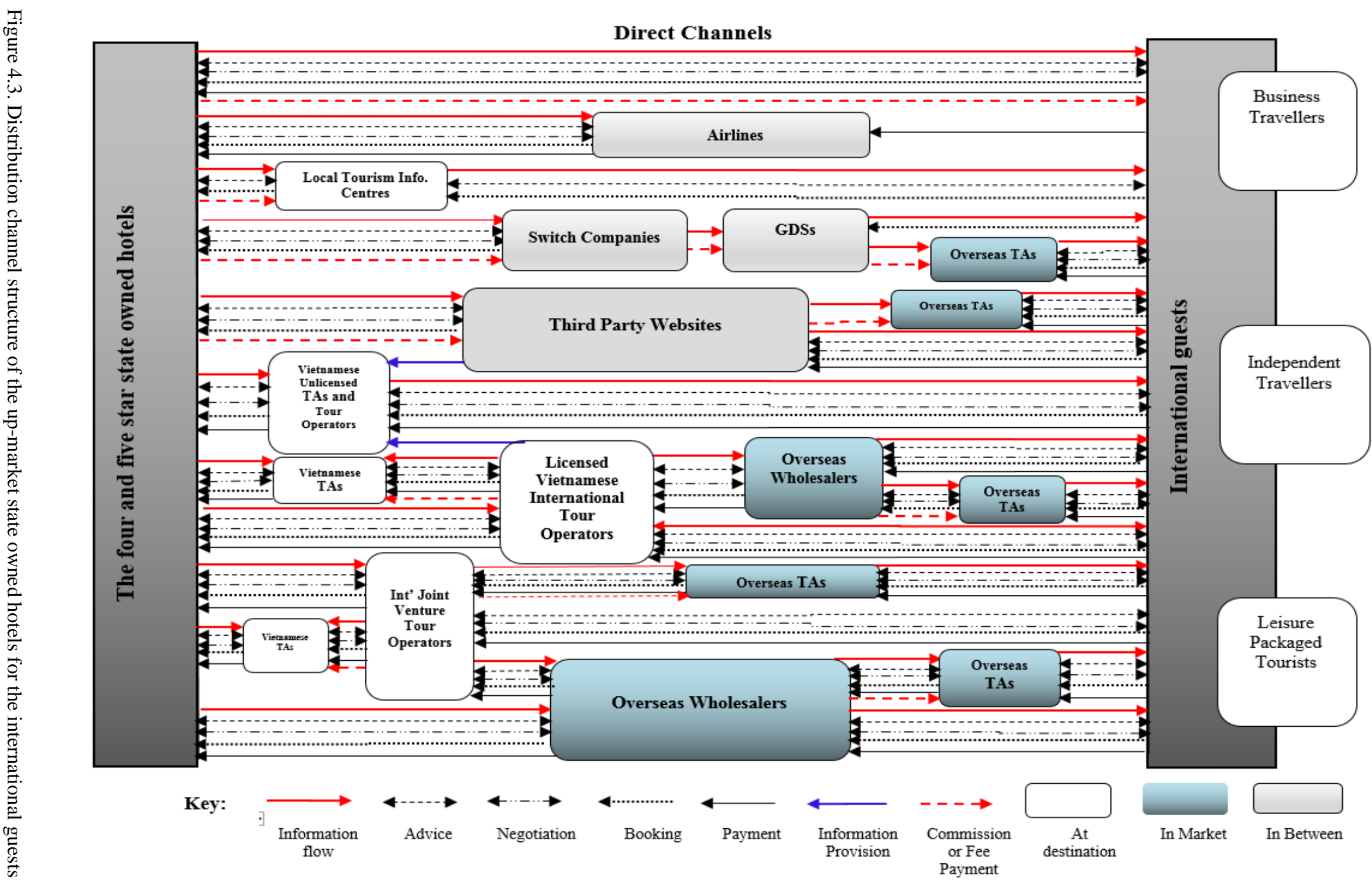


operate as a single party between the hotels and guests at the destination are also shown as a part of this structure.

Most of the types of intermediary appearing in this structure commonly occur in the global hotel industry. However, some unlicensed companies and the separation of domestic and international TOs are peculiar to the Vietnamese situation. In Vietnam, the Tourism Law classifies travel companies into two types based on their capacity. While the domestic TOs are allowed to arrange tours or hotel services for the domestic guests travelling within Vietnam, the IBOs, including joint venture, are permitted to bundle products and services together as packaged holidays and to sell a hotel's products and services for outbound and inbound guests or for trips in Vietnam for Vietnamese people. In other words, international TOs or IBOs are authorised to do many things beyond what a domestic company is limited to. In order to get this business licence, an individual or an organisation must meet some official requirements in terms of staff and tour programmes. A deposit of 250 million Vietnam Dong in a bank is also a compulsory step for those that want to serve the outbound or inbound guests ${ }^{6}$. The government argues that this is applied to the international TOs only, but not for domestic travel companies. This is because IBOs deal with insurance problems for guests who are away from home. When urgent cases happen to these tourists, money deposited in the bank will be used immediately to resolve issues. Moreover, the Vietnamese people do not have the habit of buying insurance when they are on holiday abroad, or the travel companies intentionally exclude the insurance in order to reduce to tour price (Xuan Toan, 2005).

Unlicensed TOs and TAs exist in Vietnam for several reasons. First, the easy procedures to become TOs and the difficulties to gain an international tour operator license have resulted in a boom of unlicensed TOs and TAs aiming at organising tours or hotel rooms for foreigners because of the high profitability. These TOs often copy tour programmes and hotel room rates from licensed international TOs and some OTAs to design their own products and services and sell them to consumers. Second, this activity has been supported by the development of the internet and online sales since it

\footnotetext{
${ }^{6}$ On $6^{\text {th }}$ of January 2015, 500 million Dong is US\$ 22,301 and NZ\$ 33,438. Retrieved from http://eximbank.com.vn/home/Static/Exchangerate.aspx
} 
is not easy for overseas tourists, and even locals, to recognise which websites belong to the licensed organisations. The operation of thousands of unlicensed TOs and TAs has posed challenges for not only the industry practitioners but also for the government to clear up because of the weakness in law enforcement. Accordingly, tourists are still confused between legal and unlicensed travel companies (Director of Hanoitourist Travel Company).

Hotel representative offices of independent hotels and airlines are either direct or indirect channel members in this structure in the context of Vietnam. In principle, elsewhere in the world, hotel representatives act as indirect channels because they carry out sales and reservations for a number of non-competing hotels to get profitability. Airlines could maintain an inventory of room and sell them together with seats for those who would like to make a full arrangement of accommodation and flight through airlines (Kaven, 1974). In Vietnam, these modes have not yet become popular since hotels are completely running the sales offices outside of their headquarters by their own. Certain numbers of hotels are working with local airlines to produce a package of "Free and Easy" for the customers ${ }^{7}$. However, most of the hotels sign contracts with various airlines to accommodate the crew and passengers of cancelled and delayed flights or to provide rooms for airlines' crew to stay before their next trips.

\section{Direct channels}

Accounting for approximately 27 percent of total international guests, direct channels are considered the shortest form of distribution and have become increasingly common since the advent of information and communication technology. Guests are given information, advice and the chance to negotiate bookings before purchasing through a 24 hour-telephone service, email or website and ways of payment. However, the direct sales may be also supported by other channels of distribution (Pearce \& Tan, 2006). In particular, information advice that is considered beyond the information exchange between guests and hotels, may help potential guests gain awareness of hotels or the hotel brand in the market through independent channels and travel guidebooks or social networks such as Lonely Planet guidebooks and Facebook. Several benefits can be

\footnotetext{
7 "Free and Easy" is a promotional programme initiated by Vietnam Airlines and some hotels to combine the sale of airline seats and hotel rooms. This mode of sales has become increasingly popular not only for Vietnam Airlines and hotels in Vietnam but also for consumers since other airlines copied it.
} 
gained from direct sales because hotels' products and services are potentially given an online global reach or sold at a higher price than indirect channels. However, due to the limitation of marketing budgets, human resources and lack of brand awareness, the direct distribution channels of the SOHs cannot compete in terms of the geographical reach, and, consequently delivering high sales volumes through them is challenging. As the Director of Sales and Marketing of Oscar Hotel in Ho Chi Minh City stated, direct distribution channels are currently organised and implemented as follows:

Our hotel gets bookings directly from the emails, telephones or facsimiles of guests. They are the loyalty consumers, anyone who may know the hotel through our own website, recommendation of guests' friends, brochures or they are walk-in guests. In addition, our hotel regularly sends the emails to the guests that the hotel recorded from their previous stays to update the rooms and services promotion in the hope of getting them back.

The target market for Vietnam tourism is mostly the distant countries, including Australia, England, France, Germany, Italy, Japan, Spain, Russia, USA and some Scandinavian countries (VNAT, 2012b). The challenge to reach these long-haul markets is also taken into account by SOHs regarding direct channels; the Director of Sales and Marketing, Rex Hotel in Ho Chi Minh City commented:

[A semi-independent hotel like Rex Hotel] we will never have enough resources and abilities to promote the Rex brand and its products and services directly to the global tourism market while 90 percent of Rex's customers are overseas consumers. According to the recent hotel's statistics, our guests come from 197 countries and territories in the world, so it is very difficult to know where all the potential customers are, and Rex Hotel is also unable to market directly to these countries or territories.

\section{Indirect channels}

Indirect sales contribute about 73 percent of international guests for the SOHs. As mentioned, limited resources for reaching diverse distant markets have resulted in the variety and length of indirect channels. Involvement of hotels with their international business partners in the global tourism market allows the guests in the long-haul markets to gain more ready access to hotel products and services and vice versa. The 
first traditional channel members include local hotel representative offices who conduct the sales and marketing activities on behalf of headquarters; local tourism information centres; and airlines when crew or passengers are contracted to stay overnight at these urban hotels when they wait for another trip or flights are cancelled or delayed. Most of the SOHs are also providing a package of airline ticket and hotel room products to attract guests of airlines such as the "Free and Easy" package. However, international TOs and TAs are the main intermediaries that these hotels rely on to distribute rooms to the end-users throughout the world. At the destination, international TOs establish their own TAs, sign contracts with individual(s) to run booking offices or they work directly with hotels to buy rooms before selling them to tourists as part of packaged tours or as room only. These TOs cooperate with a number of foreign partners to sell their bundled products and services or to distribute rooms to the end consumers. Although international TOs may still meet the international guests directly, overseas wholesalers and TAs are widely chosen to either reduce their limited capacity or to widen the global sales. Apart from the conventional members, electronic channels consisting of OTAs, switch companies and GDS play specific roles in connecting hotels with foreign tourists, particularly the OTAs that are becoming increasingly important to hotels regarding revenue and image promotion. While OTAs are the third party websites who distribute rooms and get commissions from hotels, switch companies are receiving the fixed-term membership fees from hotels. The GDS service provided by switch companies is therefore the means that corporate guests and TAs use to book rooms.

By employing multiple types of third parties in Vietnam, at the market or elsewhere, hotels are reducing their weaknesses in gaining access to a wide range of international tourists. Being SOHs, particularly the hotels in Ho Chi Minh City, they are also significantly supported by state-owned travel companies like the Saigontourist (the largest one in Vietnam) in terms of generating demand from tourists and other travel wholesalers. The representatives from Grand Hotel and Oscar Hotel in Ho Chi Minh City, for example, noted that 85 percent to 90 percent of their guests comes from the long-haul markets such as Australia, England, France, USA and Northern Europe and they are reliant on a number of intermediaries. In this case, the Saigontourist Travel Company is always behind them. 


\section{Distribution channel functions}

A number of distribution functions are fulfilled by direct channels and intermediaries. As discussed earlier, direct channels attract guests with information and advice, a chance to negotiate bookings before purchasing and methods of payment through online and offline sales. With regard to indirect channels, third parties also provide guests with information, advice and chances to bargain the room rates as well as tools to pay for bookings and fees or commissions in the right place and time. The room rate in the inclusive or customised tours is indirectly negotiated between wholesalers and tour operators and between these intermediaries and hotels based on factors such as volume, reliability and quality of service (Pearce, 2008). In Vietnam, international leisurepackaged tourists occasionally make a bargain with wholesalers or IBOs (except OTAs, switch companies and GDS) for hotel rooms though room rates are normally hidden and bundled with other services such as land transport, local air tickets, meals and tour guide. For instance, the Director of Vietnam Today Travel Company in Hanoi commented that many leisure-packaged tourists want his desired or contracted company to break down the basic rates of rooms, even airfares, so they can compare and negotiate the tour price prior to purchase. This happens because published rates of these products and services are easily viewed from OTAs and other means of online sales and marketing. Accordingly, the Vietnam Today Travel Company in some cases acts only as a land service provider because guests take responsibility for airfares and hotel rooms.

In general, the roles of distribution channels both stimulate demand and facilitate the reservation and purchase of hotel products and services. Nevertheless, differences are found in how various intermediaries carry out these functions. Some members (hotel representative offices and local tourism information centres) only fulfil specific tasks, such as exchanging information and advice, sending bookings and transferring payment to hotels or getting commission; airlines pay accommodation for their crew based on the prior long-term contracts or for their passengers of delayed or cancelled flights. Overseas switch companies that are particular to the foreign market and located internationally provide rate and inventory control to the hotels, allowing travel agents and corporate guests to gain access to hotels through GDS. Switch companies and GDS deal with hotels based on business contracts to send bookings. For other members, both overseas wholesalers and the local international and joint venture tour companies, run 
businesses in a more traditional way, in other words, they coordinate with travel agents in the chain of being both sellers and buyers of hotel products and services.

The IBOs show the longest length of channel: they cooperate with a wide range of business partners including wholesalers, TAs at destination and in market. The length partially reflects that their capacity in approaching the long-haul markets is limited and final room rates that the end consumers pay for the bundled tour programmes in this chain are likely to be much higher than when they are first sold in Vietnam (Representatives from Rex Hotel in Ho Chi Minh City). Unlicensed TOs who are definitely independent at the destination undertake a process of distribution to the end consumers by copying room rates and tour programmes from others without permission to make their own sales. Online sales are the most popular way that this type of travel company seeks to attract guests.

Different channels may be used for specific market segments. Direct sales are mainly made through hotel websites and sales calls which target overseas corporate guests who frequently have business missions or temporarily work in Vietnam. Specifically, this type of guest may come from overseas investors or short-term experts of the multinational corporations' branches, big companies and non-profit and nongovernmental organisations based in Vietnam. Some online means such as OTAs and switch companies are preferred by business, independent or young travellers because these channels respond instantly to their needs and changes in travelling. A majority of leisure tourists tend to use the products and services of traditional TOs since many of them are pensioners or others who have more time compared with the above groups and early booking of fixed and packaged tour itineraries are widely accepted according to their long-term holiday plans. Other types of channel member such as local tourism information centres and unlicensed TOs meet challenges in targeting their market segment and consequently contribute a small proportion of hotel room sales as well.

Channel width for both electronic and conventional intermediaries is associated with market segments. Most of the $\mathrm{SOH}$ representatives noted that there are one or more middle parties involved in the process of room sales between hotels and guests. In order to maximise the revenues and image, hotels apply as many types of indirect sales channel they know as possible. For the electronic ones, hotels prefer to use several 
overseas OTAs (For example: www.agoda.com, www.asiarooms.com, www.booking.com, www.expedia.com, www.ratestogo.com, www.travelocity.com, and www.wotif.com) to distribute their products and services to international guests rather than locals. As the Director of Sales and Marketing of Grand Hotel in Ho Chi Minh City contended:

First of all, our hotel signed contracts with most of domestic and international tour operators in Saigon [Ho Chi Minh City], Hanoi and some other tourism centres, particularly with some large companies such as Exotissimo, Vido Tours, Buffalo Travel and Travel Indochina. Apart from these Vietnam-based business partners, we also signed agreements with some wholesalers in Australia, New Zealand and England. Second, airlines, online travel agents such as agoda.com, booking.com and expedia.com and participation in GDS through a company in Singapore are our sources of guests. Third, our hotel also establishes the sales and marketing channels at hotel's representative office and places brochures at governmental tourism information centres for guests.

Moreover, the SOHs are dependent on the local IBOs and TAs. By signing contracts with most of them, opportunities to have bookings from these business organisations are widened. In this regard, hundreds of the Vietnamese IBOs are directly contracted compared with only a few foreign wholesalers. The Director of Sales and Marketing, Rex Hotel in Ho Chi Minh City stated:

Currently, our hotel has signed the agreement contracts with approximately 2,000 tour operators both in Vietnam and some abroad. [In Vietnam], these companies are located throughout the country and each of them has a specific strength of a market segment because they may focus on one market only. For example, there is a company that are very strong at the Russian market, or another one is the number one at the Australian market

The SOHs are also attempting to mix these above direct and indirect channels to reach tourism market. Pearce (2007) defined channel mix as the combination of channels used to approach guests. By deciding a suitable channel mix, the hotel needs either to determine the coverage each channel provides to the certain market segment that the 
hotel aims at or to evaluate the profitability of each channel. With this regards, the evidence to audit the used channels, to assess the existing coverage, to compare the profitability of current channels against alternative ones in order to adjust channels is mentioned by the Director of Sales and Marketing, Rex Hotel in Ho Chi Minh City as follows:

To be honest, a hotelier should not refuse any distribution channel. If any company wants to cooperate with the hotel to sell room based on some criteria and agreements, they are welcome. Of course, the hotelier as well as distributors must select appropriate channels that generate better profitability and operational costs.

However, as commented by some representatives from Vietnamese TOs, the channel mix used by the SOHs (and DPOHs) are poor. Regardless of whether TOs have agreement contracts with these hotel ownership modes or not, if they have a relationship with the hotels they will have available rooms. In this way, analysis of selecting an appropriate channel becomes a secondary priority; that was specifically noted by a Director of Hanoi Etoco Travel Company:

For SOHs and DPOHs, their sales and marketing policies in general as well as the combination of channels are much dependent on individual decisions of senior staff. Their policies are inconsistent. We are regular customers of some hotels and we have contracts with them. However, in the peak season we could not book rooms hence we need to ask some special relationships to have rooms for contracted guests. In order to explain this phenomenon, I think these hotels lack the professionalism in management.

\subsubsection{The structure for domestic travellers staying at SOHs}

Making up 15 percent of SOHs' guests, the structure of distribution channels for the domestic travellers also consists of direct and indirect channels to reach this type of guests. The structure combines a number of electronic and conventional intermediaries, namely the local hotel representative office, local tourism information centre, airline, OTA, unlicensed Vietnamese tour operator, domestic, Vietnamese and joint venture tour operator and travel agent (Figure 4.4). Most of these intermediaries are completely 
Vietnamese owned and headquartered at the destination, except for some airlines and third party websites due to their close relationships with the domestic market. Figure 4.4 is discussed in a similar way to Figure 4.3 but domestic travellers are not segmented by travel types because the main focus of the research is on the international market. The scarcity of related research and statistics in Vietnam also hinders any segmentation of domestic visitors.

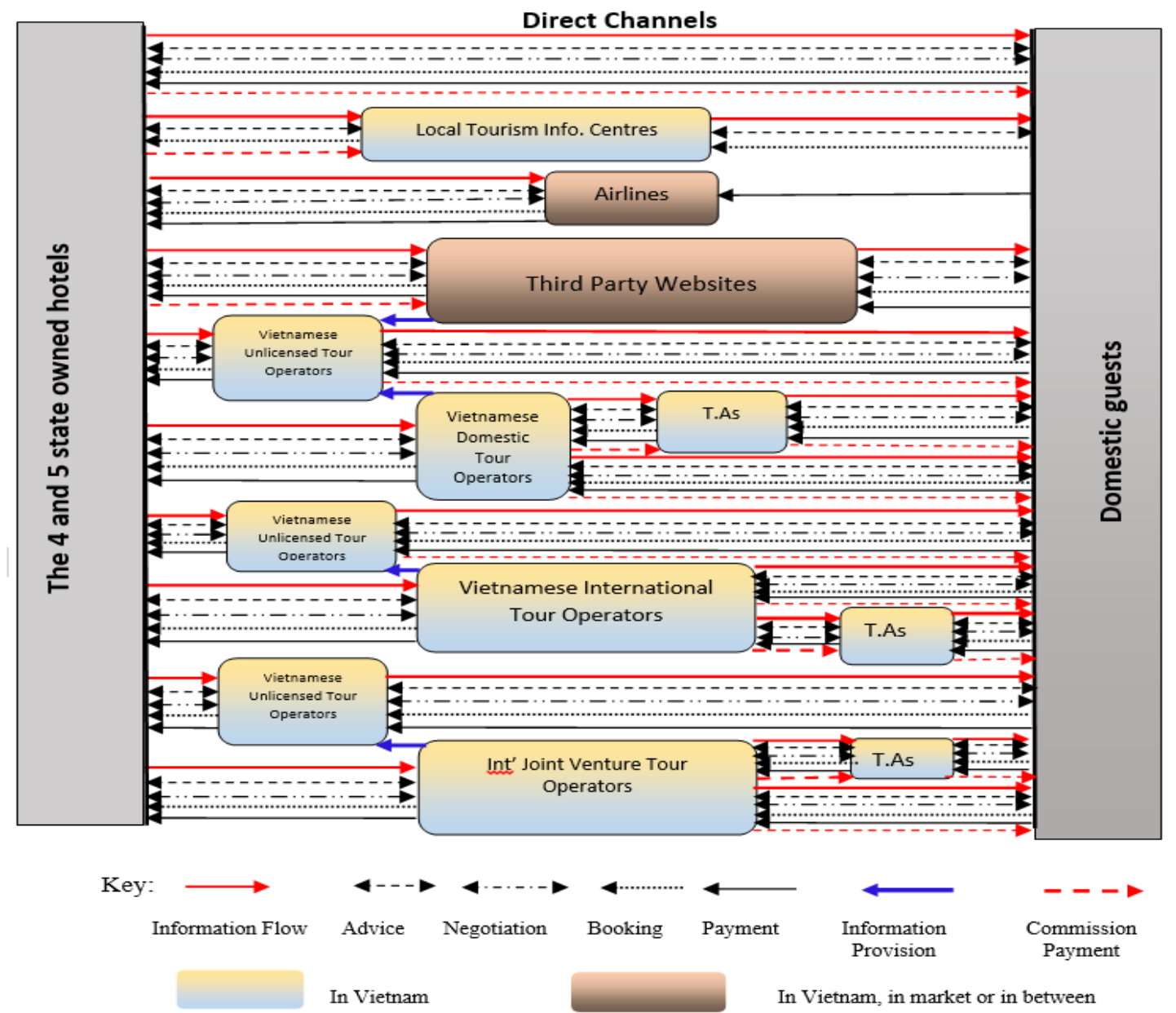

Figure 4.4. Distribution channel structure of the up-market SOHs for the domestic guests

\section{Direct distribution channels}

In this structure, intermediaries are located and functionally linked to offer their products and services to consumers alongside the direct channels. Direct sales provide guests with information, and opportunities to get advice, to negotiate room rate with hotels before purchasing and to make payment. Of the multiple mechanisms that have been established and used by the SOHs for direct distribution to domestic guests, the most popular means are the hotels' websites. Websites not only provide the domestic 
guests with the necessary and sufficient tools to search for room availability, to book and to make payments, but also they offer advice to consumers and other contact details such as email address, telephone, facsimile or GDS codes to meet the diverse demand of consumers. Other methods that hotels employ to attract direct domestic guests are guidebooks or brochures placed at the tourism information centres, sales calls within Vietnam and participation in consumer road-shows or trade fairs. Since the reputation of SOHs has gradually improved, word of mouth generates a number of bookings, especially from walk-in or online consumers. At present, walk-in guests are one of the sources that the SOHs serve because of their very convenient location in both Hanoi and Ho Chi Minh City. Public media play an important role in the strategy to enhance the reputation of the hotel brand for the direct domestic guests and those influenced by word of mouth effect, and to provide information sufficiently for further bookings.

Direct channels attract bookings from the domestic business travellers or corporate guests as a result of sales calls to local businesses or from the recommendations of the various governmental departments that the SOHs have a close relationship with. In this regard, the Director of Sales and Marketing of the Rex Hotel in Ho Chi Minh City noted:

Selling products and services of the Rex Hotel through its own website is an example of the direct sales [...]. The Rex Hotel gets a lot of support from the central government departments and the Ho Chi Minh People Committee such as their assistance in gaining access to the ministries, to the companies headquartered in the city to sell products and services.

A peculiar role to support the operation of these direct channels is prepayment of commissions. This way of paying commissions is considered unusual for direct bookings but it occurs in Vietnam. Unlawful commissions are paid by SOHs to decision makers working in government departments and state owned enterprises to get their corporate guests or incentive holidaymakers. A branch director of the Oriental Heritages Travel Company in Ho Chi Minh City contended that his company was unable to step into that segment because these guests normally work directly with hotels or through their close travel companies. If possible, it is also very time consuming to follow the unofficial commissions. The decision makers in this case, however, could also be regarded as independent, albeit unlawful channel members because money flows from 
the hotel into their own pocket in order to get bookings. This phenomenon has been acknowledged as a socio-economic factor causing the unequal business environment in Vietnam because only Vietnamese owned and managed companies operate in such a way to tap into markets (VNAT, 2013b).

\section{Indirect distribution channels}

Regarding indirect sales, thousands of domestic TOs have become an important means of arranging holidays for Vietnamese tourists. Of them, international TOs are the leading ones for this market since the Topten Domestic Tour Operator Award has regularly been given to them in recent years (Doan Loan, 2012; Thuy Ha, 2012), followed by the international joint venture TOs though there are only four of them with reliable brands, such as Intrepid from Australia (VNAT, 2014c). Hundreds to thousands of very small domestic companies still make up a noticeable proportion in the market because the development of these TOs is strongly based on the social relationships of their leaders with organisations which generate demand for hotels. For example, when the Vietnam Post Office Travel Joint Stock Company was established under the Vietnam Post Office, the director of this SOE of course has privileged access to his parent company in terms of organising incentive holidays for staff. This type of company is popular in Vietnam since it is the legacy of command economy where each organisation has its own trade union which is responsible for the welfare of workers including free incentive holidays. Unlicensed TOs exist and collect online bookings by offering unbeatable prices of tours or hotel rooms in the high seasons (Chairman of VISTA; Director of Hanoitourist Travel Company). OTAs, regardless of their origins, have also emerged as one of the popular ways that the Vietnamese travellers use to search and book hotels as Vietnamese Internet users accounted for about 31 million, equal to 35,5 percent of the population by the end of 2012 (Representatives from First Hotel, Grand Hotel and Rex Hotel in Ho Chi Minh City).

From the above structures, some discussions about channel members and their development trend are as follows. Apart from the TOs, other priority partners of SOHs are the OTAs, online channels and the wholesalers due to their regular bookings, followed by other channel members such as TAs, sales offices, airlines and GDS. Recently, OTAs and online channels have changed the ways that hotels sell their products and services because of the increasing share of guests and also payment of a 
growing amount of commission to third parties. In the past, online sales accounted for a negligible proportion of total room revenue, approximately five to seven percent. However, it is predicted that OTAs and online channels whose businesses have expanded significantly in the last few years have forced hotels to establish strategies to take advantages of them and to reduce dependence. For example, in 2012, rooms that the Grand Hotel sold through OTAs accounted for 38 percent of the total room sales; Rex Hotel's room revenue recorded around 30 percent to 40 percent from online channels (Directors of Sales and Marketing, Grand Hotel, Rex Hotel in Ho Chi Minh City). Some interviewees (First Hotel, Grand Hotel, Majestic Hotel, Palace Hotel) commented that hotels pay about 18-25 percent commission to the OTAs and they count this payment as the marketing budget. The hotels must find ways to get it back; one of these methods is to record guests' profiles and offer these guests the much lower room rate for the next direct bookings. Wholesalers are becoming important in the sales strategy of SOHs due to the higher prices they offer in comparison with Vietnam-based tour operators. However, some of the selected SOHs are planning to stop their investment on the GDS because of the low efficiency (First Hotel, Palace Hotel and Royal City Hotel Saigon). In some aspects, unlicensed TOs and TAs are still partners of SOHs although the government is finding ways to tighten the management and to increase penalties.

\subsection{Domestic privately-owned hotels}

Having discussed SOHs, a similar structure will be used to present the operational setting, description, and channel structure for DPOHs. There are some similarities to SOHs as DPOHs are also entirely Vietnamese-owned hotels. However, this type of hotel ownership emerged as a result of Vietnam's Doi Moi in 1986.

\subsubsection{Operational setting}

In the process of Doi Moi, the VCP has removed the centrally planned economy and to formulate a socialist market-oriented economy where various ownership modes have developed and participated in the economy (Beresford, 2008; Interviewees from government departments, trade organisations and academics). To create a legal platform for the emergence of different ownership modes, particularly the domestic private investors, the Law on Domestic Private Enterprises was first promulgated in 1990 and revised in 1994. This law allowed individuals and organizations to run their own 
businesses, except in some sectors such as publications, telecommunications, and international tour operators. It was valid until 2000 when the common Law on Enterprises for both domestic state- and private-owned enterprises appeared. In 2005, the replacement Law on Enterprises was issued to regulate all business modes of ownership including foreign related individuals and organizations (VNA, 2005).

The Law on the Domestic Private Enterprises in 1990 and the Law on Enterprises in 2000 particularly marked milestones when Vietnamese capitalists and entrepreneurs officially came back to play their own roles in the market after they had been banned from doing business in North Vietnam after 1954 and in the South after 1975 due to the application of the country's command economy mode (Tran et al., 2000). At present, the psychological prejudice against domestic capitalists still exists in Vietnamese society because of the initially unstable development, the low starting point as well as the unequal viewpoint of Vietnam towards this ownership mode in the Constitutions (VNA, 2013). However, discrimination has decreased since laws were put into effect and the recognition of government has changed with the non-state economy contributing approximately 46 percent of the GDP per annum in the period 2007 to 2010 (Tu Hoang, 2012). It is noted by the current Vietnamese Prime Minister that the private sector takes an increasingly important part in enhancing the competitiveness of Vietnam, avoiding the middle-income trap of a developing country as well as creating the developmental motivation of the market economy. Looking at the achievements of the domestic entrepreneurs and putting them in the right place on the way of Vietnam's international integration and cooperation with the world are timely and essential $(\mathrm{Tu}$ Hoang, 2014).

In the hotel sector, after nearly 15 years of investing and running hotels under the Law on Domestic Private Enterprises, domestic private-owned tourist accommodation has exhibited a huge developmental step. According to a survey conducted by the Vietnam Institute for Tourism and Development Research in 2004, the number of domestic private tourist establishments accounted for about 35 percent of establishments and 29 percent of the country's rooms. Most of these properties were the medium and small hotels and guest houses with an average of 17 rooms per unit (ITDR, 2005). In 2010, private hotels classified from 3-5 stars made up 61 percent of all hotels in Vietnam and 46 percent of all rooms (VNAT, 2011). The four- and five-star hotels of this ownership 
mode in Hanoi, Danang and Ho Chi Minh City constituted about 34 percent of the country's up-market capacity. With the trend of privatization of the SOHs (Section 4.2.1), the merger and acquisition process and priority in the government's macro policy towards the private sector, the number of DPOHs will probably increase. This is due to the hotel industry being one of the economic sectors in which the Vietnamese government does not hold either 100 percent or a majority (50 percent or more) of shares. Selling state-owned properties to the market is an opportunity for domestic nonstate or international investors to become owners of former SOHs (Deputy Director of Hotel Department, VNAT; Vo, 2006; VPM, 2007).

However, as Vietnam has not yet finished its economic transition and remains a mixed economy system, where market principles and the central planning system interact and conflict, Vietnam needs to act more in terms of legislation for the stronger development of the private sector. As the current Vietnamese Minister of Planning and Investment noted in response to a question of what is the socialist market oriented economy that Vietnam has been pursuing since 1986: "We ourselves have studied that economic mode [for almost 30 years] but we still have no answer. That mode does not exist to be found in this world" (Tu Giang, 2014). He added that the country has hitherto run out of the motivation to develop because everything has completely reached a peak. Another economic reform is therefore becoming critical to create the fresh impetus for growth. Also, the statement of the Vietnamese Prime Minister (Huynh, 2014; Tu Hoang, 2014) mentioned above must be put into action to foster the growth of non-state economy because this is not only a dilemma for the Vietnamese government but also one which private business people are now facing.

\subsubsection{Brief description of the up-market DPOHs}

As with SOHs, the key features of the DPOHs in Hanoi, Danang and Ho Chi Minh City were also gathered from the analysis of the interview transcripts, the hotels' websites and documents collected regarding the nature of ownership, management mode and growth of them in the context of Vietnam's economic reform. Of the 14 DPOHs that agreed to participate from the population of 18, various types of management mode are found, namely independent hotels, domestic hotel chains and franchising (Table 4.2). Seven of the DPOHs are operating independently, five belong to domestic hotel chains and two are franchised with international hotel groups (the Daewoo Hanoi Hotel and the 
Furama Resort Danang). Of the 14 hotels investigated, 11 were four-star hotels and three were five-stars. It should be noted that an additional four hotels, including two five star ones (the Hilton Hanoi Opera and the Crowne Plaza Hanoi), currently managed by the international hotel chains declined to take part in the research.

Table 4.2. Management modes of the DPOHs studied

\begin{tabular}{lccc}
\hline & \multicolumn{3}{c}{ Management Model } \\
\cline { 2 - 4 } & Independent & Domestic Hotel Chain & International Franchising \\
\hline Hanoi $(\mathrm{n}=6)$ & 3 & 2 & 1 \\
\hline Ho Chi Minh City $(\mathrm{n}=4)$ & 3 & 1 & 0 \\
\hline Danang City $(\mathrm{n}=4)$ & 1 & 2 & 1 \\
\hline Total & 7 & 5 & 2 \\
\hline
\end{tabular}

Source: Interview Data, 2013

Table 4.3. Independent DPOHs

\begin{tabular}{lcccc}
\hline Hotel & Location & Star & \multicolumn{2}{c}{ Room } \\
\cline { 5 - 5 } Rating & & $\begin{array}{c}\text { Room } \\
\text { Number }\end{array}$ & $\begin{array}{c}\text { Room } \\
\text { Occupancy Rate } \\
\text { (percent) }\end{array}$ \\
\hline Prestige & Hanoi & 4 & 95 & 60.0 \\
\hline Silk Path & Hanoi & 4 & 80 & 70.0 \\
\hline Brilliant & Hanoi & 4 & 106 & 65.0 \\
\hline Golden Saigon & Danang & 4 & 102 & 60.5 \\
\hline New Pacific Saigon & Ho Chi Minh City & 4 & 116 & 60.0 \\
\hline Star City Saigon & Ho Chi Minh City & 4 & 112 & 55.0 \\
\hline In average & Ho Chi Minh City & 4 & 199 & 57.0 \\
\hline
\end{tabular}

Source: Interview Data, 2013

The seven independent four-star hotels present a small range of variations in terms of operational history, scale and room occupancy rate (see Table 4.3). Except the Bao Son Hotel in Hanoi that was put into business under the four-star rating in 1995 with 95 rooms, the other hotels officially appeared as up-market hotels just five to six years ago. 
The largest one has 199 rooms (the Star City Saigon Hotel), but the average number is 116. Differences are recorded among these hotels regarding the hotel size, origin of guests, market mix and proportion of sales from segments (Tables 4.4 and 4.5).

Table 4.4. Hotels owned and operated by domestic hotel chains in the three cities

\begin{tabular}{lcccc}
\hline & Location & $\begin{array}{c}\text { Star } \\
\text { Rating }\end{array}$ & $\begin{array}{c}\text { Room } \\
\text { Number }\end{array}$ & $\begin{array}{c}\text { Room } \\
\text { Occupancy Rate } \\
\text { ( percent) }\end{array}$ \\
\hline Muong Thanh Hanoi & Hanoi & 4 & 168 & 55.0 \\
\hline Muong Thanh Xa La & Hanoi & 4 & 150 & 45.0 \\
\hline Green Plaza Danang & Danang & 4 & 173 & 54.0 \\
\hline Hoang Anh Gia Lai Danang & Danang & 5 & 206 & 60.0 \\
\hline Grand Silverland & Ho Chi Minh City & 4 & 89 & 45.0 \\
\hline In average & & & 157 & 52 \\
\hline
\end{tabular}

Source: Interview Data, 2013

Hotel chains may be defined as "multi-unit service organisations in which units operate under a system of decision-making permitting coherent policies and a common strategy through one or more decision-making centres, and where hotel units and corporate functions are linked to add value to each other by ownership or contractual relationships" (Litteljohn, 1997, p.15). The shared costs and centralized functions can contribute to greater profitability because marketing budgets associated with promoting the chain can be allocated to member hotels. In return, the hotel has to pay the supplier a fee according to the fixed term (Litteljohn, 1997; Zhang, Pine, \& Lam, 2009). Compared with this, the five private hotels in the sample belonging to the local chains present only the very basic characteristics of a chain hotel and are very similar to the independent ones in the way that these properties operate and reach the tourism market. All of them were invested in or bought by their parent companies who own several hotels throughout the country under specific registered brands. However, legally each hotel is registered and operated independently. A common marketing network such as central reservation system (CRO) has also not yet been established and each hotel in the chain is responsible for its own sales and marketing activities since in each case the parent companies' main field of business focuses on construction and property or other sectors 
outside of the tourism industry. For instance, the Muong Thanh Hotel Group are both the investor and operator of more than 20 hotels in Vietnam. Likewise, the Hoang Anh Gia Lai (HAGL Group), the VinGroup, the Thien Thanh Group and the Tan Hai Long Silver Land Hotel Group are in turn the owners of the Hoang Anh Gia Lai Hotels, Vin Pearl Hotels, Green Hotels and the Silver Land Hotels. Member hotels of these domestic chains do not have to pay fees to use their parent's brands as member hotels of international chains must do.

Regarding the franchising of the two hotels in Hanoi and Danang, a difference is also found between these franchised hotels with how hotels in other parts of the world are franchised. It is recognised that when international hotel groups enter foreign markets, they face two options: (i) investing in any properties fully or partially and (ii) selling their management techniques under the forms of franchising, management contract or leasehold contract (Litteljohn, 1997; Xiao, O’Neill, \& Wang, 2008). When a hotel becomes a franchisee, the franchisor offers it a package of operational know-how such as product or service design, trade mark, corporate image, reservation system and essential assistance like pre-opening preparation, equipment, training and management techniques. This agreement brings the franchisee easier market access, lower cost of bulk purchasing and economies of scale. Furthermore, franchised hotels are also given the benefits of shared mass advertising campaigns and product research and development in the network (Pine, Zhang, \& Qi, 2000). However, both the Hanoi Daewoo Hotel and the Furama Resort Danang receive only a very small part of these common franchising benefits. Owners of these hotels bought the brands of Daewoo and Furama under fixed term contracts. Moreover, they also join the World Hotels ${ }^{8}$, an exclusive group of independent hotels throughout the world, to promote their business. While the Furama is linked to GDS and CRO services through membership of the World Hotels, the Hanoi Daewoo Hotel has used neither the CRO from World Hotels nor from Daewoo, the latter because Deawoo is a brand of a Korean engineering and heavy industry corporation. This hotel plans to utilise the GDS from www.travelclick.com based in the United States of America in the future. In this regard, the Director of Sales and Marketing of the Furama Resort Danang said:

\footnotetext{
${ }^{8}$ See www.worldhotels.com
} 
In terms of the management mode, our hotel is neither a chain hotel nor an independent one because Furama International Hong Kong used to be a very strong partner in Hong Kong, but it sold a number of hotels there. In Vietnam, two hotels are using the Furama trademark. One is the Caravelle Saigon Hotel, another is Furama Danang under... how can I say, the franchising. The current owner of our hotel is Sovico who bought the right to use the Furama trademark of the Furama International Hong Kong.

Most of the up-market DPOHs were newly built and began operations around five to seven years ago with certain variations regarding amenities and facilities. However, the Hanoi Daewoo Hotel and the Furama Danang in turn opened in 1995 and 1997. Before being purchased by the Vietnamese entrepreneurs, these two five-star hotels were originally international joint ventures between the state-owned companies and foreign investors in the middle of 1990s. The Bao Son, which was small in terms of size and low quality, was upgraded into a four-star hotel in 1997. For some other four star hotels (such as the Muong Thanh Hanoi and the Muong Thanh Xa La owned by the Muong Thanh Hotel Group), their facilities are a little higher than the four-star hotel standards regulated by VNAT. However, the Hoang Anh Gia Lai Hotel of the HAGL Group in Danang is not really considered as five stars as some interviewees mentioned that it equal to 4.5 stars $^{9}$. The hotels of Bao Son, Hoang Anh Gia Lai or Muong Thanh groups are examples of how the Vietnamese private economy has grown and widened their businesses.

The Director of ITDR noted that the owners of DPOHs have only invested in the facilities and paid little attention to the software that is very important in operating a business. The short period of development and the background of owners as well as the dominance of the independent management mode mean DPOHs are facing a number of challenges not only in providing the expected professional services of up-market hotels but also in reaching the market. Some interviewees mentioned that the distinction between SOHs and DPOHs with the IJVHs or FOHs in terms of target market is rooted in the investment decision. While, SOHs were built decades ago to serve guests according to the allocation of the government, some DPOHs were constructed first and

\footnotetext{
${ }^{9}$ Currently, hotels in Vietnam are classified into five scales in terms of quality: from one to five stars.
} 
then market research is conducted. The foreign related parties often aim at specific market segments before building or running a hotel (Vice Rector, Hanoi Tourism College; Chairperson, VISTA).

In the context of Vietnam, questions of the real owners of any properties are sometimes raised because information is unpublished or hidden. In other cases, ownership information has only recently become available with the appearance of the stock market in July 2007 (Tuong Vi, 2014) and published merger and acquisition details. Some owners tend to establish the hotel businesses as one of the supplements to their main fields of making money. A typical instance of this is the Muong Thanh Hotel Group that are independently running more than 20 hotels from two to five stars throughout Vietnam. This investor said to the media that the hotel business is to relax because it is his "left-hand job". Hotels are built to generate employment for society and to promote the development of property and construction business (Chau Anh, 2013). The way that several owners of the private hotels have accumulated a large amount of money in a short time to purchase or to build new hotels is also questioned. This will certainly affect the way that these hotels approach the market effectively to get consumers. For example, the Green Plaza Danang Hotel that used to be owned by a state-owned enterprise was acquired by the Thien Thanh Group. However, it is unclear how the Green Plaza and other hotels under the brand of Green Hotel will continue to develop after the Chairman, the Chief Executive Officer and the chief accountants were arrested and convicted in relation to financial fraud in July 2014 (Hoai Nam \& Dinh Quan, 2014). Likewise, a question mark is also raised over the ambition of the Ocean Group to turn the Star City Saigon together with a couple of under-construction hotels into a domestic hotel chain. Police detained the founder and chairman of the Ocean Group on suspicion of financial irregularities in banking business at the end of October 2014 (Mai Nguyen, 2014).

In summary, the ownership issues and types of management applied by DPOHs reflect the early stage of development and dynamic of private hoteliers compared with the state-owned hotels. Variations in terms of quality, professionalism and management modes are found. The low level of professionalism of some hotels is associated with an independent management mode as indicated in this statement by the director of the 
Environmentally Socially Responsible Tourism Project (ESRT) under the Ministry of Culture, Sport and Tourism:

Overall, the DPOHs perform with a poor level of professionalism and limited knowledge [in hotel and tourism]. If they themselves manage their hotels, it become worse because most of these investors are not from the hotel and tourism business, they are successful from other economic fields such as property and construction. Although this sector represents a high level of independence and adaptability, they are completely afraid of doing things outside of their own experience.

\subsubsection{Patterns of demand and distribution of DPOHs}

Regardless of the owners' background, most of the sales and marketing staff of DPOHs identify the strategies to reach their market segments and to manage the in-house guests relatively clearly in terms of guest origin, types of international guests and modes of sales. The short- and long-term plans to attract tourists are established based on analysing the advantages of independence and limitation of brand and resources. Some interviewees contended that the independent management mode enables them to make decisions quickly compared with SOHs and the IJVHs. With limited resources and a little known brand, these hotels define their market niche and offer products and services to satisfy specific market needs, price range and the demographics (Representative from the Prestige Hotel in Hanoi).

The following examples illustrate the sales and marketing strategies undertaken by the more recently opened DPOHs to survive and grow along with other modes of hotel ownership that have a longer history of development. First, to enter the tourism market and to compete with other hotels having similar levels of professionalism, the long-term strategies of distribution to attract potential guests are revealed by the Director of Sales and Marketing of the Furama Resort in Danang City:

Our hotel builds the strategies of sales and marketing for the different target markets. The hotel reaches each market based on the strategies called "tailormade techniques". For instance, to attract MICE guests, we advertise our products and services in the specialised magazines in Vietnam and abroad. 
Table 4.5. Capacity and patterns of demand and sales for selected DPOHs in 2012

\begin{tabular}{|c|c|c|c|c|c|c|c|c|c|c|}
\hline \multirow[t]{2}{*}{ Hotels } & \multirow[t]{2}{*}{ Location } & \multicolumn{2}{|c|}{ Rooms } & \multicolumn{2}{|c|}{ Guest Origin } & \multicolumn{3}{|c|}{ Types of Inbound Guests } & \multicolumn{2}{|c|}{ Sales $^{b}$} \\
\hline & & Number & $\begin{array}{c}\text { Annual } \\
\text { occupancy rate } \\
\text { (percent) }\end{array}$ & $\begin{array}{l}\text { Domestic } \\
\text { (percent) }\end{array}$ & $\begin{array}{l}\text { International } \\
\text { ( percent) }\end{array}$ & $\begin{array}{l}\text { Business } \\
\text { (percent) }\end{array}$ & $\begin{array}{c}\text { FIT } \\
\text { (percent) }\end{array}$ & $\begin{array}{c}\text { Leisure } \\
\text { packaged } \\
\text { (percent) }\end{array}$ & $\begin{array}{c}\text { Direct } \\
\text { ( percent) }\end{array}$ & $\begin{array}{l}\text { Indirect } \\
\text { (percent) }\end{array}$ \\
\hline Silkpath Hotel (4*) (Independent) & Hanoi & 106 & 65.0 & 12.0 & 88.0 & 5.0 & 10.0 & 80.0 & 16.0 & 84.0 \\
\hline Bao Son Hotel (4*) (Independent) & Hanoi & 95 & 60.0 & 40.0 & 60.0 & 20.0 & 5.0 & 70.0 & 9.0 & 91.0 \\
\hline $\begin{array}{l}\text { Muong Thanh Hanoi Hotel }(4 *) \\
\text { (Domestic chain) }\end{array}$ & Hanoi & 168 & 55.0 & 45.0 & 55.0 & N/A & $\mathrm{N} / \mathrm{A}$ & Mostly & 5.0 & 95.0 \\
\hline $\begin{array}{l}\text { Muong Thanh Xa la }\left(4^{*}\right) \\
\text { (Domestic chain) }\end{array}$ & Hanoi & 150 & 45.0 & 35.0 & 65.0 & $\mathrm{~N} / \mathrm{A}$ & N/A & Mostly & 3.0 & 97.0 \\
\hline Prestige Hotel (4*) (Independent) & Hanoi & 80 & 70.0 & 10.0 & 90.0 & 3.0 & 15.0 & 80.0 & 14.0 & 86.0 \\
\hline $\begin{array}{l}\left.\text { Daewoo Hanoi ( } 4^{*}\right) \\
\text { (International franchised) }\end{array}$ & Hanoi & 411 & 68.0 & 0.6 & 99.4 & N/A & $\mathrm{N} / \mathrm{A}$ & N/A & 24.0 & 76.0 \\
\hline $\begin{array}{l}\text { Green Plaza Danang }\left(4^{*}\right) \\
\text { (Domestic chain) }\end{array}$ & Danang & 173 & 54.0 & 65.0 & 35.0 & 88.0 & N/A & 12.0 & 55.0 & 45.0 \\
\hline Brilliant (4*) (Independent) & Danang & 102 & 60.5 & 49.0 & 51.0 & 20.0 & 57.0 & 23.0 & 26.0 & 74.0 \\
\hline $\begin{array}{l}\text { Hoang Anh Gia Lai Danang }\left(5^{*}\right) \\
\text { (Domestic chain) }\end{array}$ & Danang & 206 & 60.0 & 50.0 & 50.0 & N/A & $\mathrm{N} / \mathrm{A}$ & Mostly & $\mathrm{N} / \mathrm{A}$ & N/A \\
\hline $\begin{array}{l}\left.\text { Furama|Danang ( } 5^{*}\right) \\
\text { (International franchised) }\end{array}$ & Danang & 198 & 59.0 & 25.0 & 75.0 & 15.0 & 50.0 & 25.0 & 25.0 & 75.0 \\
\hline $\begin{array}{l}\text { New Pacific Hotel Saigon (4*) } \\
\text { (Independent) }\end{array}$ & Ho Chi Minh City & 112 & 55.0 & 24.0 & 76.0 & 14.0 & 7.0 & 69.0 & 17.0 & 83.0 \\
\hline $\begin{array}{l}\text { Golden Hotel Saigon }(4 *) \\
\text { (Independent) }\end{array}$ & Ho Chi Minh City & 116 & 60.0 & 12.0 & 88.0 & 20.0 & 15.0 & 65.0 & 13.0 & 87.0 \\
\hline Star City Saigon (4*) (Independent) & Ho Chi Minh City & 199 & 57.0 & 8.0 & 92.0 & 15.0 & 10.0 & 70.0 & 19.0 & 81.0 \\
\hline $\begin{array}{l}\text { Grand Silverland (4*) Domestic } \\
\text { chain) }\end{array}$ & Ho Chi Minh City & 89 & 45.0 & 21.0 & 89.0 & 10.0 & 17.0 & 73.0 & 10.0 & 90.0 \\
\hline Average in Hanoi ( $\mathrm{n}=6)$ & Hanoi & 168 & 61 & 24 & 76 & 9 & 10 & 77 & 12 & 88 \\
\hline
\end{tabular}




\begin{tabular}{|c|c|c|c|c|c|c|c|c|c|c|}
\hline \multirow[t]{2}{*}{ Hotels } & \multirow[t]{2}{*}{ Location } & \multicolumn{2}{|c|}{ Rooms } & \multicolumn{2}{|c|}{ Guest Origin } & \multicolumn{3}{|c|}{ Types of Inbound Guests } & \multicolumn{2}{|c|}{ Sales* } \\
\hline & & Number & $\begin{array}{c}\text { Annual } \\
\text { occupancy rate } \\
\text { (percent) }\end{array}$ & $\begin{array}{r}\text { Domestic } \\
\text { (percent) }\end{array}$ & $\begin{array}{l}\text { International } \\
\text { (percent) }\end{array}$ & $\begin{array}{r}\text { Business } \\
\text { ( percent) }\end{array}$ & $\begin{array}{c}\text { FIT } \\
\text { (percent) }\end{array}$ & $\begin{array}{c}\text { Leisure } \\
\text { packaged } \\
\text { (percent) }\end{array}$ & $\begin{array}{c}\text { Direct } \\
\text { ( percent) }\end{array}$ & $\begin{array}{c}\text { Indirect } \\
\text { (percent) }\end{array}$ \\
\hline Average in Ho Chi Minh City $(n=4)$ & Ho Chi Minh City & 129 & 54 & 16 & 86 & 15 & 12 & 69 & 15 & 85 \\
\hline Average by 4 star hotels $(\mathrm{n}=11)$ & & 126 & 57 & 29 & 72 & 13 & 17 & 66 & 17 & 83 \\
\hline Average by 5 star hotels $(n=3)$ & & 272 & 62 & 25 & 75 & 15 & 50 & 25 & 24.5 & 75.5 \\
\hline Average by independent hotels $(n=7)$ & & 116 & 61 & 22 & 78 & 14 & 17 & 65 & 16 & 84 \\
\hline Average by domestic chains $(\mathrm{n}=5$ ) & & 157 & 52 & 43 & 57 & 49 & 17 & 42 & 18 & 82 \\
\hline Average by franchised hotels $(\mathrm{n}=2)$ & & 304 & 64 & 13 & 87 & 15 & 50 & 25 & 25 & 75 \\
\hline Overall average $(n=14)$ & & 158 & 58 & 28 & 72 & 14 & 21 & 62 & 18 & 82 \\
\hline
\end{tabular}

b. International guests only

Source: Interview data, 2013 
Second, positioning hotels in the market by applying pricing policies is one of the choices of DPOHs. The Director of Sales of the Hanoi Daewoo Hotel, a domestic private-owned hotel, explained:

Regarding the room rates and the professionalism level of hotels in Hanoi, they are clearly categorised. For instance, the Sofitel Metrople Hanoi [The Sofitel Legend Metropole Hanoi Hotel] sells its rooms with the lofty price, so do the InterContinental Hanoi and the Sheraton Hanoi Hotel. The Hanoi Daewoo Hotel knows where we are in the market, so we design room rates to compete with those which are applying the same mode of independent management and are located around us.

Competitive room rates are also employed:

Due to the disadvantages of location and brand, our hotel is offering the unbeatable price of the four star hotel facilities and services to attract the corporate guests and leisure packaged tourists both in Vietnam and from some countries like China, Malaysia and Thailand (General Manager of the Muong Thanh Xa La Hotel in Hanoi)

Likewise, a participant from a hotel in Danang City mentioned that the pricing policy and flexible sales and marketing strategies are its strengths:

Our hotel applies the flexible pricing policy based on the change of markets, seasons and the actual room occupancy rate. In addition, the hotel also designs the priority room rates for the MICE market, travellers from Thailand, South Korea, China (Director of Sales and Marketing, Brilliant Hotel, Danang).

Third, the DPOHs are heavily dependent on seasonal demand and the development trends of local tourism in designing and selling their products and services. Sales forecasts are often arbitrary due to low budgets for product and market research and staff may not have the skills to carry out this analysis. In Danang, when reflecting why domestic tourism has been recently booming, the Director of Hotel Management Division under the Danang City Department of Culture, Sports and Tourism concluded 
that the significant economic growth of Vietnam after 1986 has improved the living condition of people, resulting in a change from "enough food and warm cloth" to "delicious dishes and fashionable wear". The Danang Tourism Authority identifies its main products as MICE tourism and beach holidays to attract travellers from Hanoi, Ho Chi Minh City and international tourists (Danang, 2011). Danang has experienced a rapid growth in the domestic market. In this regard, the Director of Sales and Marketing, the Green Plaza Danang Hotel said:

When our hotel opened, we planned the target market as follows: 60 percent of the total guests were international guests and 40 percent were domestic guests. But from 2010 to present, the actual rate of guest origin is contrary to the initial plan. The domestic guests account for 65 percent and the international guests make up approximately 35 percent of the total guests because of our own parent company business. The tourism products of Danang destination are also more suitable for domestic travellers in summer.

Table 4.5 presents hotel room numbers, annual occupancy rates and forms of demand including types of travel and proportion of sales to international guests via direct and indirect distribution channels for the DPOHs studied. The average room number of the 14 selected DPOHs is 158 , ranging from 80 to 411 . The average room occupancy rate in 2012 was approximately 58 percent, with the lowest being 45 percent and the highest, 70 percent. The two franchised hotels exhibited the highest average room occupancy rate (64 percent), followed by the independent hotels (61 percent) and the domestic chain hotels (52 percent). In particular, the hotels of the Muong Thanh Group, the Grand Silver Land Hotel and the Green Plaza Hotel showed very low room occupancy rates, ranging from 45 percent to 54 percent. Interestingly, a number of hotels with low room occupancy rates recorded a very high volume of leisure tourists because of their low room rates, for instance the hotels of the Muong Thanh Group and the Hoang Anh Gia Lai Hotel.

As with the SOHs, the sources of guests are divided according to the average percentage of room nights sold to domestic (28 percent) and international tourists (72 percent). In terms of star rating, there is a slight difference between categories with the Vietnamese travellers accounting for 29 percent of the room nights sold at the four-star ones and 25 
percent at the five-star hotels. However, more variation is found regarding the location. Domestic travellers accounted for 47 percent in Danang hotels, compared with 24 percent in Hanoi and 16 percent in Ho Chi Minh City. This is because Danang is not only a business centre for central Vietnam but also a beach city for domestic summer holiday makers. The franchised hotels attracted more international guests to stay with them, 87 percent of the total occupants in comparison with 57 percent at the domestic chain hotels and 78 percent at the independent ones. Some hotels are strongly dependent on domestic travellers, particularly the Vietnamese and businesspersons or highly positioned staff who are the partners of their parent companies such as the Bao Son Hotel (40 percent), the Muong Thanh Hotel (45 percent), the Green Plaza Danang (65 percent) and Hoang Anh Gia Lai Danang (50 percent).

Differences are found among hotels concerning travel types and number of international guests. In general, leisure-packaged tourists constituted the largest segment of inbound guests (62 percent), followed by the FITs ( 21 percent). Some hotels are much more reliant on business guests (the Green Plaza Danang, 80 percent), and packaged tourists such as hotels of the Muong Thanh Hotel Group and the Hoang Anh Gia Lai Danang. For example, 91 - 95 percent of the Muong Thanh and Muong Thanh Xa La Hotel's room nights were sold to this type of tourists by the local travel agents and international tour operators. In the two five-star hotels, FITs were the dominant guests (50 percent), followed by leisure packaged tourists ( 25 percent) and business travellers (15 percent). However, as mentioned, chain hotels attracted a high proportion of business guests (49 percent).

Variations among hotels also occurred regarding the use of distribution channels to reach the various types of international guests. Direct sales produced on average 18 percent of the total inbound guests' room nights and intermediaries brought 82 percent. Most of the four-star hotels were dependent on intermediaries to distribute their products and services as 83 percent of room nights are sold through these channels. Conversely, the two five-star hotels recorded a higher percentage of the guests who booked rooms directly, 24 percent for the Hanoi Daewoo Hotel and 25 percent for the Furama Danang. In some hotels in Danang City like the Green Plaza Hotel, direct sales accounted for up to 55 percent. Most interviewees commented that their leisure guests normally book rooms through TAs and TOs but businesspersons prefer to use direct 
channels to book their accommodation. However, the DPOHs have strong relations with intermediaries in comparison with $\mathrm{SOHs}$ in distributing products and services because these parties not only support independent hotels to reach their target markets but also they can help hotels overcome the disadvantages of their marketing budget. In this regard, the Director of Sales and Marketing of the Furama Resort Danang said:

To some extent, establishing and carrying out the distribution channels completely depend on the knowledge of the hotel general managers or the hotel owner. Some people think that intermediaries and third party websites are the killjoys but tour operators and OTAs are the real business partners of independent hotels and maybe all the hotels. Actually, they are not the killjoys because they have invested a huge resource to formulate their brands to get 20 percent of commission per booking. It is not an accidental deal.

\subsubsection{Domestic privately-owned hotels' distribution channel structure}

\subsubsection{The structure for international guests}

This section represents the structure of the channels that the selected DPOHs in Hanoi, Danang and Ho Chi Minh City apply to distribute their products and services to international and domestic tourists. As displayed in Table 4.5, international guests (72 percent) who stay at these hotels occupy a much larger number in comparison with domestic ones (28 percent). Therefore, the distribution channel structure for international guests will be presented first, followed by the structure for domestic travellers. The structures for the two sources of guests are presented in line with the previous section dealing with the distribution channels of state-owned hotels. Channel length, types of channel member as well as their functions and market segments are displayed and discussed according to channel structure diagrams. Channel width is not exhibited in these diagrams but it is mentioned through the ways that hotels deal with intermediaries to reach the market. However, some differences in channel members and their functions are found which differentiate those diagrams with those of the SOHs (see Figure 5.3 and 5.4), for example, the absence of the GDS and particular channel member functions (business partners of hotels). In terms of channel mix, this function of DPOHs is relatively the same with SOHs that was discussed in Section 4.2.5.1. Specifically, the channel mix used by DPOHs were poor. Regardless of whether TOs have agreement contracts with this hotel ownership modes or not, if they have a 


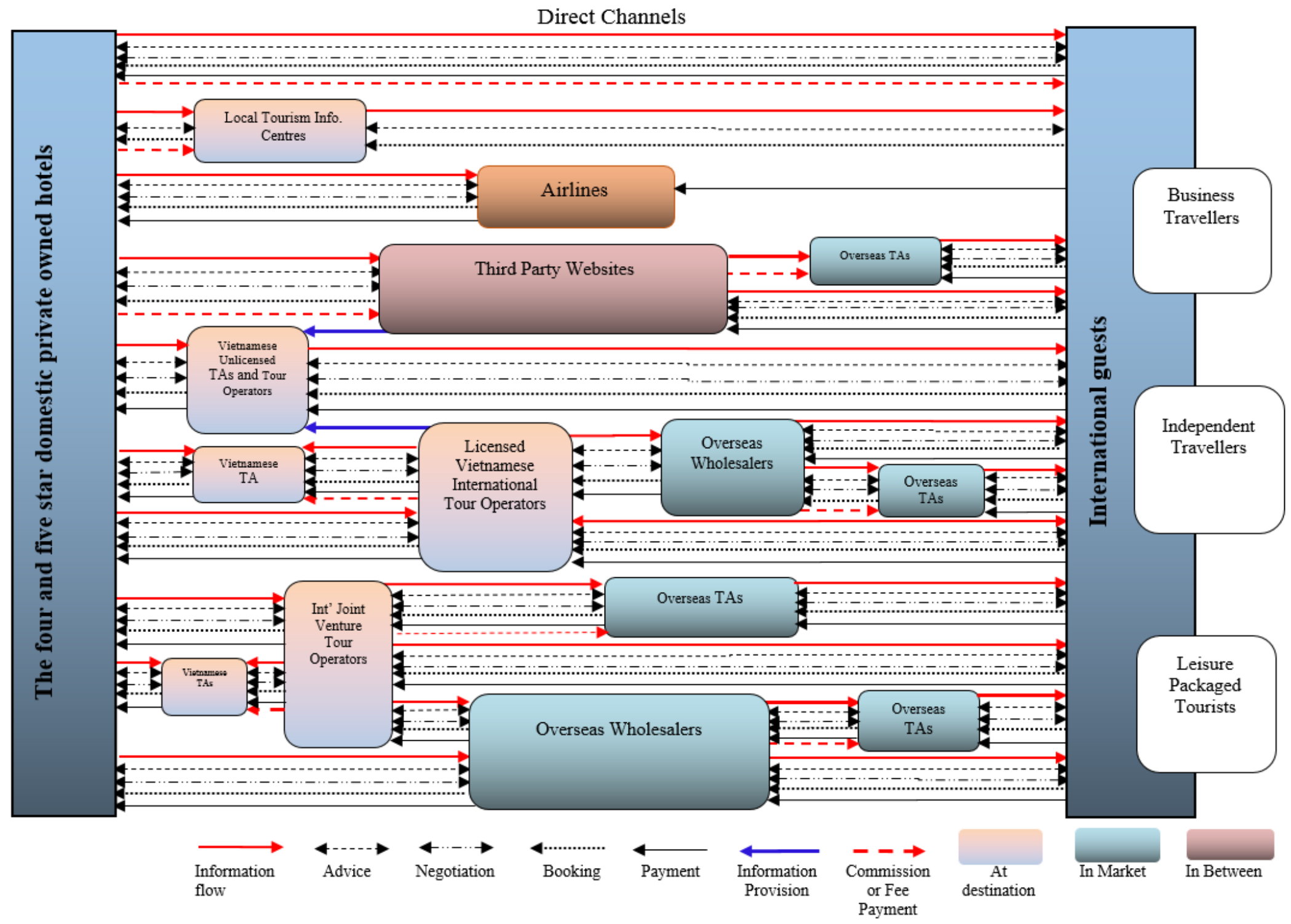


relationship with the hotel they will have rooms. Therefore, analysis of selecting an appropriate channel becomes a secondary priority.

\section{Direct distribution channels}

In 2012, direct sales generated approximately 18 percent of the total hotel room nights sold to international guests. The most popular direct distribution channels are through hotel websites, hotel representative offices, airlines, sales calls and mail. Only some of the DPOHs run the sales representative offices outside of their headquarters. These offices may contribute considerably to sales and marketing activities. They are not considered here as a separate channel member but as an extension of the hotel. Operational costs have hindered small hotels such as the Bao Son, Prestige, Brilliant and the Grand Silverland from establishing representative offices. Except the Furama Danang that is working with local airlines to produce a "Free and Easy" package for the customers (see Section 4.2.5.1), airlines in this structure are considered as direct partners; they generate a negligible number of guests when crews stay overs or for passengers of delayed or cancelled flights.

Information provision, advice from hotels and the chance to negotiate room rates before booking as well as convenience of payment are mutual benefits for both certain consumers and hotels, resulting in attention from private hoteliers to promote this type of distribution. As the Director of Sales of the Hanoi Daewoo Hotel said:

We sell our products and services directly to the end consumers in different ways such as online sales. If potential guests already know us through some sources, they just make several clicks on booking engine of hotel website to reserve rooms. However, direct guests could be either the persons who call us or people who go straight to our hotel because they are loyalty guests.

Moreover, direct distribution channels are designed to target specific types of consumers. For example, most of the business travellers and corporate guests of the Hoang Anh Gia Lai Hotel book rooms directly. In this regard, the Director of Sales and Marketing of the Brilliant Hotel in Danang noted: 
Our hotel's sales and marketing executives are categorised into groups based on market-search functions. Tourists include packaged group travellers, business guests and FITs. Therefore, sales and marketing activities and distribution system are divided into two channels, namely direct channels to attract FITs, business guests and indirect ones to gather packaged leisure groups.

\section{Indirect distribution channels}

As shown in Table 4.5, indirect sales accounted for about 82 percent of international guests' room nights. In order to gain this, challenges occur when DPOHs try to reach distant markets directly in the hope of getting higher profitability because of their resource limitation. Therefore, intermediaries play a very important role in identifying the sales and marketing strategies of these hotels.

As we [DPOHs] are the independent hotels, we do not belong to any hotel groups so business partners take a key part in our distribution system. For example, international chain hotels are significantly supported by their groups, they can conduct the sales and marketing tasks elsewhere in the world. For us, we even cannot cover everything in Vietnam, therefore, cooperating with tour operators is essential. Travel intermediaries are currently generating the main bookings and profitability for our hotels (Director of Sales, Hanoi Daewoo Hotel).

The choice of travel intermediaries is dependent on each hotel but commonalities in cooperating with indirect channels are seen. This is discussed by the representative from the Hanoi Daewoo Hotel:

The selection of business partners in distributing hotel's products and services is flexible. It is the same with going shopping, when we see an attractive item, we will ask the price. If it is too expensive for us to buy, we will move over to the next. Selling rooms is relatively the same with this process, we firstly need to get to know the target market and hotel requirement of a series of travel companies. Secondly, we analyse these information to select the partners to cooperate. 
Specifically, international TOs and TAs, including the unlicensed companies, are the core channel members of the private hotels in distributing their rooms to the ultimate consumers. At the destination, international TOs cooperate directly with hotels or via a series of TAs to buy rooms before selling. Towards the international marketplaces, travel companies in Vietnam on one hand sell their products and services directly to the travellers, on the other hand they work with a number of wholesalers to distribute rooms to tourists as part of packaged tours or as room only. However, apart from the two large hotels: the Daewoo and the Furama, the remainder of smaller hotels connect with a limited number of international wholesalers. Referring to this, the Director of Sales and Marketing of the Furama said that:

Our hotel is cooperating with most of the international tour operator in Vietnam such as the Saigon Tourist, Vido Tour, Trail of Indochina, etc. We need more and more tour operators to sell our products and services because with the room occupancy rate of 59 percent, these travel companies are important. For foreign business partners, the trend is that direct cooperation between large hotels and overseas wholesalers is becoming popular. For example, our hotel has worked directly with the TUI of Germany.

Tourism information centres are where hotels place brochures to provide details for FITs and to market promotional room rates with the hope of attracting walk-in guests at the destination.

Our hotel place brochures and DVDs at some tourism information centres in Hanoi, Danang and Ho Chi Minh City for non-packaged leisure tourists. However, the hotel has not measured the efficiency of this mean of sales and marketing (The Sales Manager of the New Pacific Hotel in Ho Chi Minh City).

Apart from the conventional intermediaries, the DPOHs also employ a number of electronic channels but the use of them varies among the hotels. OTAs are widely accepted and used by all hotels, but only the two former IJVHs (the Hanoi Daewoo and the Furama) that are the members of the World Hotels exploit the GDS service. The CRO is used by the Furama as supplementary service of the World Hotels, but as the 
Director of Sales and Marketing of the Furama commented, its efficiency is not clear though his hotel is in agreement to use the GDS service of Gallileo and Sabre.

Channel width for conventional and electronic middle parties is related with market segments of hotels and guests' demands. Most of the DPOHs have cooperated with hundreds of international tour operators for collecting leisure-packaged tourists and popular OTAs such as Agoda, Booking and Expedia for FITs and corporate guests. These travel companies are mostly located in Vietnam and only few wholesalers are abroad since most of these independent hotels do not have the high performance and reputation in the market to attract the wholesalers.

\subsubsection{The structure for domestic guests}

Accounting for 28 percent of the total room nights, the structure of distribution channels for the Vietnamese travellers is established in the same way with SOHs to reach domestic tourists (Figure 4.6). This system contains specific differences from the structure for international guests.

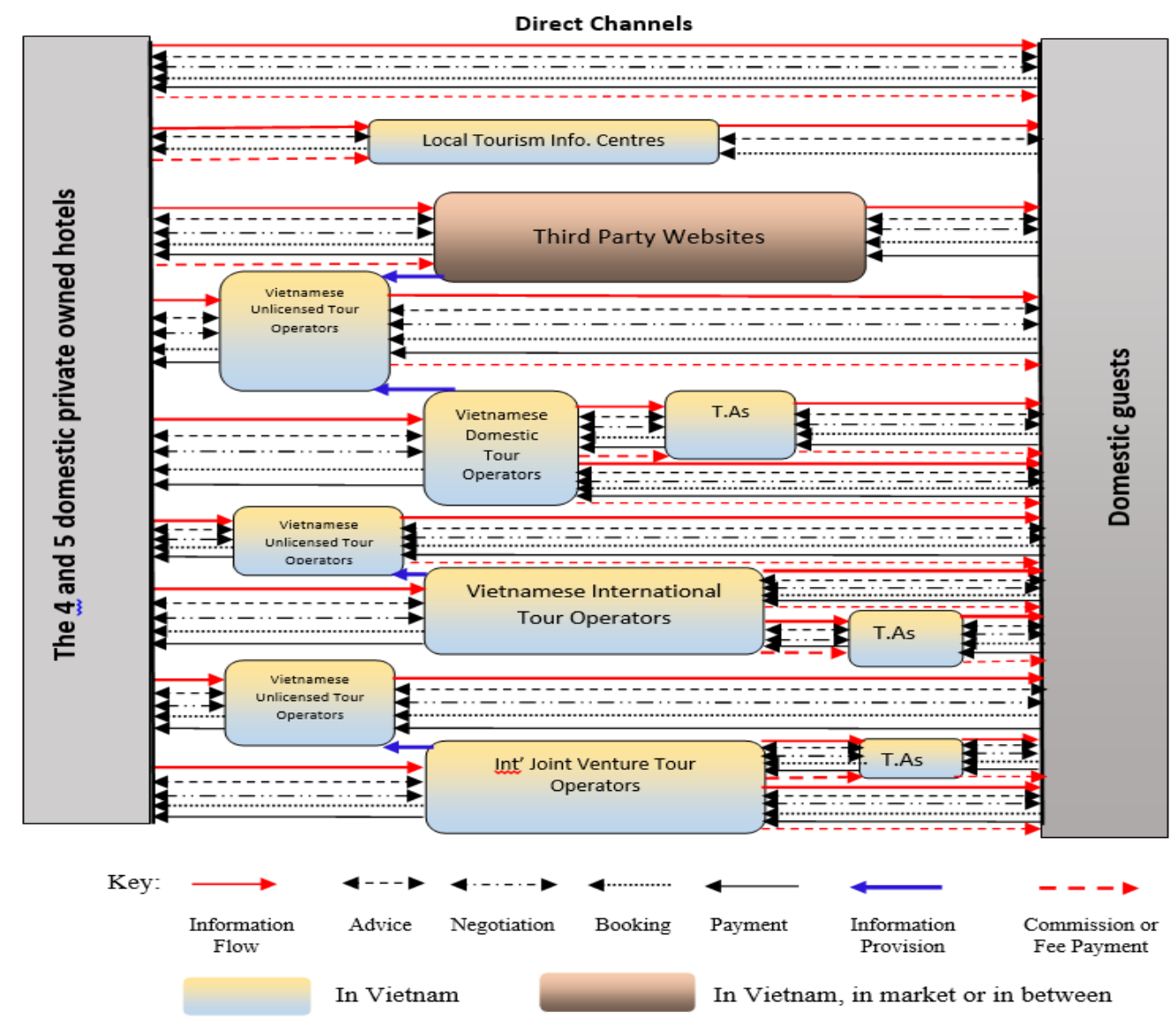

Figure 4.6. Distribution channel structure of the up-market DPOHs for the domestic guests 


\section{Direct distribution channels}

Firstly, the most common means of direct sales used by private hotels to reach potential consumers and to gather bookings also consist of hotel websites, sales representative office, phone calls, on-site sales calls, emails and airlines. Sales and marketing representative offices located outside of hotels are also the direct channel members that frequently look for corporate guests and take care of intermediaries. Other ways that the hotels collect direct bookings were also mentioned. By advertising their products and services on newspapers and TV, participating in some social activities such as charity and sponsorship and carrying out the "tailor-made" strategies, hotels hope to get the FITs from these marketing actions. This sales tactic was noted by the Director of Sales and Marketing of the Furama Danang:

The sales and marketing staff of our hotel find the best way through advertising networks to approach the Vietnamese families to sell our summer holiday and honey moon product packages, followed by the hotel website. Another way is to distribute rooms to members of some associations such as Golf Club.

Specifically, promotional plans were undertaken on the newspapers, magazines and TV to make sure that sufficient information was publicly provided to certain types of guests prior to sales calls. This was important to domestic travellers when people often paid attention to hotels for their vacations during some long holidays in Vietnam such as summer and new year. To illustrate this, the Director of Sales and Marketing of the Brilliant Hotel in Danang noticed:

Direct sales are designed to sell the hotel's products and services to FITs, business travellers and corporate guests, including domestic guests. This way of sales is strongly carried out through hotel websites, in person sales calls, telesales after we advertised hotel's products and service on newspapers, TV or some other means of marketing before the peak seasons.

Secondly, as mentioned earlier, corporate guests who are the business partners of hotels' parent companies make up a large proportion among types of travellers stayed at DPOHs (the Brilliant, the Green Plaza and the Hoang Anh Gia Lai). Social relationships 
of hotel owners to government also affect the way that sales calls are conducted to get bookings.

The Hanoi Daewoo Hotel pays significant attention to attract the invited guests of government, particularly from some ministries. In fact, this type of guest makes up a noticeable proportion of total domestic guests' room nights and hotel revenue. When sales calls are made, we take advantages of owner's social relationship in Vietnam because the Chairman of Hanel [the parent company of the Daewoo Hotel] is currently a member of the Vietnam National Assembly.

Thirdly, the products and services distributed directly to the end consumers are sometime combined with other members in the tourism industry. The Director of Sales and Marketing of the Furama noted the Free and Easy package:

The hotel must diversify its products and services to meet certain demand of types of guests and to find ways to sell them. [...]. One of the tour packages sold directly to tourists, rooms that are combined with airline seats have become increasingly important for domestic guests.

DPOHs also paid unlawful commissions to some state organisations or government bodies to have direct bookings of rooms and other types of services such as banqueting and conferences. This was reflected as follows:

Commissions are only applied to some ministries of the Vietnam government. However, our hotel is thinking of reducing and controlling the commission policy [for the bookings from government] because it is fairly a sensitive issue. Moreover, unlawful commissions are not the sustainable trends of development (Director of Sales, the Hanoi Daewoo Hotel).

\section{Indirect distribution channels}

In Figure 4.6, of the channel members involving in the distribution structure for domestic guests, the dominance of travel intermediaries is seen. If business, corporate guests and FITs prefer to book hotels on their own, the Vietnamese leisure tourists often have intermediation arranged and their holidays are bundled. In other words, TAs and 
international TOs have become the main business partners of hotels, helping them not only reach the holiday makers but also generate bookings and revenues. This is because, the flexible and competitive pricing policies and lower requirements of the Vietnamese travellers in comparison with foreigners regarding the hotel amenities and services have promoted strong cooperation between various types of travel companies and hotels. In addition, most hotel representatives noted that hundreds of travel companies are currently working with them; however, all newly opened companies are welcome since the low room occupancy rate means hotels need additional guests.

Among properties in Hanoi, Danang and Ho Chi Minh City, particularly those with high percentages of room nights sold to domestic tourists, unlicensed TAs and TOs appear to be an important source of guests. Competitive offers of room rates resulted in one of the facts that unlicensed travel companies send many of their guests to stay at these hotels because low hotel price was the most important input to build cheap tours and sell them online. As discussed above, unlicensed TAs and TOs existed and got bookings by offering tours and hotel rooms as the lowest price possible in the high season. Of course, a number of other channel members such as tourism information centres and OTAs also took part in the sales process of DPOHs, nonetheless, these channels were not mentioned interviewees.

\subsection{Conclusion}

This chapter presented the structures of distribution channels for international and domestic guests used by the up-market SOHs and DPOHs in the three largest urban cities in Vietnam. Detailing the operational settings, the brief description of samples, and then patterns of demand and sales for the selected hotels have provided a more holistic understanding of how these hotel ownership modes have grown and how they approached the marketplace. It sheds light on the nature of each hotel distribution channel structure and its relationships with ownership modes in a specific transitional economy. Chapter Five will continue to explore how IJVHs and FOHs structure their distribution channels to reach domestic and international guests, and then concluding thoughts of Chapters Four and Five will be produced by the end of Chapter Five. 


\section{CHAPTER 5. THE DISTRIBUTION CHANNEL STRUCTURES OF INTERNATIONAL JOINT VENTURE AND THE WHOLLY FOREIGN- OWNED HOTELS}

\subsection{Introduction}

The chapter begins with the operational setting shared by the remaining two hotel ownership modes (IJVHs and FOHs). This section reviews the different Constitutions of Vietnam and various versions of foreign investment laws that gradually contributed important roles in generating a business environment for foreigners today. It then presents the main characteristics of the selected hotels within each mode and patterns of demand as well as the structures used to distribute their products and services to international guests and domestic travellers. It concludes with a summary of the findings from this chapter and the previous one.

\subsection{Common operational setting for foreign-related hotels}

Although the Vietnamese private capitalists came back into the market and became involved in the economic development from 1990, international investors were officially allowed to do business again in Vietnam from 1977 by a Decree of the Vietnamese Council of Ministers and a number of related laws ${ }^{10}$. These laws on one hand indicated the strong commitment of Vietnam to creating an attractive investment environment for foreign investors, and on the other hand they have indirectly represented Vietnam's integration into the world through the appearance of international enterprises.

Two years after the end of the US-Vietnam War, the unified government of the Socialist Republic of Vietnam inaugurated a legal document called Decree 115-CP on regulations of foreign investments in Vietnam. This document, which was formulated based on the Constitution of the North Vietnam in 1959 where the state economy was owned by the people and economic relationships were led by state-owned enterprises and collectives, aimed at attracting international resources to rebuild and restructure the country. This regulation also enabled foreigners to collaborate with Vietnamese partners to establish

\footnotetext{
${ }^{10}$ In 1997, the Vietnamese Council of Ministers issued a Decree No 115-CP of 18 April 1977 on regulations of foreign investments in Vietnam.
} 
joint venture collectives or enterprises in specific areas of business. In the context of a newly liberated country, such a law passed by a post-war government was recognised as an important step and signal of Vietnam's transformation from an entire command economy into a market one. However, statistical figures for this period of foreignrelated companies have not been widely published except some joint venture enterprises in oil exploitation between Vietnam and the former Soviet Union. This decree was found to have some shortcomings in terms of the duration and mode of investment and commitment of the government to protect the investors' rights. For example, these joint venture projects often lasted from ten to fifteen years. Wholly foreign owned enterprises had not yet been fully permitted to establish. In some cases, the assets of foreign investors could be nationalised with appropriate compensation from the government though the nationalisation did not eventually happen.

In 1980, the Vietnam National Assembly announced another constitution for the unified Socialist Republic of Vietnam replacing the one promulgated in 1959. The new law on foreign investments was also prepared and issued to undertake the new spirit of this legislation. Firstly, the constitution, in which Vietnam determined to move straight to socialism by skipping the developmental stage of capitalism, identified the state economy as the leading force and gave it the highest priority. Secondly, the replacement law on foreign investments was passed by the National Assembly in December 1987. In this law, Vietnam for the first time allowed overseas individuals or organisations to invest directly by establishing either joint venture corporations or 100 percent foreignowned companies. In terms of the equity contribution of parties involved in the joint venture enterprises, the foreign businesses must register at least 30 percent of the legal capital. The government was highly committed to protect any assets of investors in Vietnam; under no circumstances would their properties to be confiscated or nationalised. The new Constitution and this law on foreign investment arrived in the context of the post-war country, which was experiencing a socio-economic crisis and galloping inflation of up to 450 percent per annum, which had forced Vietnam to strictly apply the stamp ration system to manage the serious shortage of goods as well as food (Nguyen, Nguyen, Jen \& Tarlok, 2014). The limited economic relations with specific member countries in the former Soviet Bloc and the embargo and sanctions against Vietnam imposed by the USA had caused many difficulties for Vietnam. On account of 
this, foreign companies had also not appeared as expected, urging Vietnam to accelerate changing its legal system.

In 1992, Vietnam changed the Constitution promulgated in 1980 as a result of Doi Moi in 1986. The law on foreign investments was consequently revised several times to adapt to the new socio-economic environment. Firstly, viewpoints on the economic mechanism of the country were re-identified in the way that the socialist marketoriented economy was built and developed with the equal participation of multiple ownership modes. Secondly, two other versions of the laws on foreign investment continued to encourage overseas investors to do business in Vietnam based on the regulations of 1987 and 1977 (VNA, 2000). Overseas organisations or individuals were offered highly favourable conditions to invest in Vietnam. For instance, the exemption of land and enterprise tax in a specific period as well as clearing the ground prior to projects were popularly applied by both central and provincial authorities to attract investors. Thirdly, the embargo against Vietnam imposed and led by the USA was lifted in 1995 after the US president announced the formal normalization of diplomatic relations between the two countries. Fourthly, Vietnam had been recognised as a full member of ASEAN on 28 July 1995, demonstrating its commitment to economic cooperation in the region, to the opening up of her economy and to trade liberalization. These political events and the new law were major milestones that directly and strongly facilitated foreign investments in Vietnam.

The other legal document marking the increasing influx of FDIs in Vietnam was the common law on investment for all investors passed by the National Assembly in 2005. In this law, a stronger commitment of government was generally applied for all investors regardless of their nationalities. Specifically, any foreign investment activities in Vietnam must firstly comply with the provisions of this and other relevant laws. In the case of the absence of Vietnam laws in the field of investment, the involved parties may agree in the contract to apply any foreign laws if they were not contrary to the fundamental principles of Vietnam's legal system. The Law on Investment in 2005 is highly appreciated by the investors since the Vietnamese government commits to address any disputes which occurred in the FDI enterprises by applying not only the local laws but also treaty(ies) to which the Socialist Republic of Vietnam is a contracting party (VNA, 2005). The significant changes in the legal system led to the 
booming of FDI enterprises in the beginning of 2000s and gave positive assurance to the existing joint ventures. In the tourism sector, there was consequently growth in the accommodation sector with the deep involvement of international hotel groups.

However, further amendments were made to the Law on Investments in 2005 (VNA, 2013). Changes to this law are expected to follow the current bill of Law on Enterprise and the new constitution passed by the Vietnam National Assembly in 2013 as well as a number of international treaties that the Socialist Republic of Vietnam signed. First, the Law on Amending Article 170 of the Law on Enterprise allows foreign-related companies to extend or to end their businesses invested in Vietnam before 2006. Second, the bill of enterprise law discussed and examined by the National Assembly will probably have some breakthroughs in terms of renovating the legal platform for businesses. Accordingly, individuals or organisations are entitled to freely invest in and run businesses in any fields that are not prohibited by law. These changes are extremely important to encourage investors to use their resources and to decide their own operation instantly without changing or adding the new fields of businesses in the registration certificate. Together with this bill, some laws such as the Law on Investment and Law on State Capital Management will be revised to avoid the conflict among legal documents (VNA, $2014 \mathrm{a}, \mathrm{b}$ ). Third, according to the current constitution, Vietnam continues to develop the socialist market-oriented economy with the equal involvement of various economic sectors and ownership modes, in which the state economy plays the leading role. Legal assets of individuals and investors are absolutely protected and are not being nationalised in any circumstances. Moreover, the changes are probably subject to the fact that Vietnam, which was accepted as the $150^{\text {th }}$ member of the World Trade Organisation in January 2007, has been taking into account its commitments with this trade organisation by revising its laws. These legal backgrounds strongly affect how foreign investors decide to invest in Vietnam including in the hotel industry.

\subsection{The international joint venture hotels}

\subsubsection{Brief description}

An IJVH in this study is defined as the hotel owned by an international joint venture enterprise. This type of company is established under the following combinations: (1) international and Vietnamese investor(s), (2) Vietnamese overseas who hold foreign 
citizenship to carry out investment activities with local partner(s), or (3) a Vietnamese enterprise, which foreign investors purchase shares from, merge with or buy (VNA, 2005). In this study, all of the selected IJVHs have been formulated based on the direct contributions of Vietnamese investor(s) with foreign investor(s) under an international joint venture company. In other words, these IJVHs are the results of FDIs in which these investors are involved directly the management of their investments.

In line with Chapter Four, the main characteristics of IJVHs in Hanoi, Danang and Ho Chi Minh City are drawn from the interview transcripts, the hotels' websites and other secondary sources in terms of the nature of ownership, management mode and growth of them. As mentioned in Chapter Three, of the 18 IJVHs that agreed to participate from the population of 34, most of them are classified as five-star hotels (15); only three properties in Danang are rated as four stars. The average room number of the selected IJV is 310. The 18 hotels consist of eight in Ho Chi Minh City, six in Danang and four in Hanoi. All the studied IJVHs are branded under a management contract with wellknown international hotel chains including Grand Mercure, InterContinental, Meliá, Nikko, Novotel, Park Hyatt, Pullman, Renaissance, Sheraton and Sofitel.

By the late 1980s and during the 1990s, Vietnam witnessed a boom of joint venture hotel projects due to the introduction of the economic reform in 1986 and the effect of the law on foreign investment in 1987. It is noted that the open-door policy of Vietnam had resulted in increasing FDIs, businesspersons and investors who looked for investment opportunities and this in turn caused a high demand for luxury accommodation, particularly in the three largest cities in Vietnam. Under this developmental trend, the government and the SOHs recognised chances to welcome a new flow of Western guests outside of the traditional markets. Most of the SOHs were located in ideal places for hospitality business but performed poorly regarding the quality of facilities and services. Limited resources in terms of capital and hotel management know-how had hindered SOHs from renovating facilities and expanding sales volumes (Sections 4.2.1 and 4.2.2). The need to establish international joint venture enterprises was initiated.

In such a context, the government allowed SOHs to call for cooperation from foreign investors to upgrade hotel amenities and services through a programme known as the 
Pilot Plan (The Director of the ESTR). For example, in 1987, the French Pullman Hotels chain entered into a joint venture with the Hanoi Tourist Corporation to restore the Unification Hotel to meet international standards. The hotel was completely rebuilt, and reopened in 1992 as the five-star Pullman Metropole Hotel. The hotel later moved from the Pullman to the Sofitel brand and was placed in their exclusive Legend division as the Sofitel Legend Metropole Hanoi. A similar process happened with some other IJVHs in Hanoi and Ho Chi Minh City, for instance, Meliá Hanoi, Hanoi Pullman (formerly Hanoi Horison managed by the Swiss-Belhotel International), InterContinental Hanoi, Sofitel Plaza Hanoi, Caravelle Hotel Saigon, New World Hotel Saigon and Renaissance Riverside Saigon. The Pilot Programme in permitting SOHs to cooperate with foreign entrepreneurs achieved a positive effect in promoting the development of tourism, enhancing the country's hotel image and generating experiences for policy makers to revise the related laws as well as encouraging other hotel investors to come to Vietnam. Consequently, there were hotels beginning operation in the 2000s as the next developmental phases of foreign investment in the hotel sector, such as Nikko Saigon, Park Hyatt Saigon, Sheraton Saigon. In Danang, some IJVHs appeared more recently since this city has become an attractive destination for tourists and investors such as Hyatt Regency Danang, InterContinental Danang and Grand Mercure Danang.

Regarding the nature of ownership and modes of management in these IJVHs, capital contributions have basically been allocated to related parties according to a 30-70 formula for a period of 30 to 50 years. All of the studied IJVHs have been under management contracts with global hotel chains, it means owners of these hotels have hired international hotel groups such as Accor, IHG, Meliá and Starwood to run their properties. The capital contribution formula means that the Vietnamese sides normally contribute 30 percent of the total registered capital in the enterprise through their own property or land. The foreigners are responsible for the remainder, including budgets to build a new hotel or to renovate. This mode of contribution and management modes initially benefited both sides in the joint ventures since it met requirements of them in operating a modern hotel and hiring a globally well-known hotel chain to manage the hotel. The international investors also saved time and other resources to adapt to the new business environment. However, conflicts among parties sometimes occurred later in management and profitability when the decision-making process did not satisfy 
members of the enterprises. The result of this is that ownership would be possibly changed; a smaller contribution side may withdraw its capital from joint venture company (The Deputy General Director of New World Hotel Saigon and the Director of Hotel Management, the Danang Department of Culture, Sports and Tourism).

The IJVHs play a key role in creating the country's hotel image, partially ensuring the attractiveness of its tourism. Global hotel brands bring trust to international guests, particularly to people who either have yet come to Vietnam or lacked information about Vietnam (The Director of Sales, Park Hyatt Saigon Hotel). The Deputy Director of the Hotel Management of VNAT and the Head of the Hotel Division of the Ho Chi Minh City's Department of Culture, Sports and Tourism also said foreign investors have brought their knowledge of hotel management into the young industry in Vietnam. They trained staff and transferred managerial techniques to help the Vietnamese hoteliers gradually gain access to the developmental level of hotels in the region and in the world. This is because global brands mean that the professionalism of services has been popularly recognised by tourists. In addition, the former Director of the Hotel Management division of the Danang Department of Culture, Sports and Tourism contended that the appearance of a series of large-scale hotels during the 1990s managed by the international hotel chains was regarded as a benchmark, setting a new standard of amenities and services for owners of DPOHs and other types of accommodation. The quality of this type of hotel ownership compared with the whole hotel market was stressed by the general director of the Hanoitourist Travel Company:

The run by international hotel chains normally have a very good reputation and they attract a large number of loyalty consumers. There are tourists who always choose to stay at famous branded hotels of Accor or Meliá. By hearing a brand of Sofitel, consumers could imagine what the quality of a hotel is regardless of its location or region. The same is with Novotel, Ibis, Mercure because these hotels are managed based on the same standards. For the local hotels or the local brands, the Unification Hotel is an instance, it is difficult for consumers to recognise how they are because they are quite local.

Likewise, the Deputy Director of the Vietnam Railway Trade Union Tourist Service Company commented: 
If you ask me which type of hotel ownership I would like to cooperate with, my instant answer is the hotels managed by foreigners or international hotel chains. Let me take an example, do you see any presidents and VIPs who visit Vietnam and stay at SOHs? Of course, no. A president of a country never stays at De La Thanh, Kim Lien, he or she will choose to live with Nikko, Hilton, etc.

At present, although IJVHs make up a small number of the total tourist establishments across Vietnam, these hotels constitute a considerable proportion of total rooms in the high-end hotel market (see Table 5.1). Of the 205 hotels classified from four to five stars, joint venture ones accounted for 17 percent of hotels and 30 percent of rooms of the country's up-market capacity. The four- and five-star hotels of this ownership mode in Hanoi, Danang and Ho Chi Minh City took up about 64 percent of the high-end rooms. With the rapid trend of international integration of Vietnam, the high growth rate of tourism development and the process of mergers and acquisitions in the business, the number of IJVHs will probably increase and continue to dominate the up-market hotels.

Table 5.1. Joint venture hotels over other hotel ownership modes by the end of 2012

\begin{tabular}{lccc}
\hline \multicolumn{1}{c}{ Hotels } & Number & Total Room & Average Room \\
\hline Investigated IJV hotels in the three cities (1) & 18 & 5,574 & 310 \\
\hline Total IJV hotels in the three cities (2) & 34 & 9,815 & 364 \\
\hline The total upmarket hotels in the three cities (3) & 64 & 15,294 & 158 \\
\hline Total upmarket hotels in Vietnam (4)* & 205 & 32,325 & \\
\hline $\begin{array}{l}\text { IJVs as a percentage all four and five star hotels in } \\
\text { the three cities (2)/(3) }\end{array}$ & $53 \%$ & $64 \%$ & \\
\hline $\begin{array}{l}\text { IJVs in three cities as percentage of the country's } \\
\text { (2)/(4) } \\
\text { Four and five star hotels }\end{array}$ & $17 \%$ \\
\hline
\end{tabular}

Source: Interview data, 2013

* the Ministry of Culture, Sports and Tourism, 2012

The presence of IJVHs has led to some changes in the Vietnamese tourism and hotel industry. Initially, foreign investors not only bring money, know-how, experience and industry connections to the Vietnam hotel sector, but they have also been active in 
encouraging the government to take a progressive stance on other facets of the tourism sector. The tourism image of country significantly benefits from this appearance. When the open-door policy was implemented, international investors were totally reliant on local enterprises in order to establish joint ventures since domestic partners were more familiar with navigating the Vietnamese and legal processes. It is likely that Vietnamese partners were also more able to anticipate and adapt to the rapid changes that characterised the transitional period in Vietnam. This resulted in an unwritten law, "which gives the minority shareholder the same control and rights as the majority partner, gives Vietnamese firms an added incentive to team up with foreign investors" (Suntikul et al., 2010b, p. 269). However, this situation is changing with much more transparency in the legal system, stronger commitments and more involvement of Vietnam in international trade. The above comment of Suntikul et al. is now less applicable as most joint ventures are now completely dominated by foreigners. This is simply because the higher percentage of ownership in the enterprise you have, the more power you have to decide the management mode (New World Hotel Saigon representative).

The situation of mergers and acquisitions presents the Vietnamese government with a question of the efficiency of IJVHs regarding tax payments. Most of the joint venture hotels continuously report losses in their business that has considerably threatened the contribution of the Vietnamese partners who are known to be lacking capital and management experience. In the near future, the FDI projects in general will be possibly controlled more tightly and some initial priorities to attract international investment, such as exemption of land usage or enterprise tax, will be revised or cut. The accounting system applied by joint ventures will be also taken into account to be compatible with the Vietnamese system to reduce the money loss to foreigners. In this regard, the Director of the Hotel Management Division of the Danang Department of Culture, Sports and Tourism noted that:

[In Danang] At the beginning of the economic reform, there were two, namely the Furama and Non Nuoc [the Sandy Beach]. In both hotels, the Vietnamese sides contributed about 49 percent of the total capital by their lands or other assets; the international investors were responsible for building and deciding the management mode. After three to five years of operation, the Vietnamese 
side's contribution in the Furama Hotel was lost because the low business efficiency was continuously reported although room occupancy rate and room price, in fact, were always high.

Regarding the sales and marketing strategies carried out by the IJVHs, as the foreign partners make the dominant capital contribution, the outstanding knowledge of hotel management in the enterprises and the recognised standard of hotel groups they hire, the distribution structure set up by employed international hotel brands in the IJVHs are applied. As the Deputy General Manager of the New World Hotel Saigon stated, the role of Saigontourist in the joint venture hotel is becoming unclear. The Hong Kong party brought a hotel company branded New World that is less well-known in the hotel industry to manage the hotel. The strategy of sales and marketing is completely decided by the New World. An issue is that he could not understand why the room occupancy rate was not as high as expected, even in the peak season.

\subsubsection{Patterns of demand and distribution}

The patterns of demand and distribution of the IJVHs are discussed in terms of market mix, travel type and number of inbound guests and proportion of sales from segments. Table 5.2 indicates the figures of room size, annual occupancy rate and patterns of demand: guest origin, travel types and proportion of sales of international guests via direct and indirect channels. The annual room occupancy rate is approximately 63 percent, that is lower than that of the SOHs (75 percent) and higher than the DPOHs (58 percent). As with the previous types of ownership, the origin of guests who stayed at the IJVHs is also classified into the percentages of room nights sold to the Vietnamese and international travellers. The travel types of inbound guests are characterised by purpose of travel, including business travellers, FITS and leisure-packaged tourists. Most of the IJVHs' room nights were occupied by international guests (92 percent) and only eight percent were sold to domestic travellers. Similar to the SOHs and DPOHs, leisurepackaged tourists constituted the largest segment of international guests (49 percent), followed by the business travellers ( 31 percent) and FITs ( 20 percent). The number of international guests who purchased their accommodation through direct and indirect channels is recorded. Over one third of international tourists (38 percent) used direct channels to book rooms while 66 percent used intermediaries to arrange their accommodation. 
Table 5.2. Capacity and patterns of demand and sales for selected IJVHs in 2012

\begin{tabular}{|c|c|c|c|c|c|c|c|c|c|c|}
\hline \multirow[t]{2}{*}{ Hotels } & \multirow[t]{2}{*}{ Location } & \multicolumn{2}{|c|}{ Room } & \multicolumn{2}{|c|}{ Guest origin } & \multicolumn{3}{|c|}{ Types of international guests } & \multicolumn{2}{|c|}{ Sales $^{\mathrm{a}}$} \\
\hline & & Number & $\begin{array}{c}\text { Annual } \\
\text { occupancy } \\
\text { rate } \\
(\%)\end{array}$ & $\begin{array}{c}\text { Domestic } \\
(\%)\end{array}$ & $\begin{array}{c}\text { International } \\
(\%)\end{array}$ & $\begin{array}{c}\text { Business } \\
(\%)\end{array}$ & $\begin{array}{l}\text { FIT } \\
(\%)\end{array}$ & $\begin{array}{c}\text { Leisure } \\
(\%)\end{array}$ & $\begin{array}{c}\text { Direct } \\
(\%)\end{array}$ & $\begin{array}{c}\text { Indirect } \\
(\%)\end{array}$ \\
\hline Meliã Hanoi & $\mathrm{HN}$ & 306 & 66.0 & 0.9 & 99.0 & 31.0 & 23.0 & 46.0 & 37.0 & 63.0 \\
\hline Hanoi Pullman Hotel & $\mathrm{HN}$ & 242 & 59.0 & 2.0 & 98.0 & 27.0 & 15.0 & 58.0 & 50.0 & 50.0 \\
\hline Hotel Nikko Hanoi & $\mathrm{HN}$ & 257 & 60.0 & 1.0 & 99.0 & 25.0 & 19.0 & 56.0 & 40.0 & 60.0 \\
\hline InterContinental Hanoi & $\mathrm{HN}$ & 359 & 65.0 & 0.5 & 99.5 & 16.0 & 32.0 & 52.0 & 40.0 & 60.0 \\
\hline Caravelle Saigon Hotel & $\mathrm{HCMC}$ & 335 & 73.0 & 10.0 & 90.0 & 30.0 & 25.0 & 45.0 & 72.0 & 28.0 \\
\hline New World Saigon Hotel & $\mathrm{HCMC}$ & 538 & 61.0 & 5.0 & 95.0 & 27.0 & 10.0 & 63.0 & 28.0 & 72.0 \\
\hline Sofitel Plaza Saigon Hotel & $\mathrm{HCMC}$ & 286 & 65.0 & 7.0 & 93.0 & 60.0 & 20.0 & 20.0 & 36.0 & 64.0 \\
\hline $\begin{array}{l}\text { InterContinental Asiana Saigon } \\
\text { Hotel }\end{array}$ & $\mathrm{HCMC}$ & 305 & 60.0 & 8.0 & 92.0 & 37.0 & 20.0 & 43.0 & N/A & N/A \\
\hline Renaissance Riverside Hotel Saigon & $\mathrm{HCMC}$ & 336 & 71.0 & 2.0 & 98.0 & 25.0 & 25.0 & 50.0 & 20.0 & 80.0 \\
\hline Hotel Nikko Saigon & $\mathrm{HCMC}$ & 388 & 57.0 & 5.0 & 95.0 & 35.0 & 10.0 & 55.0 & 25.0 & 75.0 \\
\hline Sheraton Saigon Hotel & $\mathrm{HCMC}$ & 472 & 70.0 & 6.0 & 94.0 & 40.0 & 15.0 & 45.0 & 39.0 & 61.0 \\
\hline Park Hyatt Saigon Hotel & $\mathrm{HCMC}$ & 244 & N/A & 5.0 & 95.0 & Mostly & $\mathrm{N} / \mathrm{A}$ & N/A & 60.0 & 40.0 \\
\hline
\end{tabular}




\begin{tabular}{|c|c|c|c|c|c|c|c|c|c|c|}
\hline \multirow[t]{2}{*}{ Hotels } & \multirow[t]{2}{*}{ Location } & \multicolumn{2}{|c|}{ Room } & \multicolumn{2}{|c|}{ Guest Origin } & \multicolumn{3}{|c|}{ Types of Inbound Guests } & \multicolumn{2}{|c|}{ Sales $^{\mathbf{a}}$} \\
\hline & & Number & $\begin{array}{c}\text { Annual } \\
\text { occupancy } \\
\text { rate } \\
(\%)\end{array}$ & $\begin{array}{l}\text { Domestic } \\
(\%)\end{array}$ & $\begin{array}{l}\text { International } \\
\quad(\%)\end{array}$ & $\begin{array}{l}\text { Business } \\
(\%)\end{array}$ & $\begin{array}{l}\text { FIT } \\
(\%)\end{array}$ & $\begin{array}{l}\text { Leisure } \\
(\%)\end{array}$ & $\begin{array}{l}\text { Direct } \\
(\%)\end{array}$ & $\begin{array}{c}\text { Indirect } \\
(\%)\end{array}$ \\
\hline Sandy Beach Resort & $\mathrm{DN}$ & 118 & 65.0 & 50.0 & 50.0 & 10.0 & 40.0 & 50.0 & 30.0 & 70.0 \\
\hline Hyatt Regency Danang & $\mathrm{DN}$ & 409 & N/A & 50.0 & 50.0 & 30.0 & N/A & $\mathrm{N} / \mathrm{A}$ & N/A & $\mathrm{N} / \mathrm{A}$ \\
\hline Pullman Danang Hotel & $\mathrm{DN}$ & 187 & 42.0 & $\mathrm{~N} / \mathrm{A}$ & N/A & 5.0 & 5.0 & 90.0 & 40.0 & 60.0 \\
\hline Novotel Danang Premier Han River & $\mathrm{DN}$ & 323 & N/A & N/A & N/A & N/A & N/A & $\mathrm{N} / \mathrm{A}$ & $\mathrm{N} / \mathrm{A}$ & N/A \\
\hline Grand Mercure Danang & $\mathrm{DN}$ & 272 & N/A & N/A & N/A & $\mathrm{N} / \mathrm{A}$ & N/A & $\mathrm{N} / \mathrm{A}$ & N/A & N/A \\
\hline $\begin{array}{l}\text { InterContinental Danang Sun } \\
\text { Peninsula }\end{array}$ & $\mathrm{DN}$ & 197 & N/A & $\mathrm{N} / \mathrm{A}$ & $\mathrm{N} / \mathrm{A}$ & $\mathrm{N} / \mathrm{A}$ & N/A & N/A & N/A & N/A \\
\hline Average in Hanoi & & 291 & 63 & 1 & 99 & 25 & 22 & 53 & 42 & 58 \\
\hline Average in Ho Chi Minh City & & 363 & 65 & 6 & 94 & 41 & 18 & 41 & 37 & 63 \\
\hline Average in Danang & & 251 & 54 & 50 & 50 & 8 & 23 & 70 & 35 & 65 \\
\hline Average by 4 stars & & 238 & 65 & 50 & 50 & 10 & 40 & 50 & 30 & 70 \\
\hline Average by 5 stars & & 324 & 62 & 8 & 92 & 32 & 18 & 49 & 41 & 59 \\
\hline Overall average & & 310 & 63 & 8 & 92 & 31 & 20 & 49 & 38 & 62 \\
\hline
\end{tabular}

a: International guests only

Source: Interview data, 2013 
Variations in terms of market mix, travel types and ways that rooms were booked and purchased are found within the IJVHs across the three locations. The average room occupancy rate of hotels in Ho Chi Minh City registered the highest figure (65 percent), followed by Hanoi (63 percent) and Danang (54 percent). Virtually all of the guests who stayed at the IJVHs in Hanoi were foreigners. Of these international guests in Hanoi, 53 percent of them were leisure-packaged tourists, 25 percent were business travellers, followed by FITs (22 percent). Direct channels generated about 42 percent of the total room nights in Hanoi. International travellers accounted for 96 percent of the rooms in Ho Chi Minh City. Room nights sold to business guests exhibited a large segment (36 percent), after leisure guests (46 percent). Almost three quarters of the international tourists staying at IJVHs in Ho Chi Minh City used intermediaries to arrange their rooms, while 29 percent were recorded through direct distribution channels.

Conversely, there was an even mix of international and domestic guests for all hotels in Danang. Leisure tourists made up the largest proportion of international travellers (70 percent) and business travellers were only eight percent. Direct sales generated 35 percent of the total room nights sold in this city. The average figures of IJVHs in Danang were mainly drawn from three hotels, hence the indicated variations in the market mix, proportion of sales from segments and travel types of guests are not likely to represent fully all the IJVHs in Danang. Nonetheless, as most of the interviewees explained these variables, this city is an ideal place for beach holiday of the Vietnamese and is one of the must-stop destinations of classic tours for international guests across the North to the South of Vietnam. It is a centre of local trade attracting most of the Vietnamese and a few international businesspersons from Hanoi and Ho Chi Minh City to come and stay.

Differences are also found among the four- and five-star IJVHs concerning their market mix (see Figures 5.1 and 5.3). International guests who stayed at the five-star hotels made up 92 percent of the total occupants compared with 50 percent at the four star hotels. In the five-star hotels, direct distribution channels produced 35 percent of the total room nights sold to foreign guests, compared with 30 percent in the four-star hotels. The higher percentage of direct sales conducted by five star hotels is linked with a higher number of business travellers there, about 30 percent of guests' nights purchased by these visitors. On the other hand, the four-star hotels served a higher number of FITs 
(40 percent) who often booked hotel rooms by their own. Both four- and five-star IJVHs were still dependent on sales by intermediaries, 70 percent and 65 percent of room nights, respectively.

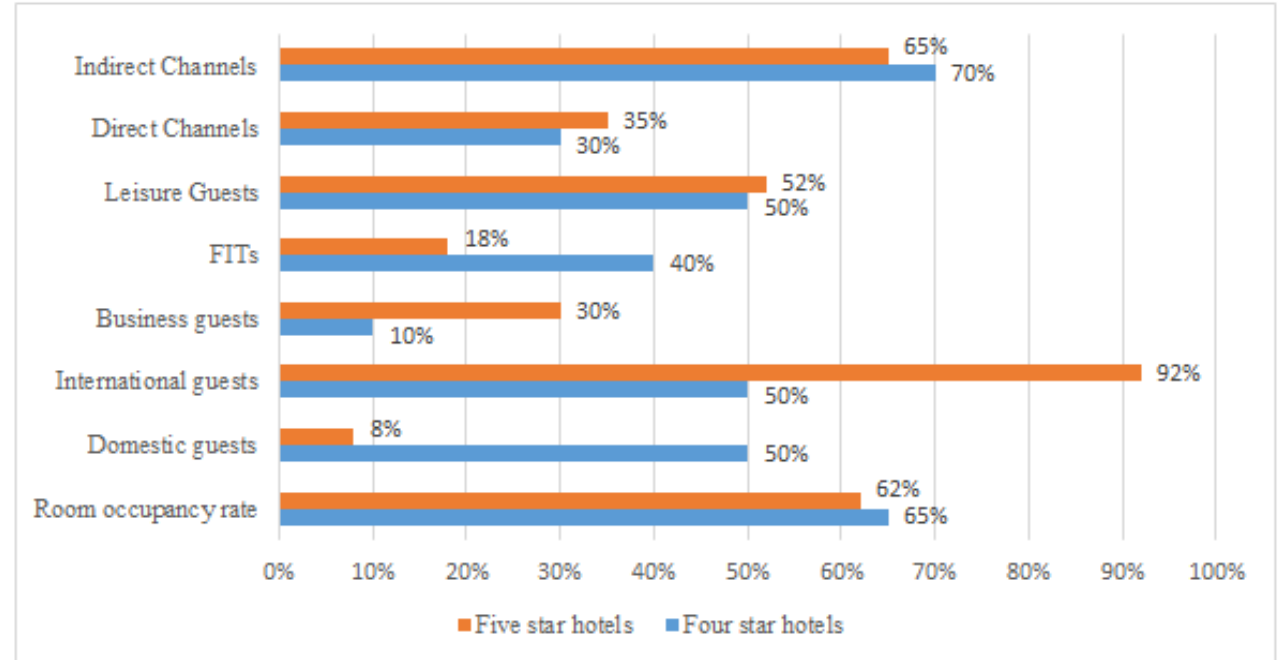

Figure 5.1. Patterns of demand and distribution channels of the four- and five-star IJVHs in Hanoi, Danang and Ho Chi Minh City (Source: Interview data, 2013)

Patterns of demand and distribution varied among individual hotels in the three cities. At the InterContinental Hanoi, Meliá Hanoi and Nikko Hanoi, over 99 percent of the total room nights were sold to international guests. Direct distribution channels generated approximately 40 percent of the sales volume of hotels managed by the wellknown brands such as Meliá, Nikko, Park Hyatt, Pullman and Sheraton. The New World Saigon Hotel, which is run by a recent management company in the global industry (New World from Hong Kong), recorded a lower percentage of direct sales (28 percent). Some hotels in Ho Chi Minh City such as the Sofitel Plaza Saigon and Park Hyatt Saigon Hotel significantly targeted business travellers over other types of inbound guests with 60 percent and "mostly", respectively. The following section will focus on how the IJVHs structure their distribution channels to reach domestic and international guests.

\subsubsection{The current structures of distribution channels for IJVHs}

The existing structures of the distribution systems for international guests and domestic travellers widely used by IJVHs are based on three key pillars: the higher quality of hotel products and services; hotel reputation; and the supporting network of sales and 
marketing organised by the management companies. As with the previous types of hotel ownership, these structural diagrams of distribution are also made up of various direct and indirect channel members located either at the destination, in the market or elsewhere outside the guests' destination and market (see Sections 4.2.4 and 4.2.5.1). Some differences in channel members are found which differentiate these diagrams from those of the SOHs and DPOHs, for example, the absence of the Vietnamese unlicensed TOs and TAs and the appearance of CROs.

Before establishing structures of distribution channels for types of guests, hotel groups identify sales and marketing strategies based on their member hotels' products and services, their target markets and roles undertaken by on-site sales and marketing departments of hotels. In this respect, the Deputy General Manager of the Caravelle Hotel Saigon highlighted that the sales and marketing activities of the hotel are directly carried out by hotels or representative offices located in Vietnam or abroad under the management and supervision of the management companies. These activities show how the structure of distribution channels is organised. The Assistant of the Director of Sales and Marketing of the Renaissance Riverside Hotel Saigon stated how the strategy of sales and marketing is defined prior to structuring distribution channels:

For each market segment, our hotel applies a particular strategy of distribution and marketing. For corporate guests, the hotel always wants to develop this market because this type of guest who stays with us has always been stable and a higher room rate is sold to them compared with tourists. Of course, the hotel also focuses on online guests and leisure packaged tourists. Referring to room sales, we divide this into two main segments, namely corporate and wholesale.

The General Manager of the Pullman Danang referred to how his hotel normally organise the sales and marketing activities.

Most of the marketing activities we do are in relation to the domestic market. We do not organise the marketing overseas. For international markets, we are considerably relying on Accor's network.

To detail the sales and marketing strategies applied by the IJVHs, the following sections will depict the distribution channel systems for inbound guests and domestic travellers. 
The structure for international tourists will be presented first (Figure 5.2) based on the market mix indicated in Table 5.2 in which international guests of IJVHs contributed about 92 percent of the total room nights.

\subsubsection{The structure for international guests}

\section{Direct distribution channels}

As shown in Table 5.2, direct sales recorded 38 percent of the total hotel room nights sold to the international guests. This figure was comparatively higher than those of SOHs (27 percent) and the DPOHs (18 percent). The hotel groups' websites and call centres or CROs have become increasingly popular ways of distributing rooms directly to the end consumers based on the powerful databases (General Manager of Hanoi Pullman Hotel). The on-site sales departments as well as the national and regional offices of international hotel chains, which play a very important role in implementing the strategies of sales and marketing defined by their headquarters, actively attract a huge number of direct bookings. Loyalty programmes also produced a number of direct bookings, followed by other forms of direct sales such as telephone, email and social networks. Direct channels, as the Senior Executive of Marketing and Communications of the Park Hyatt Danang noted, include:

Regarding the direct bookings of our hotel, I think they are made through the central reservation offices, global offices of sales and marketing of Hyatt. Guests may use our website [hotel group's website], telephone or email to book rooms directly.

The General Manager of the Pullman Danang mentioned in detail the key members and direct channels applied in his hotel.

[For direct sales] we use the Accor's network. Accor has the brand's website, so Pullman, we have pullmanhotels.com for all Pullman hotels. We have accorhotels.com. We also have a loyalty programme, so the loyalty programme is also a separate channel that works directly with consumers. Once people join this membership programme, they benefit from special discounts when they use this to book directly with us. We have international call centres, people can ring 


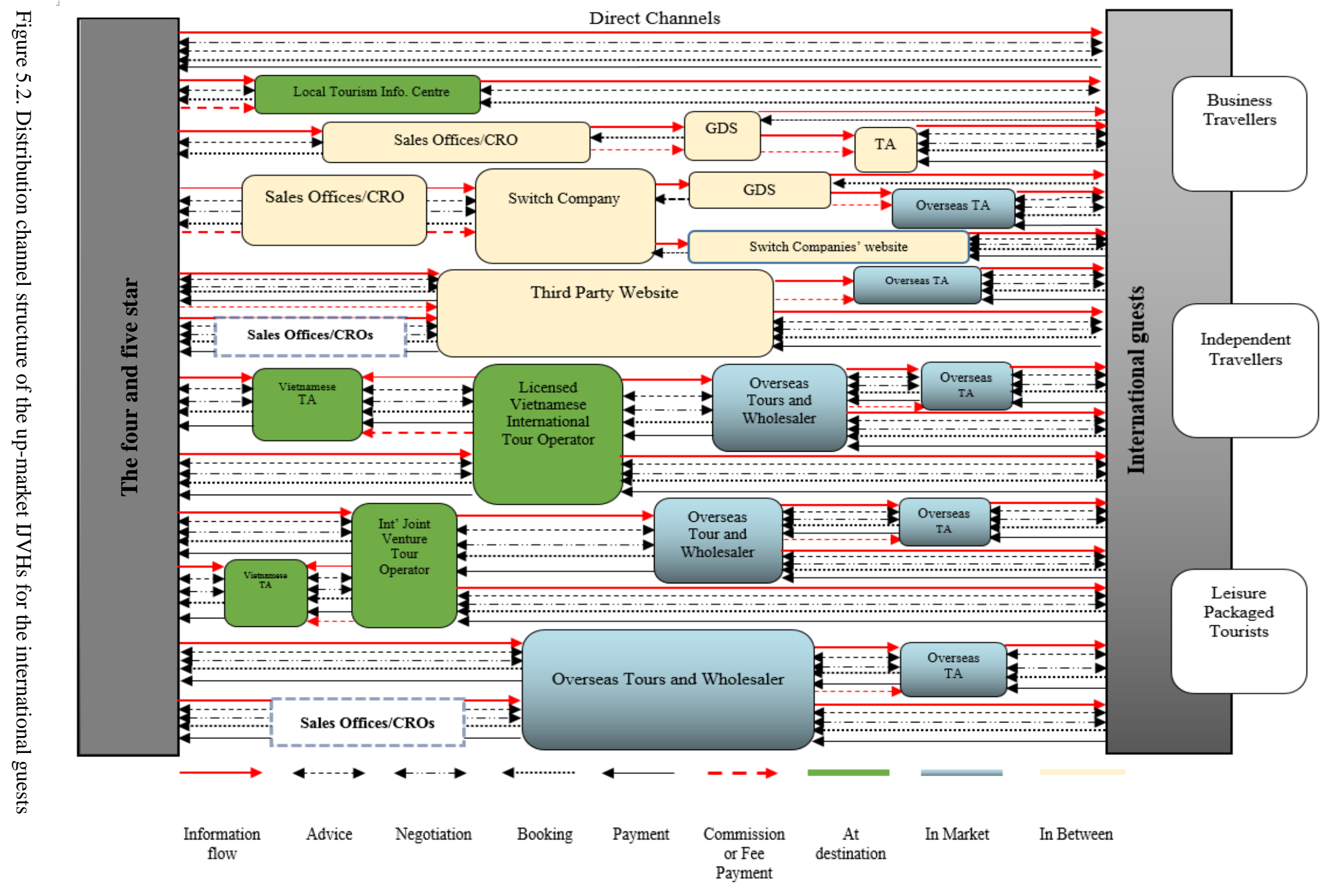


call centres to make bookings or they can go through our own website [branch website under the hotel group's site], contact hotel by email, phone, Facebook or others if they like.

While SOHs and DPOHs cooperate with airlines to have guests from crews as well as passengers of delayed flights, most of the IJVHs do not consider this channel as an important one. To this extent, the Director of Sales of the Meliá Hanoi Hotel said:

Our hotel still keep in touch with a certain number of airlines by agreement contracts to provide rooms for airline crews. The passengers of delayed or cancelled flights do not stay with us due to our high room rate. However, we do not see any bookings from airlines except Thai Airways. A possible reason is that the foreign partner of Melia Hotel Hanoi is from Thailand. The room sales from this account for a very negligible proportion.

The sales and marketing offices at the destination, in the market or in between as well as CROs or call centres take important roles in reaching guests and generating direct bookings. For the selected IJVHs under the management of hotel chains, these above channel members are directly run by their headquarters. The CROs or call centres that have so far been located outside Vietnam belonging to the regional sales and marketing offices handle both toll-free telephone and electronic reservations. In other word, CROs serve as "hubs" for making reservations for hotel group's guests (IHG, 2014). This operation of chain hotels is much different from Emmer, Tauck, Wilkinson \& Moore's comment (1993, p. 84-85) on how CROs and hotel representative offices of independent hotels generally operated elsewhere in the world.

Central reservation offices and hotel representative companies provide the same basic services for hotels. Generally, they provide a central toll-free reservation service, GDS services, and other marketing services. If a guest calls the hotel directly, the hotel reservations office typically processes the reservation inhouse. Otherwise, the reservation comes through the CRO or hotel reps. By maintaining a comprehensive database of rates, availability, special packages, negotiated rates, and descriptions of each property, these reservation centres are able to confirm bookings instantly. 


\section{Indirect distribution channels}

As indicated in Table 5.2 and Figure 5.2, indirect sales contributed approximately 62 percent of international guests' room nights for the selected IJVHs. This number is lower than the SOHs (73 percent) and the DPOHs (82 percent), but indirect channels constituted higher profitability per available room for IJVHs compared with SOHs and DPOHs. Most of the respondents from all hotel ownership and other respondents agreed that direct distribution channels can bring the hotels more benefit compared with indirect ones. If the hotels produce a low proportion of indirect sales, it means that commission payment to intermediaries is reduced, and the highest room rates are also sold to the end tourists via direct channels. However, the IJVHs still currently cooperate with both traditional and electronic intermediaries to reach and to sell products and services to multiple types of guests for desired room revenues.

First, local information centres operated by tourism authorities and private sectors are one of the conventional distribution channel members being employed to attract walk-in guests or to mainly promote the hotel image for further bookings. However, as the Assistant of Sales and Marketing Director of the Renaissance Riverside Hotel Saigon noted, the total guests' room nights from this channel is relatively limited.

In Vietnam, tourism information centres are not as useful for tourists as they must be. Although our hotel pays fee to place brochures at some centres, but the efficiency is actually not as expected.

Second, the electronic distribution channels remain important members in the structure of sales used by the IJVHs of chain hotels to generate a wide range of bookings. Apart from direct bookings, most of the IJVHs are considerably reliant on sales offices and/or reservation centres in many countries in the world with 24-hour operation to handle bookings, including bookings from GDSs. The hotels receive bookings from sales offices and CROs or directly from switch companies who provide guests with means of reservation through GDS services such as Sabre, Amadeus, Galileo and Worldspan (Assistant of Director of Sales and Marketing, Renaissance Riverside Hotel Saigon and Director of Sales, Park Hyatt Saigon Hotel). The most popular indirect channels that connect the hotels with the end guests are recognised as: (1) Hotel to CROs to GDSs to the end guests of corporations, (2) hotel to CROs to GDSs to overseas TAs to the end 
guests, (3) hotel to switch companies to GDSs to the end consumers of corporations, (4) hotel to switch to GDS to TAs to the end consumers, and (5) hotel to switch to switch websites to the TAs and corporations.

Third, various OTAs such as agoda.com, travelocity.com, expedia.com, booking.com, wotif.com and some local ones like mytour.vn, ivivu.com and chudu24.com are employed by the IJVHs to distribute rooms. The way that these OTAs cooperate with hotels is illustrated by the Director of Sales and Marketing of the Nikko Hanoi Hotel:

The online travel agents are increasingly becoming the "hot" partners in the hotel industry today because their roles in catching huge bookings for hotels. They have a specific number of guests and they have helped us to approach and cover the markets that we cannot reach. When working with them, these websites have to sign contracts directly with our hotel or the Nikko regional sales offices in which their published room rates on the websites must be the same with room rates published by the member hotels of Nikko Hotel International.

Moreover, the way that the third party websites send bookings to the member hotels of chains is noted by the General Manager of the Hanoi Pullman Hotel:

A lot of OTAs have connections to accor.com, so the guests make bookings through these websites and we receive many travellers from them.

Likewise, the selected IJVHs also cooperate with a number of conventional tour operators in Vietnam. These business partners produced a wide range of bookings and were the most important ones among the existing middle parties because of their high volume of bookings and room nights. In the near future, as the Assistant to the Director of Sales and Marketing at the Renaissance Riverside Hotel Saigon noted, the hotels will continue to need support from the traditional travel companies to expand their sales and marketing capacity. Good pricing policies will also be applied for these travel companies. In this regard, the Director of Sales of the Park Hyatt Saigon Hotel talked about the Vietnamese international TOs, including joint venture travel companies, and how her hotel selected these business partners: 
At present, the Park Hyatt Hotel cooperates with various travel companies in Vietnam. The large ones, which often bring the high expenditure guests to city such as Saigon Tourist, Vido Tours, Travel Indochina and Exotissimo, are in contracts with the hotel. Each company has its own target markets, so the hotel actively identifies the relevant sales and marketing strategy to work with them and to arrange the suitable services and facilities prior to their guests' arrival.

Fourth, a number of overseas TOs and wholesalers have been an important part of the IJVHs in distributing their products and services to tourists. The General Manager of the Pullman Hanoi Hotel noted about the trend that his hotel works with overseas travel companies and wholesalers:

At present, the Pullman Hanoi Hotel works with different channels. Besides our hotel group CROs, call centres, global and regional sales offices, the trend is that our hotel will work directly with overseas wholesalers and we try to be flexible to meet their demands.

To describe business relationships between hotels, overseas TOs and wholesalers and the end consumers, the Assistant to the Director of Sales and Marketing at the Renaissance Riverside Hotel Saigon commented:

Our hotel cooperates with some overseas tour operators and wholesalers such as American Express. This type of cooperation occurs when these companies have a big group travelling to Vietnam. At that time, they make bookings directly with any regional sales and marketing offices of Marriott or with our hotel. The guests of these companies are normally incentive tourists. Based on initial information, the Marriott transfers bookings to its member hotel. For instance, there is a tour group coming to Ho Chi Minh City - Vietnam, the sales and marketing office in the United States of America sends a list of guests to the regional office in Singapore, then the Singaporean office will handle this and pass to Ho Chi Minh City. Because the Renaissance Riverside Hotel Saigon is the only member of Marriott in Ho Chi Minh City, our hotel will take over this group. 
The Director of Sales of the Park Hyatt Saigon emphasised the importance of international trade shows and tourism fairs in the sales and marketing strategies of IJVHs in general and for her hotel in particular, which other types of hotels are found to often participate in independently. These carefully selected fairs or events organised by the management companies have strongly fostered their member hotels' image and generated a number of new wholesalers for further cooperation.

There are several big tourism fairs such as ITB [International Travel Trade Show Berlin] and WTM [World Travel Market, London], our hotel would consider how the importance of them is in relation to the hotel target markets. However, the management company mostly decides to attend these events on behalf of its member hotels. On the other hand, the Park Hyatt Group often organises trade shows and promotional programmes at the key sending guest markets to refresh the current relationships between the Park Hyatt and its partners and to connect with the new wholesalers.

\section{Functions of channel members}

In terms of roles carried out by channel members to link the IJVHs with the end guests, six functions that are in line with the previous types of ownership modes are found, namely information provision and advice, negotiation, booking, payment for booking and payment of fees or commission. These functions are taken into account differently depending on a single channel member or a group of travel intermediaries. For direct distribution channels, the business relationships between the JIVs and their guests are commonly based on the first five functions, the IJVHs or international hotel groups do not pay any commissions to the customers, although it was observed in the SOHs and the DPOHs that commission payment was made to some organisational representatives (e.g. governmental departments) for business. Regarding the indirect channels, each channel in the structure handles the functions of distribution according to the policy of each hotel chain, the local legal regulations and/or international norms and laws. The electronic channel members such as the switch companies, and GDS service providers work directly with the IJVHs in Vietnam to facilitate bookings from guests. For GDS service, apart from TAs who are the traditional customers of GDS, corporate guests now gain access to GDS to look for room availability and then make bookings. These bookings are then handled by CROs or sales offices before coming to the hotel. For 
OTAs, most of the IJVHs are working directly with them to update room status and price according to the last minute rules since hotels are issued their own user name and password. However, some OTAs get information of hotels and other related requirements to facilitate their guests' booking and payment through both hotels and sales offices and/or CROs. Bookings from OTAs are passed to hotels and full payments are paid at hotels as well but guests have to pay a part of booking for room guarantee with websites. For these transactions, commissions are applied per bookings.

For conventional travel companies, as mentioned earlier in this section, the IJVHs cooperate with a variety of companies in Vietnam or abroad. From the hotels to local TOs to overseas TOs or wholesalers, five functions of distribution including information provision and advice, negotiation, booking and payment are found to connect them according to the pricing policies. If the TAs connect the hotels or guests with TOs or wholesalers, commission payments occur within these relations because of the Vietnamese laws or regulations in the market and in between.

\section{Channel length and width}

The channel length used by the IJVHs refers to the number of intermediaries within a distribution chain. The Senior Executive of Marketing and Communications of the Hyatt Regency Danang noted that her hotel always tries to manage its products and services from designing to post-sales period. This process enables the hotel to adjust its products to meet the detailed demand of guests as well as to address any complaints. The interviews and some existing sources of secondary documents such as websites of international hotel groups indicate the IJVHs' length of distribution channels. Notably, the headquarters and various regional sales and marketing offices of international hotel groups make the channel length that their member hotels approach the end consumers shorter than those of the SOHs and the DPOHs. This is applicable to all of the selected IJVHs, which are currently run by various global hotel chains. Their sales offices and/or CROs are regionally located to gain access to the target markets, the distance between hotels and the end consumers are indirectly connected by the travel intermediaries and being directly supported by sales offices and/or CROs. The nature of how the IJVHs connect with the local TOs and oversea wholesalers was emphasised by the Deputy General Manager of the Caravelle Saigon Hotel: 
At present, the Vietnam-based international tour operators have been becoming the land service providers for the overseas tour operators or wholesalers. The Caravelle Hotel has top ten accounts, of which eight are the international joint ventures or significantly backed by foreign tour operators or wholesalers. After 2018, those travel companies that will establish their own branches or offices in Vietnam or not will be dependent on the growth of the Vietnam tourism market.

In terms of channel width, the IJVHs in principle create an equal platform for all travel businesses regardless of whether they are newly established operators or old companies. However, all of the selected IJVHs mentioned that they are quite selective in cooperating with TOs among hundred companies in Vietnam based on annual room nights from these intermediaries and target markets of the hotels. The OTAs are also shortlisted hence this selection enables the IJVHs to handle enquiries well and bookings from customers. Moreover, it is found that unlicensed TOs and TAs in Vietnam are absent from their lists of travel companies. In this regard, the Senior Executive of Marketing and Communication at the Hyatt Regency Danang said:

Our hotel signs with a lot of international TOs including large, medium and ones who legally run business in Vietnam. Each year, the hotel always assesses and classifies them into different groups. However, each group of travel companies, they have specific strengths of certain markets, so we try to maintain the business relationship with them.

Likewise, the Assistant of Director of Sales and Marketing at the Renaissance Riverside Hotel Saigon mentioned:

Our hotel cooperates with a variety of local TOs and overseas ones to sell rooms. It is right to say that each group of companies has their own strengths of certain markets. For instance, the Vido Tours focuses on the Australian market, the Exotissimo is strong at UK and European markets. Apex Vietnam and HIS are the number ones of the Japanese tourists' choice.

The General Manager of the Pullman Danang added: 
We initially work with most of the local TOs. We try to work with everybody but we will refine the list of companies for further cooperation based on their professionalism level.

The overall point of view to cooperate with both the local and overseas tour operators and wholesalers was summarised by the Director of Sales of the Meliá Hanoi as follows.

Our hotel gives priorities for the Vietnam-based travel companies to gain profitability and never let overseas ones that do not pay taxes for Vietnam put pressure on the local partners. At present, the Vietnamese companies are the regular and the largest guest senders.

Regarding channel mix, in order to determine the coverage that every channel used to reach target markets to evaluate the profitability of each channel, auditing channels annually to combine channels in the distribution structure is applied by the IJVHs. This is mentioned by the Director of Sales of the Park Hyatt Saigon:

Every year, our hotel under the assistance of the Hyatt hotel group always evaluates each channel in the distribution channel structure regarding its relation to market development, customers' feedbacks, demand trend and profitability in order to have appropriate solutions to combine channels. This is a compulsory work that each hotel member within Hyatt must undertake.

\subsubsection{The structure for domestic guests}

As indicated in Table 5.2 and Section 5.3.2, the domestic tourist market generally contributed a negligible proportion (eight percent) of the total room nights sold of the selected IJVHs across the three cities. However, this market segment has been increasingly important to the IJVHs in Danang city since it generated approximately 50 percent of room nights for the hotels studied. The IJVHs in Hanoi and Ho Chi Minh City focused on domestic corporate guests, whereas the hotels in Danang city were dependent on the seasons of tourism with a huge number of local beach holidaymakers.

\section{Direct distribution channels}

For direct distribution channels (Figure 5.3), the widely recognised reputation of the IJVHs has facilitated the search and bookings of business and corporate guests. As the 
Deputy General Manager of the Caravelle Hotel in Ho Chi Minh City contended, the Caravelle has been constantly renovated to keep the number one place out of 10 hotels of the city and being one of the top 100 hotels in the world. The local people are proud of the hotel because of its uniquely historic image in a number of movies describing the Vietnam - US War. Therefore, the hotel's website, email and phone calls based on word of mouth, and internet recommendations generated most of the direct reservations from domestic tourists.

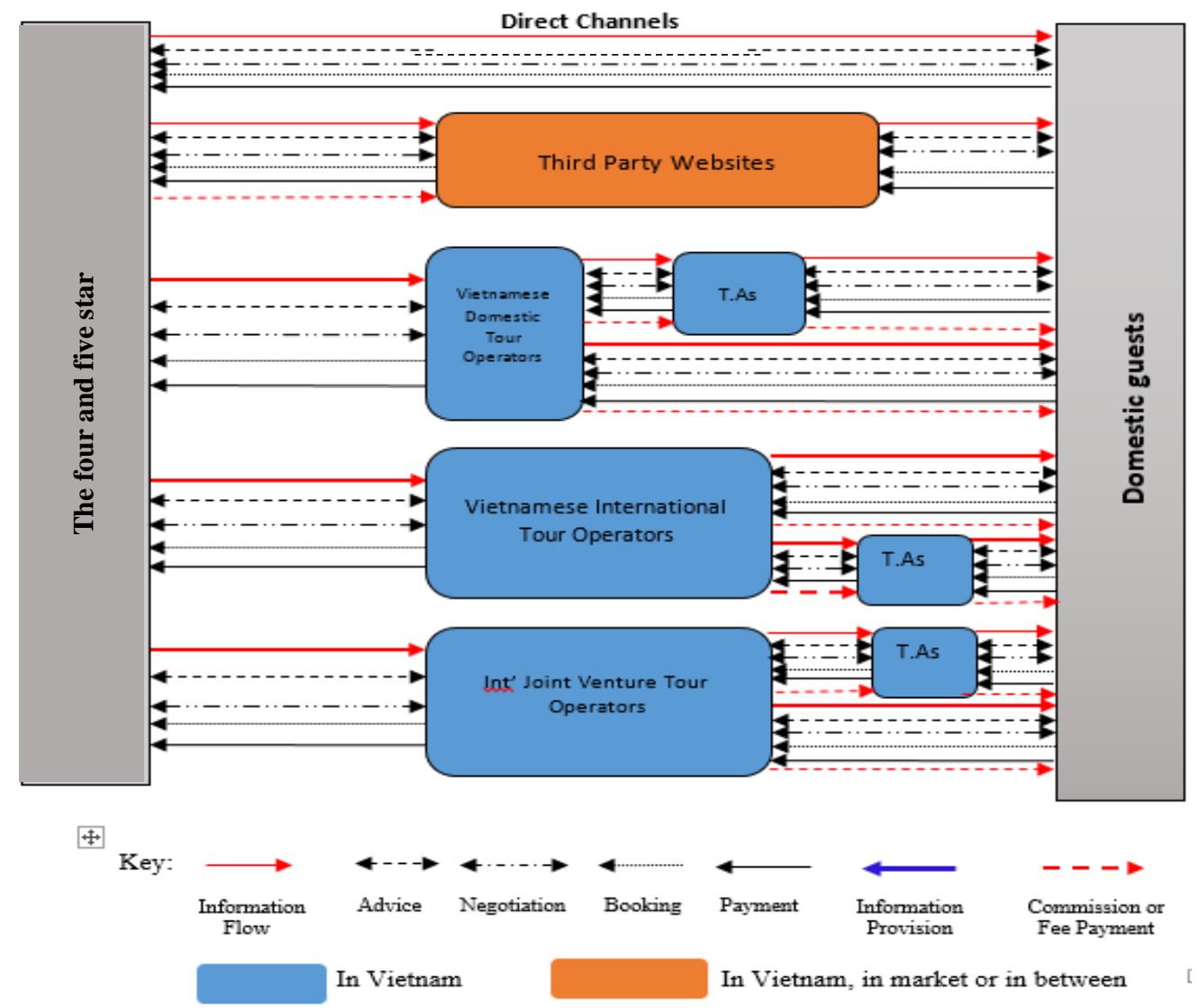

Figure 5.3. Distribution channel structure of the up-market IJVHs for domestic guests

To illustrate direct distribution channels, the Assistant to the Director of Sales and Marketing of the Renaissance Riverside Saigon said:

The domestic tourists stayed at our hotel accounted for a negligible proportion, however, the Renaissance Riverside Saigon attempts to be a hotel for corporate and business guests regardless of their origin. For direct sales, the hotel is 
mainly reliant on the website, sales calls are also undertaken directly to office buildings and industrial parks across Vietnam.

\section{Indirect distribution channels}

For indirect channels, the respondent from the Sofitel Plaza Saigon noted:

We annually record and analyse indirect bookings from the Vietnamese, most of the groups are incentive guests organised by tour operators in Vietnam. For independent travellers, it is likely that the Vietnamese tourists prefer to use third party websites to book because it is very easy to search and compare room rates among hotels in Ho Chi Minh City.

Similarly, the Director of the Hotel Management Division of the Danang City Department of Culture, Sports and Tourism commented:

For the hotels in Danang, the Vietnamese tourists are very important because Danang tourism is characterised by seasons. The high season of foreign tourists is from October of this year to April of the next year. Conversely, the school summer break lasting from the end of May to the end of August is the dominance of the Vietnamese guests. According to our statistics, I see that tour operators and online travel agents are the main partners of the high-end hotels in Danang to exploit this market mix.

In summary, of the 18 joint venture hotels which agreed to participate in the research from the population of 34 , variations are found in terms of patterns of demand and the distribution channels for international and domestic travellers. The conventional tour operators and online travel agents appear to be the important channel members used by hotels to reach leisure-packaged tourists and FITs. Direct channels such as websites of hotel groups, email and telephone are a popular means of booking for corporate guests. In particular, all of the selected IJVHs are significantly supported by global and regional networks of sales and marketing offices, which enable the IJVHs to effectively gain access to the distant markets that previous types of hotels (SOHs and DPOHs) are strongly dependent on the travel intermediaries. 


\subsection{The wholly foreign-owned hotels}

\subsubsection{Brief description}

Some characteristics of FOHs are similar to the IJVHs that have been described in Section 5.2. In this study, the FOHs are commonly recognised as hotels entirely invested in and owned by international investors, organisations and/or Vietnamese overseas. These carry out investment activities in Vietnam through a 100 percent foreign owned company or a Vietnamese enterprise, which these international investors purchase shares from, merge with or buy (VNA, 2005). The two FOHs studied were established based on the direct investment of a foreign corporation (The Grand Plaza Hanoi Hotel in Hanoi) and the result of mergers and acquisitions (The Duxton Hotel Saigon in Ho Chi Minh City). In Danang, this hotel ownership mode has not been found.

The Grand Plaza Hotel, which consists of 618 rooms, is a five-star hotel located conveniently in the newly urbanised area of Hanoi nearby the National Convention Centre, shopping complexes and sports event venues. The Grand Plaza is a combination of commercial centre, hotels and offices for lease opened in late 2010. It was wholly owned by the Charmvit Group of South Korea, a company specialising in property, construction, logistics, leisure, golf and hotel business. At present, this South Korean corporation holds the hotel while the commercial centre and the leasing offices were sold to IDJ Group of Vietnam.

In terms of the management mode, at the time of data collection, the hotel was ending its contract with the Preferred Hotel Group to be directly operated by the parent company since January 2014. At present, the hotel is an independent one managed by the Charmvit, Korea (The Assistant to the Director of Sales and Marketing, Grand Plaza Hotel). Since opening, the Grand Plaza was a member of the Preferred Hotel Group under the brand of the Summit Hotels and Resorts before applying the current management mode. This brand is a global collection of independent hotels, destination resorts, city central hotels, luxury residences, and unique hotel groups founded in 1968 by North American hoteliers. Unlike the other international hotel chains, the Preferred Hotel Group does not own, operate, or manage any of the hotels within its portfolio. All of the hotels, resorts, and serviced residences within it are independent entities; member hotels benefit from this membership by being provided a standard of unique personality, setting, design and array of amenities. Under the contract with the Summit, the Grand 
Plaza Hanoi paid annual fees based on the actual occupancy rate to use Summit Hotels and Resorts brand name, GDS services and call centres. To some extent, this mode of management of the Grand Plaza Hotel is similar to that of the Hanoi Daewoo Hotel (DPOH). It means that the Grand Plaza Hanoi Hotel was also offered a package of operational know-how such as product or service design, trade mark, corporate image, reservation system and essential assistance like pre-opening preparation, training and management techniques. When the hotel is an independent one managed by Charmvit, call centre and GDS services are established or contracted from the headquarter of Charmvit in South Korea to handle bookings because the biggest market of this hotel so far has been Korean tourists. The Grand Plaza Hotel's interviewee also emphasised that under no circumstances does his hotel apply the mode of management such as other five-star hotels in Hanoi do. However, it is likely to be difficult to develop sales and marketing strategies as other chain hotels in Hanoi since Charmvit is not an international hotel group. Charmvit only owns some hotels in Korea and only one in Vietnam.

In Ho Chi Minh City, the Duxton Hotel Saigon is currently the only 100 percent foreign owned hotel in the up-market hotel range of this city. Originally, the hotel was an IJV opened in 1995 between the Vietnam Tourism Company in Ho Chi Minh City (a stateowned travel company) and a Singaporean partner. At the time of opening, it was proud of being one of the first hotels managed by an international hotel chain (Duxton Hotels International) in Ho Chi Minh City. In 2003, the hotel was completely acquired by the Singaporean investor and the mode of management changed as well.

At the beginning period of Vietnam's economic reform, Ho Chi Minh City had witnessed another high-end FOHs called the Saigon Hotel or the Floating Hotel. This five-star floating hotel was constructed in Singapore in 1988 and located in Queensland, Australia. In 1989, the EIC Development Company of Japan bought the hotel and dragged it to Ho Chi Minh City under the management of the Australia's Southern Hotels. The hotel achieved a lot of success as it met the high demand of international tourists coming to Vietnam at that time. In 1997, the floating hotel was sold to the Hyundai Group of South Korea because of the competitive appearance of a series of IJVHs and newly renovated SOHs such as the Caravelle Hotel, New World, Sofitel Plaza Saigon Hotel, Continental, Majestic and Rex. Nowadays, it is interesting that this 
floating hotel is moored at a wharf in North Korea to wait for an economic reform or tourism development in this pure communist country which is similar to what Vietnam was 30 years ago (Thanh Tung, 2014).

The 191 room Duxton Hotel Saigon is now a franchised hotel under the Duxton Hotels International. Being similar to the Grand Plaza Hanoi and the Hanoi Daewoo Hotel in Hanoi or the Furama Danang, the Duxton brand name is commercially used according to the fixed contract between Duxton Hotels International and the hotel owners. The Duxton Hotels International handles phone calls for bookings and electronic reservations at their CROs before transferring to its member hotels. The GDS is provided by a Singaporean company under another contractual package. The main characteristics of these two FOHs partially influence the patterns of demand and how hotels distribute their products and services to the end consumers.

\subsubsection{Patterns of demand and distribution channels}

Table 5.3 presents the annual occupancy rate and patterns of demand of the two hotels in 2012. International guests notably generated up to 95 percent of room nights for both hotels, and while leisure-packaged tourists recorded the largest segment (55 percent) of the Grand Plaza Hanoi hotel, business travellers accounted for about 50 percent of room nights of the Duxton Hotel Saigon. At the Grand Plaza Hanoi Hotel, over 80 percent of the international tourists used indirect channels to book their accommodation while only 45 percent were recorded as direct distribution at Duxton Hotel Saigon.

A small difference is found among two hotels in relation to their market mix. As mentioned earlier, the Grand Plaza Hotel Hanoi began operating five years ago and its parent company's background is not in the hotel industry; these factors have strongly influenced the proportion of sales. While travel intermediaries generated 83 percent of room nights for the Grand Plaza Hanoi, these intermediaries contributed only 45 percent of room nights for the Duxton Hotel Saigon. At the Grand Plaza, room nights sold to the leisure-packaged guests made up a higher percentage (55 percent) in comparison with 35 percent for business travellers. By contrast, business and corporate tourists were the strengths of the Duxton Saigon Hotel when 50 percent of total room nights were purchased by these guests. The usage of direct distribution channels and a number of business travellers presented a link with the hotel's history and management mode as an independent hotel with limited resources requires huge support from travel 
intermediaries to reach markets. A newly opened hotel needs time to gain a reputation to attract business travellers, and promotional prices are often offered at this stage.

Table 5.3. Capacity and patterns of demand and sales of the two FOHs in 2012

\begin{tabular}{|c|c|c|c|c|c|c|c|c|c|}
\hline \multirow[t]{2}{*}{ Hotels } & \multicolumn{2}{|c|}{ Room } & \multicolumn{2}{|c|}{ Guest origin } & \multicolumn{3}{|c|}{ Types of international guests } & \multicolumn{2}{|c|}{ Sales $^{\mathbf{a}}$} \\
\hline & Number & $\begin{array}{c}\text { Annual } \\
\text { occupancy } \\
\text { rate } \\
(\%) \\
\end{array}$ & $\begin{array}{c}\text { Domestic } \\
(\%)\end{array}$ & $\begin{array}{c}\text { International } \\
(\%)\end{array}$ & $\begin{array}{c}\text { Business } \\
(\%)\end{array}$ & FIT (\%) & $\begin{array}{l}\text { Leisure } \\
(\%)\end{array}$ & $\begin{array}{c}\text { Direct } \\
(\%)\end{array}$ & $\begin{array}{c}\text { Indirect } \\
(\%)\end{array}$ \\
\hline Grand Plaza & & & & & & & & & \\
\hline Hanoi & 618 & 60.0 & 5.0 & 95.0 & 35.0 & 10.0 & 55.0 & 17.0 & 83.0 \\
\hline Duxton Hotel & & & & & & & & & \\
\hline Saigon & 191 & 70.0 & 5.0 & 95.0 & 50.0 & N/A & N/A & 55.0 & 45.0 \\
\hline
\end{tabular}

a: International guests only

Source: Interview data, 2013

\subsubsection{The current structures of distribution channels of foreign-owned hotels}

This section presents the structures of distribution channels that two FOHs in Hanoi and Ho Chi Minh City used to reach international and domestic tourists.

\subsubsection{The structure for international guests}

Figure 5.4 is the distribution channel structure used by the FOHs to reach international tourists. The direct channels mainly comprise hotel websites, call centres, telephone, email and social networks. The on-site sales departments as well as regional offices of the Grand Plaza Hotel (in Korea) and Duxton Saigon Hotel (in Japan) that also play an important role in implementing the strategies of sales and marketing attract a number of direct bookings, especially direct bookings to the Duxton. Indirect channels used by the two FOHs also include conventional and electronic channels such as local TOs and TAs, overseas wholesalers, overseas TOs and TAs and OTAs at the destination, in the market or in between. Unlicensed Vietnamese TOs and TAs are not seen in the FOHs' distribution system.

\section{Direct distribution channels}

The representative from the Grand Plaza Hanoi Hotel noted that direct sales of his hotel are undertaken in the following ways: 


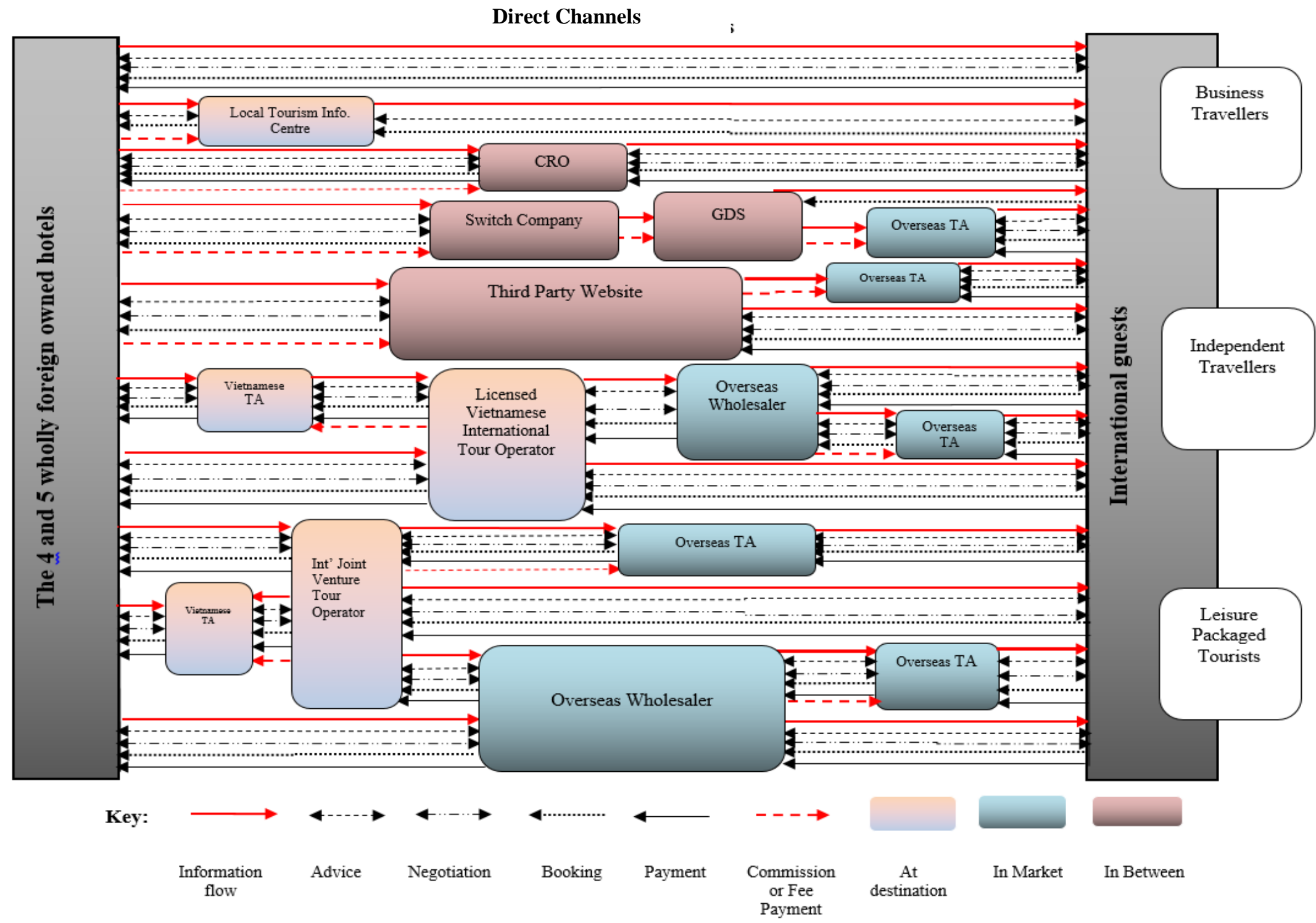


Our sales offices in South Korea, websites of our hotel and of companies under the Charmvit Group as well as email and phone calls produced a number of direct bookings for our hotel in 2012. Among 17 percent of room nights sold by direct channels, the South Korean businesspersons and corporate guests from this market have been the largest source of business guests. Direct bookings from call centres and GDS account for small proportion.

Generating approximately 55 percent of room nights sold directly to tourists, the Assistant to Director of Sales and Marketing of the Duxton Hotel Saigon described how his hotel reach the guests directly.

The Duxton Hotel Saigon itself has a website, this website links with other member hotels under the website of Duxton Hotels International. When our hotel carries out a specific promotional campaign, only guests who make bookings directly from the hotel's website benefit from that programme. I think emails and phone calls used by guests who want to negotiate the room rates or to clarify some issues prior to bookings. For business and corporate guests, we must find the ways to introduce the hotel and sell rooms directly. We have an office of sales and marketing is set up in Japan to approach the Japanese tourists.

For airlines, while the newly opened Grand Plaza Hotel cooperates with several airlines to serve their crews and passengers of delayed or cancelled flights, particularly, the crews of the Korean Air, the Duxton Saigon Hotel does not consider airlines as a channel of sales.

\section{Indirect distribution channels}

Bookings received from indirect channels vary between the two FOHs ( 83 percent and 45 percent for Grand Plaza and Duxton Saigon Hotel, respectively). Depending on the position of each hotel in the market, indirect distribution channels help the hotels overcome challenges to market their images and reach tourism markets. For the newly opened Grand Plaza Hotel, travel intermediaries have played an important role in the sales and marketing strategies of this property and brand: 
As a newly operated hotel, we cooperate with most of travel intermediaries in Vietnam and some overseas companies as you asked [TAs, TOs, CRO, tourism information centres, GDS] to sell rooms. However, conventional TOs and OTAs are the most effective channels in terms of room nights they sold. Some tour operators in South Korea also help us a lot in bringing leisure guests to our hotel (Representative from Hanoi Grand Plaza Hotel).

Similarly, the Assistant to Director of Sales and Marketing of the Duxton Hotel Saigon mentioned:

The hotel is always happy to sign contracts with most types of travel intermediaries. However, we annually refine the partners based on their room nights sold because of our scale. Some local TOs are Exotissimo, Trail of Indochina, Saigon Tourist and overseas ones such as Kuoni (UK), Virgin and Hana. Basically, these business partners vary from market to market as each company has its own strength. At present, a number of guests seem to prefer booking rooms through OTAs and hotel websites instead of GDS and CRO.

\section{Distribution channel functions}

In terms of channel width, variations between two hotels were found due to their history, hotel size and investors' background. In order to promote the image, the Grand Plaza Hotel first signed contracts with as many TOs and TAs as possible and then modes of cooperation with these TOs would be selected based on their room nights sold periodically. As mentioned in Section 5.4.1, the channel width of the Grand Plaza Hotel would be another fact that the owner's decision to their contract with the Summit Hotels and Resorts brand has resulted in changes of contracts with numerous travel companies. This process of renewing contracts with TOs still happens; promotional room rates are continuously applied to create demands from a huge number of local and overseas partners. In this regard, the Grand Plaza Hotel representative said:

Although the Grand Plaza Hotel was put into operation nearly four years ago, but we are still quite a new one in the hotel market, we attempt to promote the hotel to as many TOs and TAs as possible. In addition, the change of hotel brand takes us time to renew the hotel contact and to sign contracts with TOs 
and TAs. We ourselves cannot sell six hundreds rooms so we welcome all the travel companies both in Vietnam and abroad.

Conversely, the Duxton Saigon Hotel has identified its target markets and business partners, and the largest issue it faces is how to harmonise benefits of different types of travel companies according to the consistent application of pricing policy. By attending some local and international tourism events and trade shows, the hotel tries to intensify the relationships with current partners and to look for overseas wholesalers to shorten the length of channels.

Channel mix of the two FOHs also shows a variation. Since the Grand Plaza Hotel has been put into operation for few years only under different brands, this hotel was paying firstly attention to cooperate with as many channel members as possible and then they were in the process of auditing and evaluating outputs. By contrast, the Duxton Saigon Hotel has refined its business partners based on room nights sold in order to harmonise channel members. Compared with the IJVHs where channel mix is monitored and evaluated by the hotel's report, via software, and the sales and marketing department's statistics of the hotel group, the two franchised FOHs are likely to pay less attention to this and they may not have experience. This is seen as the representative of the Grand Plaza Hanoi made a misunderstanding between combining channel members to make channel mix and cooperating with as many TOs as possible to promote the hotel image.

\subsubsection{The structure for domestic travellers}

Generating only five percent of the total room nights for each $\mathrm{FOH}$, the structure of distribution channels for the Vietnamese travellers is established very much in line with how the IJVHs approach their domestic market (Figure 5.5). This system is different with their structure for international guests who are normally at the long-haul markets. It means that no overseas conventional TOs and fewer channel members are involved in the room sales process. For the Grand Plaza Hotel, its location outside the central business districts of Hanoi has strongly influenced the choice of the Vietnamese travellers to stay as most of them had been so far the incentive tourists. The Duxton Saigon, however, has regular guests who are from government departments, multinational corporations, and senior staff of local entrepreneurs across the country. These influence the ways that hotels organise direct and indirect distribution channels. 


\section{Direct channels}

The representative from the Grand Plaza Hotel mentioned that the hotel received bookings for the Vietnamese in the following ways:

So far, direct bookings are mostly made from hotel website, sales representative office in Ho Chi Minh City, phone calls, on-site sales calls and emails. Sales calls not only play an important role in generating bookings of rooms, but also in selling other products and services such as conferencing and banquet. I have not yet seen any walk-in guests coming with us.

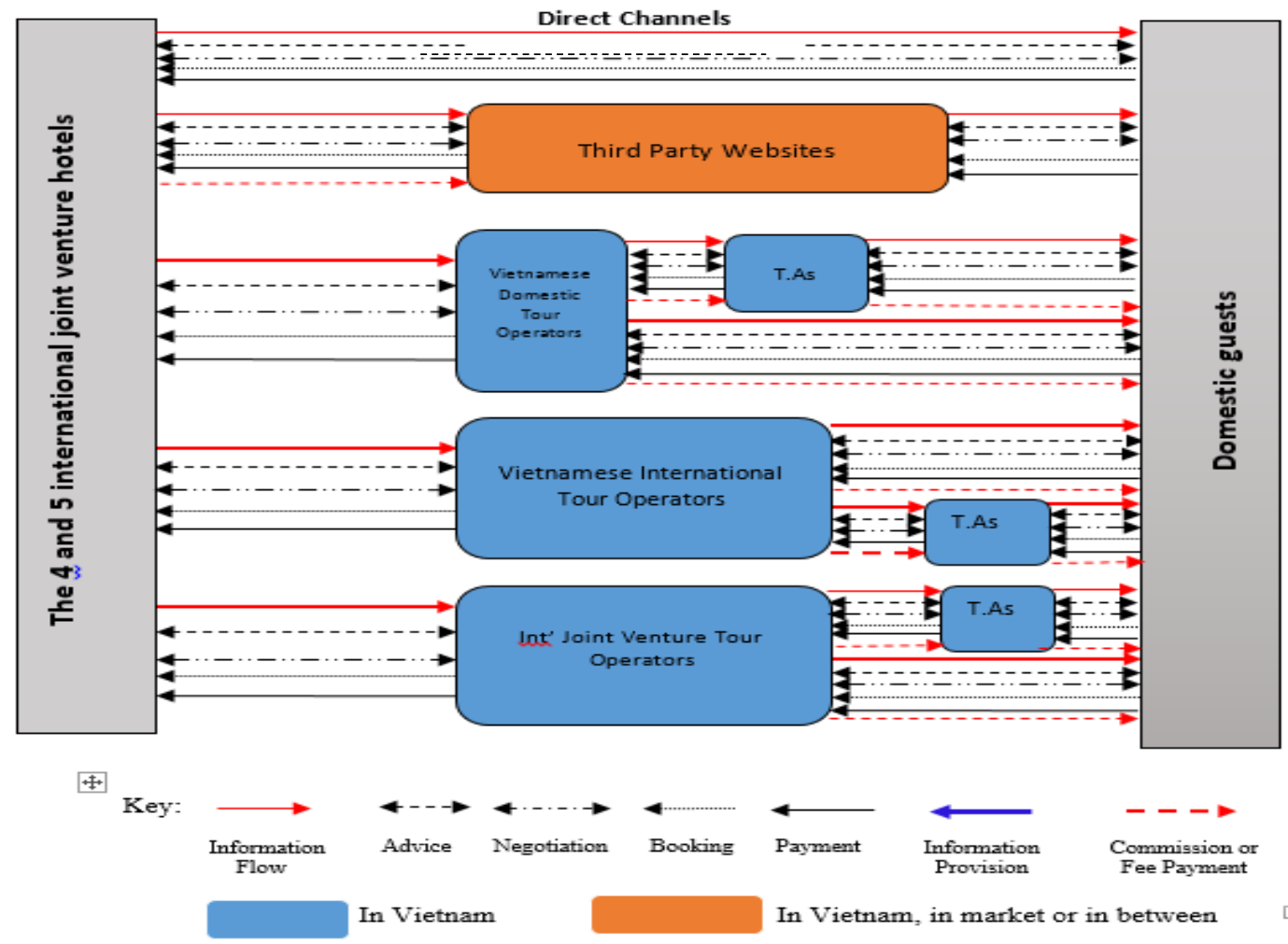

Figure 5.5. Distribution channel structure of the up-market FOHs for domestic travellers

The Assistant of Director of Sales and Marketing of the Duxton Hotel also noted:

The hotel has its own website with the update promotional room rates. At some periods of the year, we design certain sales programmes for locals to gather bookings through website, email and telephone. However, as the main target market of hotel is business and corporate guests based in Vietnam, [if in Vietnam], our sales staff have to find ways to meet them directly through sales calls to introduce the hotel and room tariffs. 
In short, the main direct distribution channels used by the two hotels to reach domestic guests include the hotel website, email, telephone, sales offices. Sales calls were also utilised to directly gain access to Vietnamese travellers, particularly corporate guests.

\section{Indirect channels}

Figure 5.6 shows the dominance of local travel intermediaries in the distribution channel structure for domestic guests. As mentioned, business and corporate guests prefer to book hotels by themselves, the Vietnamese leisure tourists often ask travel intermediaries to bundle their package of products and services. Nonetheless, some variations of using travel intermediaries to sell rooms together with other services are recorded between two hotels due to their characteristics and target markets.

As a newly opened hotel, the Grand Plaza Hanoi is in the process of positioning its target markets, and a series of travel intermediaries were employed to approach the domestic travel market. The large hotel size also urged the hotel to find guests to increase its room occupancy percentage. Although indirect distribution channels including TOs and OTAs have so far brought an amount of bookings from incentive guests and FITs, this, as the representative of the hotel contended, needs a lot of effort to maintain because room sales were developed according to the promotional campaigns.

At the Duxton Saigon, most of the in-country bookings, which are mainly made through tour operators and to some event organising companies, are for Vietnamese incentive travellers. The hotel has close relationships with these companies, hence it is said that incentive guests are predictable annually. Besides, third party websites operated in Vietnam, abroad or elsewhere are also used by FITs to reserve rooms. The hotel refines this type of partner based on the eventual payments of guests and the commission policies applied.

\subsection{Conclusion}

Together with Chapter Four, this chapter has addressed the thesis's first research question by presenting the current structure of distribution channels for international and domestic guests used by the four ownership modes for up-market hotels in the three largest urban cities in Vietnam. Chapter Four concluded by drawing comparisons 
between SOHs and DPOHs. Here, this is extended to also compare IJVHs and FOHs regarding four points.

Firstly, the operational background of each hotel ownership mode. While all of the SOHs are the legacy of the centrally planned economy, domestic private and foreign related ones are the products of Vietnam's economic reform of 1986. The IJVHs and FOHs were managed by global hotel groups or franchised with international brands. These hotel chains and brands have not only brought money, know-how, experience and industry connections to the Vietnam hotel sector, but they have also been active in encouraging the government to take a progressive stance on other facets of the tourism sector. The tourism image of the country has also been significantly benefited from their appearance. In terms of quantity, the number of SOHs is decreasing but hotels owned by domestic private investors exhibit a rapid growth since these entrepreneurs started to move into the hotel sector from their main fields of making money such as property, construction and banking. Nonethelss, after nearly 30 years of economic reform, prejudice to domestic private businesses still exists though laws have been significantly improved.

Secondly, the key characteristics of the selected hotels of the four ownership modes were described. The current SOHs in Hanoi, Ho Chi Minh City and the privatised SOHs in Danang have a longer history of development compared with other modes. In Hanoi, the only luxury SOH was constructed in the early of 1970s under the period of pure communism. In Ho Chi Minh City, most of them were built during the course of the Vietnam War and were possessed by non-government investors before being nationalised after 1975 and were renovated in the 1990s. A semi-independent management mode is applied to these SOHs because several government bodies are still involved in hotel administration. Unclear business objectives and a small marketing budget have specifically influenced the service quality and distribution strategies of SOHs. By contrast, the owners of the DPOHs have the right to run hotels themselves or to hire someone else to manage their properties. It is found that the independent management mode, the domestic chain and franchising with international hotel groups were commonly employed by these investors. Regarding the investment resources, the question of the real financial ability of these investors is raised when a number of them were accused of being involved in financial fraud or irregularities in banking business. 
For the IJVHs and FOHs, the higher level of professionalism and larger hotel size are widely recognised in comparison with their counterparts. These hotels were also managed by reputable hotel chains under management contracts except the two FOHs, of which one is franchised with Duxton Hotels International and the other is under Charmvit Korea.

Thirdly, the patterns of demand and distribution of the four hotel ownership types, variations were found among these groups of hotels in terms of average room occupancy rate, the origin of guests, types of travel and proportion of sales from segments. In general, the SOHs recorded the highest room occupancy rate (72 percent), followed by the two FOHs (65 percent), the IJVHs (63 percent) and the DPOHs (58 percent). While Vietnamese travellers tended to stay at the SOHs (15 percent of room nights sold) and the DPOHs (28 percent), the foreign ownership hotels welcomed a bigger number of international guests. Business, corporate and FITs were guests who generated a main volume of bookings for the foreign-related hotels through direct distribution channels (38 percent for the IJVHs). In contrast, the SOHs and particularly the private hotels were dependent on intermediaries to reach the markets. In 2012, direct distribution channels constituted only 18 percent of international guests' room nights of the DPOHs. Most of this hotel mode's guests were leisure packaged tourists (61.7 percent), followed by FITs (20.7 percent) and business travellers (13.6 percent). In particular, differences were also observed among the four- and five-star hotels in relation to their market mix. The five-star ones had a tendency of attracting more business travellers through direct channels due to the fact that this type of guest normally requires a higher standard of amenities and facilities than tour groups. Also, high purchasing power and high frequency of travelling result in their habit of booking rooms directly at the high-end hotels.

Lastly, the structures of distribution channels for international and domestic guests applied by the four hotel ownership modes were portrayed by diagrams depicting direct and indirect channels. Sales through websites, mail, sales calls and telephone enabled hotels to sell their products and services directly to the end consumers. For indirect distribution, all the hotels relied on a number of conventional and electronic channel members to approach their market segments, namely tourism information centres, travel agents, international tour operators, overseas wholesalers, OTAs and GDS service 
providers. However, the channel length was different among types of hotels. The IJVHs were strongly supported by their global sales offices operated by management hotel chains, creating great advantages of approaching guests in the long-haul markets. In terms of channel width, all types of hotels were likely to sign contracts with hundreds of conventional tour operators in Vietnam to collect bookings. For the electronic channels, most of the private hotels did not use the GDS service that was effectively used by the IJVHs. The SOHs contracted with some GDS service providers to link the end guests, but the efficiency was still low because this type of service normally requires global call centres or CROs with 24-hour operation to handle bookings. Notably, both the SOHs and domestic hotels used unlicensed travel agents and tour operators in Vietnam to sell rooms to international and domestic guests; the foreign-invested hotels only signed contracts with fully licensed travel companies. Paying illegal commissions to certain types of guests in the direct channels also appeared to be normal with the Vietnameseowned hotels. 


\section{CHAPTER 6. PATTERNS OF DEMAND AND DISTRIBUTION CHANNEL STRUCTURES ACROSS THE FOUR OWNERSHIP MODES}

\subsection{Introduction}

This chapter continues to address the first research question: What is the current structure of hotel distribution channels of different ownership modes in a transitional economy. Chapters Four and Five have identified separately the existing structure of distribution channels conducted by each hotel ownership mode; this chapter investigates the patterns of demand and distribution across these four modes in terms of market mix, types of travel of international guests as well as proportion of room night sales from the international markets to find out similarities and differences. These will be further interpreted and explained in Chapter Seven. The discussion will firstly focus on how different hotel ownership modes make their products and services available for domestic and international guests to purchase via direct and indirect channels that Chapters Four and Five have in turn portrayed in diagrams and via a number of distribution channel functions. Second, tables of channel members, channel length, channel width, channel functions and channel mix used by hotel ownership modes will be drawn to provide overall pictures of the up-market hotel distribution system before comparisons are made between the four existing structures. In general, variations within hotel ownership mode are found and explained but they are also seen at groups of fourand five-star hotels as well as hotels located in the three cities. Where relevant, the operational settings of hotels, hotel size and room occupancy rate will be revisited to explain commonalities and differences. Specific features of the legal and socioeconomic background of Vietnam that the four ownership modes have developed under are also re-examined.

\subsection{Commonalities and differences of demand patterns and distribution}

Tables 6.1, 6.2 and 6.3 show average figures of capacity and patterns of demand and distribution by type of hotel ownership (Table 6.1), location (Table 6.2), and star rating (Table 6.3). The data come from eight SOHs, 14 DPOHs, 18 IJVHs and two FOHs.

First, the average number of rooms and room rate occupancy of the four hotel ownership modes indicate that hotel size is firstly seen to be much bigger than the minimum requirement of the government to be classified as four- and five-star 
Table 6.1. Average figures of capacity and patterns of demand and room nigh sales of each hotel ownership mode

\begin{tabular}{|c|c|c|c|c|c|c|c|c|c|}
\hline \multirow{2}{*}{ Ownership Model } & \multicolumn{2}{|c|}{ Room } & \multicolumn{2}{|c|}{ Guest Origin } & \multicolumn{3}{|c|}{$\begin{array}{c}\text { Types of International } \\
\text { Guest }\end{array}$} & \multicolumn{2}{|c|}{ Proportion of Sales ${ }^{\mathrm{a}}$} \\
\hline & $\begin{array}{l}\text { Number } \\
\text { of rooms }\end{array}$ & $\begin{array}{l}\text { Annual } \\
\text { occupancy } \\
\text { rate } \\
(\%)\end{array}$ & $\begin{array}{c}\text { Domestic } \\
\text { ( } \% \text { of } \\
\text { room } \\
\text { night) }\end{array}$ & $\begin{array}{c}\text { International } \\
\text { (\% of room } \\
\text { night) }\end{array}$ & $\begin{array}{c}\text { Business } \\
\text { ( } \% \text { of } \\
\text { room } \\
\text { night) }\end{array}$ & $\begin{array}{l}\text { FIT } \\
\text { (\% of } \\
\text { room } \\
\text { night) }\end{array}$ & $\begin{array}{c}\text { Leisure } \\
\text { packaged } \\
\text { (\% of } \\
\text { room } \\
\text { night) }\end{array}$ & $\begin{array}{l}\text { Direct } \\
\text { (\% of } \\
\text { room } \\
\text { night) }\end{array}$ & $\begin{array}{c}\text { Indirect } \\
\text { ( } \% \text { of } \\
\text { room } \\
\text { night) }\end{array}$ \\
\hline State owned hotels $(\mathrm{n}=8)$ & 174 & 72 & 15 & 85 & 37 & 19 & 44 & 27 & 73 \\
\hline $\begin{array}{l}\text { Domestic private owned hotels } \\
(\mathrm{n}=14)\end{array}$ & 158 & 58 & 28 & 72 & 14 & 21 & 62 & 18 & 82 \\
\hline $\begin{array}{l}\text { International joint venture hotels } \\
(\mathrm{n}=18)\end{array}$ & 310 & 63 & 8 & 92 & 31 & 20 & 49 & 38 & 62 \\
\hline \multicolumn{10}{|l|}{ Wholly foreign owned hotels } \\
\hline - Grand Plaza Hanoi & 618 & 60.0 & 5.0 & 95.0 & 35.0 & 10.0 & 55.0 & 17.0 & 83.0 \\
\hline - Duxton Saigon & 191 & 70.0 & 5.0 & 95.0 & 50.0 & N/A & N/A & 55.0 & 45.0 \\
\hline
\end{tabular}

a: Room nights sold to international guests only

Source: Interview data, 2013 
hotels (80 for four stars and 100 rooms for five stars). The average hotel size was particularly high against 80 percent of Vietnamese hotels having under 80 rooms (ITDR, 2005). Specifically, one of the two FOHs, the Grand Plaza Hotel in Hanoi, is currently the largest urban hotel in Vietnam with 618 rooms. The IJVHs exhibited an average of 310 rooms per hotel and there was only a small difference between the SOHs and the DPOHs, 171 and 158 rooms per property, respectively. The annual room occupancy rate of SOHs (72 percent) was the highest in comparison with other hotel modes, which averaged around 60 percent. However, the hotel size and room rate occupancy of the four ownership modes do vary a little between location and star rating (Tables 6.2 and 6.3). Having the lowest average room number (219 rooms per hotel), the hotels in Danang recorded a low annual room occupancy rate (57 percent), compared with Hanoi (61 percent) and Ho Chi Minh City (66 percent). In terms of star rating, the average hotel size of the 21 five star hotels is double that of the four-star ones, with 322 and 153 rooms, respectively. The room occupancy rate of the four- and five-star groups were almost the same (63 and 64 percent).

The hotel size of all ownership modes, on the one hand shows that each type of hotel ownership was pressed to apply as many distribution channels as possible to sell their rooms to potential consumers. This is mentioned by the Assistant to the Director of Sales of the Grand Plaza Hanoi (FOH):

The up-market hotels in general and our hotel in particular have a couple of hundred rooms. Therefore, we face challenges to sell such a large number of room nights to the guests. Maximising a number of distribution channel members to cooperate is our first priority, and then we will select the appropriate guests from these business partners.

Second, variations are found in terms of the room nights sold to domestic and different types of international tourists (Table 6.1). In general, the domestic guests who stayed at all hotel ownership modes accounted for a lesser proportion than the international travellers. The DPOHs sold the highest proportion of room nights (28 percent) to Vietnamese guests, followed by the SOHs (15 percent), IJVHs (eight percent) and the FOHs (five percent). However, a variation in terms of market mix occurred within each ownership group. For instance, domestic guests made up a very high proportion of room 
nights of some hotels of different ownership modes: 40 percent of the Victory Hotel Hanoi (SOH), 65 percent of the Green Plaza Danang (DPOH) and 50 percent of Hyatt Regency Danang (IJV). For the international segment, approximately 85 percent and 72 percent of room nights were purchased by international guests from the SOHs and DPOHs, respectively, compared with 92 percent of room nights of the IJVHs and 95 percent of FOHs.

Similarities and differences were also found in the international guests who were categorised into business travellers, FITs and leisure-packaged tourists. The leisurepackaged tourists constituted the largest proportion of total room nights sold by all hotel modes. The DPOHs registered the highest proportion (62 percent), and about half of the SOHs and IJV room nights were occupied by international leisure guests (44 percent and 49 percent). For the two FOHs, the Grand Plaza Hanoi sold 55 percent of its rooms to leisure travellers compared with 40 percent at the Duxton Saigon Hotel. The SOHs and IJVHs sold approximately one third of room nights to international business travellers (37 and 31 percent, respectively), but this segment fell to only 14 percent for the DPOHs. FITs accounted for approximately 20 percent of room nights sold across all ownership modes.

The number of international guests who purchased their accommodation through direct and indirect channels varies among modes of hotel ownership (Table 6.1). Direct sales generated the highest volume of room nights for the IJVHs (38 percent) and some IJVHs gained a very high number of room nights sold by direct distribution channels such as the Caravelle Hotel Saigon (72 percent), and the Hanoi Pullman (50 percent). The SOHs had relatively lower direct sales: 27 percent. The two FOHs were different: while direct channels generated 55 percent of room nights to the Duxton Hotel Saigon, the Grand Plaza Hotel in Hanoi sold only 17 percent of its international room nights via direct channels. The direct distribution channels constituted only 17 percent of rooms sold at the DPOHs. Regarding indirect distribution channels, most of the hotels were found to be dependent on travel intermediaries to get international bookings. However, the IJVHs were least reliant on indirect distribution channels, with 62 percent of international sales, compared with 73 percent of the SOHs. The DPOHs were remarkably reliant on third parties to get bookings, with 82 percent of room nights transacted via indirect channels. The two FOHs differed in terms of indirect sales, only 
45 percent of the Duxton Hotel Saigon's room nights were sold to travel intermediaries, the Grand Plaza Hanoi was 83 percent.

Table 6.2. Capacity and patterns of demand and sales for the selected up-market hotels by locations

\begin{tabular}{|c|c|c|c|c|c|c|c|c|c|}
\hline \multirow[b]{2}{*}{ Hotel } & \multicolumn{2}{|c|}{ Room } & \multicolumn{2}{|c|}{ Guest Origin } & \multicolumn{3}{|c|}{$\begin{array}{c}\text { Types of International } \\
\text { Guests }\end{array}$} & \multicolumn{2}{|c|}{ Sales a } \\
\hline & $\begin{array}{l}\text { Room } \\
\text { Number }\end{array}$ & $\begin{array}{c}\text { Room } \\
\text { Occupancy } \\
\text { Rate } \\
(\%)\end{array}$ & $\begin{array}{c}\text { Domestic } \\
\text { ( } \% \text { of } \\
\text { room } \\
\text { nights) }\end{array}$ & $\begin{array}{l}\text { Int }^{2} \\
\text { (\% of } \\
\text { room } \\
\text { nights) }\end{array}$ & $\begin{array}{c}\text { Business } \\
\text { (\% of } \\
\text { room } \\
\text { nights) }\end{array}$ & $\begin{array}{l}\text { FIT } \\
\text { (\% of } \\
\text { room } \\
\text { nights) }\end{array}$ & $\begin{array}{l}\text { Packaged } \\
\text { (\% of } \\
\text { room } \\
\text { nights) }\end{array}$ & $\begin{array}{c}\text { Direct } \\
\text { (\% of room } \\
\text { nights) }\end{array}$ & $\begin{array}{c}\text { Indirect } \\
\text { (\% of } \\
\text { room } \\
\text { nights) }\end{array}$ \\
\hline $\begin{array}{l}\text { Hanoi } \\
(n=12)\end{array}$ & 232 & 61 & 17 & 83 & 20 & 16 & 64 & 22 & 78 \\
\hline $\begin{array}{l}\text { Ho Chi } \\
\text { Minh } \\
\text { City } \\
(n=20)\end{array}$ & 241 & 66 & 9 & 91 & 39 & 17 & 44 & 31 & 69 \\
\hline $\begin{array}{l}\text { Danang } \\
(\mathrm{n}=10)\end{array}$ & 219 & 57 & 48 & 52 & 13 & 38 & 47 & 35 & 65 \\
\hline
\end{tabular}

Source: Interview data, 2013

Variations in the room nights sold to domestic and international tourists are also seen in terms of geographical locations (Table 6.2). There were not any big differences in terms of the average hotel room size and occupancy rate among hotels located in Hanoi, Danang and Ho Chi Minh City. Nonetheless, in terms of the market mix, domestic guests constituted 48 percent of room nights for the hotels in Danang, followed by 17 percent in Hanoi (17 percent) and only nine percent in Ho Chi Minh City. In particular, domestic guests generated a high proportion of room sales for some domestic private properties such as the Muong Thanh Hotel in Hanoi (45 percent), and a number in Danang: the Brilliant (49 percent), the Green Plaza (65 percent) and the Hoang Anh Gia Lai (50 percent). This meant that the hotels in Hanoi and Ho Chi Minh City received proportionately more international guests than those in Danang.

Variations are also found across the three cities in terms of the total room nights sold to different types of international guests. Overall, leisure-packaged tourists continued to account for the largest number of room nights sold by the hotels across the cities: Hanoi (64 percent), Ho Chi Minh City (44 percent) and Danang (47 percent) (Table 6.2). Differences are seen in other types of guests: business travellers contributed 39 percent to the international room nights sold by hotels in Ho Chi Minh City, followed by the 
hotels in Hanoi (20 percent) and only 13 percent in Danang. Regarding the ways that the hotels in three cities approach their guests, most of the hotels were dependent on indirect distribution channels, for example, about 78 percent of room nights of the hotels in Hanoi were sold via travel intermediaries.

Table 6.3. Capacity and patterns of demand for the selected up-market hotels by star rating

\begin{tabular}{|c|c|c|c|c|c|c|c|c|c|}
\hline \multirow[b]{2}{*}{ Hotel } & \multicolumn{2}{|c|}{ Room } & \multicolumn{2}{|c|}{ Guest Origin } & \multicolumn{3}{|c|}{ Types of International Guests } & \multicolumn{2}{|c|}{ Sales $^{\mathbf{a}}$} \\
\hline & Number & $\begin{array}{c}\text { Room } \\
\text { Occupancy } \\
\text { Rate } \\
(\%) \\
\end{array}$ & $\begin{array}{c}\text { Domestic } \\
\text { (\% of } \\
\text { room } \\
\text { nights) }\end{array}$ & $\begin{array}{l}\text { Int' } \\
\text { (\% of } \\
\text { room } \\
\text { nights) }\end{array}$ & $\begin{array}{l}\text { Business } \\
\text { (\% of } \\
\text { room } \\
\text { nights) }\end{array}$ & $\begin{array}{l}\text { FIT } \\
\text { (\% of } \\
\text { room } \\
\text { nights) }\end{array}$ & $\begin{array}{l}\text { Packaged } \\
\text { (\% of } \\
\text { room } \\
\text { nights) }\end{array}$ & $\begin{array}{l}\begin{array}{l}\text { Direct } \\
\text { (\% of } \\
\text { room } \\
\text { nights) }\end{array} \\
\end{array}$ & $\begin{array}{l}\text { Indirect } \\
\text { (\% of } \\
\text { room } \\
\text { nights) }\end{array}$ \\
\hline $\begin{array}{l}5 \text { stars } \\
(\mathrm{n}=21)\end{array}$ & 322 & 63.5 & 11 & 89 & 29 & 22 & 47 & 36 & 64 \\
\hline $\begin{array}{l}4 \text { stars } \\
(\mathrm{n}=21)\end{array}$ & 153 & 62.4 & 25 & 75 & 20 & 18 & 60 & 21 & 79 \\
\hline
\end{tabular}

Source: Interview data, 2013

Differences are also found among the four- and five-star hotel groups across the three cities concerning the hotel capacity and patterns of demand (Table 6.3). The average room number of the 21 five-star hotels was 322 rooms, compared with 153 rooms per four-star hotel. Meanwhile, international guests who stayed at the five-star hotels made up 89 percent of the total room nights sold, this figure was 75 percent at the four-star hotels. These figures of market mix found in this study were consistent with the Grant Thornton Vietnam's survey of the Vietnamese four- and five-hotels in 2013 (Grant Thornton, 2013). In terms of travel types, in that study the leisure-packaged tourists made up nearly two thirds (60 percent) of room nights of the four-star hotels, while, only 47 percent at the five-star ones. International business travellers also accounted for 29 percent of the five-star hotels' room nights compared with only 20 percent at the four-star ones. Direct distribution channels were found to generate a higher percentage of room nights sold by the five-star hotels (36 percent), compared with 21 percent of the four star hotels. 


\subsection{Similarities and differences of the current structures of distribution channels}

\subsubsection{Structures for international guests}

\subsubsection{Channel members}

Table 6.4 summarises a number of similarities and differences across the four types of hotel ownership regarding channel members or channel depth as detailed in Chapters Four and Five. First and foremost, most participants contended that the up-market hotels tended to cooperate with a number of distribution channel members to reach the market. As the Director of Sales of the Hanoi Daewoo Hotel (DPOH) noted, channel members employed by the up-market hotels to distribute their products and services to consumers appear to be the relatively similar, particularly for the five-star hotels in the large urban cities such as Hanoi and Ho Chi Minh City. Indeed, direct bookings are commonly undertaken by all hotel ownership modes via websites, email, telephone, social networks, local hotel representative office(s) and sales calls. Indirect channel members mainly consist of conventional and electronic travel trade companies located at the destination, in the market or in between, namely local information centres, TAs, OTAs, international TOs, overseas wholesalers, and overseas tour operators.

As Table 6.4 indicates, there are also differences in the number of channel members used by different hotel ownership modes to reach the markets. For direct distribution channels, most of the SOHs and DPOHs cooperated with airlines to sell rooms for their crews to stay overnight and for passengers of delayed or cancelled flights but data did not show that IJVHs worked with airlines because of a difference of demand and supply. In other words, the airline carriers could not purchase rooms offered by the IJVHs for their guests and crews because of high rates. The private- and state-owned hotels used their own websites, but the IJVHs and FOHs also obtained direct bookings from the websites of the associated hotel chains of which they are members or franchisees. Another difference seen was that hotels undertake sales and marketing activities via their sales offices. The entirely Vietnamese owned and managed hotels ( $\mathrm{SOH}$ and DPOHs) have widely established this type of office at the destination to reach independent travellers already in Vietnam. Additionally, these offices carried out other functions such as handling sales and marketing activities with local TAs, TOs or business organisations to get bookings. However, the foreign-related counterparts (IJVHs and FOHs) gained access to the end consumers through a number of global and regional sales in the markets or where tourists are in transit to travel to the destinations. 
Table 6.4. Key similarities and differences of using distribution channel members across the four ownership modes

\begin{tabular}{|c|c|c|c|c|c|c|}
\hline \multirow{2}{*}{$\begin{array}{c}\text { Hotel } \\
\text { Ownership } \\
\text { Models }\end{array}$} & \multicolumn{3}{|c|}{ Similarities } & \multicolumn{3}{|c|}{ Differences } \\
\hline & $\begin{array}{l}\text { Direct channels for } \\
\text { international and } \\
\text { domestic guests }\end{array}$ & $\begin{array}{l}\text { Indirect channels for } \\
\text { international guests }\end{array}$ & $\begin{array}{l}\text { Indirect channels for } \\
\text { domestic guests }\end{array}$ & $\begin{array}{l}\text { Direct channels for } \\
\text { international guests }\end{array}$ & $\begin{array}{c}\text { Indirect } \\
\text { channels for } \\
\text { international } \\
\text { guests }\end{array}$ & $\begin{array}{l}\text { Indirect channels } \\
\text { for domestic guests }\end{array}$ \\
\hline $\begin{array}{l}\text { State Owned } \\
\text { Hotels }\end{array}$ & $\begin{array}{l}\text { Website, email, telephone, } \\
\text { social networks and local sales } \\
\text { representative offices, sales } \\
\text { calls }\end{array}$ & $\begin{array}{l}\text { Local information centres, } \\
\text { travel agents, third party sites, } \\
\text { international tour operators } \\
\text { and overseas wholesalers. }\end{array}$ & $\begin{array}{l}\text { Local information centres, } \\
\text { travel agents, third party } \\
\text { sites, domestic and } \\
\text { international tour operators }\end{array}$ & $\begin{array}{l}\text { Hotel own website, airlines, sales } \\
\text { calls to government and business } \\
\text { organisations }\end{array}$ & $\begin{array}{l}\text { Airlines, GDS, } \\
\text { local unlicensed } \\
\text { travel agents } \\
\text { and tour } \\
\text { operators }\end{array}$ & $\begin{array}{lr}\text { Unlicensed travel } \\
\text { agents and tour } \\
\text { operators }\end{array}$ \\
\hline $\begin{array}{l}\text { Domestic Private } \\
\text { Owned Hotels }\end{array}$ & $\begin{array}{l}\text { Website, email, telephone, } \\
\text { social networks and local sales } \\
\text { representative offices, sales } \\
\text { calls }\end{array}$ & $\begin{array}{l}\text { Local information centres, } \\
\text { travel agents, third party sites, } \\
\text { international tour operators } \\
\text { and overseas wholesalers. }\end{array}$ & $\begin{array}{l}\text { Local information centres, } \\
\text { travel agents, third party } \\
\text { sites, domestic and } \\
\text { international tour operators }\end{array}$ & $\begin{array}{l}\text { Airlines, sales calls to } \\
\text { government and business } \\
\text { organisations }\end{array}$ & $\begin{array}{l}\text { Airlines, local } \\
\text { unlicensed } \\
\text { travel agents } \\
\text { and tour } \\
\text { operators }\end{array}$ & $\begin{array}{lr}\text { Unlicensed travel } \\
\text { agents and tour } \\
\text { operators }\end{array}$ \\
\hline $\begin{array}{l}\text { International } \\
\text { Joint Venture } \\
\text { Hotels }\end{array}$ & $\begin{array}{l}\text { Website, email, telephone, } \\
\text { social networks and local sales } \\
\text { representative offices, sales } \\
\text { calls }\end{array}$ & $\begin{array}{l}\text { Local information centres, } \\
\text { travel agents, third party sites, } \\
\text { international tour operators } \\
\text { and overseas wholesalers. }\end{array}$ & $\begin{array}{l}\text { Local information centres, } \\
\text { travel agents, third party } \\
\text { sites, domestic and } \\
\text { international tour operators }\end{array}$ & $\begin{array}{l}\text { Hotel chain' website, sales calls } \\
\text { to government and business } \\
\text { organisations, regional and global } \\
\text { sales offices, CROs and call } \\
\text { centres }\end{array}$ & $\begin{array}{l}\text { GDS, CROs } \\
\text { and call centres }\end{array}$ & $\begin{array}{l}\text { Do not use unlicensed } \\
\text { travel agents and tour } \\
\text { operators }\end{array}$ \\
\hline $\begin{array}{l}\text { Wholly Foreign } \\
\text { Owned Hotels }\end{array}$ & $\begin{array}{l}\text { Website, email, telephone, } \\
\text { social networks and local sales } \\
\text { representative offices, sales } \\
\text { calls }\end{array}$ & $\begin{array}{l}\text { Local information centres, } \\
\text { travel agents, third party sites, } \\
\text { international tour operators } \\
\text { and overseas wholesalers. }\end{array}$ & $\begin{array}{l}\text { Local information centres, } \\
\text { travel agents, third party } \\
\text { sites, domestic and } \\
\text { international tour operators }\end{array}$ & $\begin{array}{l}\text { Hotel own website, hotel chain' } \\
\text { site, sales calls to government and } \\
\text { business organisations, regional } \\
\text { sales office, CROs/call centres }\end{array}$ & GDS & $\begin{array}{l}\text { Do not use unlicensed } \\
\text { travel agents and tour } \\
\text { operators }\end{array}$ \\
\hline
\end{tabular}

Source: Interview data, 2013 
Regarding indirect channels, the SOHs and DPOHs use fewer channel members than other ownership modes, particularly the electronic intermediaries. All ownership modes, excluding most of the DPOHs, have contracted with the GDS service providers to get bookings from travel agents and from large corporations for business travellers. However, bookings from GDS and the outputs of this channel vary between hotel modes. The Director of Sales and Marketing of the First Hotel (SOH in Ho Chi Minh City) and the Assistant Director of Sales and Marketing of the Duxton Hotel (FOH in Ho Chi Minh City) revealed that bookings and room nights from GDS accounted for a negligible proportion of sales. This kind of distribution channel has been becoming less popular for them due to the appearance of a series of online travel agents. Specifically, some of the SOHs (First, Palace and Royal City Hotel in Ho Chi Minh City) were planning to stop contracts with their GDS service providers because of the low efficiency in comparison with their investment. In contrast, the IJVHs still generated bookings from GDSs. Traditionally, overseas TAs are the main users of GDSs. However, various large corporations who today are the regular customers of the premier GDSs such as Amadeus, Galileo, Sabre and Worldspan reserve rooms for their staff's business missions. Overseas wholesalers are becoming increasingly important partners of some IJVHs when this type of hotel ownership attempts to increase room rates. For instance, representatives from two IJVHs said that they would try to push up the direct cooperation with overseas wholesalers or tour operators because of their pricing policy and advantages of sales networks.

The last difference seen among types of hotel ownership modes was that the SOHs and DPOHs worked with unlicensed TAs and TOs at the destination to collect bookings from international guests. In principle, this kind of cooperation does not exist and must be condemned immediately by the tourism enterprises and the relevant authorities as it violates the law, causing unequally competitive business environments for other licensed TAs and TOs. However, as some representatives from the SOHs and DPOHs in Danang and Ho Chi Minh City noted, most of the unlicensed TOs are the domestic travel companies which are normally small and the regular customers of their hotels. If the unlicensed TOs sent bookings of international guests, these hotels would accept and give them a chance of further cooperation and development. Nonetheless, the IJVHs and FOHs do not receive bookings from unlicensed TOs or at least these hotels declined to give information on this. 


\subsubsection{Channel length}

The channel length of the distribution structures represented similarities and differences among the hotel ownership modes in using indirect distribution channels as well (Table 6.5). The length of channel is the number of channel members within a certain type of channel linking the hotels with tourists. The similarities and differences of channel length were found when the selected hotels in this study attempted to shorten this length to control and adjust their products and services sold to the end tourists. In the context of Vietnam, as the Operation Manager of the Apex Travel in Ho Chi Minh City and the Deputy Director of the Vitour in Danang said, the typical relationship among channel members from the hotels to their end guests in Vietnam was found according to the order: hotel - local TAs - local TOs - overseas wholesalers - overseas TOs - overseas TAs - tourists.

From the above structure, looking back at the target markets of the Vietnam tourism, it is noted that the Vietnam tourism development strategy has identified the East Asia (China, Japan and South Korea), Asia Pacific (Indonesia, Malaysia, Singapore, Thailand and Oceania), Western Europe (England, France, Germany and Netherlands), North Europe, North America, Russia and some emerging markets such as India and Middle East countries as the key tourist sending countries for 2011 to 2030 (VNAT, 2012b). In fact, the VNAT's statistics in 2012 showed that the country's top international arrivals were from these short and long haul markets (VNAT, 2013b). The target markets of Vietnam tourism and statistics of international tourists also indirectly indicated the channel length of different hotel ownership modes because, as noted by some representatives from the hotels and travel industry, hotels as well as Vietnam tour operators were very reliant on overseas wholesales to reach the end guests. However, a number of factors such as hotel resources and transportation influence this channel length, as will be discussed in the Chapter Seven.

A close relation between the distant markets and channel length was firstly found across the four hotel ownership types. All of the hotel ownership modes aimed to establish a sufficient distribution system to reach international guests with appropriate channels. The entirely Vietnamese-owned hotels met certain difficulties to organise the number of channel members within a channel; the two FOHs, which were the franchisees of lesser known brands of hotel management and engineering companies, also had limited 
Table 6.5. Key similarities and differences of channel length, channel width, channel functions and channel mix across the four ownership modes

\begin{tabular}{|c|c|c|c|c|c|c|c|c|}
\hline \multirow[b]{2}{*}{$\begin{array}{c}\text { Hotel } \\
\text { Ownership } \\
\text { Model }\end{array}$} & \multicolumn{4}{|c|}{ Similarities } & \multicolumn{4}{|c|}{ Differences } \\
\hline & Channel length & Channel functions & Channel width & Channel mix & Channel length & $\begin{array}{l}\text { Channel } \\
\text { functions }\end{array}$ & Channel width & Channel mix \\
\hline $\begin{array}{l}\text { State Owned } \\
\text { Hotels }\end{array}$ & $\begin{array}{l}\text { Hotel - local TAs - local } \\
\text { TOs - Overseas } \\
\text { Wholesalers -Overseas } \\
\text { TOs - Overseas TAs - } \\
\text { the end tourists }\end{array}$ & $\begin{array}{l}\text { Flow of information, } \\
\text { advice, negotiation, } \\
\text { booking, making payment } \\
\text { for finalised bookings and } \\
\text { paying commission or fees } \\
\text { to relevant business partners }\end{array}$ & $\begin{array}{l}\text { Signing agreement } \\
\text { contracts with a wide } \\
\text { range of travel } \\
\text { companies within a type } \\
\text { of channel member }\end{array}$ & $\begin{array}{l}\text { All of the hotels used } \\
\text { multiple channels to } \\
\text { approach different types } \\
\text { of guests and market } \\
\text { segments }\end{array}$ & $\begin{array}{l}\text { Meeting difficulties to } \\
\text { manage the number of } \\
\text { channel members within a } \\
\text { channel }\end{array}$ & $\begin{array}{l}\text { Illegal commission was } \\
\text { paid via the payment } \\
\text { function }\end{array}$ & $\begin{array}{l}\text { - As many travel companies } \\
\text { within a type of channel } \\
\text { member as possible } \\
\text { - Cooperation with unlicensed } \\
\text { TAs and } \mathrm{TO}_{\mathrm{s}}\end{array}$ & $\begin{array}{l}\text { Less paid attention to channel } \\
\text { mix }\end{array}$ \\
\hline $\begin{array}{l}\text { Domestic } \\
\text { Private } \\
\text { Owned } \\
\text { Hotels }\end{array}$ & $\begin{array}{l}\text { Hotel - local TAs - local } \\
\text { TOs - Overseas } \\
\text { Wholesalers - Overseas } \\
\text { TOs - Overseas TAs - } \\
\text { the end tourists }\end{array}$ & $\begin{array}{l}\text { Flow of information, } \\
\text { advice, negotiation, } \\
\text { booking, making payment } \\
\text { for finalised bookings and } \\
\text { paying commission or fees } \\
\text { to relevant business partners }\end{array}$ & $\begin{array}{l}\text { Signing agreement } \\
\text { contracts with a wide } \\
\text { range of travel } \\
\text { companies within a type } \\
\text { of channel member }\end{array}$ & $\begin{array}{l}\text { All of the hotels used } \\
\text { multiple channels to } \\
\text { approach different types } \\
\text { of guests and market } \\
\text { segments }\end{array}$ & $\begin{array}{l}\text { Meeting difficulties to } \\
\text { manage the number of } \\
\text { channel members within a } \\
\text { channel }\end{array}$ & $\begin{array}{l}\text { Illegal commission was } \\
\text { paid via the payment } \\
\text { function }\end{array}$ & $\begin{array}{l}\text { - As many travel companies } \\
\text { within a type of channel } \\
\text { member as possible } \\
\text { - Cooperation with unlicensed } \\
\text { TAs and } \mathrm{TOs}^{-}\end{array}$ & $\begin{array}{l}\text { Less paid attention to channel } \\
\text { mix }\end{array}$ \\
\hline $\begin{array}{l}\text { International } \\
\text { Joint } \\
\text { Venture } \\
\text { Hotels }\end{array}$ & $\begin{array}{l}\text { Hotel - local TAs - local } \\
\text { TOs - Overseas } \\
\text { Wholesalers -Overseas } \\
\text { TOs - Overseas TAs - } \\
\text { the end tourists }\end{array}$ & $\begin{array}{l}\text { Flow of information, } \\
\text { advice, negotiation, } \\
\text { booking, making payment } \\
\text { for finalised bookings and } \\
\text { paying commission or fees } \\
\text { to relevant business partners }\end{array}$ & $\begin{array}{l}\text { Signing agreement } \\
\text { contracts with a wide } \\
\text { range of travel } \\
\text { companies within a type } \\
\text { of channel member }\end{array}$ & $\begin{array}{l}\text { All of the hotels used } \\
\text { multiple channels to } \\
\text { approach different types } \\
\text { of guests and market } \\
\text { segments }\end{array}$ & $\begin{array}{l}\text { - Managing the number of } \\
\text { channel members by adding } \\
\text { offshore members such as } \\
\text { CROs or global and regional } \\
\text { sales offices } \\
\text { - The IVIs' length of } \\
\text { channel was shorter }\end{array}$ & & $\begin{array}{l}\text { Cooperation with selective } \\
\text { travel companies within a type } \\
\text { of channel member }\end{array}$ & $\begin{array}{l}\text { The IJVs use software and } \\
\text { report of hotel groups to } \\
\text { measure outputs of each } \\
\text { channel }\end{array}$ \\
\hline $\begin{array}{l}\text { Wholly } \\
\text { Foreign } \\
\text { Owned } \\
\text { Hotels }\end{array}$ & $\begin{array}{l}\text { Hotel - local TAs - local } \\
\text { TOs - Overseas } \\
\text { Wholesalers - Overseas } \\
\text { TOs - Overseas TAs - } \\
\text { the end tourists. }\end{array}$ & $\begin{array}{l}\text { Flow of information, } \\
\text { advice, negotiation, } \\
\text { booking, making payment } \\
\text { for finalised bookings and } \\
\text { paying commission or fees } \\
\text { to relevant business partners }\end{array}$ & $\begin{array}{l}\text { Signing agreement } \\
\text { contracts with a wide } \\
\text { range of travel } \\
\text { companies within a type } \\
\text { of channel member }\end{array}$ & $\begin{array}{l}\text { All of the hotels used } \\
\text { multiple channels to } \\
\text { approach different types } \\
\text { of guests and market } \\
\text { segments }\end{array}$ & $\begin{array}{l}\text { - Managing the number of } \\
\text { channel members by adding } \\
\text { offshore members such as } \\
\text { CROs or global and regional } \\
\text { sales offices } \\
\text { - Limited resource to expand } \\
\text { CROs, global sales offices. }\end{array}$ & & $\begin{array}{l}\text { - An old one selected travel } \\
\text { companies within a type of } \\
\text { channel member to cooperate } \\
\text { - A newly opened one } \\
\text { cooperated with as many travel } \\
\text { companies within a type of } \\
\text { channel member as possible }\end{array}$ & $\begin{array}{l}\text { Less paid attention to channel } \\
\text { mix }\end{array}$ \\
\hline
\end{tabular}

Source: Interview data, 2013 
support from the parent companies and a limited budget for sales and marketing to structure the channel length. The IJVHs, which were operated by international hotel chains, took their advantages of financial resources and marketing budget by having more offshore members such as CROs or global and regional sales offices to support sales and marketing in general and the structure of distribution channels in particular. In other words, the IJVHs' channel length was shorter than those of other ownership modes, particularly the Vietnamese-owned and managed hotels. The difference of channel length presented by these hotel modes indicated a number of consequences: (1) the relationship between hotel room rates sold to the end guests and channel length. An example is that, the former Head of the Hotel Management Division of the Danang Department of Culture, Sports and Tourism said when she accepted an invitation to be a General Manager of a three-star hotel (DPOH) after retirement, she found an interesting point in terms of the channel length and the final payment of guests for rooms. Her hotel signed agreement contracts with local international TOs, these travel companies sold rooms to their overseas wholesalers, and then these wholesalers sold these rooms to overseas TOs or other parties before the end tourists could purchase. She did not know the length of channel and the process of selling that hotel rooms to the end tourists but she received numerous complaints from the long-haul market's guests on arrival when they compared the purchased room rates with the room amenities. The room rates were actually much higher than they were first sold to the Vietnamese tour operators. (2) In this regard, the IJVHs addressed this issue better since the regional and global sales offices and/or call centres located in a number of their target markets or in between the destination and the markets connected the IJVHs with overseas wholesalers and TOs directly to avoid pricing conflicts. These sales offices also handled enquiries and bookings from travel intermediaries and end guests. As a result, the length between hotels and the end consumers via travel intermediaries was being supervised by sales offices and/or CROs, which was not seen at the entirely Vietnamese hotels (SOHs and DPOHs).

\subsubsection{Channel functions}

The functions of channel members carried out by the four modes of hotel ownership basically appear to be similar (Table 6.5). As indicated in Chapters Four and Five, these functions were widely employed to directly and indirectly connect hotels with tourists (information flow, advice, negotiation, booking, payment, and information provision). 
Popular electronic and conventional intermediaries such as GDS service providers, online and offline OTAs, TOs, wholesalers, international sales offices and CROs in the global hotel industry were seen to apply their roles in the distribution systems consistent with the international tourism business norms and the current regulation of the Vietnam laws. Specifically, the GDSs and OTAs that act as automated systems and semi-auto sites do not allow TAs or corporations to pay bookings through systems, but guarantees are needed. Accordingly, once tourists or their agents reserve rooms and these are confirmed, final payments are made upon arrival by guests.

While they are mostly similar, some variation is found across the four ownership modes regarding the use of the payment function; this differed between the Vietnamese-owned and managed hotels (SOHs and DPOHs) and the foreign-invested hotels (IJVHs and FOHs). For the SOHs and DPOHs, it was recognised that illegal commission was paid to some local organisations or governmental departments to get direct bookings of their invited international guests to Vietnam. To some extent, the basic function of payment of distribution channel was extended to carry out illegal commission, which was not yet seen at the IJVHs or the FOHs.

\subsubsection{Channel width}

The channel width is understood as the number of travel intermediaries employed for each channel member (Pearce, 2007). For instance, when cooperating with the tour operator to sell rooms, a number of SOHs and DPOHs signed agreement contracts with hundreds of TOs to sell their rooms. The similarities and differences of channel width across the four hotel ownership modes are presented in Table 6.4. Overall, the channel width of the entirely Vietnamese-owned and operated hotels (SOHs and DPOHs) were greater than those of IJVHs and FOHs.

Electronic and conventional travel intermediaries were mentioned by most of participants in terms of channel width. In the context of Vietnam, electronic travel companies referred to OTAs (located in Vietnam, in the market or elsewhere), and traditional travel companies were known as international tour operators. Within a certain channel, most of the hotel representatives noted that in order to maximise the possibility to increase the revenue and image, hotels were likely to cooperate with as many companies as possible because each of them had a strength at a certain market. 
For instance, a number of OTAs in the market or at the destination were used by hotel ownership modes including Agoda, Expedia, Ivivu to distribute their products and services to international guests. The situation is similar with conventional intermediaries as most of the hotels were remarkably dependent on the international TOs and local TAs. By signing contracts with hundreds of these traditional travel companies (TOs and TAs), the hotels believed that opportunities to have bookings were widened.

However, a difference is found when channel width of both electronic and conventional travel intermediaries were associated with market segments and hotel ownership modes. The IJVHs, which were supported by global and regional sales offices of hotel chains to target some markets, normally refined a list of travel intermediaries including electronic and conventional ones to create a shortlist of companies to cooperate. A list of the selective international tour operators enabled the IJVHs to have better cooperation with travel companies in terms of sales and marketing strategies and distribution. In contrast, the SOHs and DPOHs tended to accept hundreds of conventional travel companies and a number of OTAs. On the one hand, this did waste time of these hotels on refining and managing the contracts, on the other hand it indicated the unclear target markets and professional level of hotels in handling the sales and marketing as well as the consumer services of hotels that Chapter Seven will discuss in more detail.

Variations of channel width among hotel ownership modes are also found based on hotels' history, investors' background and hotel management mode. First, the newly opened hotels or inexperienced hoteliers tended to use as many travel intermediaries within a channel member as they could. For instance, the Grand Plaza Hotel in Hanoi cooperated with as many international TOs as possible to promote its image and to increase the possibility of room sales because (1) the hotel owner's background in construction and property meant that they needed time to understand the hospitality industry, and (2) as a newly opened hotel with an unknown brand, marketing activities of the hotel were largely invested to promote its image to the markets. Conversely, the Duxton Saigon (FOH) and a number of IJVHs with a longer history of operation and globally recognised brands have significantly identified their target markets and business partners. A shortlist of international TOs were created by these hotels to manage the distribution channel members according to the consistent application of commission and pricing policies. However, the Duxton and IJVHs also cooperated with 
a number of travel companies that were not on their shortlist because they would like to balance customers; moreover, these secondary business partners possibly become important accounts in the future. The phenomenon of channel width of the Grand Plaza Hotel was also seen at the SOHs and DPOHs which shared the comparatively same characteristics of hotel owners' background, and less well-known hotel brands.

\subsubsection{Channel mix}

Channel mix is the combination of channels used to approach guests. By deciding a suitable channel mix, the hotel needs to determine the coverage each channel provides to certain market segments that the hotel aims at or to evaluate the profitability of each channel. With this regard, both SOHs and DPOHs have attempted to mix direct and indirect channels to reach the tourism market. In contrast, the IJVHs and FOHs are clearly seen to use software and the hotel group's sales and marketing statistics to determine the coverage that every channel reaches, to evaluate the profitability of each channel and to audit channels annually to combine channels in the distribution structure. Compared with the IJVHs where channel mix is monitored and evaluated by the hotel, the two franchised FOHs paid lesser attention to this because of their history of operation, investor' background and management mode.

\subsubsection{The structures for domestic travellers}

As mentioned in Chapters Four and Five, patterns of domestic demand and distribution were analysed, and the current diagrams of distribution channels of different hotel ownership modes were depicted based on data collected from secondary sources such as hotel websites, Vietnamese online newspapers and local international tour operators' websites. Due to the validity and richness of data, discussions on channel members, channel length, channel functions as well as channel width of the structure for domestic travellers conducted by each hotel ownership modes were limited.

As Table 6.1 indicated, the market shares of the domestic guests accounted for only small proportion of room sales of most hotel ownership modes. To gain bookings from this market mix, most of the hotels shared a commonality in using a wide range of direct and indirect channel members to approach these domestic travellers. The trend of using conventional travel companies was seen in all the hotel ownership modes, but OTAs were recorded as the only electronic channel used to meet the domestic guests' demands. 
As with the structures for international guests, the notable difference in terms of domestic channel was that unlicensed travel companies were used by SOHs and DPOHs but not by the IJVHs and FOHs. The SOHs and DPOHs also took advantage of their social relationships with local organisations and government departments to get bookings.

In terms of the channel length and channel functions, different hotel ownership modes represented relatively the same. The width of channels, particularly for travel agents and tour operators, was accordingly large with the participation of hundreds of both domestic and international tour operators in the structures of distribution channels to reach domestic tourists.

\subsection{Conclusion}

This chapter has identified the key commonalities and differences of hotel ownership modes in terms of hotel capacity and patterns of demand as well as distribution channel structure. By providing four comparative tables of patterns of demand and distribution, key similarities and differences of using channel members, aspects of distribution across four hotel ownership modes, this chapter indicates insights into patterns of demand and distribution channel structures used by the hotels to reach tourism markets.

In general, patterns of demand for different hotel ownership modes showed a commonality regarding the average number of rooms, market mix, types of guests and proportion of sales via direct and indirect channels. The average size of the four hotel ownership modes was much bigger than the country average and the government minimum requirement to be classified as four- and five-star hotels ( 80 and 100 rooms per hotel, respectively). Across the three cities, hotel size and occupancy rate of the four- and five-star groups were almost the same. Domestic guests also accounted for a lesser proportion of sales than that of the international travellers. Among international tourists, the leisure-packaged tourists constituted the largest proportion of total room nights sold by most of the hotel ownership modes, and the FITs contributed approximately 20 percent of room nights of all ownership modes regardless of their location or star rating. Most of the hotel ownership modes were reliant on travel intermediaries to get bookings. 
However, key differences were found in terms of hotel size, room occupancy rate and other patterns of demand across the four ownership modes. The average room size of 21 five-star hotels was double that of the four-star ones (322 and 153 rooms respectively). The SOHs had the highest room occupancy rate and the hotels in Danang recorded the lowest annual room occupancy rate. Regarding the market mix, the DPOHs welcomed a higher proportion of Vietnamese guests compared to: SOH (15 percent), IJVHs (8 percent) and the FOHs (five percent). Some of the SOHs and DPOHs were particularly dependent on domestic tourists, such as the Victory Hotel Hanoi and the Green Plaza Danang, and nearly 50 percent of room nights of the hotels in Danang were purchased by the Vietnamese travellers. Five-star hotels attracted proportionally more international guests than four-star ones.

Variations were also seen in terms of types of guests and proportion of room nights sold via direct and indirect distribution channels by these hotel ownership modes. While the leisure-packaged tourists were the largest international market for all hotel ownership modes, they were particularly important for DPOHs (62 percent) compared with 44 percent to 55 percent of the other ownership modes. This type of guests was also dominant at the four-star hotels rather than the five-star ones, with 60 percent and 47 percent, respectively. The IJVHs attracted more business travellers, followed by the SOHs. The up-market hotels in Ho Chi Minh City welcomed the largest proportion of business tourists, followed by Hanoi then Danang. Regarding the channels that hotels used to get bookings, direct distribution channels generated the highest room nights sold to the end tourists compared with SOHs and DPOHs. These channels also constituted a higher volume of room night sales of the five-star hotels than that of the four-star ones. For the two FOHs, meanwhile, the Duxton Saigon Hotel sold about 55 percent of total room nights via direct channels, the Grand Plaza Hotel in Hanoi recorded as low as 17 percent.

The structure of distribution channels conducted by the four hotel ownership modes also represented similarities and differences regarding channel mix, channel members, length, channel width, channel functions and channel mix. It appeared that all of the hotel ownership modes worked with popular conventional and electronic channel members to structure their own distribution channels. However, most of the private hotels did not use the GDS service that was effectively used by the IJVHs. The SOHs 
contracted with some GDS service providers to link with the end guests, but as some of representatives from this hotel mode noted, the efficiency was low because this type of service normally required global call centres or CROs with 24-hour operation to handle bookings. Notably, both the SOHs and domestic hotels used unlicensed TAs and TOs in Vietnam to sell rooms to international and domestic guests, whereas the foreign invested hotels only signed contracts with fully licensed travel companies. For channel length, it was found to be different across types of hotel ownership. Although the two FOHs were connected with their target markets by a CRO and a sales offices, the IJVHs were strongly supported by a wide number of global sales offices operated by management hotel chains, creating for them the great advantages of approaching guests at the long-haul markets; therefore the channel length of this hotel ownership mode was considered to be shorter than other modes. In terms of channel width, all types of hotels were likely to sign contracts with hundreds of conventional tour operators in Vietnam to collect bookings. Regarding channel functions, paying illegal commissions to certain types of guests in direct channels appeared to be normal with the SOHs and DPOHs, but this form of payment was not seen at the IJVHs or FOHs. The IJVHs are also seen to apply effectively channel mix to reach tourism markets. 


\section{CHAPTER 7. FACTORS INFLUENCING THE CURRENT HOTEL DISTRIBUTION CHANNEL STRUCTURES ACROSS THE FOUR HOTEL OWNERSHIP MODES}

\subsection{Introduction}

This chapter will address the second research question: What factors influence the current distribution channel structures of the different hotel ownership modes. The chapter is structured around Figure 7.1, which shows that internal and external factors are inter-related. First, Vietnam's economic renovation and transitional economy in the context of the country's integration into the world are the background and underlying factors of the internal dimensions. They have promoted changes to Vietnam's legal system, economic development, tourist demand, technological advances and the financial and banking system and Doi Moi has also enabled the up-market hotels to integrate into the global tourism market. Therefore, coupled with international factors such as becoming a member of the WTO, Doi Moi has created ownership and management modes that emerge as the factors directly leading to the current structures of distribution channels and patterns of demand. Doi Moi and the economic transitional process also indirectly impact on other internal factors within the hotels including hotel resources, products and services, business objectives and target markets. These internal factors of different hotel ownership modes have influenced the distribution channel structures.

\subsection{Factors influencing the current hotel distribution channel structures}

As the literature review and the conceptual framework (Figure 2.5) have suggested, factors including Vietnam's economic renovation, its transitional economic process to a full market economy and a number of other internal and external factors are recognised as affecting the hotel distribution channel structures. Following data analysis, Figure 7.1 was developed to depict the linkages and relationships among these internal and external components. The conceptual framework identified the main factors but Figure 7.1 presents these main factors in detail. For instance, the patterns of demand factors now contain the origin of guests, types of guests and room occupancy rate. Rather than presenting the hotel distribution channel structure as a single system, Figure 7.1 details each element of distribution channels, namely channel mix, direct and indirect distribution, channel member, channel length, channel width and channel functions. 
Therefore, this figure constitutes the foundation to be used for interpreting the distribution channel structures in terms of their commonalities and differences.

Using Figure 7.1, the background factors, namely Vietnam's economic renovation and transitional economy, will be examined first as they generate a variety of the national elements: legal system, economic development, domestic tourist demand, technological advances and the country's financial and banking system. A number of parallel international factors including Vietnam's membership of the WTO, international tourist demand, technological advances, financial and banking development and transportation to Vietnam will be analysed in conjunction with national factors as Vietnam becomes increasingly integrated globally. Moreover, most of the guests of the high-end hotels are from international markets.

Beyond the background factors, as a consequence of the economic renovation and transitional economy, the ownership mode appears to be the most important internal factor influencing the distribution channel structures, followed by management mode. The owners decide the level of investment and apply a mode of management. A number of supplementary internal factors, which are the result of ownership and the hotel management mode, include hotel resources, nature of products and services, business objectives and target markets.

Patterns of demand, which are the result of Vietnam's economic renovation and transitional economy as well as the country's integration into the world, have also influenced how the various hotel ownership modes establish their distribution channel structures. These factors will be analysed in turn in the following sections.

\subsubsection{Vietnam's economic renovation and transitional economy}

As mentioned in Section 3.2.4, most of the participants from the hotels and tour operators have a poor knowledge of macro-economy and a blurred memory of Doi Moi, consequently data regarding the economic renovation, transitional economy and international factors were mainly provided by representatives from government departments, trade organisations, academics and secondary sources. Although a number of researchers and the Vietnamese policy makers have been calling for a second Doi 


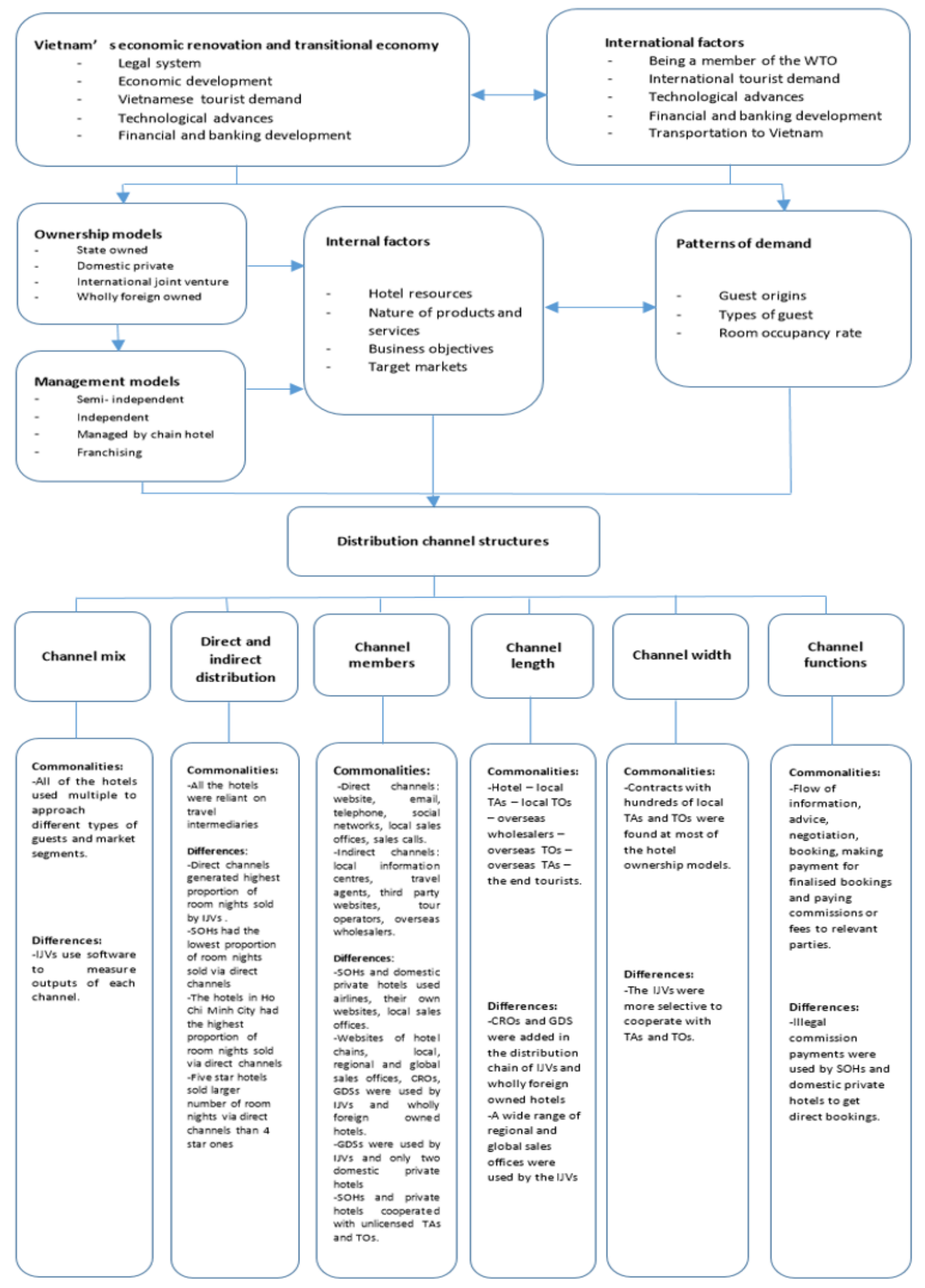

Keys: WTO (World Trade Organisation), IJV (international joint venture hotel), SOH (state owned hotel), CRO (central reservation office), GDS (global distribution system), TA (travel agent), TO (tour operator)

Figure 7.1 Factors influencing distribution channel structures of the different hotel ownership models in three largest cities in Vietnam 
Moi to enhance the economic growth (Kokko, 1998; To Vuong, 2015; Tran, 2011), Doi Moi that was introduced in 1986 has created a very important basis for the expansion of the hotel sector and hotel distribution channel structures. The legal system, economic development, domestic tourist demand, technological advances and the financial and banking system have been the underlying factors of developments. Indeed, the expansion and development of the Vietnamese up-market hotels' distribution channel structures have happened along with this milestone since competition of the local and international private hoteliers in the hotel market appeared.

First, Doi Moi and the transitional process stopped the monopoly of SOHs in the hotel market by renovating the country's legal system, and generating diverse demands of domestic and international tourists for the high-end hotels of different ownership and management modes. Before 1986, all of the SOHs were subject to the centrally planned economy. Domestic guests and most of the international arrivals from the former Soviet Bloc countries were allocated to stay at the SOHs or state guesthouses. After 1986, due to the introduction of the market-oriented economy, the living standard of the Vietnamese was improved leading to a boom in domestic tourism. The open door policy also created opportunities for international hotel investors and for international tourists travelling to Vietnam for holidays or other purposes such as business and visiting relatives. In addition, the legal recognition of the multiple ownership economy had motivated numerous local and overseas investors to build high quality hotels to meet this increasing demand. In this respect, Doi Moi has placed a very important foundation for creating a multiple hotel ownership structure and management mode as well as generating the patterns of demand for up-market hotels.

Second, the economic renovation and Vietnam's journey to a market economy have generally influenced the distribution channel structures applied by the four hotel ownership modes. During the command economy, direct bookings were not made between foreigners and the SOHs because only the Vietnam Tourism Company in Hanoi with its branches in other cities (e.g. Vietnam Tourism in Danang and Vietnam Tourism in Ho Chi Minh City) were legally allowed to arrange rooms and holidays for international guests. Organised group holiday for the domestic leisure-packaged tourists were arranged by their own employers' trade union. Business trips of government and SOEs officials who stayed at a $\mathrm{SOH}$ were arranged beforehand by referral letters and 
fax or telegraph. The transitional economy and the high competition of the hotel market have now forced all hotel ownership modes to find ways to reach guests and to obtain business targets based on their resources. Direct channels have been widely used by the hotels supported by a number of factors, for instance, the development of the legal system, information and communication technology, banking and international transportation. Indirect channels have been expanded and developed to approach the tourists in terms of channel members, channel width and channel mix.

Third, Vietnam's economic renovation, transitional economy and international integration have enabled types of guests for up-market hotels that had not been seen under the command economy. In addition to the demand of a number of leisurepackaged tourists, the open door policy and the attractiveness of a huge market with low cost labourers have lured business people looking for opportunities for investments in manufacturing projects and other economic fields. This has created a frequent flow of business guests for the up-market hotels. Besides, international tourists travelling independently have also been favoured to design their trips to Vietnam since travel barriers have been gradually removed and numerous legal commitments to protect international tourists have been enacted. Therefore, Doi Moi and the transitional process have been the main reasons leading to the diversity of tourist nationalities and types of travellers. This factor of demand together with the increasing supply of the high-end hotels have pressed the hotel owners and operators to establish strategic sales and marketing plans and to strengthen their distribution channels.

In short, Doi Moi and Vietnam's transitional economy have created the foundation for different hotel ownership modes to expand and develop their distribution channel structures to reach international tourist markets. Based on this, each type of hotel ownership depends on their resources to establish their distribution structure. The Director of Office Administration of VNAT took as an example that if a very large and beautiful hotel managed by a professional hotel chain operates in an unstable business and political environment destination, it could be said that the entire hotel operation will be negatively affected and the hotels will even ignore investing and establishing distribution channel structures. This is because an unstable business environment might attract less business guests and the chaos of politics may reduce demand from leisure tourists. In this aspect, Vietnam is now considered attractive and safe (Cooper, 2009). 
It is important to investigate in turn details of some supplementary components of Vietnam's economic renovation. Vietnam's legal system and economic development will be examined individually; other factors such as domestic tourist demand, technological advances and finance and banking will be incorporated with international factors.

\subsubsection{Vietnam's legal system}

The legal system of Vietnam is based on a system of legal documents promulgated by different agencies. The highest legal document is the Constitution passed by the National Assembly, followed by laws, ordinances, orders, decrees, government decisions, circulars, ministerial decisions and guidelines of numerous organisations including the National Assembly, the Standing Committee of the National Assembly, the State President, the Prime Minister, ministries and other state departments at the central and provincial levels (VNA, 2008). In addition to Vietnamese documents, international treaties and agreements that Vietnam signed or is a member of are also a part of this legal system.

Sections 4.2 and 5.2 have provided details on the operational setting of each hotel ownership mode, that is, international treaties or agreements to which Vietnam is a signatory, and Vietnamese laws and legal system. These regulations have not only created a legal platform for the emergence of different hotel ownership types and the existing hotel management modes, but also they have allowed hotels, travel intermediaries and travellers to meet with each other based on their demands in the distribution chain of products and services. The legal system is seen to have direct impacts on the hotel ownership and management modes as well as patterns of tourist demand and indirect influence on the distribution channel structures in a number of ways.

First, the legal framework has been gradually improved since Vietnam is attempting to become a full market economy in 2018 as it committed to the WTO. This has assured the appearance and operation of local and overseas hotel investors and hotel managing companies in Vietnam. According to VGP (2015d), the WTO is recognised as a multilateral international organisation operating based on the principles of the market economy, it is "a rules-based, member-driven organization where all decisions are made 
by the member governments, and the rules are the outcome of negotiations among members" (WTO, 2015). The values of transparency in the legal system are the valuable principles that the WTO strictly follows. Being a WTO member means that the legal system of Vietnam must be transparent, and the current Vietnamese laws might be revised to be consistent with international laws and norms. In addition, the current Vietnamese Constitution defines that Vietnam promotes a socialist market-oriented economy with multi-ownership modes of which the state economy plays a leading role. It also creates an equal business environment for all ownership modes and stakeholders.

A number of laws relating to the development of distribution channels have been promulgated or revised by the Vietnam National Assembly as follow-up actions of being a member of some bilateral and multilateral free trade agreements such as U.SVietnam, Japan-Vietnam, ASEAN-China, and ASEAN-Australia-New Zealand as well as conditions of the WTO accession. These include the Law on the Vietnam State Bank (2003), Competition Law (2004), Law on Enterprises (2005), Law on Trade (2005), Tourism Law (2005), Law on the Electronic Transaction (2006), Law on Information Technology (2006), the Consumer Protection Law (2010) and the Law on Immigration. In the tourism industry, foreign travel agencies and TOs are permitted to provide services in the form of joint ventures with Vietnamese partners with no limitation on foreign capital contribution (WTO, 2006). Wholly international tour operators have not yet appeared in Vietnam although there are some joint venture travel companies. These legal documents and international agreements were issued to regulate a number of important economic sectors and services in the market economy that had been ignored in the command economy (Vietnam Export, 2010). Importantly, these laws have provided a solid platform that enables all hotel ownership modes and management modes, travel intermediaries and tourists to have a reliable third party protector of their transaction process in the distribution chain. The hotels have opportunities to gain direct access to the overseas travel companies to sell the products and services along with their local tour operators. In particular, the laws and legal documents of the government on banking, electronic transaction and consumer protection have helped hotels and their business partners as well as tourists have a more secured, trustworthy transaction and payment in a flexible structure of distribution. 
Second, the Vietnamese government has promulgated a number of legal documents such as decrees, ministerial decisions and guidelines to support the expansion and establishment of tourism distribution channels regarding patterns of international tourist demand. Some decisions such as Decision No 201/QD-TTg of 22 ${ }^{\text {nd }}$ January 2013 on approving Master Plan of the Vietnam tourism development to 2020, vision to 2030 and Decision No 2473/QĐ-TTg of 30 ${ }^{\text {th }}$ December 2011 to consolidate the tourism development strategy of Vietnam to 2020, vision to 2030, have created a legal basis for the hotels, travel companies and investors to build their products and services. This is because the target markets of the country, forecasted growth rate of domestic and international guests and an estimate of hotel room supply have been partially calculated in these two documents. In addition, two other important decisions of the Prime Minister have detailed the above master plan and the development strategy, namely Decision No 321/QD-TTg of $18^{\text {th }}$ February 2013 on approving the action plan of the government to promote the development of tourism in the period of 2013 to 2020 and Decision No 2151/QD-TTg of $11^{\text {th }}$ November 2013 on the implementation of the national tourism promotional programmes from 2013 to 2020. These two documents have forced the VNAT, relevant ministries and provinces to take practical actions in relation to tourism. For instance, the Ministry of Foreign Affairs and the Ministry of Public Security have proposed to the Prime Minister that visas to be waived for a number of target markets such as Scandinavian countries, Japan, Korea and Russia. The Ministry of Transportation has been also requested to facilitate conditions for numerous airlines to open direct flights from long-haul markets such as the UK and Western Europe. The decisions of the Prime Minister also created a legal basis for the VNAT to organise a series of promotional campaigns, for example, attending more international tourism fairs, widening the list of countries to organise Vietnamese Cultural Weeks and conducting better research to build up a database for the purpose of sales and marketing activities. To some extent, the legal system and other legal documents of the government have helped the hotels and travel companies gain access to the right markets, diversify guest origins, and develop distribution channels. Tourists have also benefited from some policies such as those relating to visas, electronic transactions, transportation, the transparency of star rated hotels and licensed tour operators across the country. 
Third, the legal system of Vietnam, however, needs to be revised to support the hotels in expanding and developing the hotel distribution channels to attract different types of guests, particularly FITs because of the international tourist demand, development of technology as well as the financial and banking system. Most of the participants noted that the strict visa issuing policy has emerged as a barrier having a huge impact on the hotel strategies of distribution channels and the target markets. It appears to be a problem for the development of hotel distribution channel structures since direct bookings and even indirect ones are easily made on the internet. A number of representatives from the hotels and travel companies specifically commented that Vietnam's visa policy should be more flexible and open like their neighbouring countries in order to attract tourists. For example, while Vietnam only waived the visa for tourists from ASEAN countries for 30 days (14 days for Brunei) and 15 days for tourists coming from Japan, Russia, South Korea and four Scandinavian countries, approximately 61 countries and territories can travel to Thailand without visa. For Malaysia, this number is about 155, and Singapore it is 150 (VNAT, 2015h).

To illustrate how the visa procedure has affected the hotel distribution channel structures, the representative from the Park Hyatt Saigon took an example that the Park Hyatt Corporation has three hotels in Hong Kong. When the Park Hyatt organized annual promotional campaign to introduce its hotel members to travel companies, these businesses said it was very difficult to sell tours to Vietnam although it only takes 2.5 hours to fly from Hong Kong to Vietnam. The visa fee and complicated visa processing procedure were hindering the growth of tourists from this market. In addition, the representative from the Rex Hotel $(\mathrm{SOH})$ in Ho Chi Minh City highlighted that the visa issuing procedure and the increased visa price applied have had an impact on the travel decision of international guests ${ }^{11}$ (MOF, 2012). The visa fee is not a big problem but processing time causes negative impacts for travellers, particularly FITs who often make an instant decision of booking hotel rooms for their holidays when they get deals of other services such as airfares (Cat Linh, 2015). In this way, the visa policy has forced the hotels to change the target markets and the ways that hotels employ channels to approach certain types of guests. Another example is that since a proposal of VNAT to waive visas for the Japanese tourists for up to 30 days rather than 15 days was

\footnotetext{
${ }^{11}$ From $1^{\text {st }}$ of January 2013, a single entry visa to enter Vietnam increased from 25 USD to 45 USD.
} 
refused, a number of travel companies like Apex Travel Vietnam have had to change their market segment and mode of cooperation to work with some Japanese counterparts. Some channel members which were designed and established to focus on the market of Japanese retirement guests were removed (GAFIN, 2012).

Under globalisation, some other legal policies such as the tax policy, consumer protection and internet information management have also influenced hotel distribution channels and the ways that the hotels establish their relationships with some international business partners. A number of the representatives from the hotels said that the Vietnamese policies on tax had partially prevented them from establishing and expanding cooperation with OTAs since the tax authority forced the hotels to collect tax from these OTAs when they have transacted bookings. This is because the OTAs gained benefits in Vietnam so they had to pay tax to Vietnam. As the Director of Sales and Marketing of the Rex Hotel in Ho Chi Minh City noted, an issue is that methodology is not consistent so the hotels had to explain it and took a lot of time to persuade the OTAs to finalise the payment. Some of the OTAs cooperated to deduct their profit by reducing the commission rate, but many others that did not accept have caused difficulties for the hotels.

The policies of consumer protection and the management of internet information were seen to not only influence the development of channels but also to reflect the quality of laws and level of Vietnam's commitment to protect its business environment during the integration process into the world. A problem occurred with social media networks such as Facebook and Twitter. Facebook is currently considered to be a very popular social communication channel for the hotels to implement sales and marketing there because the young generation relies on comments and recommendations on the Facebook rather than offline consultants. Compared with a tourist guidebook, a message on a social network is immediately measured, liked or commented on by users so the hotels can employ this channel to reach the guests (Deputy General Manager of the Caravelle Hotel and Director of Sales and Marketing of the Rex Hotel in Ho Chi Minh City). However, Decree No. 72/2013/ND-CP of the government issued to manage internet users on providing and using the internet services and electronic information has raised concerns from internet users and relevant parties. The Embassy of the United States in Vietnam (2013) stated: “we are deeply concerned by the decree's provisions that appear 
to limit the types of information individuals can share via personal social media accounts and on websites. In addition, this decree will limit the development of Vietnam's budding IT sector by hampering domestic innovation and deterring foreign investment". In terms of the legal system defending the hotels and international TOs, a reprentative of a $\mathrm{SOH}$ in Ho Chi Minh City noted:

Our laws need to be consistent with the world to protect the hotels and travel companies. For example, when our hotel cooperates with overseas travel companies, if there are problems of a difficult - to - collect debt, who will help us to handle this issue. That is one of challenges of the hotels and Vietnamese tourism companies. The government must amend the law system to support its business community.

Shortcomings regarding Vietnamese laws in the finance and banking sector are seen to have impacts on channel members and relationship between the hotels and their customers. The exchange rate, which was not stable, has affected the pricing policy of the hotels, travel companies and relationships between the hotels and their customers since room rates and tour prices have to be frequently adjusted based on the change of currency conversion rate. The Vietnamese law on consumer protection, banking and law on internet transactions also contains limitation regarding finance and banking as well as transaction across borders. To some extent, Vietnam needs to improve the legal system to defend the transactions between the hotels and their customers via internet or banking.

Another controversial law that has influenced the policy of selling rooms and the application of distribution channels was Decree No. 72/2009/ND-CP of $3^{\text {rd }}$ September 2009 and Circular No. 02/2001/TT-BCA of $4^{\text {th }}$ May 2001 of the Ministry of Public Security whereby a woman and a man are not allowed to share a room if they do not have a marriage certificate. This regulation is strictly applicable when a foreigner shares a room with a Vietnamese. To some extent, these two legal documents have affected distribution channels of the hotels to sell rooms directly to the free independent travellers or walk-in guests. This is because this type of guest normally decides to book a room with their partner since they meet with each other in social networks or 
somewhere at the destination (Director of Sales and Marketing of the Grand Hotel in Ho Chi Minh City).

Lastly, the follow-up action plans of the promulgated laws of the relevant ministries and the VNAT were also not sufficient to promote the development of distribution channels, affecting the hotel market mix and guest types. Hotels and tour operators have not yet benefited significantly from the tourism development strategy and marketing plan of the VNAT and the provincial tourism authorities. In general, respondents felt the policies sounded very good but actions were taken poorly (Director of Hanoi Tourist, a number of hotel representatives). Some other actions, for instance, statistics on domestic tourists and international arrival were too weak to support the hotels. Most of the hotel representatives noted that hotels annually have to build up sales plans and marketing strategies for the coming years in terms of identifying sources of guests and the growth trends. A lot of information regarding government policies, tourism reports and statistics in the hotel sector must be combined and analysed to expand or to adjust the distribution channel structure. However, these sources of data were seen as poor, inaccurate and unreliable or were very difficult to access. The statistics and forecast of government are thought to be exaggerated. Some hotels must invest money in conducting research or buying reports from consultant companies to forecast the market in order to structure their distribution channels. To deal with this, the IJVHs and the FOHs carried out their own research to analyse the market for the distribution strategy as they have sufficient budget to do so. In contrast, due to limited resources, the sales and marketing plans as well as the distribution strategies of a number of DPOHs and SOHs were mainly based on experience or copied from other types of hotel ownership. The unclear tourism development strategy and exaggerated statistics of the government led to a situation where the sales and marketing team of a number of hotels were pressed by the owners or general manager regarding the structure of distribution channels. This was commented on by a representative from a $\mathrm{SOH}$ in $\mathrm{Ho}$ Chi Minh City:

Currently, our tourism development policies are too general, statistics in the tourism industry are extremely unreliable. According to forecasts, the international arrivals have annually increased, but I see that the hotel occupancy rates fell significantly in the recent years although the supply of 
rooms increased slightly. The general manager of our hotel believes in statistics and reports of the government so we are in a very high pressure to find guests.

Likewise, the Director of Sales and Marketing of the Grand Hotel in Ho Chi Minh (SOH) commented:

In early 2013, according to the Ho Chi Minh City Department of Culture, Sports and Tourism, the number of visitors to Ho Chi Minh City would increase compared with 2012. In fact, a slowdown of international guests is seen and the average hotel occupancy rate of the city decreases as well. This fact leads to a high competition between the hotels, of course, the hotels have to invest in the development of distribution channels to have bookings. However, this indirectly reflects the fact that the tourism development strategy is not practical and scientific.

In short, the legal system of Vietnam plays a very important role in the establishment of distribution channel structures of different hotel ownership modes. Laws and legal documents have been promulgated and gradually revised in order to motivate the economic developments, the hotel sector in general and distribution channels in particular. To some extent, these regulations have created a legal platform for the different hotel ownership modes, hotel management types, travel intermediaries and travellers to meet with each other based on their demands in the distribution chain for products and services in a number of ways. However, a number of negative impacts on the hotel distribution channel structures were also seen by the industry practitioners.

\subsubsection{Vietnam's economic development}

The economic growth of Vietnam has influenced some internal components of different hotel ownership and management modes such as objectives and target markets, patterns of demand and the distribution channel structures as a whole. Participants noted that the economy of Vietnam has had a noticeable impact on the hotel sector, its sales and marketing strategy in general and the ways that hotels used distribution channels to approach the guests in particular. However, they also said this factor was a combination

of local and global economic development factors as the Vietnam's economy now has been gradually integrated into the world. For instance, as a consequence of being 
members of the WTO and a number of free trade agreements, Vietnam has gained certain achievements. It is estimated that Vietnam's GDP in 2015 will grow by an additional 2.37 percent (equivalent to 17 billion USD) in comparison with not being a member of the WTO (MPI, 2008). Conversely, global integration also causes negative impacts on the country when once the world's economy is not healthy. In this aspect, most of the representatives from the government did not mention directly how the economic growth affected the patterns of demand and the structures of distribution channels but information was given by some hotel representatives and also collected from secondary sources.

Vietnam's current economic downturn began in 2008 in accordance with the crisis of the world's financial system (Huyen Thu, 2013). The national GDP growth rate decreased from 8.48 percent in 2007 to 4.9 percent in the first six months of 2013 . The annual inflation rate reached about 20 percent in 2008 and remained in double digits in 2010 and 2011. The registered loans of foreign direct investments in Vietnam also went down dramatically, from 71.7 billion USD in 2008 to as low as 12.6 billion in the first eight months of 2012 (Huyen Thu, 2013). These key indicators of the national economy raised the concerns of numerous international organisations regarding the business environment, inflation, value of Vietnamese money and balance of payments. Vietnam's economic crisis has not yet witnessed a recovery from this downturn as growth is under the expected development trend though macroeconomic stabilization has been achieved (Leung, 2015). In the hotel sector, the high-end hotels' overall room occupancy rate in 2013 was also seen to reduce by 0.3 percent compared with the previous year (Grant Thornton Vietnam, 2013). These economic facts and figures were seen by respondents to directly cause negative impacts on the high-end hotels regarding the patterns of demand, and the distribution channel structures of different hotel ownership modes.

Firstly, the recent downturn of Vietnam's economy has had an impact on the four hotel ownership modes in terms of market mix, types of guests and distribution channels. Domestic tourists are becoming an important market segment of all hotel ownership modes since all the hotel modes recorded an increase of this type of guest, particularly the hotels in Danang where approximately 50 percent of their room nights were sold to Vietnamese travellers. However, the recent downturn of the Vietnamese economy has 
not only caused negative impacts on domestic demand, but also international business guests of the up-market hotels. This was mentioned by the Director of Sales and Marketing of the Prestige Hotel (DPOH):

In recent years, the Vietnam economy has experienced a slowdown. This affects the domestic market segment of the hotel, so we have to look for other sources of guests to maintain the revenue. However, the economic crisis of Vietnam also causes a decrease of international arrivals because of a sharp drop of business travellers. Of course, we have to think of restructuring distribution channels to get bookings, international tour operators will possibly receive close cooperation as most of the guests from them are leisure tourists.

Secondly, due to the negative influence of Vietnam's economy upon the macro business environment, room nights purchased by domestic and international business travellers had commonly reduced at all hotel ownership modes. This urged all the hotels to restructure the distribution channels because of the change of market mix, types of guests and the declined room occupancy rate. This is because government expenditure and company budgets on secondary tasks such as conferencing had been controlled and cut. This phenomenon was noticed by the Assistant to the Director of Sales and Marketing of the Renaissance Riverside Saigon (IJV), that is, the market mix and specific type of guests were closely related to economic growth. The recession of Vietnam affected her hotel's domestic market segment and business travellers as follows:

In the recent years, a number of Vietnamese and international business travellers went down dramatically because of the crisis of Vietnam economy. Most Vietnamese companies meet difficulties so they cut the budget for incentive holidays or conferences. Many international investors who work with Vietnamese business partners also choose teleconferences or Skype to organise their meetings instead of conventional ones.

Similarly, the Director of Sales of the Park Hyatt Saigon (an IJV) indicated the impact of the country's economic development and the needs to consider the hotel distribution channel structure: 
Vietnam's economy has recently witnessed a downturn, leading to a sharp decrease of Vietnamese and international business travellers coming to Vietnam. This trend has urged our hotel to conduct research, change the target market or type of guests as well as distribution channels to compensate for these losses. For instance, we will enhance cooperation with tour operators and third party websites to get bookings from leisure tourists.

Thirdly, a number of participants noted that most of the up-market hotels were observed to change their strategies of sales and marketing and channel members in response to the country's current economic status and the decrease of business travellers. The Director of Hanoi Tourist and the former Director of the Hotel Division of the Danang Department of Culture, Sports and Tourism took an example of the high-end hotels of the Muong Thanh Hotel Group (a domestic private property company which owns a number of hotels under the name of Muong Thanh plus location) to illustrate this situation. The Group's hotels attracted guests by dropping room rates and working with TOs had also become a priority to get the bookings of leisure tourists. However, as noted by these two participants, the hotels of Muong Thanh Group caused chaos in the hotel market since its member hotels competed with others by offering very low room rates to travel companies. Some participants from the travel industry in turn commented on the professional level of Vietnam hotels including the up-market ones on the ways that they cooperated with tour operators:

When the room occupancy rates of the hotels go down, the hotels attempt to work with travel companies and vice versa. In terms of distribution channel structure, we found that the hotels should have a positive cooperation with the tour operators in a professional manner, the two parties should treat each other as business partners. This is because the hotels cannot decide all of the target markets and market segments and tour operators are also unable to force guests to come to Vietnam (The Director of Hanoi Tourist).

Fourthly, Vietnam's economic development also caused some differences regarding patterns of demand and hotel distribution channel structures. The decrease of both local and international guests was the main reason why the hotels in Danang experienced a sharp reduction in occupancy rate of 8.2 percent in comparison with the previous year (Grant Thornton Vietnam, 2013). Domestic tourists who were known to have lower 
expenditure than international guests accounted for the highest proportion of room nights sold by DPOHs, partially representing an impact of Vietnam's economic crisis over the purchasing power of Vietnamese travellers. As mentioned earlier, most of the hotels restructured channel members to approach the markets by enhancing cooperation with tour operators and third party websites to seek opportunities of increasing room occupancy. As also noted by representatives from some state hotels, stopping contracts with GDS service providers will possibly save expenses since the return on investment of this channel was quite low.

\subsubsection{Vietnamese and international tourist demand}

The Vice Principal of the Hanoi Tourism College contended that domestic and international tourist demand is a factor not only influencing the way that the hotels establish and operate the distribution channel structures but also how hoteliers perceive management modes. This is because it directly creates the patterns of demand and other internal factors such as hotel products and services, objectives and target markets. In principle, the tourist demand towards a certain type of hotel ownership or an individual hotel management mode is generated and formed based on a combination of factors including technology, transportation, banking and financial development, tourist consumption habits and hotel brand. Demand differs across the markets, types of guests and age groups, requiring all the hotel ownership modes to conduct research or apply their experiences before putting a distribution strategy into practice. The impacts of domestic and international tourist demand on the distribution channel structure of each type of hotel ownership and hotel management are found in a number of ways as follows.

Firstly, the demand of domestic travellers has contributed to the shift of business objectives, market segmentation and target markets of the up-market hotels in Vietnam. In recent years, a number of Vietnamese have become increasingly wealthy because of the development of the private economic sector under the market-oriented economy and, as tourists they demand luxury accommodation while travelling. Up-market hotels have started to pay attention to this type of domestic guest with the initial purpose of increasing the room occupancy rate (The Chairman of VISTA). Later, as the General Director of the Hanoi Tourist noted, this domestic demand has greatly influenced the hotel market mix because the expenditure of domestic travellers who stayed at the 
luxury hotels was seen to be as high as international tourists so these hotels pay attention to widening this market segment. Moreover, most domestic leisure tourists who take holidays during the summer, which is the low season of international guests, have driven the hotels to shift the strategy of sales and marketing. Tourism in Danang is an example of the changing market mix and the seasonal phenomenon when the hotels categorise guests into two seasons: September to April is for international tourists, the rest of the year is for Vietnamese travellers. The emergence of domestic tourists on the one hand has changed the market mix of hotels, on the other hand, it has contributed to the creation of hundreds of domestic travel companies that have widened the distribution channel.

Secondly, the growth of international tourist demand has driven the hotels to design products and services and reconsider the ways that they approach their target markets. The Deputy General Manager of the Furama Danang took an example that a decade ago the demand for villa, apartment or holiday houses was low. This trend of demand has recently risen as international guests, particularly small groups or families are strongly supported by the internet to arrange their own travel. These guests feel comfortable to cook for themselves and join other activities separately. This kind of demand has urged hotels to build the products and the channels to reach these travellers. Tailor-made products and services were often purchased by a small group or a family. This type of guest preferred to use direct channels.

The growth of international tourist demand also encouraged the hotels to identify their target markets and to establish distribution channels. Some representatives from the hotels and international tour operators noted that over 1.1 billion tourists travelled abroad in the world in 2014 (UNWTO, 2015). Many of them are predicted to choose destinations in the Asia-Pacific and the Southeast Asia regions for their holidays because of reasons such as avoiding terrorism in other regions or enjoying tropical weather. Therefore, there is an opportunity to increase bookings and both hotels and TOs will carry out a number of strategies to target international markets. The Director of Sales and Marketing of the Rex Hotel ( $\mathrm{SOH})$ in Ho Chi Minh City mentioned a relationship between the growth of international guests with the ways that his hotel design distribution channels: 
Of course, the demand of international guests has a direct influence on the establishment of hotel distribution channels. For example, when the Australian market is good, a number of Australian tourists increase. The hotel must consider Australia as a target market and prioritise resources to design channels to reach that market such as participating in travel fairs and events in Australia. Absolutely, the hotel also looks for travel intermediaries that are strong at the Australian market to cooperate.

Third, the tourist demand supported by the development of technological advances and financial and banking development at the national and international level has influenced how the different hotel ownership and management modes structure their distribution channels. Most representatives from the hotels and some tour operators mentioned that older persons usually look for information of holidays in a traditional way by reading books or newspapers and these guests tended to book hotel rooms or their trips via traditional travel companies or travel agents. In contrast, the young generation is likely to search and purchase rooms through the internet. However, a shift of international tourism demand towards the purchase of Vietnam hotel products and services was seen. In the last few years, the majority of tourists coming to Vietnam booked rooms and their holidays through traditional travel companies or central reservation systems. At present, with the development and impact of technological advances, many of them prefer to use OTAs or other online means of bookings to reserve rooms instead of GDSs and CROs. In short, the tourist demand has challenged the hotel ownership and management modes to apply a variety of distribution channels: direct and indirect ones, electronic or conventional.

\subsubsection{Vietnam and international technological advances}

In this section, information and communication technology (ICT) and its development are referred to as the element of technological advances of Vietnam and the world influencing the hotel distribution channel structures. This factor, as most of the participants commented, has had positive impacts on the hotels' sales and marketing as well as on their distribution channels. However, representatives from the government and the travel industry contended that the adoption of ICT differs across hotel ownership modes, that is, the Vietnamese owned- and -managed hotels, particularly the 
DPOHs, have not yet taken the advantages of ICT to effectively structure their distribution systems compared with what the IJVHs and FOHs.

Firstly, ICT has considerably influenced the ways that the hotels approach markets by employing direct and/or indirect distribution channels. A representative from the Park Hyatt Saigon (IJV) said that Vietnam's ICT infrastructure and technical development level have reached world level and this basis enabled the hotels to use the internet to reach guests. Within the Hyatt group, the ICT not only plays a huge role in the sales and marketing strategy but also it is used to measure the effectiveness of different distribution channels. Based on computerised analysis, the hotel structured its distribution channels by employing modes of cooperation with business partners or promoting direct sales. More specifically, representatives from the Grand Mercure Hotel (IJV) in Danang and the Rex Hotel (SOH) in Ho Chi Minh City mentioned the relationship between the ICT and the domestic market as well as possibilities to restructure distribution channels towards local travellers. In Vietnam, over one third of the Vietnamese population was using smartphones in 2014 (Thanh Truc, 2014) and there were approximately 33 million internet subscribers in 2013 (Chau An, 2014). The number of ICT consumers suggested that the hotels could approach them electronically and directly to increase profitability instead of conventional channels.

Secondly, ICT has played an important function in the growth of market shares of the hotels by developing electronic channel members and direct sales. A participant from Saigontourist highlighted that the hotels used to find opportunities to directly deliver brochures and leaflets to the end guests and travel intermediaries or at tourism fairs. However, both local and international travel companies or tourists are nowadays able to easily search the relevant hotels in Vietnam through the internet, generating opportunities for the hotels to connect with potential guests by utilising ICT. Moreover, the development of ICT has supported the hotels to get in touch with customers quickly via email, social networks or websites (Director of Sales and Marketing of the Green Plaza Hotel, a DPOH in Danang). If a hotel website is well designed, it not only attracts the end customers to book directly but also it is very useful for travel intermediaries to look for information and to recommend the hotel to their business counterparts in the international markets (The Director of a branch of the Vietran Travel in Ho Chi Minh City). 
Specifically, ICT has greatly impacted on the establishment of direct and indirect distribution channels. This factor has also contributed to changing relationships between customers and channel members. In this regard, the Director of Sales and Marketing of the Grand Hotel, a SOH in Ho Chi Minh City, said:

If the hotels categorise the guests based on their age to develop the structure of distribution channels, the young generation is now in favour to use the internet to organise their trips. They can sit at one place to find flights, booking rooms and other land services at the destinations. Consequently, ICT has been the strong factor influencing to the organisation of hotel distribution channels. It is also pushing travel companies to become the secondary business partners of the hotels.

Thirdly, the Director of Sales and Marketing of the Rex Hotel in Ho Chi Minh City noted that ICT is also affecting the future development of distribution channels. Conventional travel companies will gradually disappear because there is an increasing number of guests using the internet and smartphones to book hotel rooms and to arrange their travel via hotel websites, online travel companies and other online service providers. He gave the example of an American tourist using a smartphone to book rooms and other services for a trip in Vietnam; it is easy to get online advice from social networks about where to stay and eat and about land services. By doing this, the offline travel intermediaries are losing their functions and will likely decrease. This phenomenon happens widely since the young generation strongly believes in the recommendations or online comments on social networks rather than consulting travel agents. To illustrate this, a representative from a $\mathrm{SOH}$ in Ho Chi Minh City emphasised the result of ICT development on the patterns of demand and distribution channels:

Because of the development of ICT, the holiday booking habit of the young generation differs with other age groups. They can change jobs quickly or decisions are changed quickly as well so the habit of booking the holidays far prior to the departure is going to disappear. Therefore, the structure of distribution channels is also structured based on that trend. In fact, the direct distribution channels used to contribute a negligible proportion of room nights 
(about 5 to 7 percent of total), nowadays, direct sales channels even generate approximately 30 to 40 percent.

\subsubsection{Financial and banking development}

Of the six functions of distribution channels mentioned in Chapters 4 and 5, making payment for products and services is essential to complete the process of searching, getting advice, negotiating and booking. In the structure of distribution channels, the payment function also plays an important role in assisting travel intermediaries and hotels to pay commissions or fees to their business partners. Financial and banking services of Vietnam and the world are therefore becoming one of the factors influencing the patterns of demand and the development of distribution channel structures.

According to the participants' comments, the financial and banking development level of Vietnam has reached an international standard, enabling the up-market hotels to establish direct and indirect channels. Previously, a small number of credit cards were accepted in Vietnam since banking development was not as advanced as in other parts of the world. Consequently, the hotels faced a lot of challenges to handle the payments of international guests. To some extent, this had affected how hotels organised their distribution channels, particularly direct sales via hotel websites. Currently, this factor has a small impact because the level of financial and banking development of Vietnam has gradually reached the global standard. In particular, the emergence of some international brands of banks in Vietnam, such as ANZ, HSBC and City Bank, has enhanced the reputation and trust of the Vietnamese system of finance and banking. Most of the popular credit cards are now accepted by the high-end hotels including American Express, Visa, Master Card, JCB, Diners Club, Discover and UnionPay (VTIR, 2015). These are favourable conditions for the high-end hotels to expand and develop either direct or indirect distribution channels (The Director of ITDR and the Director of Office Administration of VNAT).

However, a number of representatives from the SOHs, DPOHs and the Vietnamese government noted that security issues in the monetary system and trust in credit card payments managed by Vietnam are still not high enough to meet current international requirements, causing some hesitation of guests, particularly the FITs, to buy the rooms of the Vietnamese owned- and -operated hotels. For instance, online payment made via 
the IJVHs' websites is often protected by companies such as GlobalSign, Thawte and TrustedSecure but there are only a few Vietnamese owned- and -managed hotels using these services. This is one of reasons that SOHs and DPOHs meet difficulties in attracting the FITs or direct bookings compared with their internationally owned counterparts. For the domestic market, according to a recent report of the Vietnam State Bank, approximately 68 million ATM cards had been issued by numerous banks but credit cards only accounted for about 3.6 percent (equivalent to 2.43 million cards). Fees are the reason for the low number of Vietnamese credit cards since the holders bear high interest rate from 1.25 to 2.65 percent per month together with other payments such as annual fee, late payment fee (VTIR, 2015). Accordingly, a number of domestic guests use credit cards to pay for their bookings are small.

\subsubsection{International transportation to Vietnam}

Regarding the development of distribution channels, most participants contended that transportation, especially international airline routes to Vietnam, has also played an important role. The Deputy General Manager of the Furama Danang (DPOH) noted that if there were no airline routes or few carriers operated other modes of transportation to connect the main tourist-sending countries to Vietnam, the hotels would certainly not waste much money and other marketing resources on marketing the hotels' products and services to those markets. Similarly, the Director of the Hanoi Tourist highlighted that the hotels were likely to attempt to develop direct distribution channels to approach the markets where direct flights or a flight with a stopover(s) are available. For less well connected markets, hotels normally cooperated with travel companies to reach markets. In fact, gaining access to Vietnam directly via airlines is still difficult for international guests from long-haul markets since many flights stop at Thailand or Singapore. Therefore, the development of transportation speeds up the development of direct distribution channels.

\subsubsection{Ownership and management modes}

As mentioned earlier section, the multi-ownership economic modes are regarded as one of the central issues of the socialist market-based economy in Vietnam. Ownership modes in the Vietnamese hotel sector not only are in close relation to hotel resources, products and services, business objectives and hotel target markets but also ownership influences the hotel management modes and the entire distribution channel structure. 


\subsubsection{Ownership modes}

First, the four ownership modes: state, domestic private, international joint venture and the wholly-foreign owned hotels have developed along with the country's economic history since 1986 representing the transition process to a market-oriented economy in Vietnam. Before 1986, the Vietnamese hotel sector was categorised as a non-production industry. Profitability was not the objective of state hotels that were run under the centrally planned economy. The concept of markets and competition had also been far from the Vietnamese people's mind as the state hotels' operation fully complied with the allocation of guests from the government. After 1986, the monopoly was partially removed and the multi-ownership economic structure was progressively implemented under the socialist market-oriented economy. The SOHs now account for a small proportion of the entire hotel sector (Section 4.2) since there has been a boom in tourism development and the number of non-state owned hotels. In addition, most of the SOHs were privatised and equitised to operate under the market mechanism. However, the legacy of command economy is found because the government still holds over 51 percent of capital in the privatised and equitised SOHs alongside the 100 percent stateowned ones. Apart from the target of revenue and profitability, the SOHs now have to meet a number of objectives in terms of politics, social affairs assigned by the parent organisation and government departments.

Table 7.1. Hotel ownership and management modes of the hotels studied

\begin{tabular}{|c|c|c|c|c|}
\hline \multirow[b]{2}{*}{ Hotel } & \multicolumn{4}{|c|}{ Management Model } \\
\hline & $\begin{array}{c}\text { Semi- } \\
\text { independent }\end{array}$ & Independent & Franchising & $\begin{array}{c}\text { Managemen } \\
\text { Contract }\end{array}$ \\
\hline State owned $(n=8)$ & 8 & & & \\
\hline Domestic private $(\mathrm{n}=14)$ & & 12 & 2 & \\
\hline International joint venture $(\mathrm{n}=18)$ & & & & 18 \\
\hline Foreign owned $(\mathrm{n}=2)$ & & & 2 & \\
\hline
\end{tabular}

Source: Interview Data, 2013

The multi-ownership structure has significantly motivated both domestic and international capitalists to invest their money into high-end hotels, driving them to 
select an appropriate mode of management (see Table 7.1). All of the SOHs have so far applied the semi-independent management mode with both a parent department and a representative of government at the SOHs in charge of running hotels (Section 4.2). Most of the DPOHs operated their hotels themselves though the two are under a franchising agreement with international hotel chains (Section 4.3). All of the IJVHs were managed by international hotel groups (Section 5.3) and the two FOHs examined were the franchisees of international hotel brands although these brands were less wellknown in the global hotel industry.

To some extent, the management mode applied by hotel ownership types is explained as follows. In Vietnam, the non-state hoteliers who are legally recognised to decide their modes of investment and management mode are allowed to design the products and services to meet the market demands for maximum profitability. In other words, the domestic private, international joint venture and wholly foreign owned hotels have been running their business based on the priority of revenue and profitability. These hotels' owners were able to select the mode of management to operate their hotels. SOHs are different because the state hotels have so far been managed by the government, although in a pilot programme in Ho Chi Minh City there are plans for some renovated hotels of Saigontourist (a state-owned company) to be managed by international hotel groups (The Deputy Director of the Office Administration of VNAT, the Director of ITDR, the former Director of Hotel Division of the Danang Department of Culture, Sports and Tourism, VNAT, 2012b). The ownership structure was explained by the Vice Principal of the Hanoi Tourism College:

In Vietnam, the nature of ownership closely relates to the cognition, knowledge and financial resource of hotel owners. If possible, the hotel owners could completely hire a good general manager, good staff to run their hotels. They could also sign contract with an international hotel group to manage the property or to be franchised. The decision is the hotel owners but this varies among types of hotels

Similarly, a representative of the Danang Department of Culture, Sports and Tourism emphasised the relationship between ownership structure and the function of owners 
who made a key decision of hotel operation regarding the management mode and organisational structure to operate the hotels based on the knowledge of hotel owners.

Ownership and the hotel owners are important. But knowledge and experience of investors vary among hotel ownership modes. For example, the state owned and managed hotels normally achieve low efficiency in terms of revenue because of their bureaucratic organisational structure. Most of the domestic private owned and managed hotels are not professional except the ones franchised with international hotel groups. The hotels of the Muong Thanh Hotel Group [DPOH] are other examples, they have attempted to enter the market by dumping the room rates and cutting the service standards.

The Deputy Director of the Vietnam Railways Trade Union Tourist Service Company highlighted the nature of SOHs' organisational structure in relation to management mode:

The ownership structure created the differences of organisation among types of hotel. For example, the General Manager of the SOHs must follow the direction of those in higher position in the government. These persons advised him or her to do this or not to do that, they are also deeply involved in the recruitment of employees and finance. Therefore, the decision of SOHs in terms of pricing normally takes a longer time.

The General Director of Wildlotus Travel in Hanoi commented that ownership structure relates to the management mode of hotels, target of profitability and the effectiveness of using distribution channels. The owners of SOHs are the government but in Vietnam the state properties belong to the people so everything seems to be unclear.

First of all, ownership relates to the way that the hotel owners attempt to raise the profitability of their hotels or not. From this point, hotel organisational structure, marketing budget and other resources for establishing and running distribution channels are identified. The SOHs are an example, the pressure of profitability of these hotels is not high compared with other hotel ownership modes. This leads to the fairly poor quality of distribution channel members. 
Indeed, the ownership mode has a strong effect on the mode of hotel management and the level of professionalism of the hotels. The financial resources, experience and knowledge of foreign investors in the IJVHs and non-Vietnamese-owned hotels have allowed them to choose the franchising and/or management contracts with international hotel groups that were believed to be better in terms of establishing distribution channels to reach the guests. For instance, after a Director of Sales and Marketing of a $\mathrm{SOH}$ had completed the official interview, he added confidentially that the average room rate occupancy of the SOHs was much lower than published or reported. He also mentioned that the occupancy rate of the IJVHs was recorded as much higher than those of Vietnamese-owned and -managed hotels. The professionalism level varied among hotel ownership modes in different ways: (1) the actual percentages of domestic guests who stayed at the Vietnamese-owned and -managed hotels was higher than other types of hotel ownership; (2) the IJVHs and FOHs sold a higher number of room nights to business travellers in comparison with the Vietnamese-owned and -managed hotels and (3) direct distribution channels generated a higher proportion of room nights for the IJVHs than those of the SOHs and DPOHs.

Second, ownership mode influences the hotel resources, objectives, target markets and market segments of the selected hotels. As discussed in Section 4.2, the SOHs were primarily hotels built in the middle or last decades of the $20^{\text {th }}$ century, with the limited resources, experience and level of professionalism of the parent companies in expanding and renovating resulting in their current size and the nature of products and services. The domestic private entrepreneurs who appeared as a consequence of economic transformation are in the initial process of stepping into the hospitality industry and accumulating capital to invest in the larger hotels. They may have money but lack hotel management experience. The foreign investors who are recognised as being more knowledgeable, having rich experience in hotel management and financial resource compared with the local hoteliers started up their businesses in Vietnam under joint ventures or 100 percent foreign owned enterprises late in the $20^{\text {th }}$ and beginning of the $21^{\text {st }}$ century. The IJVHs and FOHs are known to be larger in scale and more professional than the Vietnamese ones. These inherent facts which influenced the business objectives, target markets and market segments of the hotels were commented on by the Director of Environmentally Socially Responsible Tourism Project under the Ministry of Culture, Sports and Tourism: 
Depending on the investment quality and scale, hotels will focus on certain target markets. For example, the state owned and managed hotels are normally the medium scale and quality level, so these hotels only meet the demands of some markets such as the government officials, a specific number of domestic guests and the middle income inbound guests. For the IJVHs and the FOHs, their overall quality of facilities and services are much higher than the Vietnamese partners, so their target markets are of the high to very high expenditure tourists. The market segments of the FOHs are relatively different with the Vietnamese counterparts because of the better investment quality, facilities and management.

Likewise, the Chairman of VISTA noted the relationship between ownership, hotel quality and patterns of demand and sales among types of hotel ownership:

The ownership forms have consequently created differences in target markets, market segments, the various structures of distribution channels throughout the four types of tourist property and so on in Vietnam. Hence, ownership decides the mode of hotel operation that influences the efficiency of hotel business.

Third, ownership modes have created differences and similarities among hotels in terms of business objectives and the nature of products and services. Most hotels have been continuously looking for various sources of high expenditure guests regardless of the market mix by building up sales and marketing strategies. However, the specific markets approached by the hotel ownership modes are different. The SOHs' facilities and amenities were considered to be fairly out of date compared with other ownership modes, and they also have close relationships with the government departments, leading to the strength of serving the government departments' guests and the local tourists who were known not to require the high standard of facilities and services. The Victory Hotel in Hanoi (SOH) is an example: approximately 40 percent of its room nights were sold to domestic guests. For some of the domestic private owned and managed hotels, their target markets were comparatively unclear (Section 4.4). In contrast, the foreign owned hotels, particularly the IJVHs, identifed the market segments clearly because most of them were managed by well-known hotel groups based on internationally accepted quality of facilities and services with the strong advantages of global network 
of sales and marketing. Accordingly, international guests who are known to be the higher expenditure tourists compared with the locals are the target markets of these hotels (The Director of ITDR, the General Secretary of VITA, the Deputy Director of Travel Department, VNAT, the Director of Hotel Management Division, the Ho Chi Minh City Department of Culture, Sports and Tourism).

Explanation for these similarities and differences was mentioned by a number of participants based on the initial investments, and sales and marketing strategies of hotel modes. The up-market hotels, especially the IJVHs and FOHs, normally targeted certain markets or market segments when investment decisions of owners were made. This type of investment was particularly practical since feasibility studies of projects were carried out carefully to make sure that hotels would generate profit. Most interviewees from the government departments also commented that better sales and marketing strategies were actively undertaken by the IJVHs and FOHs compared with domestically owned ones. After about 30 years of Vietnam's economic renovation and international integration, although the gap among types of ownership has been gradually narrowed because of the increasing exchange of knowledge of hotel management brought in by the IJVHs, the SOHs and DPOHs have still paid limited attention to the sales and marketing activities. The Vietnamese-owned and -managed hotels, particularly the SOHs, have benefited from their convenient locations for hospitality business in the cities and the long history of operation, so a number of guests of these hotels themselves find by chance rather than the result of marketing.

Fourth, the ownership mode influences the establishment of distribution channel structures of different ownership modes. Ownership indicates the investor(s) with the power to make decisions and to be responsible for the efficiency of hotels. In general, the high-end hotels all need to establish a wide range of channels and channel members to sell their large number of rooms via online and offline channels because neither direct nor indirect distribution channels alone can deliver the desired profitability for hotels. All of the hotel ownership modes know this, but, selecting and combining channel members to structure the distribution system varied from mode to mode. This point is clearly explained by taking the case of SOHs and DPOHs as follows. 
In general, the SOHs were partially affected by the old management mode during the command economy in the way that sales and marketing activities were carried out. The SOH general managers' background was commonly from another industry, the preliminary condition of holding their hotel management position being that he or she was a government official and a member of the Vietnamese Communist Party. This condition may lead to bureaucracy of hotel organisation, for instance, the SOHs all have a Division of Communist Party that some Communist members are in. This type of organisation is not yet found in the non-state hotels although the Vietnamese Communist Party issued a Directive No. 07-CT/TW on 23 November of 1996 on developing members of the Communist Party in the domestic private, joint venture and foreign owned enterprises.

To some extent, the structure of distribution channels used by SOHs looks relatively the same as the structure applied by the IJVHs but the quality of some channel members of the SOHs and DPOHs such as websites, email and telephone responses were poorly funded or lacked professionalism. Resources invested in establishing and operating some distribution channels were considered like pouring salt into the sea (The Director of the ITDR). In other words, the budget for sales and marketing of SOHs and DPOHs was unable to cover all markets. Moreover, the flexibility of the sales and marketing team of SOHs was also low because this strategy also needed approving by the parent government department before implementation. These facts led to the poor quality of some channel members and how they were combined to undertake the distribution of SOHs.

The domestic private hotel owners were more practical compared with the SOHs when seeking a range of members in their distribution channels. General Managers of the SOHs sometime needed appreciation from their parent organisations and the government so they reported using a wide range of channel members as one of their good achievments. For the DPOHs, the background of the hotel owners and the familybased management mode strongly influenced the way that hotels cooperated with direct and indirect channels. Most of the DPOHs preferred to work with traditional travel intermediaries rather than electronic channels. In this regards, the Director of ITDR emphasised the growth of the SOHs and DPOHs in terms of sales and marketing as follows: 
After 30 years of economic transformation, the state hotels and domestic private owned hotels have not yet established significant strategies of sales and marketing, many bookings and business partners come to them naturally rather than their own efforts of seeking markets. They have inherited the sales and marketing outputs of other large hotels [the IJVHs and FOHs], of tour operators and the country.

Section 7.2.3 futher discusses how the IJVHs and FOHs have influenced the sales and marketing activities of the SOHs and DPOHs.

In short, the ownership mode not only influences hotel capacity and patterns of demand but also it strongly determines the distribution channel structures. Apart from these direct influences, ownership also generates a series of other supplementary factors affecting the above distribution channel structure such as the choice of management mode, hotel resources, hotel objectives, the nature of products and services and hotel target market that the following section will discuss.

\subsubsection{Hotel management modes}

Along with ownership, the management mode employed is increasingly becoming an important factor influencing the hotels' nature of products and services, business objectives and target markets as well as patterns of demand and distribution channel structures. This aspect was mentioned by a number of representatives from the government that international tourists strongly consider the hotel brand when selecting the hotels to book and mostly chose those managed by global hotel groups. This influences aspects of the distribution channels used. Most respondents also noted that the hotels which are operated by global hotel chains normally establish their distribution structures based on the high performance of their staff, international networks of sales and marketing and the marketing budget of the parent chain. That is currently the case of the IJVHs in Vietnam. In contrast, poorer management performance, weak brands and limited financial resources were seen at independent and semi-independent hotels (e.g. SOHs and DPOHs; see Table 7.1), leading to the limitation of hotel capacity, their current markets and distribution channel structures employed. This was mentioned by the Director of Sales and Marketing of the Rex Hotel ( $\mathrm{SOH}$ in Ho Chi Minh City) as follows: 
The current management mode of our hotel influences the establishment of distribution channel structure. I mean, international chain hotels are examples, they have rich resources of marketing. The IHG group has about 15,000 members throughout the world, each hotel contributes a drop of water to the marketing budget so the IHG has a sea of money. Our hotel with limited resource only learns, copies and uses the appropriate techniques that international hotel groups have been applying.

Likewise, the Director of Sales and Marketing of the Grand Hotel, which is also a member of Saigontourist like the Rex Hotel, highlighted the disadvantage of the SOH semi-independent management mode regarding the sales and marketing strategy and the development of distribution channel structure:

The Grand Hotel itself is also managed by the parent company [Saigontourist]. Once the parent company approves the sales and marketing plan, revenue and staff, the hotel will start to carry out our own plan. This administrative procedure makes our hotel loose flexibility. In contrast, the general manager of the non-state hotels, particularly the IJVHs, have a clear right to plan their sales and marketing strategy.

Furthermore, the Director of Sales of the Hanoi Daewoo Hotel (a domestic private hotel that is franchised with the Daewoo International Corporation) noted that his hotel's brand of Daewoo only brought a small advantage in the Korean market as this name was not famous in the global hotel industry. Support from the Daewoo International Corporation in terms of hotel sales and marketing was also weak because of the corporation's background outside tourism. He said that it was fine if the Hanoi Daewoo was understood as an independent hotel since room night sold via travel intermediaries generated a large proportion of room sales for such hotels (Table 4.1 and 4.5):

Hotels such as the Hanoi Daewoo Hotel only carry out limited sales and marketing. A hotel managed by a global hotel group is supported remarkably by the sales and marketing network of the chain. We ourselves have to undertake everything, so the hotel is very reliant on travel intermediaries to approach the international markets. 
Indeed, the hotels managed by international hotel groups have a lot of advantages in terms of undertaking sales and marketing strategies including attracting direct bookings and working with travel intermediaries to develop distribution channel structure. These prominent advantages originated from the hotel brand, the worldwide network of sales and management experience. These were confirmed by the Assistant of the Director of Sales and Marketing of the Renaissance Saigon Riverside Hotel (IJV in Ho Chi Minh City):

Regarding the management mode of our hotel, Renaissance is a brand of the Marriott International so we strongly benefit from the global network of sales and marketing. It could be said that this factor determines the success of sales and marketing of our hotel.

Some representatives from the travel industry also discussed the relationship between the hotels managed by global hotel groups and the development of their distribution channel structures. They mentioned that criteria that intermediaries used to select the hotels to cooperate with mainly consist of (1) hotel location, (2) the appropriateness of hotels' products and services with companies' target markets, and (3) the selection of overseas wholesalers. Among these criteria, the viewpoint of the wholesalers appeared to be the most important condition because most of the Vietnamese tour operators' markets are dependent on their foreign counterparts. In addition, overseas travel companies normally have a good understanding of international hotel brands. Accordingly, the Vietnamese tour operators followed these instructions in order to save time in introducing the Vietnamese hotel products and services to the overseas business partners. To detail this point, the Former Director of Hotel Division of the Danang Department of Culture, Sports and Tourism contended:

The international tourists and oversea travel intermediaries are likely to trust the global branded hotels. This is because the tourists often do not know the hotel until they check in. The oversea travel companies, which are the customers of the hotels, are also unable to inspect the hotels frequently. Therefore, the well-known brands of the hotels are very important. 
The IJVHs actively participate in global marketing and distribution chains to sell their products and services. Single hotels within chains or franchisees were strongly supported by the global networks of sales and marketing. Many of the IJVHs in particular only handled sales at the destination because the marketing actions to certain markets were mainly undertaken by their groups' regional and global sales offices. This was noted by the Director of Hanoi Branch of the Phoenix Voyages Travel:

International hotel chains themselves have a lot of advantages compared with the independent hotels [and semi-independent]. For instance, the room occupancy rate of the Hotel Sofitel Legend Metropole Hanoi managed by the Accor Group was always full in the last May and June [2013]. This rate was supported by the overseas sales offices [of Accor]. The hotel cannot be reliant on the Vietnamese travel companies to sell over 300 rooms a day.

From the advantage of being a member of the chain, markets of the IJVHs were also segmented because of the particular strength of each management company. The Deputy Director of Office Administration of VNAT noted:

Some examples of foreign related hotels' markets are listed as follows. The Hotel Sofitel Legend Metropole Hanoi is always the first choice of the French tourists, the Nikko Hotel focuses on the Japanese guests, the Hilton Hanoi Opera is strong at the American market and the Grand Plaza Hotel is for Korean guests. In contrast, the Vietnamese owned and managed hotels are the top priority for the Vietnamese tourists or the government departments' guests.

More specifically, management mode and hotel resources influence the distribution channel structures regarding direct and indirect channels. For the IJVHs and FOHs, the global involvement and stronger financial resources of these hotel owners presented premier ability, reputation, experience and management knowledge compared with the Vietnamese counterparts. These factors allow the IJVHs and FOHs to use effectively direct distribution channels to approach guests. In this regards, the Director of ITDR said: 
For the direct distribution channels, most of the up-market hotels have made their ultimate efforts to enhance the sales volume via direct distribution channels, particularly their own website. However, while hotels owned and managed by international hotel chains are taking great advantages of their reputation, resource and experience in using direct channels to reach the guests, the less well-known and independent hotels owned and operated by the Vietnamese meet difficulty in gaining access directly to the end consumers.

Likewise, the General Secretary of the Vietnam Tourism Association contended that the SOHs and DPOHs were often operated by inexperienced managers, their staff were also not well trained. These two factors were compounded by limited investment in sales and marketing, leading to difficulties of carrying out direct distribution channels. In contrast, he said: "the IJVHs and FOHs are using effectively the selected direct and indirect distribution channels to approach the guests. Due to their better resources for sales and marketing, professional staff and reputation, these hotels are becoming less dependent on travel companies".

In particular, the management mode represented the professionalism level of the hotels in the way that they cooperated with travel intermediaries to construct their distribution structure. In other words, different hotel management modes showed a variation of combining multiple channels to approach guests. On the one hand, the IJVHs and FOHs attempted to develop sales via direct distribution channels, on the other hand they still kept close contacts with tour operators. In contrast, the SOHs and DPOHs showed a difference since a number of tour operators complained that they met difficulty in sending guests to these hotels in the high season because they refused bookings although agreement contracts were signed and rooms were found to be available. This was noted by the Deputy Director of Vitour in Danang:

For the foreign invested and managed hotels, apart from the cooperation with some conventional travel intermediaries, they are quite strong at direct distribution channels because of their financial resource experience. However, these hotels are very professional since they always attempted to allocate rooms for local travel companies and overseas wholesalers for sustainable development. 
The sales policy applied by international hotel groups was implemented consistently according to contracts and their recognised standardisation. The representative of Vitour noted that pricing policies of IJVHs and FOHs were not as flexible as the hotels directly managed by owners: the SOHs and DPOHs. This was one of the reasons why travel companies often complained about Vietnamese-managed hotels since contracts were not always respected. The relationship between distribution channel structure and the professionalism of hotel ownership was also indicated by the Director of the Asianway Travel Company in Hanoi:

The foreign owned and place a very high pressure on sales and marketing staff to get bookings so these hotels normally have a good relationship with travel intermediaries. The quality of working with channel members to gain bookings from other types of hotels, particularly the state owned hotels, is still limited. Probably, the pressure of revenue of the SOHs is not high.

The Deputy Director of the Vietnam Railway Trade Union Tourist Service Company summarised the ways that different hotel ownership modes structured distribution channels, undertaking and following up differently to complete a circle of products and services because of the management mode used. He said:

Although the structure of distribution channels applied by the four hotel modes looks relatively the same, the quality of them is quite different. First, many SOHs found our company from the internet and tried to send us agreement contracts, they sometimes ignore the follow-up actions such as how we pay attention to the contract and the way to keep in touch. In contrast, the IJVHs establish the structure of distribution channels quite well based on professional team of sales and marketing. They meet us frequently to update room rates or promotional programs. Once bookings are made, they cooperate carefully with our company to serve guests.

However, the Deputy General Manager of the Furama Danang (DPOH) that used to be an IJV managed by the Furama Hotels and Resorts International argued the advantage of the hotels managed by international hotel groups regarding the distribution channel structures. He was not sure about the future growth of this management mode and its 
above mentioned advantages since the rapid development of the internet has allowed tourists to arrange their own holidays by purchasing hotel rooms and land services separately and conveniently. The internet and the appearance of numerous online sales and marketing service providers also permit the hotels to carry out the distribution channel structure independently instead of spending money for international hotel chains. He said:

I think many hotels will stop contracts with the managing companies to return to the independent mode because the world is now flat. Companies and hotels themselves can sign the contract of using GDS with numerous providers. I also think that, there are fewer and fewer guests using the websites of hotel groups to find rooms. For example, the site www.accor.com will attract less customers because tourists will look around third party sites such as www.agoda.com for where to stay. If the website of Accor only provides a certain number of its hotels in a certain place, there are a wide range of hotels that appear in the third party websites within a city or across the country for guests to make any comparisons.

In summary, the management modes applied by the hotels have brought in their advantages and disadvantages in terms of structuring the distribution channels. These points also lead to commonalities and differences of the structures of distribution channels. While the semi-and independent hotels with limited resources learn, copy and use the appropriate techniques that international hotel groups have been undertaking, the hotels managed by international hotel groups have a lot of advantages to carry out the sales and marketing strategies such as mixing distribution channels, attracting a variety of direct bookings, working with travel intermediaries professionally to develop the distribution channel structure. These prominent advantages originated from the hotel brand, the worldwide network of sales and management experience. In addition, the management mode and hotel resources as well as hotel brand also have affected the hotels' patterns of demand because the nature of products and services, objectives and target markets of each hotel management mode that will be discussed in the following sections are seen to be slightly different. 


\subsubsection{Other factors within ownership and management modes}

\section{Nature of products and services}

As a result of the ownership and management mode, the nature of products and services of the up-market hotels was categorised into two groups: the SOHs and DPOHs and the IJVHs and FOHs. These differences in products and services lead to the difference of the patterns of demand that were mentioned earlier and the proportion of room night sold via direct and indirect channels in the distribution channel structures. This was noticed by the Director of the Hanoitourist Travel in Hanoi:

Because of the limited quality of facilities and services, a large number of guests of SOHs and DPOHs are local tourists or medium range international guests, there are few free independent and business travellers who stay at these Vietnamese owned and managed hotels.

The Tour Operation Manager of Apex Travel Vietnam in Ho Chi Minh City also emphasised that hotels' products and services closely relate to the selection of the hotels to send his company's guests to. Most of the IJVHs and FOHs meet the requirements of tour operators and the end guests, particularly the high expenditure tourists from certain markets. He said:

The main source of our company's guests is the Japanese tourists with the high requirements of products and services. Approximately 80 percent of hotels that we are sending guests to are the IJVHs. This is because most of our guests want to stay at globally guaranteed standard hotels. [...]. In the future, the Apex Travel will still select the IJVHs and FOHs to cooperate with in order to avoid the unforeseen risk of services and products.

Some international TOs also complained about the services provided by the SOHs and domestic-owned hotels. The low level of professionalism led to the quality of cooperation between travel companies and these hotels. This was noted by the Director of Hanoi Etoco Travel in Hanoi:

I see that the sales and marketing of the international joint ventures and 100 percent foreign owned hotels are better than those of the local. The state hotels and private hotels are much more dependent on individuals or personal 
relationship, their sales policy and services are not consistent. In the high season, we know that these hotels still have rooms available but they do not sell them to our company. To explain this reason, I think, they lack professionalism.

The proportion of room sales of different hotel ownership modes was mentioned by the Manager of Product Development Research of the Vietravel in Ho Chi Minh City. She noticed that the market mix, type of international guests and channel distribution structure originated from the nature of hotel products and services as follows:

I think that the Vietnamese owned and managed hotels, particularly the SOHs, should have a dramatic change of services. If the change does not happen, these hotels cannot compete with the IJVHs and FOHs. The products and services they provided are for the lower expenditure guests compared with the IJVHs and FOHs. Most of the Vietnamese owned, and managed hotels are very much reliant on tour operators. We complained a lot about the services but I have not yet seen a change as well.

The Operation Manager of Becker Travel Vietnam directly outlined the relationship between the nature of products and services of different hotel management modes and their proportion of room sales via direct and indirect distribution channels as follows:

In general, the brand awareness level of different hotel management modes varies based on the nature of products and services. The that are often managed by well-known global hotel chains are advantageous in terms of getting direct bookings from international guests because these hotels' products and services are normally hassle free, a number of tourists will book rooms directly without visiting local travel agents and tour operators.

\section{Hotel objectives and target markets}

In general, the target markets of the IJVHs and FOHs are different from DPOHs and SOHs though these urban up-market hotels are officially classified at the same range of quality by the government. The overall objective was that the hotels, regardless of ownership modes, must be profitable. As mentioned in Chapter Five, a few hotels such 
as the hotels of Muong Thanh Hotel Group (a domestic private company) were found to consider profitability as a secondary purpose of the investor. In a narrow aspect, the IJVHs and FOHs had a tendency to get bookings from diverse sources of highexpenditure international tourists, and the local-owned and -managed hotels targeted a lower market segment in terms of guests' purchasing power. The main reasons mentioned that led to this difference of patterns of demand were ownership structure, management mode, the nature of products and services. This section will provide further insights into other factors that have impacts on the distribution channel structures of the hotels; they are hotel objectives and hotel target markets.

Specifically, hotel objectives and target markets of different hotel types have affected the ways that the hotels structure distribution channels. The Deputy Director of the Vietnam Railways Trade Union Tourist Services Company said:

At the SOHs, the properties are of the government and the people. The general managers only complete their jobs, if any difficulties occurred, they just report to the parent organisations to find solutions. For the IJVHs and FOHs, their own money was invested so the owners have to get it back. This is why they clearly identify hotel objectives and target markets.

In addition, the Director of ITDR explained how the hotel objectives and target markets of the $\mathrm{SOH}$ and DPOHs were recognised in a broader aspect. The SOHs not only needed to reach the profitability targeted by the parent organisations, but also they had to undertake some social and political matters of the government. The DPOHs were mostly invested in the facilities, and concepts of sales and marketing in the global hotel industry were not at the forefront of the domestic owners' mind. In contrast, the Vice Principal of Hanoi Tourism College noted that the IJVHs and FOHs identified their objectives, target markets and market segments comparatively clearly once investment decisions were made. These facts are seen to have significantly influenced the channel mix, channel member and channel width of the hotels.

Clear business objectives and target markets mean the hotels know who and where the end guests are or which channels and/or channel members the hotels have to send sales message to. Therefore, the hotels will invest resources in sales and marketing strategies, 
identifying competitors as well as monitoring mode of cooperation with channel members based on the outputs. In this regard, all of the hotels employed multiple channels or cooperated with a wide range of channel members in Vietnam or abroad to approach the end guests. However, the channel mix and channel member employed by the IJVHs and FOHs differed from the other types since these foreign hotels used computerised software to measure the output of each channel. In this case, the IJVHs and FOHs balanced the cooperation mode between channel members in their structures to make sure that all of the business partners bring in profits. Rejecting the low efficiency channel members and travel intermediaries in each type of channel made the IJVHs and FOHs' distribution structure different with the local-owned and -managed hotels. The mode of cooperation conducted by hotel ownership modes in relation with these facts was mentioned by the Director of Asianway Travel in Hanoi:

For the SOHs and DPOHs, the flexibility of room rates is very high. It means that these hotels can make any changes compared with room rates in the contracts. For the IJVHs and FOHs, they understand markets and classify markets into segments clearly so room rates are accordingly stable for each market segment.

\subsection{Conclusion}

In this chapter, it was acknowledged that it is challenging to separately categorise the factors into internal and external ones to find out how they affect the numerous aspects of the current distribution channel structures of different hotel ownership modes. This is because of interrelationships between the factors. However, a series of internal and external factors had been identified and the ways that they influence the distribution channel structures have been discussed. Data gathered indicated that Vietnam's economic renovation and its transitional economy in the context of Vietnam's integration into the world have been the background factors, playing an important role in the development of distribution channel structures of all hotel ownership modes. These two national factors have generated a basis for a change in the country regarding the legal system, economic development, tourist demand, technological advances and financial and banking systems. Furthermore, the economic transformation of Vietnam has directly created the multi-ownership structure in the up-market hotels and allowed the appearance of global hotel management chains in Vietnam, promoting patterns of 
demand and increasing the overall room occupancy rate. These are the factors directly caused the commonalities and differences of hotel distribution channel structures today in Vietnam in terms of channel mix, direct and indirect distribution, channel member, channel length, channel width and channel functions. 


\section{CHAPTER 8. IMPLICATIONS OF THE CURRENT DISTRIBUTION CHANNEL STRUCTURES AND FACTORS INFLUENCING THESE STRUCTURES}

\subsection{Introduction}

This chapter addresses the last research question of the study: What are the implications of the structures of hotel distribution channels and factors influencing them for hotel and tourism development in Vietnam.

First, a summary of the internal and external factors discussed in Chapter Seven influencing aspects of distribution will be presented in Section 8.2. Explanation of the reasons why Figure 7.1 emerged in relation to the conceptual framework will be also mentioned in this section to guide the discussions of implications. Second, this chapter focuses on discussing implications for tourist accommodation establishments (including the up-market hotels, lower star rating hotels and other types of tourist accommodation), travel intermediaries, policy makers and other researchers in Vietnam. Where relevant, implications for different parties and scholars in other transitional economies and elsewhere in the world are mentioned based on the findings in the context of Vietnam. In particular, notable implications for Cuba are emphasised. It is due to a fact that this country has been likely to adopt the economic mode of China and Vietnam, and the open door policies that were recently introduced by the Cuban Communist Party ${ }^{12}$ are relatively the same with Doi Moi in Vietnam in the late 1980s. Specifically, Sections 8.3 and 8.4 highlight implications of the current hotel distribution channel structures and factors influencing them for different parties in Vietnam. Section 8.5 extends these implications to relevant parties in other transitional economies and elsewhere in the world. Section 8.6 is the concluding thought of the chapter.

\subsection{Summarised factors influencing aspects of distribution channel structures}

Table 8.1 presents factors influencing aspects of the hotel distribution channel structures. This table shows the level of influence of internal and external elements that have impacts on channel mix, direct and indirect distribution, channel members, channel

12 Cuba Is Reforming, But Wealth And Success Are Still Frowned Upon (Retrived from http://www.businessinsider.com.au/cubas-economic-transition-2012-9?r=US\&IR=T). 
length, channel width and channel functions (together these are referred to as aspects of distribution). The conceptual framework for hotel distribution channels was developed from the literature to frame this investigation of the hotel distribution systems in a transitional economy. Based on the empirical research, Figure 7.1 and Table 8.1 were also developed. Figure 7.1 depicted in detail the ways in which a number of factors influence distribution channel structures of up-market hotels in Vietnam regarding commonalities and differences of the aspects of distribution. In doing so, it clarified some components shown in the conceptual framework. For instance, hotel ownership modes appeared in Figure 2.5 but were explained in Figure 7.1 to contain the SOHs, DPOHs, IJVHs and FOHs; and the management modes are semi-independence, independence, franchising and management contracts, and patterns of demand include the guest origin, types of guests and room occupancy rate. The conceptual framework together with all of these sub-elements shown in Figure 7.1 guided the analysis of data in Chapters Four to Seven. In this chapter, Table 8.1 summarises the level of influence of the factors presented in Figure 7.1. These are classified into primary and secondary factors. Implications of these above factors for different parties in the Vietnamese hotel and tourism, transitional economies and elsewhere will be discussed based on this classification.

Vietnam's economic reform, international factors, ownership and management modes, and patterns of demand all have an important impact on the structures of hotel distribution channels. First, Vietnam's economic renovation, transitional economy and international factors have created a positive change and developments in the legal system, economy, tourism demand, technological advance, and the financial and banking system. These factors have enabled the appearance and operation of direct and indirect channel members such as Vietnamese owned TOs and TAs, international joint venture TOs and OTAs. They also have great impacts on direct and indirect distribution. Room night sales from direct distribution are seen to have increased as Vietnam has closer connection with the world. A booming of local TOs and TAs as well as the appearance of a variety of overseas wholesalers and travel companies as a result of Vietnam's Doi Moi and open door policy have enabled a considerable part of hotel room night sales via indirect channels. Second, economic development, tourism demand and globalisation also have important impacts on channel length of all hotel ownership modes. These factors have created a connection between Vietnamese travel 
Table 8.1. Summarised factors influencing the hotel distribution channel structures

\begin{tabular}{|c|c|c|c|c|c|c|c|c|c|c|c|c|c|c|c|}
\hline \multirow[b]{2}{*}{$\begin{array}{l}\text { Distribution } \\
\text { channel structures }\end{array}$} & \multicolumn{5}{|c|}{ Vietnam's economic renovation and transitional economy } & \multirow{2}{*}{ 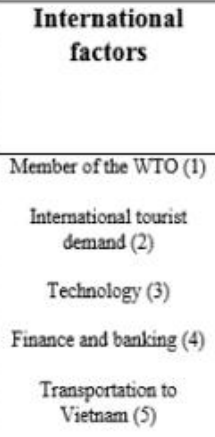 } & \multicolumn{6}{|c|}{ Ownership Modes } & \multicolumn{3}{|c|}{ Patterns of demand } \\
\hline & $\begin{array}{l}\text { Legal } \\
\text { system }\end{array}$ & $\begin{array}{c}\text { Economic } \\
\text { development }\end{array}$ & $\begin{array}{l}\text { Tourist } \\
\text { demand }\end{array}$ & $\begin{array}{l}\text { Technological } \\
\text { Advances }\end{array}$ & $\begin{array}{c}\text { Financial } \\
\text { and } \\
\text { banking }\end{array}$ & & Ownership & $\begin{array}{l}\text { Managem- } \\
\text { ent model }\end{array}$ & $\begin{array}{c}\text { Hotel } \\
\text { resources }\end{array}$ & $\begin{array}{l}\text { Products } \\
\text { and } \\
\text { services }\end{array}$ & $\begin{array}{l}\text { Business } \\
\text { objectives }\end{array}$ & $\begin{array}{l}\text { Target } \\
\text { markets }\end{array}$ & $\begin{array}{l}\text { Guest } \\
\text { origin }\end{array}$ & $\begin{array}{c}\text { Types of } \\
\text { guests }\end{array}$ & $\begin{array}{c}\text { Room } \\
\text { occupancy }\end{array}$ \\
\hline Channel mix & $\mathrm{x}$ & $\mathrm{x}$ & $\mathrm{x}$ & $\mathrm{x}$ & $\mathrm{x}$ & $\mathrm{X}$ & $\mathrm{X}$ & $\mathrm{X}$ & $\mathrm{x}$ & $\mathrm{x}$ & $\mathrm{X}$ & $\mathrm{x}$ & $\mathrm{x}$ & $\mathrm{X}$ & \\
\hline $\begin{array}{l}\text { Direct and indirect } \\
\text { distribution }\end{array}$ & $\mathrm{X}$ & $\mathrm{X}$ & $\mathrm{X}$ & $\mathrm{X}$ & $\mathrm{X}$ & $\mathrm{X}(2,3,5)$ & $\mathrm{X}$ & $\mathrm{X}$ & $\mathrm{X}$ & $\mathrm{X}$ & $\mathrm{X}$ & $\mathrm{X}$ & $\mathrm{X}$ & $\mathrm{X}$ & \\
\hline Channel members & $\mathrm{x}$ & $\mathrm{x}$ & $\mathrm{x}$ & $\mathrm{x}$ & $\mathrm{x}$ & $\mathrm{x}$ & $\mathrm{X}$ & $\mathrm{X}$ & $\mathrm{X}$ & $\mathrm{x}$ & $\mathrm{X}$ & $\mathrm{X}$ & $\mathrm{x}$ & $\mathrm{x}$ & $\mathrm{x}$ \\
\hline Channel length & $\mathrm{x}$ & $\mathrm{X}$ & $\mathrm{X}$ & $\mathrm{x}$ & $\mathrm{x}$ & $\mathrm{X}$ & $\mathrm{X}$ & $\mathrm{X}$ & $\mathrm{X}$ & $\mathrm{x}$ & $\mathrm{X}$ & $\mathrm{X}$ & $\mathrm{X}$ & $\mathrm{x}$ & $\mathrm{x}$ \\
\hline Channel width & $\mathrm{x}$ & $\mathrm{x}$ & $\mathrm{x}$ & $\mathrm{x}$ & $\mathrm{x}$ & $\mathrm{x}$ & $\mathrm{X}$ & $\mathrm{X}$ & $\mathrm{X}$ & $\mathrm{x}$ & $\mathrm{X}$ & $\mathrm{X}$ & $\mathrm{x}$ & $\mathrm{x}$ & $\mathrm{x}$ \\
\hline Channel functions & $\mathrm{X}$ & $\mathrm{x}$ & $\mathrm{x}$ & $\mathrm{x}$ & $\mathrm{x}$ & $\mathrm{x}$ & $\mathrm{X}$ & $\mathrm{X}$ & $\mathrm{x}$ & $\mathrm{x}$ & $\mathrm{X}$ & $\mathrm{x}$ & $\mathrm{x}$ & $\mathrm{x}$ & $\mathrm{x}$ \\
\hline
\end{tabular}

Key:

$\mathrm{X}$ : Primary factors

$\mathrm{x}$ : Secondary factors 
intermediaries and overseas counterparts within a distribution chain. Third, ownership and management modes of the hotels are interrelated and together are crucial factors influencing most of the aspects of the distribution channel structures. Lastly, the study findings indicate that patterns of demand regarding the origin of guests, types of guests and annual room occupancy are important for the hotels to determine their channel mix and to organise direct and indirect channels. Especially, guest origin is a primary factor influencing the channel length. This is because guests at short- or long- haul markets have impacts on the ways that the hotels apply modes of cooperation with various travel intermediaries to reach them.

The factors presented in Table 8.1 have created differences in the distribution channel structures used by the hotels. In the context of the Vietnam's economic renovation and transitional economy, the percentage of room nights sold via direct distribution channels of the IJVHs and FOHs was higher than the SOHs and DPOHs because of the foreign hotel owners' capital, brand, experience and knowledge in the international hotel industry. The legal system that created the Vietnam's business environment applied to all hotels, but the SOHs and DPOHs were found to work with unlicensed travel companies and pay illegal commissions to get direct bookings, e.g. from government ministries. The IJVHs and FOHs also took advantage of international factors and their network of sales and CROs to shorten the length of channel to reach guests, whereas the SOHs and DPOHs were mostly dependent on travel intermediaries. These differences were recognised to originate from ownership and management modes.

\subsection{Implications of the current hotel distribution channel structures}

This section presents notable implications of the distribution channel structures for Vietnamese tourist accommodation establishments (including up-market hotels and other types of tourist accommodation), travel intermediaries, policy makers and other researchers. For the Vietnamese tourist accommodation, Section 8.3.1 will focus on examining significances of the different channel structures for the up-market hotels first, followed by other tourism properties.

\subsubsection{Up-market hotels and other tourist accommodation establishments}

As mentioned in Section 1.2.3, the Vietnamese government categorises tourist accommodation into six main types: hotel, holiday village, tourist villa, tourist serviced 
apartment, camping site and guesthouse. Implications of the commonalities and differences of the distribution channel structures are accordingly discussed not only for the up-market hotels themselves but also for lower star rated and the remaining types of tourist establishments all over the country. This is because high-end properties located in Hanoi, Danang and Ho Chi Minh City are considered the leading providers of hotel products and services, management and distribution strategies that other tourist establishments in Vietnam can learn and apply.

Firstly, each up-market hotel ownership mode benefits from a clearer picture of distribution channel structures to update their knowledge of distribution in order to organise sales and marketing activities. This is because the study has identified key advantages and disadvantages of how each hotel mode mixes and employs channels and channel members to reach domestic and international travellers based on management mode, resources, products and services, target markets and external factors. Along with channel width or ways to select TOs and TAs as consumers applied by the IJVHs, these findings bring techniques of sales and marketing from the IJVHs and FOHs to the entirely Vietnamese owned- and -operated hotels. Based on limited hotel resources, the SOHs and DPOHs could copy appropriate sales techniques from foreign ownership hotels to organise channels and channel members in their distribution systems. For instance, while many SOHs and DPOHs ignored enquiries of bookings in the high season from TOs and TAs who the hotels had signed agreement contracts with to welcome FITs with high expenditure, they may not know the IJVHs' respected mode of cooperation with different channels and channel members to make sure that the hotels and TOs gained mutual benefits. Moreover, CROs are also not suitable for independent hotels since this channel needs strong support from an international sales and marketing system.

Secondly, the study findings that analysed the proportion of sales via direct and indirect channels in relation to the management mode across the four up-market hotel ownership modes are significant for the up-market SOHs and DPOHs to approach a market niche and to select appropriate channels. In general, direct distribution channels were likely to generate higher profitability for the hotels compared with indirect ones. However, the effectiveness of direct channels normally requires hotel resources and a strong support of global networking, hence direct channels are also costly for independent management 
hotels to apply. In this case, the IJVHs and FOHs are taking their advantages of their owners' backgrounds and membership of hotel management chains to organise this type of sales. Therefore, this finding is particularly useful for the entirely Vietnamese-owned hotels to select suitable channels to distribute their rooms to tourists. It is more critical in the context that most of the SOHs and DPOHs, which lack sufficient research and statistics, are attempting to expand direct distribution. Instead of investing in direct channels to increase sales volume from them, the SOHs and DPOHs should establish strong relationships with TOs and TAs.

Thirdly, patterns of demand regarding the guest origin, types of guests and room occupancy rate enrich each up-market hotel ownership mode's understandings of market niche or market segmentation of their competitors in the context of a lack of public statistics and reports of the Vietnam's hotel business. As mentioned in Section 4.3.3, the market niche defines the hotel products and services aimed at meeting specific market needs, the price range and the demographics. By analysing the market segmentation performed by each hotel mode and the dominance of the IJVHs and FOHs in attracting high-end guests, the SOHs and DPOHs will therefore establish more effective distribution channel structure to survive from stronger competitors.

More broadly, the up-market hotels in other regions of Vietnam, lower star rating hotels and the remaining types of tourist accommodations also benefit from the differences and commonalities of the aspects of distribution regarding the combination of channels employed by the four high-end hotel ownership modes in their distribution structures. The channel mix analysis showed multiple available channels to reach different types of guest, market segments and target markets. As an example of combining channels to reach the market, the IJVHs provided a good lesson for other types of hotels to mix channels to lower operational costs. As Pearce (2007, p. 30) noted: "most tourism suppliers require several channels in order to cater to a range of segments, to meet the needs and preferences of different customers and to extend coverage of their product". In fact, the tourism market is segmented and tourist establishments target either international tourist sources or domestic markets based on suitable products and services for specific types of guests and segments. Multiple channels allow accommodations to maximise sales and marketing campaigns in terms of promoting brand and creating opportunities to increase the volume of room sales. 
Differences in channel mix presented in Figure 7.1 assist the hotels and other tourist accommodations in managing available channels to reach types of guests and to penetrate market segments. Pearce (2007) stated that using multiple channels requires ongoing management to ensure their sustainable implementation and to balance the hotels' profitability and resources against the customers' needs for a long-term sales strategy. The study findings indicated that tourist accommodations should pay close attention to monitoring bookings and availability of rooms when a variety of channels are used because conflict between channel members with different needs and motivations may occur. For example, the IJVHs were found to use computer software to measure the outputs of each channel periodically, therefore a combination of channels is evaluated to reduce the labour costs of supervising channels based on its outputs. Mode of cooperation between the IJVHs and travel intermediaries, pricing policy and commissions are accordingly decided and adjusted periodically. The Vietnamese owned- and -managed hotels seemed to pay less attention to measuring the effectiveness of channels for further cooperation since most of the travel intermediaries were welcome to sign agreement contracts, overbookings and conflicts between TOs and the hotels frequently happened. In other words, lessons from using channel mix enables all the hoteliers to know the ways in which channels are to be effectively combined.

As a result of channel mix, several methods applied by various up-market hotels to manage possible conflicts between channels are useful for other hotels and tourist accommodation operators in Vietnam. Apart from direct channels, a number of the hotels in the three cities classify travel intermediaries into online and offline partners and then a one-price policy is applicable via agreement contracts to each group to reduce resources in managing rate conflicts. The main weakness of this way is that the hotels meet difficulties in identifying who are loyalty customers for long-term cooperation. In contrast, a number of hotels, particularly the IJVHs and FOHs' closely work with travel intermediaries based on the audited outputs of room nights sold periodically. Pricing policy and priority are accordingly given to the channel(s) that send a large volume of guests to the hotels. This way has strengthened the cooperation between channel members and combination of channels in the established distribution structure. 
Direct and indirect distribution channels are found to have both advantages and disadvantages, so it is essential for other hotels and accommodations to learn from the up-market hotels to select appropriate direct or indirect channels based on available resources. Distribution via direct channels constituted a lower proportion of room nights sold for all types of hotel ownership compared with indirect ones (Table 6.1). However, most of the up-market hotels in the three cities attempted to gather bookings directly from the end tourists. Direct sales enabled the hotels to better manage the pricing policy and to avoid the difficult-to-collect or long-term debt from travel intermediaries. Another advantage is that direct distribution allowed the hotels to discuss directly with the end guests in order to adjust their products and services immediately. These reduced further possible complaints due to any misunderstandings of the guests prior to check-in. Depending on the hotels, a database of these guests is constructed for the purpose of sales and marketing as the guests of direct bookings have the potential to be loyalty customers. In contrast, direct channels also have some disadvantages, as they are costly to operate effective sales and marketing activities to sell a large number of rooms to different types of guests. The hotels must invest in skilled staff and ICT resources. For independent hotels, it is more costly compared with chain hotels to build systems such as call centres and regional or global sales offices. Some participants noted that CROs and call centres as well as overseas sales offices are not likely to be suitable with small and medium hotels.

The up-market hotels in the three cities are largely dependent on travel intermediaries to distribute their rooms to the end guests. Leisure-packaged tourists accounted for the largest proportion of room nights sold by all of the hotel ownership modes (Table 6.1) and this type of guest tends to purchase their holidays via travel companies rather than booking each service and product separately. Furthermore, cooperating with numerous travel intermediaries helps the hotels to minimise risks and, as such, to increase the hotel brand recognition in the market as each company often has its own strength for certain markets or segments. Importantly, the volume of bookings from travel agents and TOs are commented to be more stable than those of direct channels as intermediaries can add value to the service with their knowledge and expertise. In contrast, indirect distribution challenges the hotels in different aspects such as the conflict of pricing offered for intermediaries, the appearance of difficult-to-collect debt, harmonisation between local tour operators and overseas travel businesses. Feedbacks 
of the products and services from the guests from TOs are managed by these tour operators, thus the hotels meet difficulties to adjust the pricing policies or services. On account of this, the hotels carry out several strategies to manage comments by placing in-room feedback forms or talking directly with the guests to know where the feedbacks originated. Indirect channels are especially suitable to independent hotels and less famous brands.

The ways that different modes of hotel ownership work with local and overseas travel companies are also significant for other hotels and tourist accommodations. The overall trend is that IJVHs and FOHs find ways to increase room sales to overseas travel businesses, and most of the Vietnamese-owned and -managed hotels favour working with the local TOs and TAs because of their limited resources, management experience of handling offshore sales and marketing know-how. In addition, the Vietnamese laws are likely to protect in-country transactions better than cross-border ones and a number of overseas wholesalers have established business relationships with local counterparts to promote sales instead of their own companies. The cooperation mode with local and foreign companies of the up-market hotels to reach markets suggests other hotels and smaller tourist accommodations with limited resources to select travel intermediaries to cooperate when the Vietnamese law and the country's position in the world are still limited to protect its enterprises.

In addition to channel mix, direct and indirect distribution, findings of the channel members used by the up-market hotels provide other hotels and Vietnamese tourist accommodations with an up-to-date list of available channel members as well as the reasons why these hotels employ them to reach domestic and international tourism markets. The popular direct channel members include hotel websites, email, telephone, social networks, local sales offices and sales calls; indirect channel members are popularly recognised such as information centres, TAs, OTAs, TOs and overseas wholesalers. However, differences of channel members used by the various types of the up-market hotel ownership are found, indicating the hotels' resources, and marketing budget invested in developing distribution. For instance, IJVHs and FOHs employ local and regional sales offices, websites of hotel chains and CROs that SOHs and DPOHs have not yet used. 
The study findings show that there has been an increasing development of OTA such as Agoda, Booking and Expedia. This trend brings both advantages and disadvantages for Vietnamese hotel marketers as these OTAs have successfully penetrated the hotel market and strongly compete with conventional travel companies, GDS and CROs. In many up-market hotels, room nights sold by the OTAs accounted for noticeable proportion of sales. However, as these high-end hotels had to pay a high commission (up to 25 percent) and became dependent on these online travel intermediaries, many hotels returned to cooperation with traditional travel companies. Some hotels revealed that they gave priority to local and conventional travel intermediaries in room allocation because they are loyalty customers. Thus, tourist establishments should balance the selection of electronic and traditional channel members to sustain profitability and build the pricing policy relevant to different business partners in order to avoid dependence on certain channels and channel members.

The findings on channel length are significant for both new and established hotels and other tourist accommodations to understand and structure their distribution channels. Findings show that the common channel length is hotel - local TAs - local TOs overseas wholesalers - overseas TOs - overseas TAs. All types of the up-market hotels desire to shorten this length in order to avoid possible conflicts between the end guests and the hotels by reducing intermediaries in a distribution chain. As a representative from Danang said, some guests complained about the hotel quality compared with their payment when they checked in. What the hotel received was much less than guests paid to the travel company. This fact forces different hotel ownership modes to cooperate with as few intermediaries within a channel as possible to shorten the channel length and to manage room rates offered to travel companies at the destination, in between and in the market. Shortening the channel length also enables the tourist accommodations to adjust products and services based on direct handling of guests' enquiries. It also reduces commission payments to intermediaries. In this case, the IJVHs and FOHs with their resources establish a number of channel members to immediately handle the guests' enquiries and to process bookings: regional and global sales offices and CROs. This fact, to some extent, has benefited other hotels and Vietnamese tourist accommodation, including new and established ones. 
The commonalities and differences of channel width reveal a lesson for other hotels and tourist accommodations of how the up-market hotels have dealt with a huge number of local travel companies to reach guests. In Vietnam, although many hotels desire to cooperate with these intermediaries to maximise potential bookings, the operations of hundreds of small licensed and unlicensed TOs have caused difficulties for the hotels to select and sign agreement contracts. As a representative from a $\mathrm{SOH}$ in $\mathrm{Ho}$ Chi Minh City noted, the hotels should not refuse to sign contracts with any TOs; if anyone of them meets the hotels' requirements in terms of pricing, an agreement contract should be made because opportunities to increase the volume of bookings are widened. However, this seems to be more prevalent with SOHs and DPOHs rather than foreign ownership hotels. The IJVHs and FOHs are more selective in cooperating with local TOs to reduce operational cost in handling paper work and market conflicts among travel businesses. These entirely Vietnamese-owned hotels signed contracts with hundreds of TOs but they did not have enough staff and resources to respond to the enquiries of tour operators regarding bookings. The findings show that many of the intermediaries complained about the professionalism level of a number of SOHs and DPOHs due to channel width. Hence, the hotels and other accommodations should be selective in choosing how many intermediaries to cooperate with to save resources.

Lastly, the functions of each channel in the four distribution channel structures employed by various hotel ownership modes are significant for other hotels and tourist establishments in understanding how these structures operate, particularly the international investors. Depending on Vietnamese laws and international norms, each channel has its own functions; however, seven common functions applied by the hotels are seen: a flow of information, advice, negotiation, booking, making payment, information provision and paying fees or commissions to relevant parties. Differences in using some channel functions found at the SOHs and DPOHs compared with IJVHs and FOHs illustrate an aspect of the hotel business environment in Vietnam. Illegal commission payments to some local organisations were made by SOHs and DPOHs to get direct bookings. The implications of this will be discussed in detail in Section 8.3.3.

\subsubsection{Implications for travel intermediaries}

The various distribution channel structures undertaken by the four hotel ownership modes show where Vietnamese travel companies are the connections between 
Vietnam's tourist accommodation and the global tourism market. Their position in the distribution chain enables travel businesses to design relevant products and services as well as marketing strategies to make their brand occupy a distinct position in the mind of the customers. This is due to the fact that a well-positioned company will probably beat the competition that has a comparable offering from hundreds of existing conventional channels. In addition, when a majority of Vietnamese TOs, and TAs' international tourists are from overseas wholesalers, this position in the chain suggests the way in which cooperation mode between Vietnamese travel companies with overseas wholesalers, TOs and TAs is made.

Each diagram presented in Chapters Four and Five provided local TOs and TAs with information that the up-market hotels cooperated with multiple channels to reach the target markets. The study findings indicated that the rapid growth of OTAs has generally challenged conventional intermediaries in Vietnam since OTAs offer guests with multiple choices of competitive hotel room rates for guests to design their own trip. Although most of the Vietnamese up-market hotels are found to depend on conventional TOs, in the context of technological advancement, these hotels have attempted to reach the end guests directly by investing in websites, CROs and call centres or by participating in social networks and electronic devices. This trend has considerably challenged the development of traditional travel intermediaries. Conventional companies should take advantages of resources that OTAs do not have, such as providing face-to-face services or expert knowledge of the destination. The OTAs mostly focus on booking hotel rooms while in-person customer services are available at most of the traditional TOs and TAs for guests to arrange all elements of the trip at the market, in between or at the destination.

Another implication is that channel width and channel functions in the distribution channel structures revealed a challenging environment in Vietnam; thus, to develop, Vietnamese TOs have to improve their level of professionalism. With the boom of hundreds of small TOs, dropping price by reducing the quality of products and services in a tour is one of the popular tactics that many travel companies used to get bookings from overseas wholesalers, TOs or the end tourists. Unlicensed TOs and TAs appeared not only to raise a question for the Vietnamese travel business community and legal system, but also, legal travel intermediaries themselves should be aware of this chaos 
for further business planning. Legal TOs need to increase the professionalism level to survive from the challenging environment, and to become trusted by the tourist accommodation and overseas customers since a number of hotels complained about the time that they spent answering queries from local companies. In contrast, many local TOs and TAs are also unable to book rooms at the SOHs and DPOHs in high seasons although contracts had been made. Therefore, one of suggestions from this finding is that Vietnamese travel companies and accommodations must review all clauses in agreement contracts carefully to avoid such a practice.

\subsubsection{Implications for policy makers}

The interview data show that most of the participants from the government departments and trade organisations have a blurred knowledge of components making up the current hotel distribution channel structures. In particular, direct and indirect channels, electronic channels such as CROs and GDS and the nature of these terminologies as well as their functions in the distribution structure had been used and explained inappropriately by these participants. The misunderstanding of domestic TOs and TAs with international TOs and TAs in the structures also occurred. For instance, there are some functional differences of OTAs and conventional TOs as these companies operate their businesses based on commissions or pricing policies offered by the hotels. The operational nature of these websites differs from websites of the hotels or hotel chains. Many international tourists booked rooms via domestic TOs and TAs that are legal providers of services for domestic guests only. Hence, it will be useful for policy makers to get insights into this way of managing travel businesses, to decide whether or not to categorise Vietnamese travel intermediaries into domestic travel companies and international TOs. This is because domestic company and international TOs cause misunderstandings and difficulties for international tourists in recognising them. Also, due to the misinterpretation of international norms regarding the operation of OTAs, some difficulties in relation to tax occur when the hotels transfer commissions to overseas OTAs.

The channel length in each distribution channel structure also informs the tourism authorities that Vietnamese TOs are strongly dependent on overseas counterparts in reaching the international tourism market. A huge number of small TOs and TAs strongly compete with each other to get that cooperation by offering low prices for tours. 
As mentioned by a TO in Hanoi, Vietnamese TOs are queuing to carry out land services for overseas wholesalers only because of the boom of Vietnamese TOs, the growth of OTAs and a lack of support from the government via the overseas country marketing offices. The majority of small TOs and TAs also suggested that the government should develop suitable strategies of managing the quality of tour services.

The existing distribution channel structures of the up-market hotels indirectly show a gap between Vietnamese-owned and -managed hotels with foreign ownership properties. The IJVHs and FOHs with better resources and management experience used a selective variety of electronic and conventional travel intermediaries to target the market. Direct channels were boosted by these hotels with the purpose of getting more direct bookings from the end guests, reducing possible pricing conflicts among intermediaries and tiers of members within a chain and managing the product and service quality by dealing with the end guests. In contrast, SOHs and DPOHs are reliant on travel intermediaries. These hotels are seen to lack the necessary resources to carry out effective distribution channels in terms of managing the channel mix, channel length and channel width in their structures. This is simply because foreign ownership hotels are recognised to have transferred managerial techniques via training skilled staff and providing both an imperative and an example for the introduction of more progressive management thinking when they entered the Vietnam hotel market where sales and marketing departments did not exist in SOHs over 20 years ago (Suntikul, Butler \& Airey, 2008). The development of SOHs and domestic hotels is at the horizontal stage when cooperation with hundreds of tour operators, unlicensed travel companies as well as illegal commission payments is evident, partially causing a chaos in the travel industry in recent years.

The above gap not only informs the policy makers where the Vietnamese-owned and managed hotels are regarding the establishment of distribution channels, but also these indicate that the government must take action on this to reduce the gap. It also helps tourists recognise the quality of each hotel to decide their bookings. As pointed out in Chapters Four and Five, the SOHs need to be privatised 100 percent in order to increase their capacity and quality as well as management, thus, the government should remove its ownership (whether 51 percent or lower) to allow domestic and international private investors to own 100 percent. As mentioned by an interviewee in Danang, only by 
possessing the whole asset can the owner invest enough resources to restructure the SOHs. Also, from the findings of the distribution structure and patterns of demand, a problem that has occurred for some DPOHs is that these hotel owners built the properties because of other purposes. One of these negative results was that these hotel room rates and services were quite low although they were certified to be four- and fivestar hotels.

The role and effectiveness of tourism information centres that are funded and operated by the government should be re-evaluated because of their low performance in the eyes of travel intermediaries and the hotels. Most of the up-market hotels commented that poor services and facilities have negatively influenced the efficiency of these centres; as a result the hotels place brochures with a view to introducing their brands rather than gathering bookings. This fact urges the government to re-invest in these properties to meet the industry practitioners' expectations. Some interviewees noted that a mode of public-private partnership is likely to be appropriate with these centres as the government invests and operates ones in remote areas; the private sector could run such centres in cities.

\subsubsection{Implications for researchers}

This study has contributed to reducing the gap in literature of the hotel distribution in Vietnam by addressing the primary research question: Taking the case of up-market hotels in Vietnam, how do the different hotel ownership modes in a transitional economy structure distribution channels? In particular, the study has identified the current structures of hotel distribution channels of different ownership modes in Vietnam. By looking at the distribution channel structures of the up-market hotels, the study has provided opportunities to examine a full range of hotel ownership modes in Vietnam. Moreover, the study is also significant for other researchers who investigate tourism and hotel distribution channels in other transitional economies or countries that share relatively the same socio-economic characteristics with Vietnam. This is because the conceptual framework (Figure 2.5) and the framework of factors influencing distribution channel structures of the different hotel ownership modes (Figure 7.1) could be used. Methodological reflections suggested avenues for other researchers to conduct this research problem in the same context with Vietnam. 
The implications for other researchers regarding avenues for further research in Vietnamese tourism and hotel distribution channels are recommended. Firstly, as this study has focused on the distribution channel structures of the urban up-market hotels, scope exists to research distribution structures of the up-market hotels in other cities or provinces, lower star rating hotels and other types of tourist accommodation throughout the country. Sampling of domestic TOs and TAs should also be selected as in this study the distribution channel structures for domestic tourists were mainly constructed based on secondary resources. Secondly, as mentioned in Section 3.3 this study has applied a qualitative approach to address the supply-side issue; questions of demand and the behaviour of consumers were addressed indirectly. Therefore, a study employing a demand-side approach or mixed approach with a sampling of overseas wholesalers, TOs, TAs and tourists would be useful. Thirdly, this study gathered some quantitative data via interviews to illustrate hotel capacity and patterns of demand, thus a quantitative method is significant to collect numbers to measure the performance of each channel in the entire channel structure of each types of hotel or accommodations.

\subsection{Implications of factors influencing the distribution channel structures}

In line with Section 8.2, this section considers the implications of various factors influencing the distribution channel structures of the different hotel ownership modes for related members in the Vietnam hotel and tourism industry, namely the Vietnamese tourist accommodation establishments including high-end hotels, travel intermediaries, policy makers and other researchers. The implications for other recipients elsewhere are also mentioned. Chapter Seven identified that the influential factors are Vietnam's economic renovation and transitional economy in the context of its international integration, hotel ownership and management modes in relation to some internal factors such as hotel resources, hotel products and services, business objectives and target markets. Patterns of demand that have impacts on similarities and differences of the hotels' distribution channel structures are also taken into account regarding guest origin, types of guest and room occupancy rate.

As discussed in Chapter Two, Figure 7.1 and Table 8.1, Vietnam's economic renovation and the process of transforming the country's centrally planned economy into the socialist market-oriented economy have increased Vietnam's accessibility and attractiveness in the international tourism market, generating an increasing flow of 
tourists around the world to discover Vietnam (Suntikul et al., 2008). The country's international integration that was marked by events such as its entry into the ASEAN bloc in 1995 and admission into the WTO in 2007 has involved huge changes to the legal system, economics, tourist demand, technology and the financial and banking system. These geo-political changes have influenced the hotel distribution channels and in turn provided implications for related parties in the Vietnamese hotel and tourism industry as follows.

\subsubsection{Implications for up-market hotels and other accommodation establishments}

First, Vietnam's economic restructuring and transitional economy presented in Sections 4.2, 4.3, 5.2, 5.3 and 7.2.1 as well as their recorded impacts on distribution are significant for the up-market hotels themselves and other Vietnamese tourist accommodations' current operators, potential investors in Vietnam and abroad in establishing their own businesses, structuring and managing issues associated with the distribution channels. The reviewed laws and regulations show that the Vietnamese government has legitimated in detail the material ownership of investors regarding the means of production, which had not been seen in the command economy. In other words, the accommodation owners' rights have been legally protected under any circumstances, creating a better environment of trustworthiness for current owners to organise ways to reach guests for profitability and providing potential investors with an understanding of the hotel and tourism business environment. The review of revised laws since Doi Moi in 1986 also indicates that there have been ongoing movements and dynamic changes in terms of putting Vietnam's commitments to international organisations into their laws. Possible prejudices or differences in laws towards international hotel investors have been narrowed down. For instance, the Law on Enterprise and the Law on Investment that were issued in 2014 by the Vietnam National Assembly have replaced previous regulations to each type of company or investment conducted by the locals or foreigners. Regardless of nationality origin, all of the companies and types of investments are administrated under the same laws. These will hopefully reduce and/or reject possible prejudices amongst investors and provide a very important understanding of Vietnamese laws for further decisions of investments.

Second, the factors of Vietnam's economic development, demand from domestic and international tourists, global and Vietnamese technological advances as well as financial 
and banking services and transportation are useful for types of up-market hotels and other tourist accommodations when these factors are taken into analysis. In other words, the feasibility of their distribution channel structures is studied and established based on these factors. The findings show that the ups and downs of the national economy, the fluctuation of GDP per capita and inflation rate have strongly affected the volume of not only domestic guests but also international travellers. When the country's economy develops, appropriate channels such as direct ones should be focused on to target a larger number of international business travellers and high expenditure domestic guests. In contrast, leisure-packaged tourists seem to be a regular source of guests when Vietnam's economic slowdown was recorded. The findings also suggest up-market hotels and other large size accommodations invest in conducting research and development work regarding the macroeconomics, statistics, government reports and the tourism market prior to building up specific channels. In fact, the economic development reports and statistics of the government and consultant companies are frequently purchased by global hotel chains to forecast demand of domestic and international tourists. This has enhanced sales and marketing strategies of these hotels regarding the effective distribution channel structures.

Third, the up-market hotels, tourists and a huge number of travel intermediaries in the distribution channel structures that are driven differently by various targets of profitability and other socio-political purposes cause a complicated business environment, that is, an incomplete market mechanism. In general, different hotel ownership modes are equal and free to establish their business and channels to reach the tourist market in search of profits. However, a problem of law enforcement is raised in relation to the quality of laws and government officials to manage business activities well when an equal business environment is, to an extent, beyond the hand of the government. More transparent policies should be made. This is useful for current and future tourist accommodation investors and operators, particularly foreigners who have less knowledge and experience of the legal system, hotel business environment and the sales and marketing activities of the hotels in Vietnam to know.

\subsubsection{Implications for travel intermediaries}

First and foremost, the international integration of Vietnam and its commitments to the WTO will widely allow foreigners to do travel business in Vietnam under 100 percent 
foreign-owned or international joint venture companies. This reveals a very challenging environment that local TOs and TAs will face. Most of the representatives from the TOs noted that overseas wholesalers and TOs have not yet opened their own branches or companies in Vietnam because of the current size of the Vietnamese hotel and tourism market. However, before the possible appearance of these international travel companies in Vietnam, most of the Vietnamese TOs and TAs have been dependent on them because of their volume of guests. This raises a question of how TOs and TAs will survive or develop in the future when Vietnam probably becomes a more popular destination with better infrastructure for overseas tourists. A number of international wholesalers, as believed by some TOs, will operate their own travel businesses in Vietnam by 2018 onwards. As mentioned earlier, the level of professionalism and a cooperation mode among these travel companies under the VISTA to enhance TOs and TAs' capacity also need to be looked at. Each company should have a long-term strategy of development. This information enriches the understandings of overseas wholesalers, TOs who sent guests to Vietnam and intend to operate their own business in Vietnam.

Secondly, technological advances, the development of the finance and banking system in Vietnam and the world and international transportation to Vietnam have been changing the ways in which the up-market hotels meet the end guests. Vietnamese travel intermediaries should acknowledge these factors to buy and sell hotel rooms in order to combine with other products and services to make added-values. As mentioned earlier in this chapter, OTAs have been increasingly important buyers of hotel room nights, generating a certain proportion of room nights sold due to the development of information technology, easier transportation to Vietnam and the compatibility of Vietnamese and global financial and banking systems. However, as Kracht and Wang (2010) noted, the advance of ICT has not reduced the number of travel intermediaries in the distribution channel structure but rather has resulted in an increasingly complex array of intermediaries. Most of the hotels and different members in the distribution channel structures are aware of how these factors influence their business. A number of respondents noted in the previous chapters that connections between accommodation suppliers and buyers are immediately made via some clicks to complete a holiday or a tour. The buyers in this transaction could be either travel intermediaries at the destination, in between, in the market or the end guests. Nevertheless, it is useful for all 
TOs to know that the visa policy of Vietnam is recognised as the main obstacle to hinder this electronic purchasing process. At present, the Vietnamese TOs must take advantage of the people who can provide invitation letters to guests for visas issuance before visa may be waived in a large number of markets. Together with the above challenges, Vietnamese TOs should review their development strategy to avoid being the land service providers for overseas intermediaries.

Thirdly, the finding of the nature of products and services in relation to hotel ownership modes and management styles is significant for not only local travel intermediaries, but also benefits overseas wholesalers, TOs and tourists. To some extent, ownership and management modes reflect the hotels' professionalism level, and there is a difference between the quality of products and services of these hotel modes. In terms of pricing, it is not surprising if any travel intermediaries require the hotels to apply the pricing policy consistently with signed agreement contracts. However, some representatives from local travel companies have complained about a sudden increase of room rate of some SOHs and domestic private hotels in the high seasons without notice. Contracts are not always obeyed and respected by these hotels; hence, TOs must have plan to reduce risks for their own businesses because rooms have already been sold to tourists. Another example to illustrate the business of some SOHs: it is found that many hotels only release room rates for the coming year in November because of their slow sales and marketing planning approval procedure. It is considered to be late for travel intermediaries and tourists to finalise their plans. These findings suggest to travel companies and wholesalers the ways to cooperate with certain types of the hotels in structuring distribution channels.

\subsubsection{Implications for policy makers}

First, some of the influential factors related to Doi Moi are global integration and Vietnam's accession to a number of the free trade areas, and the international and Vietnamese legal systems, which have been widely mentioned in both domestic round table discussions and written reports of the Vietnamese government. These factors are seen to have influenced the aspects of distribution channel structures. However, they have not yet been addressed properly by the government and tourism authorities to create a better platform for businesses. Broadly, Pham (2015) cited a statement made by the General Director of the Vietnamese Centre Institute for Economic Management, that 
the integration of Vietnamese enterprises into the world economy looks like a person who crosses a river via a very narrow bridge with the burden of fees and administrative papers on their shoulder. The entrepreneurs have to bend their back to gradually step in order to avoid falling down to the river, and as a result they are unable to look far ahead at international markets. Pham Huyen (2015a) also highlighted that the Vietnamese legal system has changed slowly for three decades since a viewpoint of the government to control enterprises in the command economy still exists. What the government has undertaken so far is likely to pay attention to commitments only; the country's economic renovation is extremely slow. Therefore, the government should implement and revise the legal system to make sure that it meets the requirements of a pure market economy. In the tourism and hotel industry, a reminder to policy makers is that information, tourism statistics, market trend prediction reports, and annual analysis reports are important and should be accurate and timely released to meet the needs of the tourist accommodations in their structuring and establishment of distribution channels. For instance, participation in international travel fairs, strategies to penetrate target markets and a list of visa exemptions for target markets should be widened as neighbouring Malaysia, Singapore and Thailand do. The visa issuing procedures must be facilitated.

Second, the relationship between hotel ownership and management modes with the distribution channel structures are significant for policy makers. It is important that policy makers are in charge of creating an equal platform on which all of the hotels carry out their businesses and distribution. Notably, the SOHs were seen to have a lot of advantages when the government subsidises capital and a number of resources such as manpower, business relationships and preferential policies in terms of establishing distribution channels. Financial difficulties were mostly transferred to the state in the event of loss in business. However, the disadvantages of the SOHs were considered to be rooted in these advantages as the autonomy of the SOHs is controlled and limited when all SOHs followed the same management mode, that was the semi-independent one. The SOHs were also likely to be passive in terms of designing an effective distribution channel structure. In some circumstances, illegal commission payments to guest-sending sources and cooperation with unlicensed channels were ways to compete with other hotels. In contrast to SOHs, non-state-owned hotels independently apply management modes as well as to structure their distribution channels based on available 
resources and the drive of profitability. Apart from a number of DPOHs that were lagging behind in terms of the distribution channels due to owners' purposes, the IJVHs and FOHs were highly appreciated by the government, travel intermediaries and tourists in terms of their globally accepted products and services as well as the professionalism level in dealing with information provision, bookings and payments. A number of interviewees noted that the occurrence of these IJVHs and FOHs not only have decorated the Vietnamese cities in a modern fashion, but also these hotels brought new concepts of hotel operation and services to Vietnam. These facts of ownership and management modes once again suggest that policy makers in the hotel and tourism industry should issue policies to generate a transparent and competitive business environment. Chaos in travel business and illegal commission payments must be swept away.

The advantages and disadvantages of each hotel ownership mode and management modes applied by the up-market hotels are meaningful for policy makers. Non-state hotels, particularly foreign ownership hotels, are flexible and experienced in investing resources in designing products and services as well as identifying business objectives to meet the numerous needs of customers in the target markets. DPOHs are seen to be the novice hoteliers in the market, and excessive caution in the preservation of their money has led them to apply the self-managed mode or family-based management mode. The SOHs with a long history of operation and subsidy from the government present a bureaucratic organisational structure with the involvement of both the government and his representatives in running a hotel. Although it is widely accepted that hotels that are managed or franchised with global hotel groups bringing investors have huge advantages over other types of hotels in terms of products and services as well as distribution channel establishment; the SOHs and most of the DPOHs have so far applied semi-independent or independent modes. Of course, the customers' perception of products and services of Vietnamese-owned and -managed hotels is also limited. It is also very meaningful for the Vietnam tourism and hotel industry that the appearance of global hotel chains such as Accor, Hilton, IHG, Marriott, Meliá, and Starwood has remarkably promoted the reputation and trustworthiness of the destination to international tourists. The Vietnam tourism and hotel industry benefit from the entry of these global hotel chains as the hotels managed by them are flagships to transfer 
modern concepts of hospitality services and management techniques to the local businesses via the turnover of staff.

Third, some questions that need clear answers from the government and tourism authorities related to state ownership in the SOHs are raised, and questions about the current ability of the DPOHs associated with the development of their distribution channels are also useful for the policy makers. The analysis concluded that many SOHs and DPOHs are lagging behind and have difficulties in: (1) applying global reservation systems, (2) using effective sales and marketing techniques, (3) lacking means to measure channel outputs, (4) being weak in customer oriented services, and (5) maintaining consistent products and services. There are particular factors influencing the establishment of the SOHs and DPOHs' distribution channels including: (1) separation of ownership and management: non-commercial operation and corporate governance (SOHs and DOPHs), (2) bureaucratic organisational structure (SOHs), (3) human resources issues: employee training and development, inexperienced personnel (SOHs and DOPHs), and (4) the government policy of restructuring SOHs. For the SOHs, the Vietnamese government can allow the SOHs to sign a contract with a hotel management company to run the hotels. If possible, the general managers of the SOHs should be given full power and the autonomy in running the SOHs. In the long term, it is recommended that the government should proceed with ways to transform SOHs into non-state hotels including privatisation, mergers and acquisitions. Local or foreign investors can easily purchase both state-owned shares and legal person shares of SOHs. No limit should be imposed on the amount of shareholdings in the SOHs that investors may acquire.

Finally, as a result of the above implications, a suggestion to reduce mistaken perceptions of products and services offered by the different hotel ownership modes via various channels is that the government could categorise the hotel star rating scale into smaller classes. The patterns of demand including guest origin, types of guest and the average room occupancy rate of the Vietnamese up-market hotels provided the policy makers with another picture of the quality of each hotel ownership mode. The origin of guests who stayed at the hotels reveals the target market, the percentage of Vietnamese tourists over foreigners who stayed at the hotels. At the same star rating, lower expenditure tourists were likely to stay at the SOHs and DPOHs compared with IJVHs 
and FOHs. Accordingly, there has been a gap between the quality of different types of hotel managed by the Vietnamese or international hotel chains, hence, instead of the hotels being classified from one to five stars, the Vietnamese hotels should be categorised into smaller classes with half star grade, for instance 4 stars and 4.5 stars. Other types of tourist accommodations may be classified into star ratings in the same way.

\subsubsection{Implications for other researchers}

From the researcher's perspectives, the findings of how Vietnam's economic renovation, international factors and patterns of demand influence the distribution channel structures of the four hotel ownership modes have added an understanding of Doi Moi in Vietnam in general and economic restructuring in hotel sector in particular. As a result of Doi Moi, the multi-hotel ownership modes have a close relationship with hotel management modes. These two factors that have impacts on the up-market hotel distribution channel structures have contributed to the current thinking on the development of market orientation of the hotels in Vietnam. These findings are useful for other researchers to conduct studies focusing on sampling of other tourist establishments or lower star rating hotels in Vietnam or in other transitional economies. First, as multiple hotel ownership and management modes are considered as the main promoters, barriers and competitive factors in the development of distribution channels, the findings shed light on the special advantages and challenges that each type of hotel ownership and management mode in Vietnam faces to reach the tourism market. Second, the findings emphasize that two pillars of hotel ownership, hotel management modes plus the hotel distribution channel structures have contributed to understanding of the socialist market-oriented economy, an unprecedented economic mode that Vietnam is pursuing. A current mixture of the four ownership modes, a movement from a dominance of SOHs in the hotel sector to a majority of privatised and non-state hotels, various hotel management modes, and the different distribution channel structures on the one hand indicates the socialism where the government wants to own properties. On the other hand, it presents the trend of a market economy where a number of suppliers (non-state hotels) freely find ways to meet the consumers' demands for profitability. 


\subsection{Implications for relevant parties in other economies}

It is mentioned in Section 1.2 that Vietnam offers a good example of transitional economies, hence a number of implications of the current distribution channel structures undertaken by Vietnamese up-market hotels and the factors influencing them discussed in sections above could be extended to other transitional economies and elsewhere as follows.

First, hoteliers in other transitional economies might benefit from the clearer picture of distribution channel structures presented in this study to update their knowledge of distribution and to organise sales and marketing activities. This is because the study identified the up-to-date list of channel members, advantages and disadvantages of direct and indirect channels and the ways in which different hotel ownership modes reach the tourism market based on hotel resources, products and services, target markets, business objectives in relation to external factors. Methods applied by the IJVHs in Vietnam to manage possible conflicts among channels and channel members are also useful for the hotels in other transitional economies. Conflicts between the hoteliers and tour operators have been investigated in the context of economically developed countries (Buhalis, 2000), however, this study has pioneered examination of this relationship in transitional economies.

Second, travel intermediaries in other transitional economies and wholesalers elsewhere gain benefits from the study findings in terms of the roles and operational characteristics of travel businesses in Vietnam. In line with the studies of Buhalis and Licata (2002) regarding the future of Etourism intermediaries and Kracht and Wang (2010) in terms of the evolution of travel intermediaries in developed countries, this study has shown a a growth of travel intermediaries and OTAs in Vietnam. This trend may occur in other transitional economies, that is, the rapid growth of OTAs has generally challenged conventional intermediaries because of technological advancements. Wholesalers in developed countries, the source of a large proportion of guests of the hotels in Vietnam, are provided with a picture of the current and future travel intermediaries to design a better business strategy towards those destinations.

Third, the study is significant for the researchers who investigate tourism and hotel distribution channels in other transitional economies or countries that share similar 
socio-economic characteristics with Vietnam. The conceptual framework (Figure 2.5) and the framework of factors influencing distribution channel structures of the different hotel ownership models (Figure 7.1) could be used in other transitional countries. The diagrams of distribution channel structures applied by the four hotel ownership modes suggest to other researchers that channel functions and aspects of distribution should be taken into account when examining business relationships between travel intermediaries with the hotels and consumers. This mutual nexus may reflect the nature of a journey that post-communist countries are moving to the market-oriented economies.

Fourth, factors of the economic restructuring and transitional economy as well as their recognised impacts on distribution are significant for potential international investors in establishing their own investment, structuring and management issues associated with the distribution channels. The literature review reveals that transitional economies share common features regarding privatisation of SOHs, changes in socio-economic conditions and legal system, a boom in tourism development and the opening up to both domestic and international investments. Therefore, what has happened in the Vietnamese hotel sector could provide a good example of transitional economies for investors to understand aspects of the hotels of these countries. The Vietnamese upmarket hotel distribution and factors of the economic development, demand from domestic and international tourists, technological advances, financial and banking services are practically applicable to Cuba where a similar economic model of Doi Moi in Vietnam has been recently applied.

Fifth, questions that need clear answers from the government and tourism authorities related to state ownership in the SOHs are particularly useful for the policy makers in Cuba. In order to shorten the transitional period to the market economy in the hotel sector, lessons drawn from the study findings are that the Cuban government should quickly privatise SOHs into 100 per cent privately-owned hotels. No limit should be imposed on the amount of shareholdings in the SOHs that investors may invest in. The Cuban government could allow the SOHs to sign contracts with hotel management companies to run the hotels, or the general managers of the equitized SOHs should be given full power and the autonomy in running these SOHs. 
Finally, this study suggests that the researchers in developed countries should take into account hotel ownership modes as an important and influencing factor to examine the distribution channel structures of the hotels in their future research. Although there are no longer SOHs in the Western hotel industry, domestic privately-owned, international joint venture and wholly foreign owned hotels still exist. Therefore, the relationships between hotel ownership modes and the structures of hotel distribution channels is under-researched topic that deserves much greater attention

\subsection{Conclusion}

This chapter has focused on discussing notable implications of the current distribution channel structures and factors influencing them for hotel and tourism development in Vietnam, other transitional economies and elsewhere in the world. Implications of different distribution channel structures for related members within Vietnam's hotel and tourism including Vietnamese tourist accommodation, travel intermediaries, policy makers and other researchers are mentioned first, and then implications of influential factors for the above parties are discussed. Where relevant, significances for interested parties elsewhere in the world are also discussed.

The hotel distribution channel systems have a variety of implications for industry practitioners and the researchers. In Vietnam, each type of up-market hotel ownership benefits from an overall picture of distribution channel structures to organise and deliver their sales and marketing activities. The analysis of the proportion of sales via direct and indirect channels and patterns of demand in relation to the management modes across the four up-market hotel ownership modes are significant for up-market hotels to approach a market niche and to select appropriate channels. Lower star rating hotels and the remaining types of tourist accommodations also benefit from the differences and commonalities of the aspects of distribution regarding the combination of channels as well as an up-to-date list of available channel members used to reach domestic and international tourism markets. Vietnamese TOs were informed that the level of professionalism of Vietnamese TOs and TAs needs improving since the rapid growth of OTAs has challenged conventional intermediaries. Policy makers were brought a source to understand components making up the current hotel distribution channel structures, and to get into insights a gap between Vietnamese-owned and -managed hotels with IJVHs and FOHs. Current distribution systems also benefit other researchers who 
investigate tourism and hotel distribution channels in other transitional economies or countries that share relatively the same socio-economic characteristics with Vietnam. This is because the conceptual framework and the framework of factors influencing distribution channel structures of the different hotel ownership modes could be used in such types of research in other similar settings or elsewhere in the world.

Identified factors influence the above distribution systems are significant for hoteliers, travel intermediaries, policy makers and academics. First, Vietnam's economic restructuring, transitional economy as well as other internal and external factors assist the up-market hotels themselves and other Vietnamese tourist accommodations' current operators, potential investors in Vietnam and abroad in establishing their own businesses, structuring and managing issues associated with sales and marketing in general and the distribution channels in particular. Second, together with a strong development of ICT, transportation and banking, the international integration of Vietnam that allows foreigners to do travel business in Vietnam under 100 percent foreign-owned or international joint venture companies have again noted a very challenging business environment that local TOs will face. Third, the relationship between hotel ownership and management modes with the distribution channel structures are the reminders for policy makers that some questions of legal platform towards a market economy need to be addressed. Finally, these identified factors are particularly applicable to Cuba where the economic reform has been recently introduced. The study also suggests scholars to conduct other research in tourism and hotel distribution and other economic sectors inside or outside Vietnam with similar context to investigate these influential factors. In developed countries, this study recommends the researchers to investigate hotel ownership modes as an important factor influencing hotel distribution channel structures. 


\section{CHAPTER 9. DISCUSSION AND CONCLUSIONS}

\subsection{Introduction}

This concluding chapter firstly discusses the findings presented in Chapters Four to Seven. Strengths and limitations of the study will be outlined, and then key contributions of the thesis will be drawn.

\subsection{Discussion of study findings}

Throughout this thesis, there have been discussion sections along with the data interpretation and analysis. In this section, discussion is mainly based on two themes: First, distribution channel structures, and the factors that influence them, focusing on hotel ownership and management modes in relation to Vietnam's economic reform, trends in tourism and hotel development, the overall economy of Vietnam.

\subsubsection{Distribution channel structures}

The distribution channel structures of the Vietnamese hotel ownership modes have both commonalities and differences compared with the literature regarding the detailed aspects of distribution (channel members, channel mix, direct and indirect distribution, channel length, channel width and channel functions). As presented in Figure 7.1, most of the channel members appearing in the distribution structures of the IJVHs and FOHs are common in the international tourism and hospitality industry; however, some of them such as CROs, GDS or global and regional sales offices, are not used by SOHs and DPOHs because of hotel resources, networking and management approaches. Moreover, the cooperation of the SOHs and DPOHs with unlicensed TOs and TAs to reach international tourism market reflects three possibilities: (1) the law is ineffective in preventing such practice; (2) these hotel owners have close relationship with specific interest groups or the government to avoid fines; and (3) the room occupancy rate of these hotels is not high hence they find all possible ways to generate sales. These possibilities seem to be peculiar to a transitional economy like Vietnam since the IJVHs and $\mathrm{FOHs}$ managed by international hotel chains originated from developed countries have not found it necessary, or appropriate, to apply this type of cooperation in their businesses. 
Other aspects of distribution also reflect differences between the entirely Vietnameseowned and managed hotels with the IJVHs and FOHs in how they engage with tourism markets. As discussed in Section 5.3.1, the IJVHs are directly managed by well-known global hotel chains. These international hotel management companies are considered as flagships in the Vietnamese hotel sector since global hotel brands have brought trust to international guests, particularly to people who either have yet come to Vietnam or lack information about Vietnam. The IJVHs have also played an important part in creating the country's hotel image, partially ensuring the attractiveness of Vietnamese tourism, and encouraging other hotel investors to come to Vietnam. In the sales and marketing field, the rich resources and management experience of the IJVHs and FOHs have led to their professionalism level of combining channels, using intermediaries to balance direct and indirect sales and taking advantages of global network to shorten channel lengths. Regarding channel functions, each channel carries out functions including information provision, advice, negotiation, booking, payment for booking and payment of commission or fee(s). These functions are found at IJVHs and FOHs; however, the SOHs and DPOHs are seen to use the payment function to pay illegal commissions for direct bookings from government departments. On the one hand, the functional difference of channel used by SOHs and DPOHs with IJVHs and FOHs further explains the earlier point. On the other hand, this difference, therefore, needs to be recognised by the government in the process of creating platform for hotels to reach tourism markets. The government must improve laws to prevent illegal commissions, and the domestic owned hotels should recognise what the IJVHs and FOHs do and learn from their approaches.

The trends of electronic travel intermediaries such as OTAs and GDS, direct channels and conventional travel companies can be predicted in the distribution channel structures via analysis of patterns of demand and distribution. First, the OTAs will increasingly become a giant of the hotel booking service. These OTAs are developed and designed to be integrated with internet search engines such as Google and Yahoo, offering guests clear hotel information and rooms available to book easily and conveniently. Room sales from OTAs will accordingly account for a large proportion of sales of Vietnamese up-market hotels. However, as commented by some hotel representatives, the growth of the OTAs will become saturated. Most of the hotels have been strongly investing in e-marketing tactics to escape their dependence on OTAs and 
to avoid paying high commission (around 20 per cent). Tactics include upgrading the hotel websites to get direct bookings, and strategies to attract guests of the OTAs to become direct consumers in their coming holidays. Second, it is believed that GDS will generate a small proportion of room sales of the hotels in the future because of the development of OTAs and their simpler booking procedures. GDS is known as a bidding platform for hotels to offer best room rates for travel agents and guests of large corporations, however, OTAs are now compatible with search engines. These OTAs' websites are easy for hotels to provide all types of guests with the most up-to-date room status and price to book or amend bookings. Third, direct channels will grow and conventional travel intermediaries will probably reduce in terms of quantity. Most Vietnamese up-market hotels studied believe that conventional TAs and TOs do not have much power to decide where the guests will stay; it is the decision of tourists so the hotels develop direct distribution channels such as websites and social networks to attract tourists. As a result, most Vietnamese traditional intermediaries have gradually changed their business purposes. For instance, they have focused on particular market segments, for example MICE or contracted land services for overseas wholesalers and tour operators.

Broadly, distribution channel structures of the four hotel ownership modes at present and over the last decades reflect a movement from a command to the socialist marketoriented economy, marking milestones of Vietnam's global integration. Under the closed-door economy before Doi Moi in 1986, there had been no direct links between domestic and international tourists and accommodation establishments; however, the structures of hotel distribution channels have been established according to a combination of direct and indirect channels in this transitioning period. These structures have been increasingly expanded and developed to meet the tourists' needs based on (1) the effectiveness of the laws promulgated after Doi Moi; (2) the development of economics, technology and banking system, (3) the appearance of non-state ownership modes; (4) a growth of the up-market IJVHs; and (5) Vietnam's international integration. Although domestic guests currently account for a small part of total room nights sold, particularly in IJVHs and FOHs, and this type of guests is also considered as substitute of international tourists, different hotel ownership modes have established the distribution channel structures to reach these domestic guests who were not seen in the command economy period. This finding is consistent with a number of studies in 
other transitional economies. That is, the economic reform leading to market liberalization, competitive pressure, and consumers' demands have combined to transform transition economies' distribution systems of firms from being supply-driven to being increasingly responsive and market-driven (Cadilhon, Moustier, Poole, Tam \& Fearne, 2006; Jiang \& Prater, 2002; Luk, 1998; Maruyamar \& Trung, 2011). These characteristics are particularly in line with findings of Jaakson (1996) and William (2002), these researchers noted that tourism in some countries in CEE became increasingly subject to globalisation because people have travelled freely within a country and abroad.

The literature review of other economic sectors in Vietnam and tourism in other transitional economies revealed that transitioning countries share certain characteristics with what has happened in the Vietnam's hotel sector regarding the movement of distribution structures (Athukorala \& Tien, 2012; Suntikul, 2010; Suntikul, Butler \& Airey, 2008, 2010a, 2010b). To some extent, the economic restructuring, the privatisation of the SOHs, the opening up of the domestic economy to international trade and global investments, and a booming of non-state hotels have become motivators for the hotel sector, promoting a competitive hotel business environment among the hotels to reach tourism markets. These motivators allow freer investments and generate the circulation of hotel products and services based on supply and demand. In agreement with findings in other economic sectors in Vietnam, this movement and the present hotel distribution channel structures provide understanding and features of the country's development towards the market-oriented economy. This is because the multi-ownership economic structure and competition between public and private sectors have replaced the monopoly of the SOHs. Each type of hotel ownership establishes its own distribution channel structures based on its ownership, management mode and other resources. If the literature showed that SOEs in transitional economies are less effective than non-state enterprises, particularly FDI enterprises, in terms of firm performance, organisational structure and employee mobility (Commander \& Svejnar, 2008; Sun et al., 2002; Tang et al., 2006), the distribution channel structure of SOHs is also likely to be less effective than those of IJVHs and FOHs.

Aspects of sales and marketing techniques regarding the establishment of distribution channel structure of the IJVHs and FOHs have been transferred to the entirely 
Vietnamese owned and managed hotels, affirming the formers' leading position in tourism market. The data analysis showed that based on available resources, the SOHs and DPOHs copy appropriate techniques from IJVHs to structure their distribution channels to reach markets. In other research, Suntikul et al. (2010b) have pointed out that the IJVHs have also played a driving role in raising the standards in Vietnam's hospitality industry. The IJVHs have forced the SOHs and DPOHs to adjust to the higher standards of service and facilities expected by the Western travellers who make up an increasing number of their customers since 1986. Long-established state-owned hotels are improving their facilities to keep up with the international market. In particular, the new hotel business environment has changed the market concept of the SOHs as these state hotels are now unable to rely on government departments to generate a large volume of room sales (Suntikul et al., 2010b). The study's findings have clarified roles of FDIs in accommodation sector that more equal and transparent business environment have recently occurred in Vietnam as a result of the socialist market-oriented economy and international integration. That is, the roles of foreign investors have been acknowledged and FDI companies are contributing to the growth of Vietnamese economy. Therefore, the conclusion of Suntikul et al. (2010b, p. 269) is now less applicable, that is "an 'unwritten law', which gives the minority shareholder the same control and rights as the majority partner, gives Vietnamese firms an added incentive to team up with foreign investors".

\subsubsection{Factors influencing distribution channel structures}

This section discusses ownership and management modes, which in turn emerge as the most important elements influencing hotel distribution channel structures as a result of Doi Moi. While state ownership and SOHs are recognised as a legacy of command economy, management modes are associated with the development of market-oriented economy. These factors are also seen as predictive signals of changes that will occur in Vietnam's hotel and tourism industry as well as the entire economy.

First, ownership modes are seen to be the main and important economic factor that influences different aspects of economy. A series of Vietnamese laws have been promulgated and revised based on the increasing changes of state ownership in keeping up with the development of the socialist market-oriented economy (VNA, 2013; 2014, 2014 a, b). In the hotel sector, ownership is also recognised as one of the key 
components that influences the way in which the hotels establish their distribution channel structures. The literature says that a command economy is characterized by collective ownership of capital, and property is owned by the State, prices and production levels are determined by the State via planning mechanism rather than supply and demand (Prishchepov et al., 2012; Svejnar, 2013). In a transitioning period, post-communist countries witness the proliferation of various types of companies including SOEs, domestic private owned-enterprises, international joint ventures and wholly foreign-owned ones, and a rise of competition among them to reach domestic and international markets. In this movement, ownership is still a common factor to differentiate types of company as firm efficiency is negatively related to SOEs while positively associated with public and employee share ownership (Commander \& Svejnar, 2008; Cvelbar \& Mihaliè, 2007; Sun et al., 2002; Tang et al., 2006). In the context of Vietnam, ownership is considered to be the source of differences among SOEs, privatised enterprises, those transitioning to privatisation, international joint ventures, and the foreign-owned companies (see Section 2.3). In this regard, the findings of the current hotel distribution channel structures of the four hotel ownership modes discussed in Section 9.2.1 are also consistent with what are found in the literature. Therefore, these findings in the hotel sector could be used to generalise ownership modes in other economic sectors such as airline and catering industry in Vietnam (Nguyen Quan, 2014) where the literature is fragmented or has so far been paid less attention by the researchers.

Second, hotel ownership modes reflect the current situation that the Vietnamese government faces the challenge of balancing its socialist ideology with globalising and commercialising influence of the international tourism market on politics, economics and Vietnamese society. This includes the privatisation of SOHs. Over the last two decades, Vietnam has listed a number of SOHs that the government would equitise and privatise to move its economy to a market mechanism. However, the Director of the ESRT (Environmentally Socially Responsible Tourism) project of VNAT said, when the government initiated the equitisation and privatisation programmes over a decade ago, many people thought that the government would complete this process in the hotel industry rapidly. This is because the SOHs are not a priority economic sector. However, the Director of ESRT project did not know when all SOHs would be 100 per cent privatised when the researcher conducted an interview with him in 2013. Actually, 
equitisation and privatisation of the Vietnamese SOEs have been generally too slow, the government only undertook equitisation of a number of small enterprises. The large state enterprises, including four- and five-star SOHs, are more difficult to privatise because it is challenging to remove different interest groups who have benefit from the SOEs. Moreover, the current political-economical ideology of the VCP in developing and maintaining roles of the government in SOEs is also hindering the privatisation process. If Vietnam considers the private economy as a real motivation of the politicaleconomic reform to establish a pure market economy, the Vietnamese government should remove its roles in SOEs such as SOHs and in some IJVHs. The economic reform in 1986 laid a platform for the development of Vietnam; however, it is time for the Vietnamese government to eliminate the exposed barriers during the last 30 years that obstruct a process of being a market economy by introducing another economic reform. Carrying out the 100 per cent privatisation of SOHs would be an example of another Doi Moi in the hotel and tourism sector.

Third, management modes have emerged as a factor having strong influences on the ways in which each type of hotel ownership establish the distribution channel structure. When the researcher proposed to investigate this research problem, ownership was considered as the only important factor. However, in the very limited literature investigating the relationship between ownership and management, company development and management modes ( $\mathrm{Su} \& \mathrm{He}, 2012)$, it is noted that enterprises with more independent management style are more efficient. In line with this conclusion, this study findings show in detail that the IJVHs and FOHs managed by well-known international hotel chains seem to structure their channels more effectively to reach tourism market compared with SOHs and DPOHs. Apart from advantages of resources, products and services, clear business objectives and target markets as well as management techniques of investors and management companies, the general managers of non-state hotels have more power to organise their sales and marketing strategies, to make decisions on financial issues or to dismiss labourers. In contrast, state hotels, with their fairly dated management mechanisms and systems, are one of the barriers to the development of market-oriented organisation in the tourism industry. These difficulties and barriers are acknowledged not only by the industry practitioners but also the policy makers interviewed in this study. This may be a signal of change in terms of enterprise management. 
The most up-to-date information on the changing management mode of SOHs has informed a change in up-market hotels related to both ownership and management. As mentioned earlier in this chapter and in Sections 2.2 and 2.3, the Vietnamese government is following a conservative transformation from a command to a socialist market-oriented economy with no change in political regime. It means that apart from 100 per cent SOEs, the government continues to hold ownership in equitised enterprises to dominate the market, particularly the up-market hotels. The government tends to hire management companies to run business for better profitability. Indeed, at least three SOHs have recently moved to being operated by international hotel chains under management contracts. In December 2015, the only state-owned hotel in Hanoi (Victory Hotel) was equitised where the government still hold dominant shares (over 51 per cent). Under the agreement of the government, these investors have hired Hilton Hotels and Resorts to operate the Victory Hotel under the name Hilton Hanoi Westlake (Bach Duong, 2015; Nhu Loan, 2015). Since the data were collected for this thesis in 2013, two other hotels that are largely owned by Saigontourist and Liberty Corporation (SOEs) have also been renovated and are now run by Accor as the Pullman Saigon Centre and Novotel Saigon Centre (Dao Loan, 2014; Phan An, 2014). These movements may indicate a developing trend in the Vietnamese hotel sector, tourism and the entire economy as the government adapts the dynamics of transitional and global economies to reach market mechanism. SOEs in general and up-market SOHs are likely to be managed by more professional management companies on behalf of the government and other investors.

\subsection{Strengths and limitations of the study}

\subsubsection{Strengths}

The first strength of this research is that findings were generated from robust data gathered from the mix of different groups of participants working in the Vietnam tourism industry including hoteliers, international TOs, government officers, trade organisations, academics and across all four hotel ownership modes. Primary data were interpreted and analysed to establish distribution channel structures and to explore factors influencing them. A variety of secondary documents gained from the Vietnamese government, VNAT, Grant Thornton Vietnam and other government departments were used as a means of triangulation with primary data. This selection has ensured the rigour and validation of data as each group of representatives' knowledge of 
Vietnam's hotel sector, hotel distribution channels and Vietnam's transitional economy complemented others. Secondary data played an important role in verifying different knowledge and information provided by respondents.

The second strength is that the research was completed with a high response rate and all of the interviewees allowed their information and opinions to be attributed to their businesses. These achievements are significant in the context of conducting research in Vietnam where researchers have noted that it is challenging to gain access to participants, particularly high-ranking government officials (Maruyamar \& Trung, 2011). Moreover, the agreement of interviewees to cite their name and/or their organisation in the thesis enables the reader to have a better understanding of the context and findings and to facilitate explanations of findings.

Thirdly, the positionality of the researcher as a $\mathrm{PhD}$ student and also an officer of VNAT aided contextualization of the research.As a student access to the international literature of tourism and hotel distribution strengthened the analysis and interpretation of a local research problem. Working experience in the Vietnamese tourism industry gave access to participants, and also provided the researcher with information about the nature of each hotel ownership mode that influenced the interpretation of the data within the Vietnamese context and academic body of knowledge.

Multiple research sites in the three largest cities in the North, Centre and South of Vietnam is a further strength as this geographical spread gave insights into factors influencing hotel distribution channel structures across the country. For example, the open culture of Saigon people and more service-minded staff in Southern Vietnam in comparison with the conservative culture of Northern Vietnam have affected the way in which hotel staff work with TOs and TAs to deliver sales.

\subsubsection{Limitations}

A number of limitations of this study were identified in Section 3.3, mainly relating to the research methodology and data collection methods. First, by taking the case of the up-market hotels, only four- and five-star hotels located in Hanoi, Danang, and Ho Chi Minh City among 63 provinces of Vietnam were chosen as the sample to investigate structures of distribution channels. This sampling has a limitation that the lower quality 
hotels, hotels and other types of tourist accommodation in other provinces, rural and mountainous areas are not considered even though these small and medium hotels play an important role in developing the market mechanism in transition economies including Vietnam. Thus, the research does not provide a complete picture of tourist accommodation distribution channel structures in Vietnam but highlights the ways in which higher quality tourist accommodation is distributed to tourists. However, the upmarket hotels are the leading edge of distribution changes and thus understanding what is currently occurring in this sub-sector has implications for the future development of other accommodation types.

Second, as the study employs a supply-side approach, questions of demand and the behaviour of consumers were only examined indirectly. As a result, this research does not directly address the demand-side or an integrated approach of both supply and demand due to the methodological considerations. Domestic travel companies, overseas travel intermediaries, visitors who serve as consumers of the hotels were referred to indirectly by some on-site suppliers, intermediaries, the Vietnam tourism industry members and secondary sources.

Third, the positionality of the researcher was regarded as an influential factor in analysing data. As an official of the VNAT, the researcher's role and background may have caused certain biases in the data collection and data analysis although the steps to conduct the fieldwork were strictly followed by the researcher according to the ethics approval of the Victoria University of Wellington.

Fourth, some quantitative data on hotel occupancy rates and sales data are missing and access was not gained to internal marketing strategies and reports of the hotels and international TOs. Quantitative data provided by the hotels were also uneven. For example, some hotels revealed all the figures of guest types and sales of room nights via direct and indirect channels, but a small number of the hotels did not, hence the overall average figures in the finding chapters have been affected. Data related to Average Daily Rate and Revenue per Available Room were not gained due to sensitively commercial reasons. 
Lastly, some parts of the data provided by the different groups of participants through interviews did not meet the researcher's expectations. Despite these advantages in gaining access to the desired participants, it was still difficult to arrange interviews with some hotel representatives and local government officials in Hanoi. Many of the invited participants from the hotels in Hanoi declined to participate in the research or to have interviews audio recorded. Most of these interviews were made through emails or notes during the talks. In contrast, the interviews in Ho Chi Minh City and Danang were mostly audio recorded; therefore this resulted in the higher frequency of interviewees' quotes from certain hotels.

Overall, while the limitations of this research are acknowledged, these need to be set against the strengths, particularly the access and familiarisation of the researcher with the Vietnamese context.

\subsection{Contributions of the study}

This study makes a number of contributions to the literature and knowledge. First, the study addresses a scarcity in the research on tourism and hotels in Vietnam, then it fills a gap in the literature on hotel distribution in terms of ownership and management modes in Vietnam, in other transitional economies or elsewhere in the world. As discussed in Chapter Two, Vietnamese tourism and hotels have been paid little attention by Vietnamese and international scholars although Vietnam is increasingly becoming a popular destination in the Southeast Asian region. Most Vietnamese researchers have neglected to investigate tourism and hotel distribution channels though they are found to be one of the important success factors of tourism enterprises in advanced economies. In the context of other transitional economies or countries with similar levels of socioeconomic development, this study also contributes to the literature on tourism and hotel distribution channels in relation to ownership and management modes.

Second, this study identifies the current distribution channel structures of the four upmarket hotel ownership modes in Vietnam. These findings not only benefit all types of hotel ownership, other members in the Vietnam's tourism and hotel industry but also lower quality hotels and other tourist accommodation. Specifically, by systematically analysing and presenting the distribution channel structures used by types of hotels to reach tourism markets, the study provides an understanding of the four hotel distribution 
channel structures and makes comparisons between them. These findings should help hotel industry members manage their marketing strategies better and assist tourism policy makers to adjust their policies towards a more market-oriented economy. In addition, these findings and the methodology used may assist other researchers to examine this research problem in other transitional economies or elsewhere in the world.

Third, the study contributes to a better understanding of the ways in which external and internal factors influence distribution structures in Vietnam's up-market hotels (Figure 7.1). This diagram demonstrates how factors influence the distribution channel structures of the different hotel ownership modes. Figure 7.1 highlighted that Vietnam's economic reform has opened the country's door to the world, initiating a process of international integration of the Vietnamese tourism and hotel enterprises into the global tourism market. This economic reform has generated a number of internal and external factors that have impacts on the establishment of the hotel distribution channel structures. Among these, hotel ownership and management modes emerge as the most important elements generating similarities and differences among the four distribution channel structures since these two factors relate to the hotel resources, the nature of products and services, business objectives and target market as well as the level of professionalism. Ownership, management modes and the findings of internal and external factors are also essential and applicable to other contexts of transitional economies when the researchers investigate hotel distribution channels or other economic sectors. This is because while most of the studies in transitional economies have recognised ownership as an important element influencing firm operations, the management modes of firms have rarely been referred to. The research findings might also benefit academics, policy makers, hoteliers in some transitional economies in Asia (e.g. China, Cuba, Laos and Myanmar) and elsewhere in terms of ownership, management modes and distribution channels.

Fourth, the study contributes to understanding of the relationship between Vietnam's transitional economy and the distribution channel structures of the up-market hotels. The findings show that the economic transformation from a command to a market economy means the Vietnamese government policies have changed the distribution systems of firms from being supply-driven to being increasingly responsive and marketdriven. Under a command economy, the structure of distribution channels was 
organized in line with the administration system, which caused disconnection among production, distribution, and consumption of the SOEs. In the transitioning period, the changes in the legal system and the proliferation of different ownership modes have enabled enterprises to structure their distribution channels to meet the consumers' needs in the market. In this regard, the insights into hotel ownership and distribution may provide useful examples for distribution in other service sectors such as air, land transportation and travel industry.

Finally, through a detailed analysis of distribution in a particular sector this study contributes to a better understanding of changes in Vietnam since its Doi Moi. For example, the discussion of the laws related to hotel development and distribution illustrate aspects of the process of transformation from a command to a market oriented economy while discussion of the regulations on controlling information provided on the internet show how the economic reform has influenced Vietnam's current hotel business..

\subsection{Conclusion}

At the time of writing this final chapter, the $12^{\text {th }}$ National Congress of the Vietnamese Communist Party took place from $21^{\text {st }}$ to $28^{\text {th }}$ of January 2016 in Hanoi to evaluate the 30-year period of Doi Moi and to determine the socio-economic development strategies for the next five years. This Congress also finalised the 180 members of Central Vietnamese Communist Party who will accordingly become the top leaders of various ministries, provinces and other organisations on a five-year tenure basis (Duc Binh, 2016; VGP, 2016). During the last 30 years of Doi Moi, Vietnam has gained limited successes in terms of economic developments to turn Vietnam from one of the poorest countries into a middle-income nation. Doi Moi has increased Vietnam's position in the world in a number of fields such as exports of rice, cashew, coffee, seafood, garments and footwear. However, the Congress identified a number of ongoing issues including an incomplete mode of the socialist market-oriented economy, slow economic and administrative reform, corruption, and low living standards of people in rural and mountainous areas (Duc Binh, 2016). In the next five years, with the direction of the single VCP, Vietnam aims to develop further under the global business integration. The mode of the Vietnamese socialist market-oriented economy where state enterprises play a leading role continues to be completed, although this economic model has been 
criticised by both domestic and international economists as unrealistic and an unprecedented mode in the world (Duc Binh, 2016; Huynh, 2013; Nguyen, 2016; To Vuong, 2015). The outputs of the $12^{\text {th }}$ National Congress and the conservative party members headed by the new General Secretary of VCP outweigh reformists (Le Quynh, 2016), a signal that another intensive Doi Moi or Doi Moi II is not likely to happen in the next five years. Despite this, internal and external pressures of integration and trade with the world to expand markets are strong.

In this context the factors influencing distribution channel structures identified in this thesis will continue to be important, particularly issues of state ownership and different hotel management modes. The current up-market SOHs are likely to continue to develop under the process of equitisation and privatisation and a strong growth of nonstate hotels is expected. Transitioning to a market economy may witness a boom in large DPOHs with multiple forms of management modes as these hoteliers accumulate more management experience, knowledge and capital to integrate into international markets. However, the government still holds dominant shares in the up-market equitised hotels and thus the distribution channel structures of the four hotel ownership modes is likely to continue..

As mentioned earlier, three SOHs have recently been equitised and now have international hotel group management, signalling a developmental trend of SOHs. This mode means the government as the biggest owner, still directs the policy of former 100 per cent SOHs. However, it also reflects a gradual reform to reach the market economy. Specifically, the mode of state ownership and international management is likely to be a pilot programme similar to the programme of developing joint venture hotels at the early stage of Vietnam's economic reform (see Section 5.2). The government will continue to hire international hotel groups to manage other SOHs, or not, depending on outputs of this trial strategy. In this context, the insight into distribution channel structures of the different hotel ownership modes provides a valuable picture of the transitioning process of Vietnam to a market economy. 


\section{REFERENCES}

ACV. (2014). Tan Son Nhat International Airport. Retrieved from http://en.vietnamairport.vn/page/104/ket-qua-tim-kiem/tan-son-nhatinternational-airport.

Anh Vu. (2015). Đổi mới quản trị doanh nghiệp nhà nuớc (Renovating corporate governance of state owned enterprises). Retrieved from http://www.nhandan.org.vn/kinhte/tin-tuc/item/26566602-doi-moi-quan-tridoanh-nghiep-nha-nuoc.html.

ASEAN (Association of Southeast Asian Nations). (2010). ASEAN tourism strategic plan 2011-2015. Retrieved from http://www.asean.org/resources/item/aseantourism-strategic-plan-2011-2015-2.

ASEAN (Association of Southeast Asian Nations). (2015). Tourism statistics. Retrieved from http://www.asean.org/news/item/tourism-statistics.

Asselin, P. (2007). Choosing peace: Hanoi and the Geneva Agreement on Vietnam, 1954 -1955. Journal of Cold War Studies, 9(2), 95-126.

Athukorala, P. C., \& Tien, T. Q. (2012). Foreign direct investment in industrial transition: the experience of Vietnam. Journal of the Asia Pacific Economy, 17(3), 446-463.

Aukutsionek, S. (1997). Some characteristics of the transition economy. Communist Economies and Economic Transformation, 9(3), 289-336.

Bach Duong. (2015). Khách sạn Thắng Lợi đổi tên(Victory hotel has changed its brand). Retrieved from http://kinhdoanh.vnexpress.net/tin-tuc/doanh-nghiep/khach-santhang-loi-doi-ten-3328436.html

Bachvarov, B. (1997). End of the model? Tourism in post-communist Bulgaria. Tourism Management, 18(1), 43-50.

Beck, T., \& Laeven, L. (2006). Institution building and growth in transition economies. Journal of Economic Growth, 11(2), 157-186.

Beresford, M. (2001). Vietnam, the transition from central planning. In G. Rodan, K. Hewison, and R. Robison (Eds.), The Political economy of South-East Asia: Conflict, crises and change (2nd ed., pp. 206-232). Melbourne: Oxford University Press.

Beresford, M. (2008). Doi Moi in review: The challenges of building market socialism in Vietnam. Journal of Contemporary Asia, 38(2), 221-243.

Berg, B. L. (2004). Qualitative research methods for social science (5th Ed.). Boston: Pearson Education, Inc. 
Berger, A. A. (2005). Vietnam tourism. New York: Haworth Hospitality Press.

Bevan, A. A., \& Estrin, S. (2004). The determinants of foreign direct investment into European transition economies. Journal of Comparative Economics, 32(4), 775787.

Bevan, A., Estrin, S., \& Meyer, K. (2004). Foreign investment location and institutional development in transition economies. International Business Review, 13(1), 4364.

Bich Diep. (2013). Tổng cục thống kê thìa nhận số liệu thống kê còn nhiều bất cập. (The Vietnamese General Statistics Office confessed the inconsistence of statistical figures). Retrieved from http://dantri.com.vn/kinh-doanh/tong-cuc-thong-kethua-nhan-so-lieu-thong-ke-con-nhieu-bat-cap-816579.htm

Blaikie, N. (2003). Analyzing quantitative data. London: SAGE Publications.

Bowen, G. A. (2009). Document Analysis as a Qualitative Research Method. Qualitative Research Journal, 9(2), 27-40

Brotherton, B. (2008). Researching hospitality and tourism. London: SAGE Publications

Brown, D., Taylor, C., Baldy, G., Edwards, G., \& Oppenheimer, E. (1990). Computers and QDA - can they help it? A report on a qualitative data analysis programme. Sociological Review, 38(1), 134-150.

Bruha, J., \& Podpiera, J. (2007). Transition economy convergence in a two-country model: implications for monetary integration. Retrieved from http://papers.ssrn.com/sol3/papers.cfm?abstract_id=971017\#\#

Bryman, A. (2008). Social research methods. New York: Oxford University Press Inc.

Bryman, A. (2012). Social research methods (4 ${ }^{\text {th }}$ Ed.). New York: Oxford University Press Inc.

Buhalis, D. (2000). Relationships in the distribution channel of tourism: Conflicts between hoteliers and tour operators in the Mediterranean region. International Journal of Hospitality \& Tourism Administration, 1(1), 113-139.

Buhalis (2001). Tourism distribution channels: practices and processes. In D. Buhalis and E. Laws (Eds.), Tourism Distribution Channels: Practices, Issues and Transformations (pp. 7-32). London: Continuum.

Buhalis, D., \& Laws, E. (Eds.). (2001). Tourism distribution channels: Practices, issues and transformations. London: Continuum.

Buhalis, D., \& Licata, M. C. (2002). The future eTourism intermediaries. Tourism Management, 23(3), 207-220. 
Bui, T. H. N. (2009). Potentiality of Vietnam Online Tourism-The Case of Skydoor. Retrieved from http://www.divaportal.org/smash/record.jsf?pid=diva2\%3A233610\&dswid=3852.

Bui, H. T., \& Jolliffe, L. (2011). Vietnamese domestic tourism: an investigation of travel motivations. Austrian Journal of South-East Asian Studies, 4(1), 10-29.

Bui, T. X., Le, T., \& Jones, W. (2006). An exploratory case study of hotel e-marketing in Ho Chi Minh City. Thunderbird International Business Review, 48(3), 369388.

Cadilhon, J. J., Fearne, A. P., Moustier, P., \& Poole, N. D. (2003). Modeling vegetable marketing systems in South East Asia: phenomenological insights from Vietnam. Supply Chain Management: An International Journal, 8(5), 427-441.

Cadilhon, J. J., Fearne, A. P., Thi Giac Tam, P., Moustier, P., \& Poole, N. D. (2005). Collaborative commerce or just common sense? Insights from vegetable supply chains in Ho Chi Minh City. Supply Chain Management: An International Journal, 10(3), 147-149.

Cadilhon, J. J., Moustier, P., Poole, N. D., Tam, P. T. G., \& Fearne, A. P. (2006). Traditional vs. modern food systems? Insights from vegetable supply chains to Ho Chi Minh City (Vietnam). Development Policy Review, 24(1), 31-49.

Cat Linh. (2015). Lý do Việt Nam không miễn thị thực visa cho công dân Mỹ? (The reason why Vietnam has not waived visa for citizens of the United States of America?). Retrieved 26 June 2015, from http://vietstudies.info/kinhte/LyDoKhongMienVisa_RFA.htm.

Cervino, J., \& Cubillo, J. M. (2005). Hotel and tourism development in Cuba. Cornell Hotel and Restaurant Administration Quarterly, 46(2), 441-452.

Chau An. (2014). Việt Nam đứng thứ 7 châu Á về số người sủ dụng internet (Vietnam ranked $7^{\text {th }}$ in Asia in terms of internet users). Retrieved from http://sohoa.vnexpress.net/tin-tuc/doi-song-so/viet-nam-dung-thu-7-chau-a-veso-nguoi-dung-internet-3099194.html.

Child, J. (2002). A configurational analysis of international joint ventures. Organization Studies, 23(5), 781-815.

Choi, S. B., Lee, S. H., \& Williams, C. (2011). Ownership and firm innovation in a transition economy: evidence from China. Research Policy, 40(3), 441-452.

Chon, K. S., Pine, R. J., Lam, T., \& Zhang, H. Q. (2013). Tourism and hotel development in China: from political to economic success. New York: The Haworth Hospitality Press.

Cling, J. P., Razafindrakoto, M., \& Roubaud, F. (2013). Is the World Bank compatible with the "Socialist-oriented market economy"? A political economy approach 
applied to the case of Vietnam. Revue de la régulation. Capitalisme, Institutions, Pouvoirs, (13).

Commander, S., \& Svejnar, J. (2008). Do institutions, ownership, exporting and competition explain firm performance? Retrieved from http://deepblue.lib.umich.edu/handle/2027.42/60636.

Commander, S., \& Svejnar, J. (2012). Do institutions, ownership, exporting and competition explain firm performance? Retrieved from http://deepblue.lib.umich.edu/handle/2027.42/60636.

Cohen, D., \& Crabtree, B. (2006). Qualitative research guidelines project. Retrieved from

http://www.sswm.info/sites/default/files/reference_attachments/COHEN\%20200 $6 \% 20$ Semistructured\%20Interview.pdf.

Cooke, N., Li, T., \& Anderson, J. A. (Eds.). (2011). The Tongking gulf through history. Pennsylvania: University of Pennsylvania Press.

Cooper, M. (2000). Tourism in Vietnam: Doi Moi and the realities of tourism in the 1990s. Tourism in South and Southeast Asia: Issues and Cases, 167-177.

Cooper, M. (2009). Vietnam's Image as a Tourism Destination in Japan: an Analysis of Japanese Travel Guidebooks and Brochures, and Attribute ImportancePerformance. $\quad$ Retrieved from http://en.apu.ac.jp/rcaps/uploads/fckeditor/publications/journal/RJAPS_V25_Le _Cooper.pdf.

Creswell, J. W. (2009). Research design: qualitative, quantitative, and mixed methods approaches. Los Angeles: SAGE.

Creswell, J. W. (2014). Research design: qualitative, quantitative, and mixed methods approaches. California: SAGE.

Crichton, E., \& Edgar, D. (1995). Managing complexity for competitive advantage: An it perspective. International Journal of Contemporary Hospitality Management, $7(2 / 3), 12-18$.

Cvelbar, L. K., \& Mihaliè, T. (2007). Corporate governance mechanism in Slovenian hotels. Slovenia: University of Ljubljana.

Danang Airport (DAD). (2015). Danang airport Vietnam. Retrieved from http://www.danangairportonline.com.

Danang City. (2010). Overview of Danang City. Retrieved from http://www.danangtourism.gov.vn/portal/page/portal/dulich_en/Intro/overview_ of_da_nang_city?expandable $=0 \mathrm{~h}$.

Danang Tourism. (2014). About Danang. Retrieved from http://tourism.danang.vn/en/about-danang/da-nang.html. 
Danang Department of Culture, Sports and Tourism (DCST). (2013). Classified tourist accommodation establishments in Danang until June 2013. Six monthly report of 2013 issued by the Danang Department of Culture, Sports and Tourism.

Dang, P. (2004). The South Vietnam's economy from 1955 to 1975. Hanoi: Social Science Publisher.

Dao Loan. (2014). Liberty không bán khách sạn 5 sao Pullman (Liberty corporation do not sell a five-star hotel Pullman). Retrieved from http://www.thesaigontimes.vn/120649/Liberty-khong-ban-khach-san-5-saoPullman.html.

Davaakhuu, O., Sharma, K., \& Bandara, Y. M. (2014). Foreign direct investment in a transition economy: lessons from the experience of Mongolia. Global Business Review, 15(4), 663-675.

Davies, B. (2003). The role of quantitative and qualitative research in industrial studies of tourism. International Journal of Tourism Research, 5(2), 97-111.

De Melo, M., Denizer, C., \& Gelb, A. (1996). From plan to market: patterns of transition. World Bank Policy Research Working Paper, (1564).

Decrop, A. (1999). Triangulation in qualitative tourism research. Tourism management, 20(1), 157-161.

Denzin, N. K. \& Lincoln, Y. S. (2005) Introduction: the discipline and practice of qualitative research. In: N. K. Denzin \& Y. S. Lincoln (Eds.), Handbook of qualitative research (3rd Ed., pp ...). California: Sage Publications.

Devillers, P. (1962). The struggle for the unification of Vietnam. The China Quarterly, 9, $2-23$.

Djankov, S. \& Murrell, P. (2002). Enterprise restructuring in transition: A quantitative survey. Journal of Economic Literature, 739-792.

Doan Loan. (2012). 52 doanh nghiệp đoạt giải thuởng Du lịch Việt Nam (52 tourism enterprises were granted the Vietnam Tourism Award). Retrieved from http://vnexpress.net/tin-tuc/thoi-su/du-lich/52-doanh-nghiep-doat-giai-thuongdu-lich-viet-nam-2399900.html.

Duc Binh. (2016). Nghị quyết đại hội đại biểu toàn quốc lần thứ XII (The resolution of the $12^{\text {th }}$ National Congress of the Vietnamese Communist Party). Retrieved from http://baochinhphu.vn/Dai-hoi-Dang-toan-quoc-lan-thu-XII/Nghi-quyet-Daihoi-dai-bieu-toan-quoc-lan-thu-XII/247102.vgp.

Emmer, R. M., Tauck, C., Wilkinson, S., \& Moore, R. G. (1993). Using global distribution systems. The Cornell Hotel and Restaurant Administration Quarterly 34(6), 80-89 
Estrin, S., Hanousek, J., Kočenda, E., \& Svejnar, J. (2009). The effects of privatization and ownership in transition economies. Journal of Economic Literature, 699-728.

Estrin, S., \& Mickiewicz, T. (2011). Entrepreneurship in transition economies: the role of institutions and generational change. In: M. Minniti (Eds.), The Dynamic of Entrepreneurship: Evidence from Global Entrepreneurship Data Monitor (pp 181-208). Oxford: Oxford University Press.

Evangelista, F., \& Thuy, P. N. (2013). Does it pay for firms in Asia's emerging markets to be market oriented? Evidence from Vietnam. Journal of Business Research, 66(12), 2412-2417.

Fforde, A. (2002). Light within the ASEAN gloom? Vietnam's economy since the Asian financial crisis. Southeast Asian Affairs, 357-377.

Fforde, A. (2002). Resourcing conservative transition in Vietnam: rent switching and resource appropriation. Post-Communist Economies, 14(2): 203-226.

Filer, R. K., \& Hanousek, J. (2002). Data watch: research data from transition economies. Journal of Economic Perspectives, 16(1), 225-240.

Fink, A. S. (2000, December). The role of the researcher in the qualitative research process. A potential barrier to archiving qualitative data. In Forum Qualitative Sozialforschung/Forum: Qualitative Social Research (Vol. 1, No. 3).

Gartner, W. C. \& Bachri, T. (1994). Tour operators' role in the tourism distribution system: an Indonesian case study. Journal of International Consumer Marketing, 6(3-4), 161-179.

Gates, C., Noerlund, I. \& Vu, C. D. (2014). Vietnam in a changing world. New York: Routledge.

Gelo, O., Braakmann, D. \& Benetka, G. (2008). Quantitative and qualitative research: Beyond the debate. Integrative psychological and behavioral science, 42(3), 266290.

Google. (2015). Vietnam map. Retrieved from https://www.google.co.nz/maps/@17.7118994,107.8940815,6z.

Government Portal. (2015). Overview on Vietnam geography. Retrieved from http://www.chinhphu.vn/portal/page/portal/English/TheSocialistRepublicOfViet nam/AboutVietnam/AboutVietnamDetail?categoryId=10000103\& articleId=100 00505 .

General Statistics Office of Vietnam (GSO). (2011). Statistic year book. Hanoi, Vietnam.

General Statistics Office of Vietnam (GSO). (2013). Tình hình kinh tế - xã hội năm 2013 (Vietnam's socio-economics in 2013). Hanoi, Vietnam. 
General Statistics Office of Vietnam (GSO). (2014). Results of tourist expenditure survey in 2013. Hanoi: General Statistics Office of Vietnam.

General Statistics Office of Vietnam (GSO). (2015a). Chỉ số giá tiêu dùng (Consumer price index). Retrieved from http://www.gso.gov.vn/default.aspx?tabid=628.

General Statistics Office of Vietnam (GSO). (2015b). Số liệu thống kê (Statistical figures). Retrieved from http://www.gso.gov.vn/default.aspx?tabid=715.

Grant Thornton. (2013). Hotel Survey 2013. Grant Thornton Vietnam.

Grinter, L. E. (2006). Vietnam's Thrust into Globalization: Doi Moi's Long Road. Asian Affairs: An American Review, 33(3), 151-166.

Gu, H., Ryan, C. \& Yu, L. (2012). The changing structure of the Chinese hotel industry: 1980-2012. Tourism Management Perspectives, 4, 56-63.

Hai Minh. (2013). Số liệu thống kê của Việt Nam có đáng tin cậy không? (Is the statistics of Vietnam reliable?) Retrieved from http://ttvn.vn/kinh-doanh/so-lieu-thong-kecua-viet-nam-co-dang-tin--201311041359580105.htm.

Hall, D. R. (1991). Tourism and economic development in Eastern Europe \& the Soviet Union. London: Belhaven Press.

Hall, D. R. (1998). Tourism development and sustainability issues in Central and Southeastern Europe. Tourism Management, 19(5), 423-431.

Hall, D. R. (2001). Tourism, and the less developed world: issues and case studies. New York: CABI Publishing.

Hall, D. (2008). From 'bricklaying'to 'bricolage': Transition and tourism development in Central and Eastern Europe. Tourism Geographies, 10(4), 410-428.

Hamm, P., King, L. P., \& Stuckler, D. (2012). Mass privatization, state capacity, and economic growth in post-communist countries. American Sociological Review, 77(2), 295-324.

Harms, E. (2012). Beauty as control in the new Saigon: Eviction, new urban zones, and atomized dissent in a Southeast Asian city. American Ethnologist, 39(4), 735-750

Harrison, D. (Ed.). (2001). Tourism and the less developed world: issues and case studies Oxon: CABI Publishing.

Hassard, J., Morris, J., Sheehan, J. \& Yuxin, X. (2010). China's state-owned enterprises: economic reform and organizational restructuring. Journal of Organizational Change Management, 23(5), 500-516.

Havrylyshyn, O. \& Wolf, T. (1999). Determinants of growth in transition countries. Finances \& Development Magazine, 36(2). 
Hitchcock, M., King, V. T. \& Parnwell, M. (2009). Introduction: tourism in South-East Asia revisited. In M. Hitchcock, V. T. King \& M. Parnwell (Eds.), Tourism in South-East Asia: challenges and new direction (pp. 1-42). Honolulu, HI: University of Hawaii Press.

Hanoi Department of Culture, Sports and Tourism (HNAT). (2010). About Hanoi. Retrieved from http://hanoitourism-info.gov.vn/about-hanoi-1.

Hanoi Department of Culture, Sports and Tourism (HNAT). (2013). Classified tourist accommodation establishments in Hanoi until June 2013. Report issued by the Hanoi Department of Culture, Sports and Tourism.

Ho Chi Minh City. (2011). Hội tụ văn hoá ở Sài Gòn thành phố Hồ Chí Minh (Convergence of culture in Saigon Ho Chi Minh City). Retrieved from http://www.hochiminhcity.gov.vn/thongtinthanhpho/gioithieu/Lists/Posts/Post.as px?List=9efd7faa-f6be-4c91-9140-e2bd40710c29\&ID=5475\&Web=9d294a7fcaf2-456d-8ca0-36b393b8c052.

Ho Chi Minh City Department of Culture, Sports and Tourism (HCST). (2013). Classified tourist accommodation establishments in Ho Chi Minh City until June 2013. Six monthly report issued by the Ho Chi Minh City Department of Culture, Sports and Tourism.

Hoang. P. (2006). Researching and revising the legal system of Vietnam to join the WTO. Hanoi: Judicial Publishing House.

Hoang Tuy. (2016). Một thời trăn trở đổi mói (A period of thinking about doi moi). Retrieved from http://www.tiasang.com.vn/Default.aspx?tabid=111\&News=9402\&CategoryID= 2.

Hoang, X. N. \& Nguyen, K. T. (n.d.). Phát triển kinh tế hàng hóa Thăng Long - Hà Nội: Quy luật chung và nhũng biểu hiện đặc thù (Developing the economy of commodity of Thang Long - Hanoi: Common principles and distinctive characteristics). Retrieve from http://www.hids.hochiminhcity.gov.vn/c/document_library/get_file?uuid=2529b f67-aacb-41bc-ad38-838704d13e93\&groupId=13025.

Holton, R. H. \& Sicular, T. (1991). Economic reform of the distribution sector in China. The American Economic Review, 81(2), 212-217.

Hong Phuc. (2015). Người Sài Gòn mua gì, người Hà Nội thích gì? (What do Saigon people buy, and what do Hanoi people like?). Retrieved from http://www.thesaigontimes.vn/135774/Nguoi-Sai-Gon-mua-gi-nguoi-Ha-Noithich-gi.html.

Huynh, T. D. (2013). An explanation of the socialist market-oriented economy in Vietnam. Thoi Dai Moi, 1, 1-80. 
IHG.

(2014).

Glossary.

Retrieved

from

http://development.ihg.com/web/europe/glossary.

IMF. (2000). Transition Economies: An IMF Perspective on Progress and Prospects. Retrieved from http://www.imf.org/external/np/exr/ib/2000/110300.htm.

Institute for Tourism Development Research (ITDR). (2005). The Vietnamese hotel survey 2005. Hanoi: The Institute for Tourism Development Research.

Institute for Tourism Development Research ITDR. (2015). Đề tài khoa hoc (Research projects). Retrieved from http://www.itdr.org.vn/thong-tin-tu-lieu/de-tai-khoahoc.html?limitstart $=0$.

Irvin, G. (1995). Vietnam: assessing the achievements of Doi Moi. The Journal of Development Studies, 31(5), 725-750.

Iwasaki, I. \& Tokunaga, M. (2014). Macroeconomic impacts of FDI in transition economies: a meta-analysis. World Development, 61, 53-69.

Jaakson, R. (1996). Tourism in transition in post-Soviet Estonia. Annals of Tourism Research, 23(3), 617-634.

Jackson, J. (2006). Developing regional tourism in China: The potential for activating business clusters in a socialist market economy. Tourism Management, 27(4), 695-706.

Janesick, Valerie J. (1994). The dance of qualitative research design: Metaphor, methodolatry, and meaning. In Norman K. Denzin and Yvonna S. Lincoln (Eds.), Handbook of Qualitative Research (pp. 209-219). Thousand Oaks, CA: Sage Publications, Inc.

Jennings, G. R. (2005). Interviewing: a focus on Qualitative Techniques. In B.W. Richie, P. Burns, \& C. Palmer (Eds.), Tourism research methods. (pp. 99-107). Wallingford, UK: CABI Publishing.

Jennings, G. (2010). Tourism research ( $2^{\text {nd }}$ Ed.). Milton, Australia: WILEY.

Jiang, B. \& Prater, E. (2002). Distribution and logistics development in China: The revolution has begun. International Journal of Physical Distribution \& Logistics Management, 32(9), 783-798.

Johnson, M. (1997). Hungary's hotel industry in transition, 1960-1996. Tourism Management, 18(7), 441-452.

Jones, D. C. \& Mygind, N. (1999). The nature and determinants of ownership changes after privatization: Evidence from Estonia. Journal of Comparative Economics, 27(3), 422-441.

Kang, B., Brewer, K. P. \& Baloglu, S. (2007). Profitability and survivability of hotel distribution channels: An industry perspective. Journal of Travel \& Tourism Research, 22(1), 37-50. 
Karhunen, P., Löfgren, J. \& Kosonen, R. (2008). Revisiting the relationship between ownership and control in international business operations: Lessons from transition economies. Journal of International Management, 14(1), 78-88.

Kaven, W. H. (1974). Distribution channels of the hotel industry. Cornell Hotel and Restaurant Administration Quarterly, 14(21), 21-23.

Kerlinger, F. N., \& Lee, H. B. (2000). Foundations of behavioral research. New York: Harcourt College Publishers.

King, B., \& Choi, H. J. (1999). Travel industry structure in fast growing but immature outbound market: The case of Korea to Australia travel. International Journal of Tourism Research, 1, 111-125.

King, N., \& Horrocks, C. (2010). Interviews in qualitative research. London, UK: SAGE Publications Ltd.

Kokko, A. (1998). Vietnam: ready for doi moi II?. ASEAN Economic Bulletin, 15(3), 319-327.

Kokko, A., \& Thang, T. T. (2014). Foreign Direct Investment and the Survival of Domestic Private Firms in Viet Nam. Asian Development Review, 31(1), 53-91.

Kornai, J. (1993). Transformational recession: a general phenomenon examined through the example of Hungary's development. Economie Appligue, 46(2), 181-227.

Kracht, J., \& Wang, Y. (2010). Examining the tourism distribution channel: evolution and transformation. International Journal of Contemporary Hospitality Management, 22(5), 736 - 757.

Lai, W. H., \& Vinh, N. Q. (2013). How promotional activities and evaluative factors affect destination loyalty: evidence from international tourists of Vietnam. International Journal of Marketing Studies, 5(1), 70-85.

Lam, T. (2013). Vietnam's tourism industry: its potential and challenges. In K. S. Chon (Eds.), Tourism in Southeast Asia: A New Direction, (157-164). New York: The Haworth Hospitality Press.

Le, D. D. (2003). Foreign direct investment in Viet Nam: results, achievements, challenges and prospect. Retrieved from http://www.imf.org/external/pubs/ft/seminar/2002/fdi/eng/pdf/doanh.pdf.

Le, H. T., \& Yue, L. H. (2006). Economic reform in Vietnam and in China: A Comparative Study (Eds.). Hanoi: The Gioi Publisher.

Le, N. D. H. (2015). Quá dễ dàng để đóng dấu mật (it is so easy to stamp "secret”). Retrieved from http://vietnamnet.vn/vn/tuanvietnam/276611/qua-de-dang-dedong-dau-mat.html. 
Le Quynh. (2016). TBT Trọng 'ở lại thêm một năm'? (TBT Trong “remains the General Secretary one more year'?). Retrieved from http://www.bbc.com/vietnamese/vietnam/2016/01/160111_hoi_nghi_14_khai_ mac.

Le, T. V., \& Buck, T. (2011). State ownership and listed firm performance: a universally negative governance relationship?. Journal of Management \& Governance, 15(2) 227-248.

Leung. S. (2015). The Vietnamese Economy Seven Years after the Global Financial Crisis. Journal of Southeast Asian Economies. 32(1), 1-10.

Lewy, G. (1980). America in Vietnam. New York: Oxford University Press.

Liamputtong, P., \& Ezzy, D. (Ed). (2005). Qualitative research methods (2 ${ }^{\text {nd }}$ Ed.). Melbourne: Oxford University Press.

Li, M. H., Cui, L., \& Lu, J. (2014). Varieties in state capitalism: Outward FDI strategies of central and local state-owned enterprises from emerging economy countries. Journal of International Business Studies, 45(8), 980-1004.

Litteljohn, D. (1997). Internationalization in hotels: current aspects and developments. International Journal of Contemporary Hospitality Management, 9(5/6), 187-192.

Lloyd, K. (2003). Contesting control in transitional Vietnam: the development and regulation of traveller cafes in Hanoi and Ho Chi Minh City. Tourism Geographies, 5(3), 350-366.

Lloyd, K. (2004). Tourism and transitional geographies: Mismatched expectations of tourism investment in Vietnam. Asia Pacific Viewpoint, 45(2), 197-215.

Luk, S. T. (1998). Structural changes in China's distribution system. International Journal of Physical Distribution \& Logistics Management, 28(1), 44-67.

Mak, B. (2008). The future of the state-owned hotels in China: Stay or go? International Journal of Hospitality Management, 27, 355-367.

March, R. (1996) Organizational Linkages in Australia's Japanese Inbound Travel Market. In: G. Prosser (Eds.), Tourism and Hospitality Research: Australian and International Perspectives (pp. 337-349). Canberra: Bureau of Travel Research.

Marinov, S., \& Kazandzhieva, V. (2010). Improving the distribution of Bulgarian seaside holiday hotels. Journal of Economics, 1(1), 29-38.

Maruyamar, M., \& Trung, V. L. (2011). Modern retailers in transition economies: the case of Vietnam. Journal of Macromarketing, 32(1), 31-51

McMillan, J., \& Woodruff, C. (2002). The central role of entrepreneurs in transition economies. Journal of Economic Perspective, 16(3), 153-170. 
Medve-Bálint, G. (2014). The role of the EU in shaping FDI flows to East Central Europe. JCMS: Journal of Common Market Studies, 52(1), 35-51.

Michaud, J. (2000). The Montagnards and the state in Northern Vietnam from 1802 to 1975: a historical overview. Ethnohistory, 47(2), 333-368.

Middle, T. C., \& Clarke, J. (2001). Marketing in travel and tourism (3rd Ed.). Oxford: Butterworth-Heinemann.

Miles, M. B., \& Huberman, A. M (1994). Qualitative data analysis: an expanded source book. California: SAGE.

MOF (Ministry of Finance). (2012). Thông tư sưa đổi, bổ sung Thông tu số của Bộ Tài chính quy định chế độ thu, nộp, quản lý và sử dụng lệ phí cấp hộ chiếu, thị thưc, giấy tờ về nhập cảnh, xuất cảnh, quá cảnh và cu trú tại Việt Nam (Circular No. 190/2012/TT-BTC dated 9th November 2012 on revising and amending Circular No. 66/2009/TT-BTC dated 30th March 2009 on the management of fees from issuing passport, visa and residential certificate of the Vietnamese overseas and foreigners). Hanoi: Ministry of Finance.

MOF (Ministry of Finance). (2013). Brief report of Vietnam's accession to the World Trade Organisation. Retrieved from http://www.mof.gov.vn/portal/page/portal/mof_vn/1371620/1371622/1371631/ 45916490?p_page_id=2202417\&pers_id=45919860\&item_id=45973127\&p_de tails $=1$.

Mok, C., \& Lam, T. (1997). Hotel and tourism development in Vietnam. Journal of Travel \& Tourism Marketing, 7(1), 85-91.

Morse, J. M. (1994). Designing funded qualitative research. In Norman K. Denzin and Yvonna S. Lincoln (Eds.), Handbook of qualitative research (pp. 220-235). Thousand Oaks, CA: Sage Publications, Inc.

MPI (Ministry of Planning and Investment). (2008). Đánh giá tác động của gia nhập WTO tới nền kinh tế Việt Nam: Sư dụng mô hình cân bằng tổng thể CGE (Impact assessment of the WTO's accession on Vietnam's economy: Using CGE model). Hanoi: Development Strategy Institute of the Ministry of Planning and Investment.

Muller, H. S. (2005). Private-sector development in a transition economy: the case of Vietnam. Development in Practice, 15(3-4), 349-361.

Müller, H. M., \& Wärneryd, K. (2001). Inside versus outside ownership: a political theory of the firm. RAND Journal of Economics, 527-541.

Nellis, J. (1999). Time to rethink privatization in transition economies?. Washington, D.C: The World Bank and International Finance Corporation.

Ngoc Quang. (2015). Đổi Mới hay là chết? (Doi Moi or die?). Retrieved from http://giaoduc.net.vn/Xa-hoi/Doi-moi-hay-la-chet-post158049.gd. 
Nguyen, Q. D. (2016). Điểm lại mấy vấn đề then chốt sau đại hội đảng (Outlining key issues after the $12^{\text {th }}$ National Congress of the Vietnamese Communist Party). Retrieved from http://www.vietstudies.info/kinhte/NQuangDy_SauDaiHoiDang.htm.

Nguyen Quan. (2014). Vietnam Airlines sẽ bị phá thế độc quyền vì hàng không giá rẻ (Vietnam Airlines is strongly competed by low cost carriers). Retrieved from http://giaoduc.net.vn/Kinh-te/Vietnam-Airlines-se-bi-pha-the-doc-quyen-vihang-khong-gia-re-post151222.gd.

Nguyen, N. (2015). Phát triển du lịch Đà Nã̃ng còn nhiều thách thức (It is challenging for tourism development in Danang). Retrieved from http://danangupi.vn/phattrien-du-lich-da-nang-con-nhieu-thach-thuc-51840.aspx.

Nguyen, T. P., Nguyen, D. T., Jen, J. S., \& Tarlok, S. (2014). Shifts in exchange rate regimes and inflation Persistence in Vietnam, 1992 - 2010. Journal of South East Asian Economies, 31(2), 256-275.

Nguyen, T. T., \& Van Dijk, M. A. (2012). Corruption, growth, and governance: Private vs. state-owned firms in Vietnam. Journal of Banking \& Finance, 36(11), 29352948.

Nguyen, V. L. (2009). Tourism market. Hanoi: Vietnam National University Publishing House.

Nhat Anh. (2013). Sân sau của quan chưc hưu! (Back yards of retired high-ranking government officials). Retrieved from http://www.tienphong.vn/xa-hoi-chuyenhom-nay/san-sau-cua-quan-chuc-huu-611972.tpo.

Nhu Loan. (2015). Khách sạn Thắng Lợi nâng cấp thành Hilton Hanoi Westlake (Thang Loi Hotel is being renovated and renamed as Hilton Hanoi Westlake). Retrieved from http://vietnamtourism.gov.vn/index.php/items/19600.

O'Connor, P., \& Frew, A. J. (2002). The future of hotel electronic distribution: expert and industry perspectives. The Cornell hotel and restaurant administration quarterly, 43(3), 33-45.

OECD (2013), Economic outlook for Southeast Asia, China and India 2014: beyond the middle-income trap. Paris: OECD Publishing.

O'Toole, C. M., Morgenroth, E. L., \& Ha, T. T. (in press). Investment efficiency, stateowned enterprises and privatisation: Evidence from Viet $\mathrm{Nam}$ in Transition. Journal of Corporate Finance.

Oxford Dictionaries. (2015). Channel. Retrieved from http://www.oxforddictionaries.com/definition/english/channel.

Page, J. P., Brunt, P., Busby., \& Connel, J. (2001). Tourism: a modern synthesis. London: Thomson Learning. 
Patton, M. Q. (2002). Qualitative research and evaluation methods (3rd Ed.). Thousand Oaks: Sage.

Pearce, D. G., Tan, R., \& Schott, C. (2004). Tourism distribution channels in Wellington, New Zealand. International Journal of Tourism Research, 6, 397410.

Pearce, D. G., \& Tan, R. (2004). Distribution channels for heritage and cultural tourism in New Zealand. Asia Pacific Journal of Tourism Research, 9(3), 225-237.

Pearce, D. G., \& Schott, C. (2005). Tourism distribution channels: the visitor's perspective. Journal of Travel Research, 44(1), 50-63.

Pearce, D. G., \& Tan, R. (2006). The distribution mix for tourism attractions in Rotorua, New Zealand. Journal of Travel Research, 44(3), 250-258.

Pearce, D. G., Tan, R., \& Schott, C. (2007). Distribution channels in international markets: A comparative analysis of the distribution of New Zealand tourism in Australia, Great Britain and the USA. Current Issues in Tourism, 10(1), 33-60.

Pearce, D. G. (2007). Paths to the market: developing an effective tourism distribution strategy. Wellington: Victoria Management School, Victoria University of Wellington.

Pearce, D. G., \& Taniguchi, M. (2007). Channel Performance in Multichannel Tourism Distribution Systems. Journal of Travel Research, 46, 256-267.

Pearce, D. G. (2008). A needs-function mode of tourism distribution. Annals of Tourism Research, 35(1), 148-168.

Pearce, D. G. (2009a). Beyond tiers: A network approach to tourism distribution. Tourism Analysis, 13, 517-530.

Pearce, D. G. (2009b). Channel design for effective tourism distribution strategies. Journal of Travel and Tourism Marketing, 26(5-6), 507-521.

Pearce, D. G. (2012). Researching tourism distribution. In C. H. C. Hsu and W. C. Gartner (Eds), The Routledge Handbook of Tourism Research (pp. 54-63). New York: Routledge.

Pham, H. (2013). Vietnam is a country, not a war-trauma and nostalgia in the anthology The Perfume River. Creative Industries Journal, 6(1), 17-27.

Pham, H. (2014). Sếp dôi du đi về đâu? (How to arrange unnecessary labourers and leaders in SOEs after equitisation and privatisation?). Retrieved from http://vietnamnet.vn/vn/kinh-te/180246/sep-doi-du-di-ve-dau-.html.

Pham, H. D. (2014). Nhiều chura hẳn tốt (Quantity or quality). Retrieved from http://tiasang.com.vn/Default.aspx?tabid=110\&News=7596\&CategoryID=36. 
Pham, H. (2015). Doanh nghiệp Việt Nam hội nhập nhu đi trên cầu khỉ (The integration of Vietnamese enterprises into global business community is likely to cross a river via a small bridge). Retrieved from http://vietnamnet.vn/vn/kinhdoanh/258908/dn-hoi-nhap-nhu-di-tren-cau-khi.html.

Pham, L., Pham, L. N., \& Nguyen, D. T. T. (2011). Determinants of e-commerce adoption in Vietnamese small and medium sized enterprises. International Journal of Entrepreneurship, 15, 45-72.

Pham, N. Q., Trinh, B., \& Nguyen, T. D. (2007). Economic performance of Vietnam, 1976-2000: New evidence from input-output mode (Working Paper Series No. 2007/13). $\quad$ Retrieved from https://www.researchgate.net/profile/Bui_Trinh/publication/4799699_Economic _performance_of_Vietnam_1976-2000_New_evidence_from_inputoutput_mode/links/54e6fcfb0cf2cd2e0290f4b4.pdf.

Phan An. (2014). Khai trưong khách sạn 5 sao hiện đại nhất TP HCM: Pullman Saigon Center (Opening ceremony of a five-star hotel in Ho Chi Minh City: Pullman Saigon Center). Retrieved from http://dulich.nld.com.vn/thoi-su-du-lich/khaitruong-khach-san-5-sao-hien-dai-nhat-tp-hcm-pullman-saigon-center20140108025948459.htm.

Phillips, R. (1996). Communism strikes back: Cultural blockages on the road to reform in the post-Soviet tourism sector. In M. Robinson, N. Evans and P. Callaghan (Eds.), Tourism and Culture: Image, Identity and Marketing (pp. 147-164). Sunderland: Business Education Publishers.

Pincus, J. (2015). Why doesn't Vietnam grow faster?. Journal of Southeast Asian Economies, 32(1). 26-51.

Pine, R., Zhang, H. Q., \& Qi, P. (2000). The challenges and opportunities of franchising in China's hotel industry". International Journal of Contemporary Hospitality Management, 12(5), $300-307$.

Prishchepov, A. V., Radeloff, V. C., Baumann, M., Kuemmerle, T., \& Müller, D. (2012). Effects of institutional changes on land use: agricultural land abandonment during the transition from state-command to market-driven economies in post-Soviet Eastern Europe. Environmental Research Letters, 7(2), 01-13.

Qu, R., Ennew, C. T., \& Sinclair, T. (2004). The impact of regulation and ownership structure on market orientation in the tourism industry in China. Tourism Management, 26(3), 939-950.

Qu, R., \& Ennew, C. T. (2005). Developing a market orientation in a transitional economy: The role of government regulation and ownership structure. Journal of Public Policy \& Marketing, 24(1), 82-89. 
Qu, R., Ennew, C., \& Sinclair, M. T. (2005). The impact of regulation and ownership structure on market orientation in the tourism industry in China. Tourism Management, 26(6), 939-950.

Quynh Anh. (2015). Du lịch Hà Nội: Tăng trưởng trong giai đoạn khó khăn (Hanoi tourism: Growth in difficulty period). Retrieved from http://hanoi.gov.vn/30//hn/ZVOm7e3VDMRM/7320/2704217/du-lich-ha-noi-tang-truong-trong-giaioan-kho-khan.html;jsessionid=+Y2VLU17TKrh8bNA3CJHFa6G.app2.

Ramstetter, E. D., \& Ngoc, P. M. (2013). Productivity, ownership, and producer concentration in transition: Further evidence from Vietnamese manufacturing. Journal of Asian Economics, 25, 28-42.

Sadi, M. A., \& Henderson, J. C. (2001). Tourism and foreign direct investment in Vietnam. International Journal of Hospitality \& Tourism Administration, 2(1), 67-90.

Samiee, S. (1993). Retailing and channel considerations in developing countries: a review and research propositions. Journal of Business Research, 27, 03-33.

Schott, C. (2007). Selling adventure tourism: a distribution channels perspective. International Journal of Tourism Research, 9, 257-274.

Scott, S., Miller, F., \& Lloyd, K. (2006). Doing fieldwork in development geography: research culture and research spaces in Vietnam. Geographical Research, 44(1), $28-40$.

Sharda, S., \& Pearce, G. D. (2006). Distribution in emerging tourism markets: the case of Indian travel to New Zealand. Asia Pacific Journal of Tourism Research, 11(4), 339-353.

Shi, M. M., \& Zhang, X. J. (2009). Distribution system in the transition economy and the paradigm shift of distribution economics. Retrieved from http://en.cnki.com.cn/Article_en/CJFDTOTAL-SYJG200908004.htm.

Short, A. (2014). The origins of the Vietnam War. New York: Routledge.

Smallbone, D., Welter, F., Voytovich, A., \& Egorov, I. (2010). Government and entrepreneurship in transition economies: the case of small firms in business services in Ukraine. The Service Industries Journal, 30(5), 655-670.

Smith, K. A. (2007). Distribution channels for events: Supply and demand-side perspectives. Journal of Vacation Marketing, 13(4), 321-338.

Smith, L. J. S. (1988). Defining tourism: a supply-side view. Annals of Tourism Research, 15, 179-190.

Smith, K. A., \& Garnham, R. (2006). Distribution channels for convention tourism. Journal of Convention \& Event Tourism, 8(1), 1-30. 
So Van hoa, The thao va Du lich Danang (DCST). (2009). Văn hoá xú Quảng (Quang region culture). Retrieved from http://www.cst.danang.gov.vn/chitiet?idcat $=67709 \&$ articleId $=67755$.

Song. H. (2012). Tourism supply chain management. New York: Routledge.

Stahl, D. O., \& Alexeev, M. (1985). The influence of black markets on a queue-rationed centrally planned economy. Journal of Economic Theory, 35(2), 234-250.

Stuart, P., Pearce, D. G., \& Weaver, A. (2005). Tourism distribution channels in peripheral regions: the case of Southland, New Zealand. Tourism Geographies, 7(3), 235-256.

Su, D., \& He, X. (2012). Ownership structure, corporate governance and productive efficiency in China. Journal of Productivity Analysis, 38(3), 303-318.

$\mathrm{Su}, \mathrm{N}$. D. (2009). Finding the driver of Internet and Web technology adoption in Vietnam Hotel marketing. Retrieved from http://ir.lib.stu.edu.tw:80/ir/handle/310903100/1845.

Sun, Q., Tong, W. H. S., \& Tong, J. (2002). How does government ownership affect firm performance? Evidence from China privatisation experience. Journal of Business Finance and Accounting, 29(1-2), 1-27.

Suntikul, W., Butler, R., \& Airey, D. (2008). A periodisation of the development of Vietnam's tourism accommodation since the open door policy. Asia Pacific Journal of Tourism Research, 13(1), 67-80.

Suntikul, W. (2010). Tourism and political transition in reform-era Vietnam. Tourism and Political Change, 133-143.

Suntikul, W., Butler, R., \& Airey, D. (2010a). Implications of political change on national park operations: doi moi and tourism to Vietnam's national parks. Journal of Ecotourism, 9(3), 201-218.

Suntikul, W. Butler, R., \& Airey, D. (2010b). The influence of foreign direct investment on accommodation patterns in Vietnam as a result of the open-door policy. Current Issues in Tourism, 13(3), 261-277.

Svejnar, J. (2002). Transition economies: Performance and challenges. Journal of Economic Perspectives, 3-28.

Svejnar, J. (Eds.). (2013). The Czech Republic and Economic Transition in Eastern Europe. California: Academic Press, Inc.

Szondi, G. (2007). The role and challenges of country branding in transition countries: The Central and Eastern European experience. Place Branding and Public Diplomacy, 3(1), 8-20. 
Tallman, S., Sutcliffe, A. G., \& Antonian, B. A. (1997). Strategic and organizational issues in international joint ventures in Moscow. In B. W. Beamish and J. P. Killing (Eds.), Cooperative Strategies: European Perspective (pp. 184-210). San Francisco: The New Lexington Press.

Tang, F. F., Xi, Y., Chen, G., \& Wang, R. (2006). Ownership, corporate governance, and management in the state-owned hotels in the People's Republic of China. Cornell Hotel and Restaurant Administration Quarterly, 47(2), 182-191.

Thanh Truc. (2014). Hơn 1/3 ngườ Việt sủ dụng smartphone (Over one third of Vietnamese population use smartphones). Retrieved from http://nhipsongso.tuoitre.vn/tin/20140911/hon-1-3-nguoi-viet-dungsmartphone/644458.html.

Thanh Tung. (2014). Khách sạn nổi huyền thoại của Sài Gòn trôi dạt sang Triều Tiên (The legendary Saigon floating hotel was dragged to the North Korea). Retrieved from http://dantri.com.vn/quoc-te/khach-san-noi-huyen-thoai-cua-saigon-troi-dat-sang-trieu-tien-948073.htm.

The Embassy of the United States in Vietnam. (2013). Internet content decree. Retrieved from http://vietnam.usembassy.gov/pr080613.html.

Thi Hong Nguyen, H., Wood, S., \& Wrigley, N. (2013). The emerging food retail structure of Vietnam: Phases of expansion in a post-socialist environment. International Journal of Retail \& Distribution Management, 41(8), 596-626.

Thi Phuong Thao, H., \& Swierczek, F. W. (2008). Internet use, customer relationships and loyalty in the Vietnamese travel industry. Asia Pacific Journal of Marketing and Logistics, 20(2), 190-210.

Thuy Hien. (2013). Tăng trương vẫn dụa chủ yếu vào vốn và tài nguyên (The growth is based on loan and natural resources). Retrieved from http://www.vietnamplus.vn/tang-truong-van-dua-chu-yeu-vao-von-va-tainguyen/235264.vnp.

To Vuong. (2015). Chuyện chiếc kẹo dồi và co hội Đổi mới lần hai (A traditional candy and opportunity to implement the second economic renovation). Retrieved from http://baodautu.vn/chuyen-chiec-keo-doi-va-co-hoi-doi-moi-lan-haid13850.html.

Tran, N. T. (2015). Nhận thức mới về kinh tế thị trường định hướng XHCN? (New recognition of the socialist market oriented economy?) Retrieved from http://www.thesaigontimes.vn/127167/Nhan-thuc-moi-ve-kinh-te-thi-truongdinh-huong-XHCN.html.

Tran Nhat Minh. (2015). Điểm sáng của du lịch Việt Nam (An outstanding destination of Vietnam). Retrieved from http://tphom.chinhphu.vn/diem-sang-cua-du-lichviet-nam. 
Tran, V. T. (2011). Việt Nam tù̀ năm 2011: Vuợt lên sụ nghiệt ngã của thời gian (Vietnam since 2011: Overcoming the challenge of time). Hanoi: Tri Thuc Publishing House.

Tran, V.T., Nguyen, N. D., \& Nguyen, Q. (2000). Kinh tế Việt Nam 1955-2000: Tính toán mới, phân tích mói. (The Vietnamese Economy 1955-2000: New calculations and new analyses) Hanoi: Statistical Publishing House.

Tran, V. T. (2013). Vietnamese economy at the crossroads: new doi moi for sustained growth. Asian Economic Policy Review, 8(1), 122-143.

Trung Hieu. (2016). Đất nước qua 30 năm đổi mói - Kỳ 2: Nhân chứng trong 'Cái đêm hôm ấy... đêm gì? (The country went over 30 years of doi moi: The witness of that night). Retrieved from http://thanhnien.vn/thoi-su/dat-nuoc-qua-30-namdoi-moi-ky-2-nhan-chung-trong-cai-dem-hom-ay-dem-gi-659369.html.

Truong, V. D. (2013). Tourism policy development in Vietnam: a pro-poor perspective. Journal of Policy Research in Tourism, Leisure and Events, 5(1), $28-45$.

Tsang, E. W., Nguyen, D. T., \& Erramilli, M. K. (2004). Knowledge acquisition and performance of international joint ventures in the transition economy of Vietnam. Journal of International Marketing, 12(2), 82-103.

Tu Giang. (2014). Cải cách thể chế tù câu hỏi chura có lời giải (The economic reform originates from unanswered question). Retrieved from http://www.thesaigontimes.vn/114301/Cai-cach-the-che-tu-cau-hoi-chua-co-loigiai.html.

Tuong Vi. (2014). Thị trường chứng khoán và nhũng cú rơi lịch sủ (Stock market and historical falls). Retrieved from http://www.tienphong.vn/Kinh-Te/thi-truongchung-khoan-va-nhung-cu-roi-lich-su-711721.tpo.

UNWTO. (2012a). International tourism strong despite uncertain economy. Retrieved from http://www2.unwto.org/en/press-release/2012-11-05/internationaltourismstrong-despite-uncertain-economy.

UNWTO. (2012b). Tourism plays major role in Vietnam's socio-economic development says Vice-President. Retrieved from http://media.unwto.org/press-release/201205-02/tourism-plays-major-role-vietnam-s-socio-economic-development-saysvice-pre.

UNWTO. (2012c). Vietnam's Vice Minister Discusses Future Collaboration with UNWTO. Retrieved from http://asiapacific.unwto.org/en/news/2012-1107/vietnam-s-vice-minister-discusses-future-collaboration-unwto.

UNWTO. (2014). UNWTO Annual report 2014. Madrid: The World Tourism Organisation. 
UNWTO (World Tourism Organisation). (2015). Over 1.1 billion tourists travelled abroad in 2014. Retrieved from http://media.unwto.org/press-release/2015-0127/over-11-billion-tourists-travelled-abroad-2014.

Van Arkadie, B., \& Mallon, R. (2003). Vietnam: A transition tiger?. Canberra: ANU E Press and Asia Pacific Press.

Veal, A. J. (2006). Research Methods for Leisure and Tourism: A Practical Guide. London: Prentice Hall.

Venard, B. (1996). Vietnamese distribution channels. International Journal of Retail \& Distribution Management, 24(4), 29-40.

VGP (Vietnam Government Portal). (2015a). Đề xuất quy định 3 hình thức sở hũu (Proposing three modes of ownership [in Civil Code]). Retrieved from http://baochinhphu.vn/Lay-y-kien-nhan-dan-ve-du-thao-Bo-luat-dan-su-suadoi/De-xuat-quy-dinh-3-hinh-thuc-so-huu/218242.vgp.

VGP (Vietnam Government Portal). (2015b). Overview on Vietnam geography. Retrieved from http://www.chinhphu.vn/portal/page/portal/English/TheSocialistRepublicOfViet nam/AboutVietnam/AboutVietnamDetail?categoryId=10000103\&articleId=100 00505.

VGP (Vietnam Government Portal). (2015c). Giới thiệu khái quát về Thành phố Hồ Chí Minh (Brief introduction about Ho Chi Minh City). Retrieved from http://www.chinhphu.vn/portal/page/portal/chinhphu/cactinhvathanhpho/tphochi minh/thongtintinhthanh?view=introduction\&provinceId $=1158$.

VGP (Vietnam Government Portal). (2015d). Tổ chức thưong mại thế giới (The World Trade Organisation). Retrieved from http://www.chinhphu.vn/portal/page/portal/chinhphu/NuocCHXHCNVietNam/C hiTietVeToChucQuocTe?diplomacyOrgId=125.

VGP (Vietnam Government Portal). (2016). Toàn cảnh phiên khai mạc đại hội Đảng toàn quốc lần thư 12 (An overall picture of the $12^{\text {th }}$ National Congress of the Vietnamese Communist Party). Retrieved from http://baochinhphu.vn/Tin-noibat/TOAN-CANH-Phien-khai-mac-Dai-hoi-Dang-toan-quoc-lan-thu$\mathrm{XII} / 246469 . v g p$.

Vietnam Government. (2003). Quyết định số 145/2003/QD-TTg ngày 15 tháng 7 năm 2003 của Thủ tuóng Chính phủ về việc công nhận Đà Nẫng là đô thị loại 1 (Decision No. 145/2003-TTg of the Vietnamese Prime Minister on approving Danang as one of the central cities). Retrieved from http://chinhphu.vn/portal/page/portal/chinhphu/hethong vanban?class_id=1\&_pa ge $=384 \&$ mode $=$ detail\&document_id=12077.

Vietnamese Ministry of Foreign Affairs (MOFA). (2015a). General information about The Socialist Republic of Viet Nam. Retrieved from http://www.mofa.gov.vn/en/tt_vietnam/. 
Vietnamese Ministry of Foreign Affairs (MOFA). (2015b). About Vietnam. Retrieved from http://www.mofa.gov.vn/en/tt_vietnam/geo/.

Vietnam Export. (2010). Báo cáo chiến lược tổng thể phát triển ngành dịch vu tới năm 2020 và tầm nhìn tới năm 2025 (The master strategy of service sector development to 2020 and vision 2025). Retrieved from http://vietnamexport.com/bao-cao-chien-luoc-tong-the-phat-trien-nganh-dichvu-toi-nam-2020-tam-nhin-toi-nam-2025/vn2521330.html.

Vietnam Government. (2015). Một số nhiệm vụ và biện pháp cần thưc hiện trong quá trình hội nhập kinh tế quốc tế (Some tasks and solutions need to be undertaken in the process of international integration). Retrieved from http://www.chinhphu.vn/portal/page/portal/chinhphu/kinhtedoingoai?categoryId $=870 \&$ articleId $=2823$.

Vietnam Airlines. (2014). Noi Bai international airport. Retrieved from http://en.vietnamairport.vn/page/102/ket-qua-tim-kiem/noi-bai-internationalairport.

VNA (Vietnam National Assembly). (2000). Ordinance on entry, exit and residence of foreigners in Vietnam. Hanoi: Vietnam National Assembly.

VNA (Vietnam National Assembly). (2005). Law on Tourism. Hanoi: Vietnam National Assembly.

VNA (Vietnam National Assembly). (2008). Luật ban hành văn bản quy phạm pháp luật (Law on promulgating legal documents). Hanoi: The Vietnamese National Assembly.

VNA (Vietnam National Assembly). (2010). Pháp lệnh Thủ đô (Ordinance on capital city). Hanoi: Standing Committee of the Vietnam National Assembly.

VNA (Vietnam National Assembly). (2013). The constitution of the Socialist Republic of Vietnam. Hanoi: Vietnam National Assembly.

VNA (Vietnam National Assembly). (2014). Law on enterprises. Hanoi: Vietnam National Assembly.

VNA (Vietnam National Assembly). (2014a). Law on state capital management. Hanoi: Vietnam National Assembly.

VNA (Vietnam National Assembly). (2014b). Law on investment. Hanoi: Vietnam National Assembly.

VNAT (Vietnam National Administration of Tourism). (2005). Báo cáo kỷ niệm 45 năm ngày thành lập ngành du lịch Việt Nam (Report on the 45th Anniversary of Vietnam Tourism). Hanoi: Vietnam National Administration of Tourism.

VNAT (Vietnam National Administration of Tourism). (2010). Vietnam Tourism Annual Report. Hanoi, Vietnam: Vietnam National Administration of Tourism. 
VNAT (Vietnam National Administration of Tourism). (2011). Vietnam Tourism Annual Report. Hanoi: Vietnam National Administration of Tourism.

VNAT (Vietnam National Administration of Tourism). (2012a). Six Monthly Statistics of Vietnamese Hotels in 2012. Hanoi, Vietnam: Vietnam National Administration of Tourism (VNAT).

VNAT (Vietnam National Administration of Tourism). (2012b). Chiến lược phát triển du lịch Việt Nam đến 2020, tầm nhìn 2030 (The tourism development strategy of Vietnam to 2020, vision 2030) Hanoi: Vietnam National Administration of Tourism (VNAT).

VNAT (Vietnam National Administration of Tourism). (2013). Statistical number of classified tourist accommodation establishments in Vietnam until June 2013. Hanoi: Vietnam National Administration of Tourism.

VNAT (Vietnam National Administration of Tourism). (2013a). Khách quốc tế đến Việt Nam tháng 12 và 12 tháng năm 2013 (International tourist arrivals in December 2013 and the entire year 2013). Retrieved from http://vietnamtourism.gov.vn/index.php/items/13104.

VNAT (Vietnam National Administration of Tourism). (2013b). Quy hoạch tổng thể phát triển du lịch Việt Nam đến năm 2020, tầm nhìn đến năm 2030 (Master Plan of Vietnam tourism development to 2020, vision 2030). Hanoi: Vietnam National Administration of Tourism.

VNAT (Vietnam National Administration of Tourism). (2013c). Khách du lịch nội địa giai doan 2000-2013 (Vietnamese domestic travellers in the period from 2000 to 2013). Retrieved from http://vietnamtourism.gov.vn/index.php/items/13460.

VNAT (Vietnam National Administration of Tourism). (2014a). Cở sở luu trú du lịch đã xếp hạng 3-5 sao (Classified tourist accommodation establishments from 3-5 stars). Retrieved from http://vietnamtourism.gov.vn/index.php/cat/97.

VNAT (Vietnam National Administration of Tourism). (2014b). Khách quốc tế đến Việt Nam tháng 12 và 12 tháng năm 2014 (International tourist arrivals in December 2012 and the entire year 2014). Retrieved from http://vietnamtourism.gov.vn/index.php/items/16397.

VNAT (Vietnam National Administration of Tourism). (2014c). Co sở dĩ liệu doanh nghiẹp lĩ hành quốc tế (Database of international tour operators). Retrieved from http://vietnamtourism.gov.vn/index.php/cat/99.

VNAT (Vietnam National Administration of Tourism). (2015). Báo cáo kỷ niệm 55 năm ngày thành lập ngành du lịch Việt Nam (Report on the 55th Anniversary of Vietnam Tourism). Hanoi: Vietnam National Administration of Tourism.

VNAT (Vietnam National Administration of Tourism). (2015a). The Socialist Republic of Vietnam. Retrieved from http://www.vietnamtourism.com/en/index.php/about. 
VNAT (Vietnam National Administration of Tourism). (2015b). Số liệu thống kêe (Statistical figures). Retrieved from http://vietnamtourism.gov.vn.

VNAT (Vietnam National Administration of Tourism). (2015c). Du lịch Hà Nộ kỷ niệm 55 năm thành lập Ngành và triển khai nhiệm vụ 6 tháng cuối năm (The Hanoi Department of Culture, Sports and Tourism celebrates $55^{\text {th }}$ anniversary of the Vietnam tourism). Retrieved from http://vietnamtourism.gov.vn/index.php/items/18147.

VNAT (Vietnam National Administration of Tourism). (2015d). Khách quốc tế đến Việt Nam tháng 6 và 6 tháng năm 2015 (International arrival coming to Vietnam in June and in the first six months of 2015). Retrieved from http://vietnamtourism.gov.vn/index.php/items/18075.

VNAT (Vietnam National Administration of Tourism). (2015e). Danh sách co sở luu trú du lịch đã xếp hạng (a list of classified tourist accommodation establishments in Vietnam). Retrieved from www.vietnamhotels.gov.vn.

VNAT (Vietnam National Administration of Tourism). (2015f). Doanh nghiệp lũ hành quốc tế (a list of licensed international tour operators). Retrieved from http://vietnamtourism.gov.vn/index.php/cat/99.

VNAT (Vietnam National Administration of Tourism). (2015g). Thành phố Hồ Chí Minh (Ho Chi Minh City). Retrieved from http://www.vietnamtourism.com/index.php/tourism/items/72.

VNAT (Vietnam National Administration of Tourism). (2015h). Khi bài toán visa được gõ (an answer for entry visa is resolved). Retrieved from http://vietnamtourism.gov.vn/index.php/items/17851.

Vo, H. T. (2013). Các nước che đậy, Việt Nam lại... trung ra (Other countries hide the state owned ownership, Vietnam shows). Retrieved from http://vietnamnet.vn/vn/tuanvietnam/141897/cac-nuoc-che-day--viet-nam-lai---trung-ra.html.

Vo, T. Q., Swierczek, F. W., \& Nguyen, D. K. (2013). Corporate performance of privatized firms in Vietnam. Journal of Applied Business Research, 29(5), 14371450.

VO, T. T., \& Nguyen, A. D. (2012). Experiences of Vietnam in FDI Promotion: Some Lessons for Myanmar. In Economic reforms in Myanmar: pathways and prospects, Bangkok: BRC research report No. 10, Bangkok research Center, IDE-JETRO (pp. 130-172).

VOV. (2015). 10 mặt hàng xuất khẩu chủ lục của Việt Nam đạt giá trị trên 3,5 tỷ USD (Top exporting commodities of Vietnam account for 3.5 billion USD). Retrieved from http://vov.vn/kinh-te/10-mat-hang-xuat-khau-chu-luc-cua-viet-nam-datgia-tri-tren-35-ty-usd-375739.vov.

VPM (Vietnamese Prime Minister). (2013a). The master plan of the Vietnam tourism development to 2020, vision to 2030. Hanoi: Vietnamese Prime Minister Office. 
VPM (Vietnamese Prime Minister). (2013b). The tourism development strategy of Vietnam to 2020, vision to 2030. Hanoi: Vietnamese Prime Minister Office.

VTIR (Vietnam Trade and Industry Review). (2015). Một số vấn đề về thị truoòng thẻ tín dụng tại Việt Nam (some issues of credit card market in Vietnam). Retrieved from http://tapchicongthuong.vn/mot-so-van-de-ve-thi-truong-the-tin-dung-taiviet-nam-20150310102921330p7c419.htm.

Vuong Linh. (2014). Dân số Việt Nam có gần 90.5 triệu người (Vietnamese population reached 90.5 million inhabitants). Retrieved from http://giadinh.vnexpress.net/tin-tuc/to-am/dan-so-viet-nam-co-gan-90-5-trieunguoi-3121884.html.

Wall, G., \& Mathieson, A. (2006). Tourism: change, impacts and opportunities. Toronto: Pearson Prentice Hall.

WB (World Bank). (2012). Vietnam development report 2012: market economy for a middle-income country. Retrieved from http://web.worldbank.org/WBSITE/EXTERNAL/COUNTRIES/EASTASIAPA CIFICEXT/VIETNAMEXTN/0, contentMDK:22416790 menuPK:387571 page PK:2865066 piPK:2865079 theSitePK:387565,00.html.

WEF (2015). Travel and tourism competitiveness report 2015. Retrieved from http://reports.weforum.org/travel-and-tourism-competitiveness-report-2015/.

Welsh, E. (2002, May). Dealing with data: using NVivo in the qualitative data analysis process. In Forum Qualitative Sozialforschung/Forum: Qualitative Social Research (Vol. 3, No. 2).

Whitla, P., Walters, P. G. P., Davies, H. (2007). Global strategies in the international hotel industry. Hospitality Management, 26, 777-792.

Williams, A. M. (2002). The Czech and Slovak Republics: conceptual issues in the economic analysis of tourism in transition. Tourism Management, 23(1), 37-45.

Wong, M. C., Luk, S. T., \& Li, S. C. (2005). Equity ownership and management control in sino-foreign joint venture hotels. The Service Industries Journal, 25(1), 117133.

World Bank. (2012). Vietnam Development Report (VDR) 2012: Market economy for a middleincome country. Retrieved from http://web.worldbank.org/WBSITE/EXTERNAL/COUNTRIES/EAS TASIAPACIFICEXT/VIETNAMEXTN/0,contentMDK:22416790 menuPK:387571 pagePK:2865066 piPK:2865079 theSitePK:3875 65,00.html. World Bank (WB).

World Bank. (2015). Vietnam: country at a glance. Retrieved from http://www.worldbank.org/en/country/vietnam. 
World Trade Organisation (WTO). (2006). Report of the Working Party on the Accession of Viet Nam. World Trade Organisation.

World Trade Organisation (WTO). (2015). The WTO. Retrieved from https://www.wto.org/english/thewto_e/thewto_e.htm.

Xiao, H. (2006). The discourse of power: Deng Xiaoping and tourism development in China. Tourism Management, 27(5), 803-814.

Xiao, Q., O’Neill, J. W., \& Wang, H. (2008). International hotel development: A study of potential franchisees in China. International Journal of Hospitality Management, 27, 325-336.

Ujma, D. (2001). Distribution channels for tourism: theory and issues. In D. Buhalis and W. Laws (Eds.), Tourism distribution channels: practices, issues and transformations (pp. 33-52). London: Continuum.

Yamamoto, D., \& Gill, A. (2002). Issue of globalisation and reflexivity in the Japanese tourism production system: the case of Whistler, British Columbia. The Professional Geographer, 54(1), 83-93.

Yin, R. K. (2009). Case study research: design and methods. California: Sage.

Yin, R. K. (2014). Case study research: design and methods ( $5^{\text {th }}$ Ed.). Thousand Oaks, CA: Sage Publications, Inc.

Yu, L., \& Huimin, G. (2005). Hotel reform in China a SWOT analysis. Cornell Hotel and Restaurant Administration Quarterly, 46(2), 153-169.

Zapalska, A. M., \& Brozik, D. (2004). Economic Transition. Journal of East-West Business, 10(2), 65-92.

Zecchini, S. (Ed.). (2013). Lessons from the economic transition: Central and Eastern Europe in the 1990s. New York: Springer Science \& Business Media.

Zhang, Y., \& Murphy, P. (2009). Supply-chain considerations in marketing underdeveloped regional destinations: A case study of Chinese tourism to the Goldfields region of Victoria. Tourism Management, 30(2), 278-287.

Zhang, Q. H., Pine, R., \& Lam. T. (2009). Tourism and Hotel Development in China: From political to economic success. New York: Haworth Press, Inc.

Zhu, Y., \& Fahey, S. (2000). The challenges and opportunities for the trade union movement in the transition era: Two socialist market economies-China and Vietnam. Asia Pacific Business Review, 6(3-4), 282-299. 
APPENDIX A

Referral letters used to approach the selected participants in English

MINISTRY OF CULTURE. SPORTS AND TOURISM

THE SOCIALIST REPUBLIC OF VIETNAM

VIETNAM NATIONAL ADMINISTRATION OF TOURISM

Independence - Freedom - Happiness

HOTEL DEPARTMENT

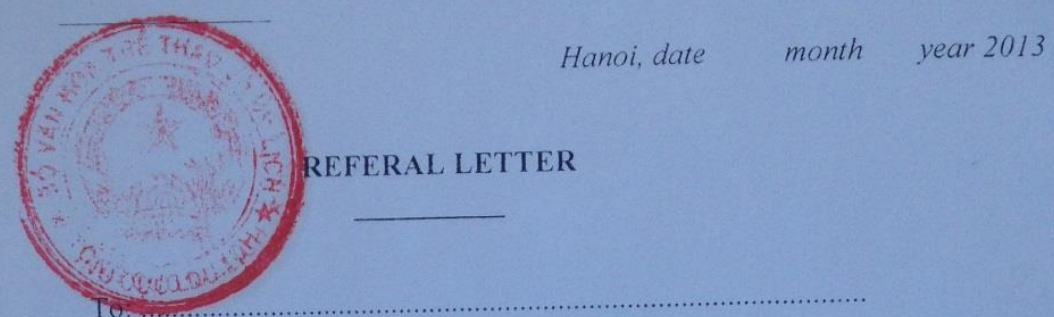

The Hotel Department - Vietnam National Administration of Tourism respectfully introduces:

Mr. Le Ngoc Tuan

Position: Official of the Vietnam National Administration of Tourism cum PhD student of Tourism Management at the Victoria University of Wellington, New Zealand

Ref: As a part of PhD course, Mr. Le Ngoc Tuan is conducting the fieldwork in Vietnam to complete his $\mathrm{PhD}$ thesis. He would like to work with the Sales and Marketing Department of your hotel to collect the necessary data by doing a face to face interview.

The Hotel Department - Vietnam National Administration of Tourism cordially requests the pleasure of you to support him to complete his job.

This referral letter is valid until 2013 and attached documents of his research are parts of this letter./.

Receiving Organization(s):

- As above;

- Filing: Administration Dept.
ON BEHALF DIRECTOR OF THE
HOTEL DEPARTMENT
DEPUTY DIRECTOR

Vu Van Thanh 


\section{APPENDIX B}

\section{Referral letters used to approach the selected participants in Vietnamese}

\section{BỌ VÃN HOÁ, THÊ THAO VẢ DU LỊCH CỌNG HOẢ XÃ HỘI CHỦ NGHĨA VIẸTT NAM}
TONG CỤC DU LỊCH
Độc lập - Tự do - Hạnh phúc

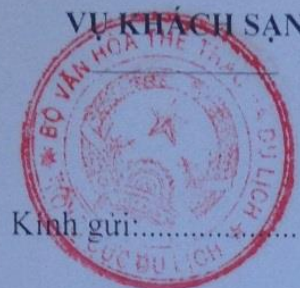

\section{GIÁY GIỚI THIỆ}

Vụ Khách sạn - Tổng cục Du lịch trân trọng giới thiệu:

Ông: Lê Ngọc Tuấn

Chức vụ: Chuyên viên của Tổng cục Du lịch. Nghiên cứu sinh chuyên ngành Quản trị Du lịch tại Đại học Victoria Wellington, New Zealand.

Tới làm việc tại:

Nội dung công việc: Thu thập các số liệu phục vụ Luận án nghiên cứu của ông Lê Ngọc Tuấn thông qua phương pháp phỏng vấn chuyên sâu với nhân viên phụ trách phòng kinh doanh và tiếp thị của khách sạn

Vụ Khách sạn - Tổng cục Du lịch trân trọng cảm ơn sự hỗ trợ và hợp tác của Quý ông/bà tạo điều kiện để ông Lê Ngọc Tuấn hoàn thành nhiệm vụ.

Thư Giới thiệu này có hiệu lực đến hết ngày tháng năm 2013. Kèm theo Giấy này là các tài liệu, thông tin về công trinh nghiên cứu của ông Lê Ngọc Tuấn./.

Nơi nhận:

- Như trên;

- Lưu: VT, TH
KT. VỤ TRỬ NGG VỤ KHÁCH SẠN PHÓ VỤ TRƯởNG
Vũ Văn Thanh
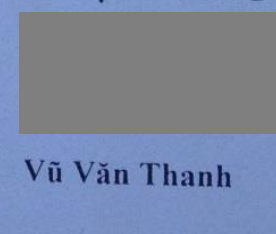


\section{A Checklist of Questions for Hotel Representatives}

\section{ABOUT THE HOTEL}

1. Firstly, could you give me some background on your hotel, including:

- hotel name

- date established

- star rating

- number of rooms

- number of employees

- annual room occupancy

2. What types of products does your hotel provide? And what is the percentage of room revenue over other products?

3. What is the ownership mode of your hotel and when was this ownership mode established? Is your hotel managed by a hotel chain company or as an independent hotel? In case of being managed by a hotel chain company, what does the management contract cover?

4. How are the sales and marketing activities of the hotel organised? Are there other sales and marketing offices of your hotel located in other cities or in other countries? If yes, could you provide me with their functions?

\section{MARKET SEGMENTATION}

5. What are the main market segments that your hotel target?

- \% domestic

- \% international (main countries/territories and/ or regions)

- \% business travellers

- \% independent

- $\%$ packaged leisure tourists

- $\%$ medium range

- \% upper end

6. Do you have different marketing and specific distribution strategies for each target market?

If yes, how would you please describe it and how did you develop this strategy?

If no, why not? 


\section{DISTRIBUTION CHANNELS}

7. What proportion of your sales is made directly to your consumers and how much is made via intermediaries

- $\%$ direct

- $\%$ indirect

\section{Direct Distribution Channels}

8. How does your hotel sell rooms directly to consumers or how do your consumers access your product? For example, do they book online or phone, or are they mainly walk-in guests?

9. What are the main advantages and disadvantages of the different direct channels you use?

\section{Indirect Distribution Channels}

10. Which intermediaries does your hotel work with? For example: Inbound tour operators, third party websites, airlines, visitor information centres, CRO, GDS, etc.

11. Could you tell me who the inbound tour operators are selling your products? Do they vary from market to market? How and why do they select you or do you select them?

12. Do you sell direct to overseas wholesalers or retail travel agents? Who are they? How do you select them or do they select you?

13. How is working with inbound operators different from working directly with overseas wholesalers or travel agents?

14. Is there a different pricing and/or commission policies/practices for each of these indirect channels of intermediaries? What are they?

15. If multiple channels are used, does this present any challenges? What are they? How are these challenges addressed?

16. Do you work with the Hanoi (Ho Chi Minh City/Danang City) Authority of Tourism in any way in distributing your service? How? If not, why not?

17. Do you work with the Vietnam National Administration of Tourism in any way in distributing your service? How? If not, why not?

18. Do you take part in any travel shows or trade fairs in Vietnam or overseas? Which ones? What part do they play in your distribution strategy?

19. What are the main advantages and disadvantages of the different indirect channels you use?

\section{FACTORS DETERMINING DISTRIBUTION CHANNEL STRUCTURE}


20. What are the main factors determining your distribution strategies at the national level?

- political change

- legal system

- technology

- country economy

- domestic demand factors

- management mode, etc.

How do these factors determine the hotel distribution channels that you use? Which is the most important? Chain or management company strategy or policy?

21. What are the main factors determining your distribution strategy at the international level?

- transportation

- financial services

- banking systems

- technology

- demand factors

- management mode, etc.

How do these factors determine the direct hotel distribution channels?

\section{IMPLICATIONS OF DISTRIBUTION CHANNEL STRUCTURES AND INFLUENTIAL FACTORS}

22. Have the government policies and strategies to develop tourism affected the expansion and development of your hotel distribution channels? If so, please explain how and why?

23. What changes do you see in the future to the distribution channels that you are presently using? What factors will bring about these changes?

24. In 2018, Vietnam will become a full market economy, committed to the World Trade Organisation. What influence do you think this event will have on current and future hotel distribution channels and the competitiveness of your hotel?

25. Are there any other observations or comments you would like to make in terms of your own distribution channels or issues of distribution with regard to tourism in your city or Vietnam in general? 


\section{TE WHARE WÃNANGA O TE OPOKO O TE IKA A MÃUI STDP VICTORIA \\ A Checklist of Questions for Representatives from Inbound Tour Operators}

\section{ABOUT THE COMPANY}

1. Firstly, could you give me some background on your company, including:

- company name

- date established

- ownership structure

- fields of business

- number of employees

- objectives

2. What are the functions of sales and marketing department regarding the travel business? Are there other sales and marketing offices of your company located in other cities or in other countries? If yes, could you provide me with their functions?

\section{MARKET SEGMENTATION AND DISTRIBUTION CHANNELS}

3. What are the main market segments that you target?

- \% domestic

- $\%$ international (main countries/territories and/ or regions)

- $\%$ business travellers

- $\%$ independent

- $\%$ packaged leisure tourists

- \% budget

- $\%$ medium range

- $\%$ upper end

4. Do you have different marketing strategies for each target market? If yes, how would you describe it and how did you develop this strategy? If no, why not?

5. Which channel(s) do you mostly use to gain access to these potential customers? How would you describe it (them) and how did you develop this channel (these channels)?

6. For each type of tourist, which channels do you mostly use to access hotel rooms? Please, explain how and why?

7. Are there any differences in how you deal with hotel ownership mode (state run, domestic private owned, joint venture and FOHs) or management mode 
(international or domestic hotel chain, independent hotels)? Please, explain how and why?

8. Is there a different pricing and/or commission policies/practices for each of these indirect channels of intermediaries? What are they?

9. Does this affect your choice of hotel or the way in which you access rooms? If yes, please explain how and why? Particularly in reference to 4 and 5 star hotels in Hanoi, Danang, and Ho Chi Minh City.

\section{FACTORS DETERMINING DISTRIBUTION CHANNEL STRUCTURE}

10. In terms of relationships between distribution channels and hotel ownership modes, do you see any similarities and differences across modes of hotel ownership of the same quality and in the same location? If yes, please explain why?

11. As a customer of hotels, what are the main factors determining the hotel distribution channel structures at the national level?

- ownership issues

- independent, domestic or international hotel chain

- political change since 1986

- legal system

- technology

- country economy

- domestic demand factors; and management mode, etc.

How and why do you think these factors determine the hotel distribution channels?

12. Specifically, what are the main factors determining hotel distribution channel structures at the international level?

- transportation

- financial services

- banking systems

- technology

- demand factors

- hotel management mode, etc.

How and why do you think these factors determine the hotel distribution channels?

13. In 2018, Vietnam will become a full market economy, committed to the World Trade Organisation. What influence do you think this event will have on current and future hotel distribution channels and the competitiveness of the Vietnamese hotels?

\section{IMPLICATIONS OF DISTRIBUTION CHANNEL STRUCTURES AND INFLUENTIAL FACTORS}

14. How have the government policies and strategies to develop tourism since 1986 (Doi Moi) affected the expansion and development of your company and distribution channels of each hotel ownership mode you use? If so, please explain how and why? 
15. How has the development of tourism and the hotel industry in Vietnam affected the expansion and development of your company and the distribution channels of each hotel ownership mode and vice versa?

16. In terms of a market economy, what changes do you think will occur with your current company and hotel distribution channels in Vietnam in the future? What factors will bring about these changes and why?

17. Are there any other observations or comments you would like to make in terms of your own distribution channels or issues of hotel distribution with regard to tourism in your city or Vietnam in general?

18. If possible, could you tell me about the future development of the Vietnamese hotels regarding the expansion and development of distribution channels, particularly the state owned hotels? 


\title{
APPENDIX E
}

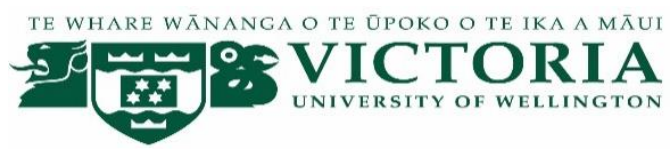

\begin{abstract}
A Checklist of Questions
(For respondents from the Vietnam National Administration of Tourism, Hanoi Authority of Tourism, Danang Authority of Tourism, Ho Chi Minh City Authority of Tourism, academics and trade organisations)
\end{abstract}

\section{ABOUT THE ORGANISATION}

1. Could you give me some background on your organisation (functions and missions)?

\section{VIETNAMESE HOTEL MARKET}

2. Since Vietnam implemented the policies of Doi Moi in 1986 (the economic reform), what changes have you seen with the Vietnamese hotel market?

3. What changes have occurred with the structure of hotel ownership in Vietnam since 1986 ? Please, tell me how and why?

4. Are there any current similarities and differences among these hotel ownership modes (state run, domestic private, joint venture and FOHs) in terms of their target markets? If so, please explain why?

5. What changes have occurred in the major markets of up-market hotels in Hanoi, Danang, and Ho Chi Minh City since 1986? Why has this occurred and what are the results of these changes in these cities?

6. Does each mode of hotel ownership in these cities focus on the different markets? If so, please explain why?

\section{HOTEL DISTRIBUTION CHANNELS}

7. What do you know about the direct and indirect distribution channels that the Vietnamese hotels are using to distribute their products?

8. How do the potential tourists of Vietnam hear of the Vietnamese hotels?

9. Are there any differences in the marketing and distribution strategies that hotels are using to reach different types of tourists? If so, what are the differences? Why are there differences?

10. Do you know any package products that hotels are selling their rooms with tourism partners, for example airlines, museum, theatre, etc? 
11. Could you tell me about the current distribution channel(s) of the four modes of hotel ownership (state run, domestic private owned, joint venture, and FOHs) in the group of 4-5 star hotels, particularly in Hanoi, Danang, and Ho Chi Minh City?

12. Do you see any similarities and differences of the distribution channel structures across four modes of hotel ownership in these cities? Please, explain how and why?

\section{FACTORS DETERMINING DISTRIBUTION CHANNEL STRUCTURE}

13. What are the main distribution challenges that Vietnamese up-market hotels are facing? What are they? How are these challenges addressed?

14. Specifically, what are the main factors determining the distribution channels of each hotel ownership mode at the national level?

- ownership issues

- political change since 1986

- hotel management

- legal system

- technology

- country economy

- domestic demand factors

- hotel management mode, etc.

How and why do you think these factors determine the hotel distribution channels?

15. What are the main factors determining the distribution channels of each hotel ownership mode at the international level?

- transportation

- financial services

- banking systems

- technology

- demand factors

- management mode, etc.

How and why do you think these factors determine the hotel distribution channels?

16. How do the hotel ownership structure and organisational factors affect the structure of hotel distribution channels? Please, explain why?

\section{IMPLICATIONS OF DISTRIBUTION CHANNEL STRUCTURES AND INFLUENTIAL FACTORS}

17. Have there been any recent changes in how each type of hotel ownership has structured its distribution channels? What has brought these changes and why?

18. What are the policies that the VNAT and/or Hanoi, Danang and Ho Chi Minh City have promulgated to promote the distribution channels of the Vietnamese hotels in general and in these cities in particular? 
19. Do you think that government policies and strategies to develop tourism in particular and the economy in general have affected the expansion and development of hotel distribution channels? If so, please explain how?

20. Do you think the development of Vietnam tourism since 1986 has affected the expansion and development of hotel distribution channels? If so, please explain how and why?

21. What impacts have changes in hotel distribution channel structures and practices had on the Vietnam tourism and hotel industry since 1986?

22. In 2018, Vietnam will become a full market economy, committed to the World Trade Organisation. What influence do you think of this event will have on current and future hotel distribution channels and the competitiveness of the Vietnamese hotels?

23. If possible, could you tell me the future development of the Vietnamese hotels, particularly the state owned hotels? 
APPENDIX F

TE WHARE WÃNANGA O TE OPOKO O TE IKA A MÃUI

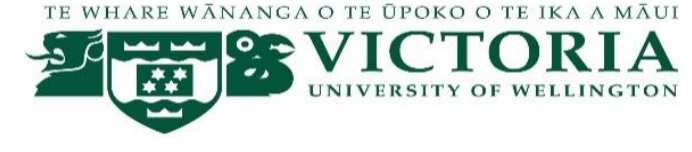

A list of international tour operators interviewed

\begin{tabular}{|c|c|c|c|}
\hline Representative's name & Position & Company & Location \\
\hline Mr. Luu Duc Ke & Director & Hanoi Tourist & Hanoi \\
\hline Mr. Tao Duc Hiep & $\begin{array}{l}\text { Deputy } \\
\text { Director }\end{array}$ & $\begin{array}{l}\text { Vietnam Railway Trade } \\
\text { Union Tourist Service } \\
\text { Company }\end{array}$ & Hanoi \\
\hline Mr. Pham Quang Hung & Director & $\begin{array}{l}\text { Vietravel - Northern } \\
\text { Vietnam Office }\end{array}$ & Hanoi \\
\hline Mr. Dam Xuan Nhat & Director & Asianway Travel & Hanoi \\
\hline Mrs. Dang Bich Tho & Director & Phoenix Voyages & Hanoi \\
\hline Mr. Nguyen Van Dung & Director & Paradise Travel & Hanoi \\
\hline Mr. Pham Van Tan & Director & Vietnam Today Travel & Hanoi \\
\hline Mrs. Tran Huyen Thanh & Director & Wildlotus Travel & Hanoi \\
\hline Mr. Le Quang Tuyen & Director & Hanoi Etoco Travel & Hanoi \\
\hline Mr. Huynh Minh Son & $\begin{array}{l}\text { Tour } \\
\text { Operation } \\
\text { Manager }\end{array}$ & Apex Vietnam Travel & Hanoi \\
\hline Mr. Nguyen The Vinh & $\begin{array}{l}\text { Deputy } \\
\text { Director }\end{array}$ & $\begin{array}{l}\text { Saigon Tourist Holding } \\
\text { Company }\end{array}$ & $\begin{array}{l}\text { Ho Chi } \\
\text { Minh City }\end{array}$ \\
\hline Mrs. Lam Thi Quynh Thu & $\begin{array}{l}\text { Deputy } \\
\text { Manager of } \\
\text { Marketing } \\
\text { and Public } \\
\text { Relation } \\
\text { Department }\end{array}$ & $\begin{array}{l}\text { Saigontourist Travel } \\
\text { Service Company under } \\
\text { Saigon Tourist Holding }\end{array}$ & $\begin{array}{l}\text { Ho Chi } \\
\text { Minh City }\end{array}$ \\
\hline Mrs. Pham Viet Huong & $\begin{array}{l}\text { Manager of } \\
\text { Product } \\
\text { Development } \\
\text { Research }\end{array}$ & $\begin{array}{l}\text { Vietravel Ho Chi Minh } \\
\text { City }\end{array}$ & $\begin{array}{l}\text { Ho Chi } \\
\text { Minh City }\end{array}$ \\
\hline
\end{tabular}




\begin{tabular}{|c|c|c|c|}
\hline Mr. Truong Nhu Quoc & Area & Grand Circle Vietnam & Ho Chi \\
\hline Khanh & Manager & & Minh City \\
\hline \multirow{5}{*}{ Mr. Tran Thanh Phong } & Director of & Vietran Tour Ho Chi & Ho Chi \\
\hline & Branch & Minh City & Minh City \\
\hline & Office in Ho & & \\
\hline & Chi Minh & & \\
\hline & City & & \\
\hline \multirow[t]{2}{*}{ Mr. Dam Van Tham } & Branch & Aurora Travel & Ho Chi \\
\hline & Manager & & Minh City \\
\hline \multirow[t]{2}{*}{ Mr. Le Xuan Hung } & Director & Oriental Heritages & Ho Chi \\
\hline & & Travel & Minh City \\
\hline \multirow[t]{3}{*}{ Mr. Nguyen Phuong Quy } & Senior & Asia Destinations Travel & Ho Chi \\
\hline & Travel & & Minh City \\
\hline & Consultant & & \\
\hline \multirow[t]{5}{*}{ Mrs. Ngo Thuy Phuong } & Vice & Becker Travel Vietnam & Danang \\
\hline & Director cum & & \\
\hline & Country & & \\
\hline & Operation & & \\
\hline & Manager & & \\
\hline \multirow[t]{4}{*}{ Mr. Cao Tri Dung } & Director of & Vietnam Tourism & Danang \\
\hline & Travel & Company in Danang & \\
\hline & Service & City & \\
\hline & Center & & \\
\hline
\end{tabular}

